\author{
UNIVERSIDADE DE SÃO PAULO \\ Faculdade de Ciências Farmacêuticas \\ Departamento de Farmácia \\ Programa de Pós-Graduação em Fármaco e Medicamentos
}

Matriz de recomendações para farmacoterapia da Hipertensão Arterial Sistêmica: recurso para subsidiar a adaptação de guias de prática clínica

\author{
NATHÁLIA CELINI LEITE SANTOS \\ Dissertação para obtenção do Título de Mestre
}

Orientadora: Prof ${ }^{\mathrm{a}}$. Dra. Eliane Ribeiro

São Paulo

2019 


\author{
UNIVERSIDADE DE SÃO PAULO \\ Faculdade de Ciências Farmacêuticas \\ Departamento de Farmácia \\ Programa de Pós-Graduação em Fármaco e Medicamentos
}

\title{
Matriz de recomendações para farmacoterapia da Hipertensão Arterial Sistêmica: recurso para subsidiar a adaptação de guias de prática clínica
}

\author{
NATHÁLIA CELINI LEITE SANTOS
}

Versão Original

Dissertação para obtenção do Título de Mestre

Orientadora: Prof ${ }^{a}$. Dra. Eliane Ribeiro

São Paulo

2019 
Autorizo a reprodução e divulgação total ou parcial deste trabalho, por qualquer meio convencional ou eletronico, para fins de estudo e pesquisa, desde que citada a fonte.

Ficha Catalográfica elaborada eletronicamente pelo autor, utilizando o programa desenvolvido pela Seção Técnica de Informática do ICMC/USP e adaptado para a Divisão de Biblioteca e Documentação do Conjunto das Químicas da USP

Bibliotecária responsável pela orientação de catalogação da publicação: Marlene Aparecida Vieira - CRB - 8/5562

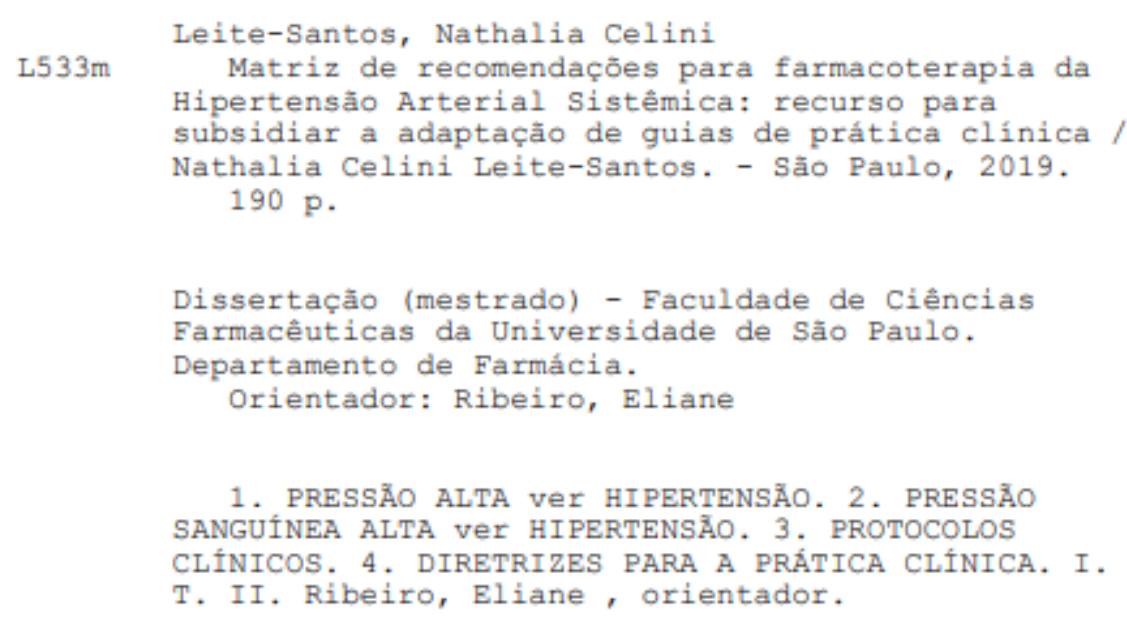


Matriz de recomendações para farmacoterapia da Hipertensão Arterial Sistêmica: recurso para subsidiar a adaptação de guias de prática clínica

\author{
Comissão Julgadora
}

da

Dissertação para obtenção do Título de Mestre

Profa. Dra.

Orientadora/Presidente

10. examinador

2o. examinador

3o. examinador

São Paulo, de de 2019. 
O presente trabalho foi realizado com apoio da Coordenação de Aperfeiçoamento de Pessoal de Nível Superior - Brasil (CAPES) - Código de Financiamento 001 
Às minhas filhas, Maria Eduarda e Helena, por serem meu alicerce e inspiração em todos os momentos. Aos meus pais Jônatas e Lourdes, a minha avó Alzira, ao meu marido José Mario e a minha irmã Carolina, pelo apoio incondicional, incentivo, carinho e compreensão. 


\section{AGRADECIMENTOS}

Agradeço primeiramente a Deus, por me honrar em todos os momentos da minha vida e pela oportunidade de aprimoramento profissional, por meio da obtenção deste título, mas principalmente por conhecer pessoas maravilhosas nessa jornada.

Aos meus pais Jônatas e Lourdes, que sempre batalharam e fizeram o possível e o impossível para que eu tivesse uma boa educação e alcançasse todos os meus sonhos, que sempre acreditaram em mim e me deram forças para nunca desistir. Não tenho palavras para explicar o tamanho da minha gratidão, sem vocês tenho certeza que não teria chegado até aqui e superado todas as batalhas da vida.

À minha avó Alzira, por todo amor e carinho. Muito obrigada por todos os anos de dedicação e amor incondicional.

À minha irmã Carolina, que mesmo sendo mais nova que eu, sempre foi um exemplo de mulher batalhadora e sempre esteve presente na minha vida.

Ao meu marido José Mario, pelo apoio diário, companheirismo e paciência nessa jornada. Passamos por momentos não tão fáceis, mas superamos todos os obstáculos juntos. Obrigada por estar ao meu lado.

Às minhas filhas, Maria Eduarda e Helena. Olhar para vocês todos os dias me dá força, coragem e vontade de vencer todos os obstáculos, para proporcionar o melhor a vocês sempre. Vocês são meu alicerce, inspiração, o que eu tenho de mais precioso na vida.

À minha orientadora Profa. Dra. Eliane Ribeiro, pela paciência, disponibilidade e dedicação a este trabalho. Obrigada por todo aprendizado acadêmico e experiência compartilhada, mas principalmente pelas lições de vida e pelo carinho, comigo e com as minhas filhas.

À Profa. Dra. Daniela Oliveira de Melo por acreditar no meu potencial, pela dedicação ao meu crescimento, pelas oportunidades que me proporcionou, pelo 
conhecimento compartilhado e principalmente pela amizade e carinho. Há três anos atrás tive o prazer de conhece-la, e o que começou com trabalho e admiração se tornou muito mais que isso. Hoje sou grata por tê-la em meu convívio, como parte integrante da minha família.

Aos integrantes do Grupo CHRONIDE, especialmente ao Rafael Mantovani, Franciele Gabriel, Caroline Molino e Sheila Kalb pela participação ativa neste trabalho, ao Alfredo pelas experiências compartilhadas e a Luciana Vasconcelos pelos ensinamentos complementares, carinho e amizade. À minha companheira de mestrado Géssica Caroline, pela amizade e momentos que compartilhamos. Vocês são mais que colegas de trabalho, e foram de suma importãncia para o sucesso deste trabalho.

A toda minha familia e amigos que estiveram presentes em um momento muito "delicado" vivenciado durante este mestrado. Sem vocês tudo seria mais difícil.

A todos os professores que participaram da minha formação e me inspiraram a seguir esse caminho.

A todos que contribuiram de alguma forma para o desenvolvimento deste trabalho.

Aos funcionários da Faculdade de Ciências Farmacêuticas da Universidade de São Paulo, especialmente ao secretário David. 
"O êxito da vida não se mede pelo caminho que você conquistou, mas sim pelas dificuldades que superou no caminho." 


\section{RESUMO}

\section{LEITE-SANTOS, NC. Matriz de recomendações para farmacoterapia da}

Hipertensão Arterial Sistêmica: recurso para subsidiar a adaptação de guias de prática clínica [dissertação]. Faculdade de Ciências Farmacêuticas, Universidade de São Paulo, São Paulo, 2019.

A hipertensão arterial sistêmica (HAS) é uma doença crônica altamente prevalente, que pode ser controlada com tratamento farmacológico. Para tal, recomenda-se aplicar as melhores evidências clínicas por meio da utilização de guias de prática clínica (GPC) de alta qualidade. No entanto, o processo de desenvolvimento de GPC requer recursos humanos e tempo, sendo a adaptação uma opção para reduzir a duplicação de esforços e adequar o GPC para uso local. O objetivo deste trabalho foi sintetizar as recomendações de GPC para o tratamento farmacológico da HAS. Aplicou-se o método de adaptação ADAPTE, realizando as duas primeiras fases: Configuração e Adaptação. Na fase de Configuração, o Grupo CHRONIDE realizou o planejamento e registrou a pesquisa no Próspero. Na fase de Adaptação, realizou-se uma revisão sistemática. Os critérios de eligibilidade foram: GPC que continham recomendações para o tratamento farmacológico da HAS em atenção primária, publicados em inglês, português ou espanhol, no período de 01/01/2011 a 31/12/2016. Em 31/11/2017 atualizou-se GPC incluídos. Para a determinação da qualidade destes GPC, três avaliadores, de forma independente, aplicaram o Appraisal of Guidelines for Research \& Evaluation II (AGREE II). Dos 37 GPC avaliados, 6 foram considerados de alta qualidade (escore $60 \%$ ou mais no domínio "Rigor de desenvolvimento" do AGREE II). As recomendações destes foram extraídas e incluídas nas matrizes. Os GPC apresentaram divergências em suas recomendações. As divergências mais relevantes foram as recomendações mais rigorosas do GPC de 2017 da American College of Cardiology e American Heart Association (ACC/AHA), que trouxe metas terapêuticas e níveis pressóricos para indicação de farmacoterapia mais baixos que os demais. A maioria dos GPC recomendou o uso de diuréticos tiazídicos como farmacoterapia de primeira linha para tratamento da HAS e contraindicou o uso combinado de inibidores da enzima conversora de angiotensina e bloqueadores dos receptores de angiotensina II. Portanto, em uma discussão para adaptação local de recomendações, um dos pontos principais, além da questão do acesso aos medicamentos, seria adotar ou não os paramêtros mais rigorosos do GPC 2017 ACC/AHA.

Palavras- chave: Guia de Prática Clínica, Hipertensão, Hipertensão Arterial, Hipertensão Arterial Sistêmica, Pressão Arterial Alta, Pressão Sanguínea Alta, Tratamento Farmacológico, Farmacoterapia, Medicina Baseada em Evidências, Prática Clínica Baseada em Evidências. 


\begin{abstract}
LEITE-SANTOS, NC. Matrix of recommendations for pharmacotherapy of arterial hypertension: resource to subsidize the adaptation of clinical practice guidelines. Dissertação (Mestrado) - Faculdade de Ciências Farmacêuticas, Universidade de São Paulo, São Paulo, 2019.
\end{abstract}

Arterial hypertension is a high prevalent chronic disease that can be controlled with pharmacologic treatment. For such, is recommended the use of the high clinical evidences presented in high quality clinical practice guidelines (CPG). However, the guideline development process requires time and capable human resources, which transform the adaptation to an option to reduce a duplication of efforts and to adapt the CPG to local use. The objective of this work was to synthesize the recommendations of CPG for the pharmacological treatment of arterial hypertension. The ADAPTE method was applied, using 2 steps: Configuration and Adaptation. In the Configuration step, the CHRONIDE group carried out the planning and the method was registered in Prospero. In the Adaptation step a systematic review was performed. The eligibility criteria were: CPG containing recommendations for the pharmacological treatment of arterial hypertension in primary care, published in English, Portuguese or Spanish, from 01/01/2011 to 12/31/2016. On 11/31/2017 it was updated the GPC included. To determine the CPG quality, 3 independent reviewers, assessed the CPG using the Appraisal of Guidelines for Research \& Evaluation II (AGREE II) tool. Of the 37 evaluated CPG, 6 were considered to being as high quality (score $60 \%$ or higher in the domain " Rigour of Development "). The recommendations were extracted and included in the matrix of recommendations. The CPG has presentes differences in their recommendations. The most relevant divergences were the further rigorous recommendations described on CPG 2017 of the American College of Cardiology and American Heart Association (ACC/AHA), which brought therapeutic goals and blood pressure levels lower for pharmacotherapy than the others recommendations. The majority of CPG has recommended the use of thiazide diuretics as first-line pharmacotherapy for the treatment of arterial hypertension and has contraindicated the combined use of angiotensin converting enzyme inhibitors and angiotensin II receptor blockers. Therefore, in a discussion for local adaptation of recommendations, one of the main points, apart from the issue of access to medicines, would be to adopt or would not be adopt the futher rigorous parameters of GPC 2017 ACC/AHA.

Key words: Practice guideline, Practice Guidelines as Topic*, Hypertension, Hypertension/therapy, Hypertension in adults, Blood Pressure, High Blood Pressure, Drug Therapy, Evidence-Based Practice, Evidence-Based Medicine. 


\section{LISTA DE FIGURAS}

Figura 1 - Cálculo da porcentagem total de cada domínio do instrumento Appraisal of Guidelines for Research \& Evaluation, versão II.................................................28

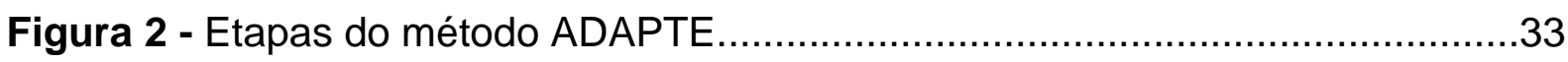

Figura 3 - Fluxograma de seleção de guias de prática clínica para tratamento farmacológico da hipertensão arterial sistêmica para avaliação da qualidade metodológica com instrumento AGREE II .44

Figura 4 - Médias dos escores obtidos por domínio do AGREE II, dos guias de prática clínica para farmacoterapia da hipertensão arterial sistêmica, obtido por revisão sistemática no período de 01/2011 a 12/2016, atualizado os GPC incluídos até $11 / 2017$ .53 


\section{LISTA DE QUADROS}

Quadro 1 - Domínios e itens do instrumento Appraisal of Guidelines for Research \& Evaluation, versão II.

Quadro 2 - Descrição do acrônimo PIPDS para a seleção dos guias de pratica clínica para tratamento farmacológico da hipertensão arterial sistêmica

Quadro 3 - Estratégia de busca por guias de prática clinica para tratamento farmacológico da hipertensão arterial sistêmica, realizada em 22/01/2017

Quadro 4 - Notas do AGREE II por domínio para cada guia de prática clinica (GPC) para tratamento farmacológico da hipertensão arterial sistêmica, obtido por meio de revisão sistemática no período de 01/2011 a 12/2016, atualizado os GPC incluídos até 11/2017

Quadro 5 - Características dos guias de prática clínica (GPC) adaptados para farmacoterapia da hipertensão arterial sistêmica com nota de $60 \%$ ou mais no domínio 3 do AGREE II, obtido por revisão sistemática no período de 01/2011 a 12/2016, atualizado os GPC incluídos até 11/2017

Quadro 6 - Principais tópicos abordados nos guias de prática clinica (GPC) para farmacoterapia da hipertensão arterial sistêmica, obtidos por meio de revisão sistemática no período de 01/2011 a 12/2016, atualizado os GPC incluídos até $11 / 2017$

Quadro 7 - Matriz das recomendações para indicação de farmacoterapia da hipertensão arterial sistêmica, de guias de prática clinica (GPC) com nota de $60 \%$ ou mais no domínio 3 do AGREE II, obtido por revisão sistemática no período de 01/2011 a 12/2016, atualizado os GPC incluídos até 11/2017

Quadro 8 - Matriz das recomendações para farmacoterapia em adultos com hipertensão arterial sistêmica, de guias de prática clinica (GPC) com nota de $60 \%$ ou mais no domínio 3 do AGREE II, obtido por revisão sistemática no período de 01/2011 a 12/2016, atualizado os GPC incluídos até 11/2017 68

Quadro 9 - Matriz das recomendações para farmacoterapia em populações/situações especificas com hipertensão arterial sistêmica, de guias de prática clinica (GPC) com nota de $60 \%$ ou mais no domínio 3 do AGREE II, obtido por revisão sistemática no período de 01/2011 a 12/2016, atualizado os GPC incluídos até 11/2017 
Quadro 10 - Matriz das recomendações para farmacoterapia da hipertensão arterial sistêmica em adultos ou idosos com comorbidades, de guias de prática clinica (GPC) com nota de $60 \%$ ou mais no domínio 3 do AGREE II, obtido por revisão sistemática no período de 01/2011 a 12/2016, atualizado os GPC incluídos até

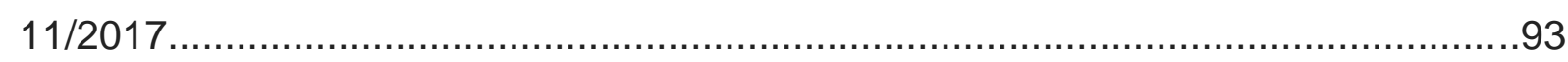




\section{LISTA DE TABELAS}

Tabela 1 - Características gerais dos guias de prática clinica (GPC) para tratamento farmacológico da hipertensão arterial sistêmica, obtido por meio de revisão sistemática no período de 01/2011 a 12/2016, atualizado os GPC incluídos até $11 / 2017$

Tabela 2 - Variação dos escores dos domínios do AGREE II para os trinta e sete guias de prática clinica (GPC) para tratamento farmacológico da hipertensão arterial sistêmica, obtido por meio de revisão sistemática no período de 01/2011 a 12/2016, atualizado os GPC incluídos até 11/2017.

Tabela 3 - Variação dos escores dos domínios do AGREE II para os seis guias de prática clinica (GPC) para tratamento farmacológico da hipertensão arterial sistêmica com alta qualidade $(60 \%$ ou mais no domínio 3$)$, obtido por meio de revisão sistemática no período de 01/2011 a 12/2016, atualizado os GPC incluídos até $11 / 2017$

Tabela 4 - Variação dos escores dos domínios do AGREE II para os trinta e um guias de prática clinica (GPC) para tratamento farmacológico da hipertensão arterial sistêmica com baixa qualidade (menos de $60 \%$ no domínio 3), obtido por meio de revisão sistemática no período de 01/2011 a 12/2016, atualizado os GPC incluídos até $11 / 2017$ .52 


\section{LISTA DE ABREVIATURAS E SIGLAS}

\begin{tabular}{ll} 
AAFP & American Academy of Family Physicians \\
AGREE & Appraisal of Guidelines for Research \& Evaluation \\
AGREE II & Appraisal of Guidelines for Research \& Evaluation - segunda edição \\
BCC & Bloqueadores dos Canais de Cálcio \\
BRA & Bloqueadores dos Receptores de Angiotensina II \\
DCNT & Doença Crônica Não Transmissível \\
EBCPG & Evidence-Based Clinical Practice Guidelines \\
ECR & Ensaio Clínico Randomizado \\
GPC & Guias de Prática Clínica \\
GRADE & $\begin{array}{l}\text { Grading of Recommendations Assessment, Development and } \\
\text { Evaluation }\end{array}$ \\
HAS & Hipertensão Arterial Sistêmica \\
IECA & Inibidores da Enzima Conversora de Angiotensina \\
IOM & Institute of Medicine \\
JNC & Joint National Committee \\
MAGIC & Making GRADE the Irresistible Choice \\
MBE & Medicina Baseada em Evidências \\
NICE & National Institute for Health and Care Excellence \\
OMS & Organização Mundial da Saúde \\
PA & Pressão Arterial \\
PAD & Pressão Arterial Diastólica \\
PAS & Pressão Arterial Sistólica \\
\hline
\end{tabular}


PBE Prática Baseada em Evidências

PCDT Protocolo Clínico e Diretrizes Terapêuticas

PIPDS Acrônimo Paciente; Intervenção; Profissional, Desfecho e Serviço de Saúde

SBE Saúde Baseada em Evidências

SPRINT Systolic Blood Pressure Intervention Trial 


\section{SUMÁRIO}

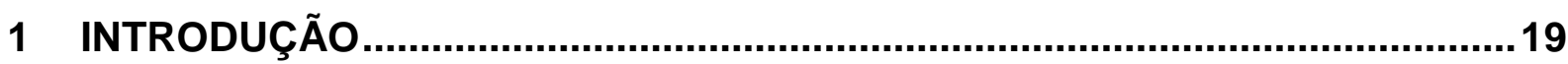

2 OBJETIVO

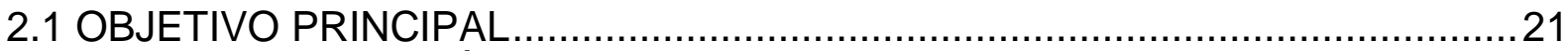

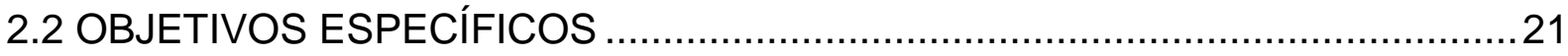

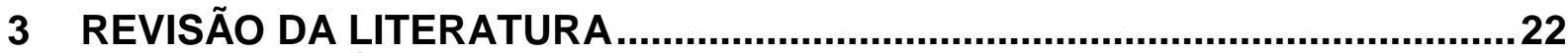

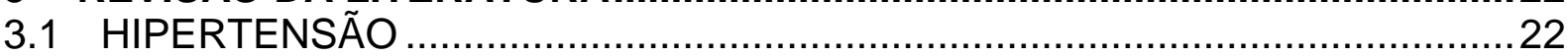

3.2 SAÚDE BASEADA EM EVIDÊNCIAS E GUIAS DE PRÁTICA CLÍNICA..........23

3.3 AVALIAÇÃO DE QUALIDADE DE GUIAS DE PRÁTICA CLÍNICA …..............25

3.4 ADAPTAÇÃO DE GUIAS DE PRÁTICA CLÍNICA ….................................29

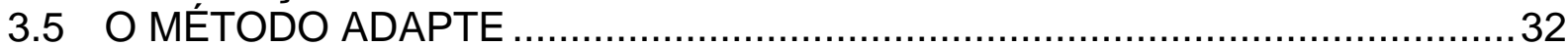

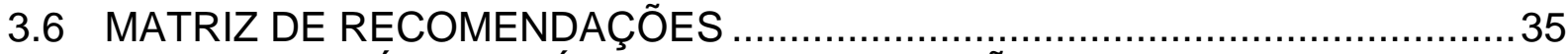

3.7 GUIAS DE PRÁTICA CLÍNICA DA HIPERTENSÃO....................................36

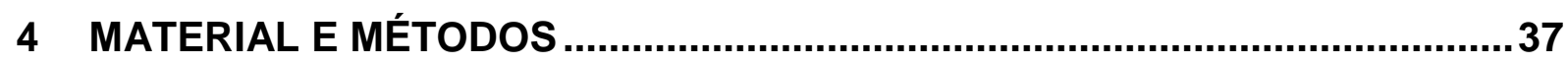

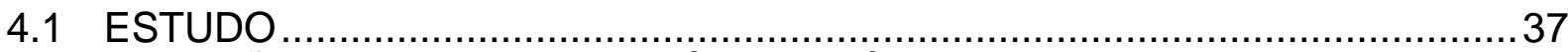

4.2 SELEÇÃO DOS GUIAS DE PRÁTICA CLÍNICA....................................... 37

4.3 EXTRAÇÃO DAS CARACTERÍSTICAS GERAIS DOS GUIAS DE

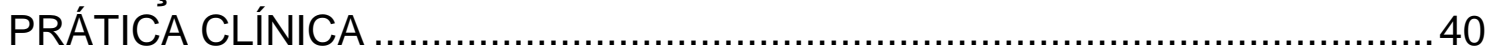

4.4 AVALIAÇÃO DE QUALIDADE DOS GUIAS DE PRÁTICA CLÍNICA.................41

4.5 MATRIZES DE RECOMENDAÇÕES PARA FARMACOTERAPIA DA

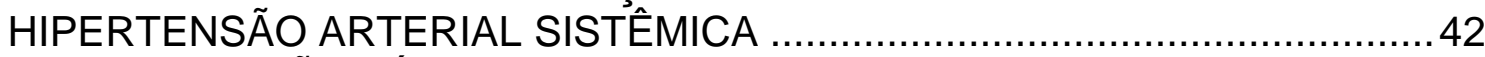

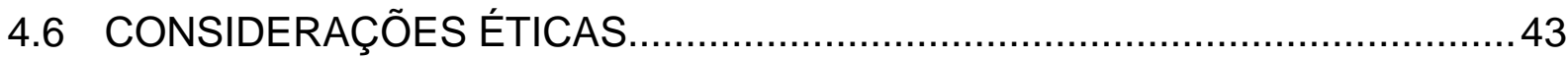

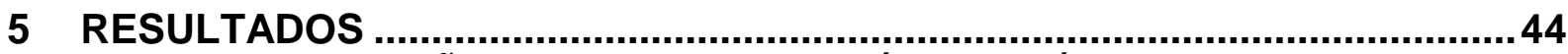

5.1 BUSCA E SELEÇÃO DOS GUIAS DE PRÁTICA CLÍNICA ............................44

5.2 EXTRAÇÃO DAS CARACTERÍSTICAS GERAIS DOS GUIAS DE

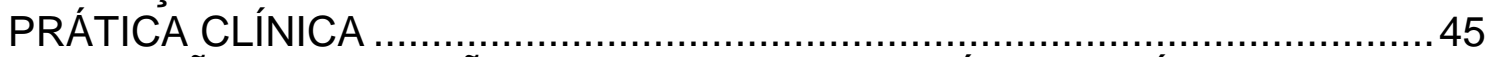

5.3 AVALIAÇÃO E SELEÇÃO DOS GUIAS DE PRÁTICA CLÍNICA COM ALTA QUALIDADE ......................................................................... 47

5.4 MATRIZ DE RECOMENDAÇÃO PARA FARMACOTERAPIA DA HIPERTENSÃO ARTERIAL SISTÊMICA ……...............................................55

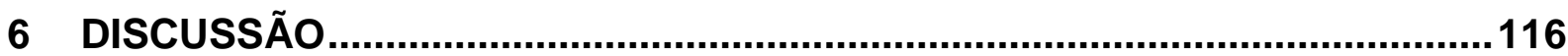

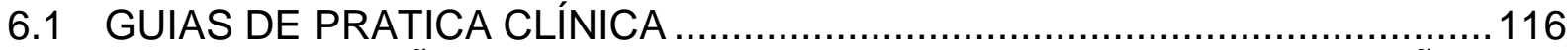

6.2 RECOMENDAÇÕES PARA FARMACOTERAPIA DA HIPERTENSÃO ARTERIAL SISTÊMICA ….............................................................119

6.2.1 Indicação de farmacoterapia e metas ...................................................119

6.2.2 Opções de farmacoterapia..................................................................124

6.2.3 Particularidades no processo de cuidado da hipertensão ..................127

6.3 LIMITAÇÕES E FORÇAS DO ESTUDO................................................... 130 
8 REFERÊNCIAS BIBLIOGRÁFICAS.

9 APÊNDICES 155

APÊNDICE 1- DOCUMENTOS SELECIONADOS PARA AVALIAÇÃO DA QUALIDADE METODOLÓGICA COM INSTRUMENTO AGREE II.

APÊNDICE 2- DOCUMENTOS EXCLUÍDOS APÓS APLICAÇÃO DOS CRITÉRIOS DE ELEGIBILIDADE.

APÊNDICE 3 - CARACTERÍSTICAS GERAIS DOS GUIAS DE PRÁTICA CLÍNICA (GPC) PARA TRATAMENTO FARMACOLÓGICO DA HIPERTENSÃO ARTERIAL SISTÊMICA PUBLICADOS NO PERÍODO DE 01/2011 A 12/2016, ATUALIZADO OS GPC INCLUÍDOS ATÉ 11/2017.

APÊNDICE 4- NOTAS ATRIBUÍDAS AOS GUIAS DE PRÁTICA CLÍNICA PARA TRATAMENTO DA HIPERTENSÃO ARTERIAL SISTÊMICA POR CADA AVALIADOR PARA CADA ITEM DO AGREE II. 


\section{INTRODUÇÃO}

A população mundial está envelhecendo aceleradamente (1). A Organização Mundial de Saúde (OMS) estimou para 2015 que a população mundial de pessoas com 60 anos ou mais era de 900 milhões, e é esperado que esse número chegue a 2 bilhões em 2050 (2). O envelhecimento populacional implica em aumento da prevalência de doenças crônicas, especialmente as doenças crônicas não transmissíveis (DCNT) $(3,4)$. As DCNT constituem um problema de saúde pública, tanto por sua prevalência quanto por atingir especialmente os grupos mais pobres e vulneráveis da população mundial $(5,6)$.

As DCNT constituem um grave problema de saúde pública e a OMS estimou que foram responsáveis por 41 milhões de óbitos em 2016 (7). Além disso, representam um custo significativo para a sociedade (8-10). Estima-se, por exemplo, que entre 12 e $16,5 \%$ dos gastos de um sistema de saúde sejam apenas para cobrir despesas decorrentes de doenças cardiovasculares (8). Uma das mais prevalentes DCNT é a hipertensão arterial sistêmica (HAS), com prevalência estimada em 1,5 bilhões em 2025 (11).

Os benefícios do tratamento farmacológico da HAS são reconhecidos e muitos guias de prática clínica (GPC) são publicados com o objetivo de nortear o cuidado ao paciente hipertenso, incluindo recomendações sobre a farmacoterapia. De fato, há muito tempo, reconhece-se a importância do processo de cuidado em saúde estar baseado na melhor evidência científica disponível (12). Nortear as decisões clínicas, com base em evidências, com a escolha das opções mais custoefetivas, aumenta qualidade e eficiência do processo de cuidado, sendo os GPC responsáveis pela disseminação dessas evidências, subsidiando a tomada de decisão na prática clínica (12).

Nos últimos 20 anos, observou-se um aumento significativo do número de GPC disponíveis, sobretudo em alguns países, como, por exemplo, Estados Unidos, Canadá, Austrália e Nova Zelândia. Em 1990, havia 73 GPC indexados no Pubmed, em 2012 esse número ultrapassava 7.500 (13). Apesar do número crescente de GPC, a qualidade de grande parte desses documentos tem sido considerada insatisfatória (14-16). Dessa forma, há grande preocupação em relação a qualidade 
do processo de análise da evidência e formulação das recomendações, confiabilidade e independência dos GPC, o que justifica a adoção de instrumentos tanto para nortear o desenvolvimento desses documentos quanto para avaliar o rigor do método utilizado na elaboração dos GPC (17).

Entre esses instrumentos, o Appraisal of Guidelines for Research \& Evaluation (AGREE) teve sua primeira versão publicada em 2003, sendo amplamente utilizado para avaliar a qualidade e o rigor metodológico dos GPC $(18,19)$. Esse instrumento foi aperfeiçoado em 2009, encontrando-se na segunda versão (AGREE II) (18).

O processo de desenvolvimento de um novo GPC exige dedicação de equipe multiprofissional e tempo para levantamento e análise das evidências (20-22). Para situações em que existem GPC de boa qualidade metodológica, discute-se que a elaboração de um novo GPC poderia ser substituída por um processo de adaptação, o que reduziria a duplicação desnecessária de esforços e do uso de recursos humanos e financeiros $(23,24)$. A adaptação de GPC deve ser realizada com base em métodos consistentes e confiáveis; e considerando a contextualização local (25). Por esse motivo, em 2005, uma colaboração formada por pesquisadores, desenvolvedores e implementadores de GPC, denominada Colaboração ADAPTE, desenvolveu o método ADAPTE para nortear o processo de adaptação de GPC (26).

$O$ método ADAPTE compreende três fases: Configuração, Adaptação e Finalização. Engloba o uso do AGREE na fase de adaptação para a avaliação da qualidade metodológica dos GPC (26) e a elaboração de uma matriz a partir das recomendações dos GPC de alta qualidade.

Embora seja esperado um processo mais simples, mesmo o ADAPTE exige habilidades mais comuns entre os acadêmicos, sobretudo para realizar o levantamento e qualificação dos GPC disponíveis na literatura. Assim, com base nos GPC de alta qualidade para tratamento da HAS em adultos e idosos na atenção primária, foi proposto elaborar uma matriz para tratamento farmacológico da HAS a fim de disponibilizar uma síntese que possa subsidiar o processo de adaptação de novos GPC. 


\section{OBJETIVO}

\subsection{OBJETIVO PRINCIPAL}

Sintetizar as recomendações para tratamento farmacológico da hipertensão arterial sistêmica (HAS) em adultos ou idosos.

\subsection{OBJETIVOS ESPECÍFICOS}

$\checkmark$ Determinar a qualidade metológica de guias de prática clínica (GPC) contendo recomendações para o tratamento farmacológico da HAS;

$\checkmark$ Desenvolver uma matriz contendo as recomendações de GPC de alta qualidade para o tratamento farmacológico da HAS;

$\checkmark$ Comparar as recomendações farmacológicas para o tratamento da HAS. 


\section{REVISÃO DA LITERATURA}

\subsection{HIPERTENSÃO}

De acordo com a OMS, a população mundial está envelhecendo rapidamente (1). Enquanto para 2015 o número estimado de idosos era de 900 milhões, é esperado que em 2050, esse número alcance 2 bilhões de pessoas (2). Em 2020, pela primeira vez na história, o número de pessoas com 60 anos ou mais será superior ao de crianças menores de 5 anos (2). Enquanto a taxa de aumento do número de idosos entre 2010 e 2050 está estimada em 71\% nos países desenvolvidos, nos países em desenvolvimento chega a $250 \%$ (1). O aumento da expectativa de vida implica em aumento da prevalência de DCNT, definidas como condições de longa duração, de progressão geralmente lenta, e que requerem acompanhamento médico contínuo e/ou limitam as atividades de vida diária, modificando assim as necessidades no cuidado em saúde $(3,4)$.

A OMS estimou que, em 2016, dos 57 milhões de óbitos, 41 milhões (71\%) seriam decorrentes de DCNT (7). Essas doenças foram responsáveis pela morte "prematura" de 15 milhões de pessoas, ou seja, pessoas que morreram entre 30 e 69 anos. Segundo a OMS, mais de $85 \%$ dessas mortes "prematuras" ocorreram em países em desenvolvimento (7).

A HAS destaca-se entre as DCNT por sua alta prevalência; pelo seu potencial para aumento da ocorrência de eventos cardiovasculares; e pela possibilidade de ser controlada por meio de tratamento farmacológico (27). A OMS estimou que em 2008 cerca de 1 bilhão de pessoas, com 25 anos ou mais, seriam hipertensas no mundo, o que representava aproximadamente $40 \%$ da população mundial (28).

Estudo basedo em dados populacional nacionais, subnacionais ou da comunidade, realizado em 2017, analisou 1.479 estudos publicados entre 1975 e 2015, incluindo 19,1 milhões de adultos, visando investigar o número de adultos maiores de 18 anos com HAS. Esse estudo estimou que o número de hipertensos aumentou de 594 milhões em 1975, para 1,13 bilhões em 2015 (29). Em revisão sistemática foi estimado que esse número chegará à aproximadamente 1,5 bilhões em 2025, representando cerca de $15 \%$ a $20 \%$ da população mundial (11). 
Apesar de ser conhecida a ótima relação custo-efetividade do tratamento farmacológico da HAS, seu controle e a adesão à farmacoterapia permanecem uma lacuna em todo o mundo (30-32). Esse é um problema particularmente relevante à medida que a HAS é importante fator de risco para doenças cardiovasculares (3335). As doenças cardiovasculares são uma das principais causas de morte na atualidade. Estima-se que tenham sido responsáveis por 17,9 milhões de óbitos em 2016 (7).

\subsection{SAÚDE BASEADA EM EVIDÊNCIAS E GUIAS DE PRÁTICA CLÍNICA}

Espera-se que as decisões no processo de cuidado de qualquer doença, inclusive HAS, sejam tomadas com base nas evidências científicas disponíveis (12). O termo Medicina Baseada em Evidências (MBE) surgiu na década de 1980 para descrever o ensino baseado em problemas reais. Esse conceito foi expandido, passando a se chamar Saúde Baseada em Evidências (SBE), ou ainda Prática Baseada em Evidências (PBE), por envolver outras áreas da saúde, não se restringindo apenas a medicina (36).

A SBE teve sua origem no Canadá (Mc Master University), e no Reino Unido (University of York), e é definida como a utilização da melhor evidência científica disponível para subsidiar a tomada de decisão clínica, sendo essa um elo entre a melhor evidência cientifica, a experiência clinica individual e os valores dos pacientes (36-38). Por meio da SBE os profissionais da área da saúde tem acesso as melhores informações disponíveis para um melhor cuidado ao seu paciente (39) Ela propõe uma pirâmide de evidências para a tomada de decisão na prática clinica, na qual os estudos com maior nível de evidência estão localizados no topo e correspondem à estudos secundários: GPC, revisões sistemáticas e meta-análises. Esses estudos secundários sintetizariam a evidência proveniente de estudos primários, sobretudo de ensaios clínicos randomizados e controlados e, na ausência desses, estudos observacionais $(40,41)$.

Atualmente, embora ainda seja bastante disseminada a proposta de classificação da qualidade da evidência de acordo com o tipo de estudo, já é discutido que também deve-se considerar o rigor metodológico do estudo primário. 
Como exemplo, pode-se citar a classificação de evidências elaborada pelo Centre for Evidence-Based Medicine, o qual classifica um ensaio clínico randomizado (ECR) com alto risco de viés no mesmo nível de evidência que um estudo coorte elaborado com alto rigor metodológico (42).

Entre os métodos disponíveis para a classificação de evidências, tem se destacado o Grading of Recommendations Assesment, Development and Evaluation (GRADE), sendo considerado um dos métodos mais adequados e amplamente utilizado pelos desenvolvedores de GPC para avaliar a qualidade das evidências e determinar a força de suas recomendações (43). Esse método permite considerar todos os aspectos relevantes para qualificação das evidências, como o desenho do estudo, a presença de viéses, custos e balancear benefícios e danos (44). Diferentemente de outros métodos, o GRADE explicita a pontuação que deve ser dada de acordo com cada item para se qualificar as evidências, minimizando erros na avaliação que podem surgir quando essa pontuação é dada de forma implicita (44).

Espera-se que a SBE possa nortear as decisões clínicas e propiciar escolhas de tratamentos mais efetivos, resultando em maior qualidade de assistência com menor custo possível. Como forma promover a SBE, os GPC, também conhecidos como diretrizes clínicas ou guidelines, são reconhecidos como ferramentas essenciais para a assistência do paciente, desde que possuam alto rigor metodológico $(12,40,41)$, sendo sua utilização recomendada pela OMS $(45,46)$.

Segundo a definição do Institute of Medicine (IOM) da National Academy of Sciences dos Estados Unidos, GPC são documentos que incluem recomendações destinadas a otimizar o atendimento ao paciente. Esses documentos são elaborados por meio de revisão sistemática das evidências existentes e da avaliação dos riscos, benefícios e custos das alternativas de cuidados (47). A elaboração e publicação de GPC teve início no final da década de 70 pelo National Institutes of Health Consensus Development Program, dos Estados Unidos, seguido por organizações holandesas e suecas e, a partir da década de 90, pelos demais países (48). Nos últimos 20 anos, observou-se aumento significativo do número de GPC disponíveis, entretanto muitos estudos identificaram que esses documentos possuíam baixa ou moderada qualidade (49-56). 


\subsection{AVALIAÇÃO DE QUALIDADE DE GUIAS DE PRÁTICA CLÍNICA}

Para avaliação da qualidade dos GPC muitos instrumentos foram desenvolvidos, sendo que a maioria analisa como foi realizada a busca sistemática, a avaliação das evidências, a síntese das evidências, e se o desenvolvimento do documento foi baseado nos princípios da SBE $(57,58)$. Poucos instrumentos avaliam conflitos de interesse e participação de pacientes, o que é primordial para a confiabilidade do GPC e a sua implementação $(57,58)$.

Os autores de uma revisão sistemática que comparou similaridades e diferenças entre instrumentos de avaliação de GPC identificaram vinte e quatro instrumentos para avaliação de qualidade de GPC, embora apenas quatro fossem validados (57). Destes quatro, somente o Cluzeau's Appraisal Instrument e 0 Appraisal of Guidelines for Research \& Evaluation (AGREE) abordaram todas as dimensões esperadas em um GPC: descrição do objetivo, população alvo, usuário alvo, problema de saúde e contexto de saúde que o GPC será aplicado; descrição do grupo elaborador, incluindo uma equipe multiprofissional e representantes de pacientes, declaração de financiamento e conflito de interesses; descrição da estratégia usada na busca na literatura, seleção e qualificação das evidências, avaliação de riscos, benefícios e custos, método usado na formulação das recomendações, como se deu a consideração da opinião de pacientes, resultados esperados e descrição das situações que o GPC pode ou não ser aplicável; descrição de revisão externa; clareza na apresentação das recomendações e documentos que facilitem a aplicabilidade do GPC; planejamento para atualização; e estratégias para implementação, disseminação e monitoramento do GPC (57).

O Cluzeau's Appraisal Instrument, foi elaborado em 1999 por autores britânicos independentes, baseando-se no instrumento elaborado em 1992 pela National Academy of Sciences, denominado instrumento provisório (A Provisional Instrument for Assessing Clinical Practice Guideline), pois o comitê elaborador acreditava que era necessário testá-lo (59). O instrumento provisório era composto por 46 itens. Esse instrumento foi destinado a pesquisadores ou clínicos especialistas, sendo seu uso mais restrito e de difícil entendimento pelo público leigo $(57,60)$. Posteriormente, foi publicado o Cluzeau's Appraisal Instrument, composto por 37 itens dispostos em 3 domínios: rigor de desenvolvimento (20 itens), clareza 
da apresentação (12 itens) e implementação (5 itens) $(61,62)$. Esse instrumento foi validado por 120 avaliadores, e posteriormente serviu de inspiração para a elaboração do AGREE $(61,62)$.

O AGREE, foi desenvolvido em 2003, pela AGREE Collaboration, como forma de auxiliar na elaboração de GPC, ainda que posteriormente tenha sido amplamente utilizado para avaliar a qualidade e o rigor metodológico desses documentos (18). O instrumento foi aperfeiçoado em 2009, com a publicação de uma segunda versão (AGREE II). Na segunda versão, foram implementadas algumas alterações em manual do usuário para facilitar o entendimento do usuário e alterações na escala de pontuação dos itens (a escala Likert de quatro pontos passou a ser de sete) para possibilitar uma avaliação mais ampla (18). O AGREE II foi validado e testado em vários países, inclusive para o português brasileiro, sendo, atualmente, amplamente utilizado para avaliação da qualidade de GPC (19). Este instrumento é de fácil entendimento, podendo ser empregado por qualquer indivíduo desde que com treinamento prévio. O treinamento está disponível na plataforma AGREE TRUST e no manual do usuário (63).

O AGREE II é composto por 23 itens, dispostos em seis domínios: escopo e finalidade; envolvimento das partes interessadas; rigor do desenvolvimento; clareza e apresentação; aplicabilidade; e independência editorial, conforme apresentado em Quadro 1 (64). 
Quadro 1 - Domínios e itens do instrumento Appraisal of Guidelines for Research \& Evaluation, versão II.

\section{Domínio 1: Escopo e finalidade}

1. $\mathrm{O}(\mathrm{s})$ objetivo(s) geral(is) da(s) diretriz(es) está(ão) especificamente descrito(s).

2. A(s) questão(ões) de saúde coberta(s) pela diretriz está(ão) especificamente descrita(s).

3. A população (pacientes, público etc.) a quem a diretriz se destina está especificamente descrita.

\section{Domínio 2: Envolvimento das partes interessadas}

4. A equipe de desenvolvimento da diretriz inclui indivíduos de todos os grupos profissionais relevantes.

5. Procurou-se conhecer as opiniões e preferências da população-alvo (pacientes, público etc.).

6. Os usuários-alvo da diretriz estão claramente definidos.

\section{Domínio 3: Rigor do desenvolvimento}

7. Foram utilizados métodos sistemáticos para a busca de evidências.

8. Os critérios para a seleção de evidências estão claramente descritos.

9. Os pontos fortes e limitações do corpo de evidências estão claramente descritos.

10. Os métodos para a formulação das recomendações estão claramente descritos.

11. Os benefícios, efeitos colaterais e riscos à saúde foram considerados na formulação das recomendações.

12. Existe uma relação explícita entre as recomendações e as evidências que lhe dão suporte.

13. A diretriz foi revisada externamente por experts antes da sua publicação.

14. Um procedimento para atualização da diretriz está disponível.

\section{Domínio 4: Clareza da apresentação}

15. As recomendações são específicas e sem ambiguidade.

16. As diferentes opções de abordagem da condição ou problema de saúde estão claramente apresentadas.

17. As recomendações-chave são facilmente identificadas.

\section{Domínio 5: Aplicabilidade}

18. A diretriz descreve os fatores facilitadores e as barreiras para a sua aplicação.

19. A diretriz traz aconselhamento e/ou ferramentas sobre como as recomendações podem ser colocadas em prática.

20. Foram consideradas as potenciais implicações quanto aos recursos decorrentes da aplicação das recomendações.

21. A diretriz apresenta critérios para o seu monitoramento e/ou auditoria.

\section{Domínio 6: Independência editorial}

22. O parecer do órgão financiador não exerceu influência sobre o conteúdo da diretriz.

23. Foram registrados e abordados os conflitos de interesse dos membros da equipe que desenvolveram a diretriz.

Fonte: AGREE II, 2009. 
Para pontuar cada um dos itens do AGREE II utilizada-se a escala tipo Likert, cuja pontuação de cada domínio é calculada por meio da soma das pontuações atribuídas por cada avaliador para cada item individual do domínio em questão. Esse instrumento recomenda que a avaliação seja realizada por 2 a 4 avaliadores (64).

De acordo com o Manual do AGREE II, as pontuações de cada domínio não devem ser combinadas numa única pontuação de qualidade. A pontuação de cada domínio é determinada pela porcentagem do total da pontuação do domínio em relação ao máximo de pontos possíveis para aquele domínio (64). O cálculo da porcentagem total de cada domínio está apresentado na equação presente na Figura 1.

Figura 1 - Cálculo da porcentagem total de cada domínio do instrumento Appraisal of Guidelines for Research \& Evaluation, versão II.

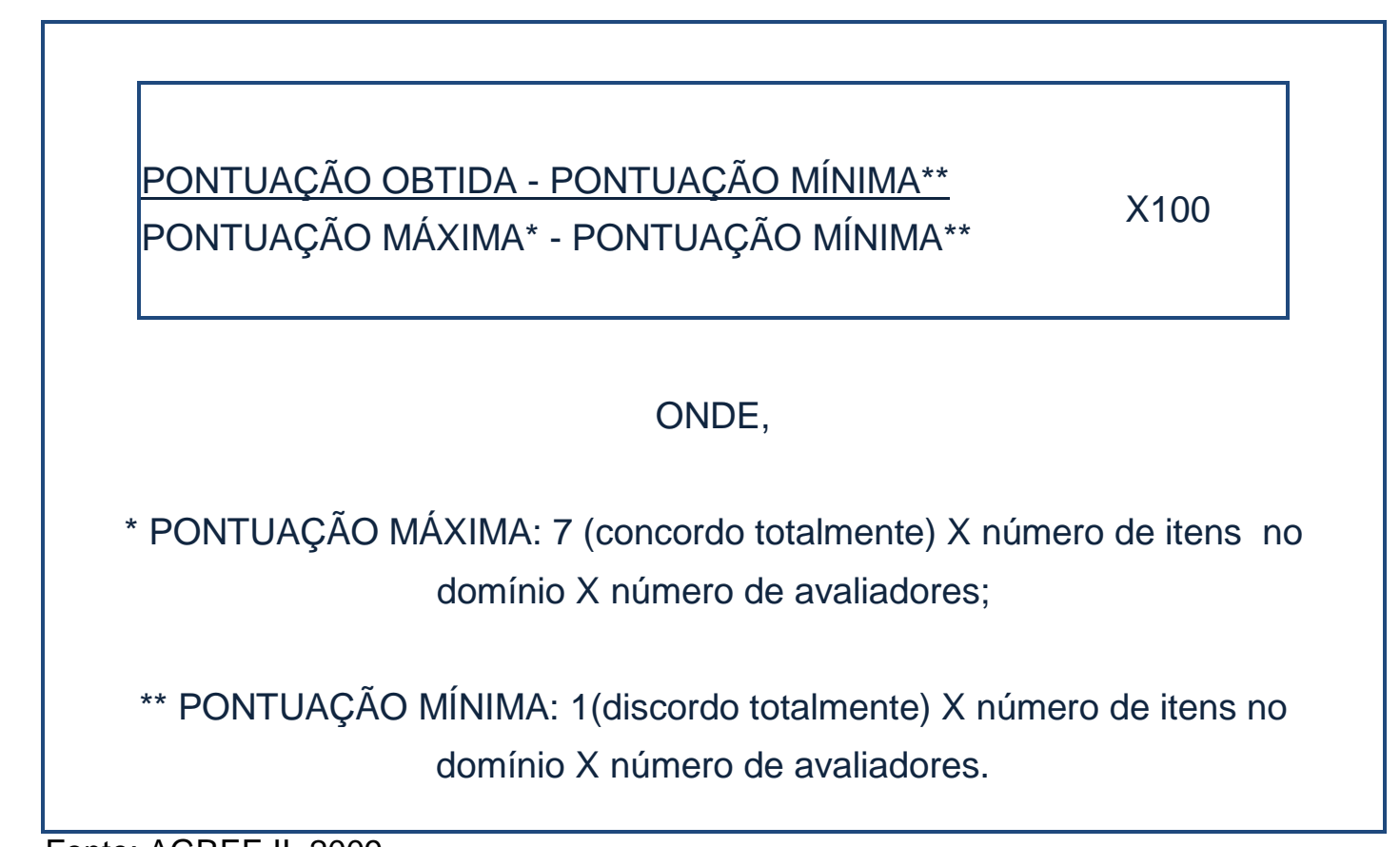

Fonte: AGREE II, 2009.

Uma revisão publicada em 2010, na qual foram analisadas 42 revisões sistemáticas sobre a qualidade metodológica de 626 GPC, publicados entre 1980 e 2007, e avaliados pelo instrumento AGREE, concluiu que a qualidade dos GPC elaborados nas últimas décadas era de baixa à moderada (14). Mais recentemente, Armstrong et al (2017) analisaram a qualidade metodológica de 25 revisões 
sistemáticas, incluindo 415 GPC, e relataram uma ligeira melhora na qualidade dos GPC ao longo do tempo, porém a qualidade ainda era de baixa a moderada (15).

Para a elaboração de um GPC partindo da revisão sistemática (um novo GPC), os elaboradores de GPC necessitam de muito tempo e de recursos humanos e financeiros o que, muitas vezes, é escasso e finito $(65,66)$. A falta de tempo foi relatada como uma das barreiras para elaboração de GPC para uso local em um estudo realizado em hospitais da Austrália, Indonésia, Malásia, Filipinas e Tailândia, no qual foram entrevistados médicos e enfermeiros (67).

Os GPC podem ser elaborados por meio de revisão sistemática a partir de estudos primários e secundários (um novo GPC); adotados, emprego de GPC já existente; ou adaptados, adequando ao contexto local (21). A adoção de GPC de alta qualidade é uma alternativa para economizar recursos, porém essa alternativa não considera as diferenças culturais e sociais locais e, portanto, não permite ajustes para as condições específicas (68).

Em cenários em que existem GPC de boa qualidade metodológica, discute-se que a elaboração de um novo GPC poderia ser substituída por um processo de adaptação, baseando-se em uma matriz de recomendações de GPC com alta qualidade metodológica. Esse processo tem 0 o intuito de reduzir a duplicação desnecessária de esforços e de recursos, principalmente por se saber que em muitos países a elaboração de um novo não se mostra viável, e a adaptação, diferentemente da adoção permite ajustes para que se leve em conta valores culturais e sociais das partes interessadas (20-22). Alguns estudos sugerem que a adaptação de GPC pode aumentar a probabilidade de sua implementação $(69,70)$. Devido as vantagens do processo de adaptação algumas instituições já aderiram a essa prática (71-73).

\subsection{ADAPTAÇÃO DE GUIAS DE PRÁTICA CLÍNICA}

A adaptação de GPC deve ser realizada com base em métodos consistentes e confiáveis; e considerando a contextualização local (25). Em uma revisão sistemática publicada em 2017, que visava identificar e descrever métodos para adaptação de GPC, foram identificadas oito ferramentas de adaptação: ADAPTE; 
The Adapted ADAPTE by the Alexandria Center for Evidence-Based Clinical Practice Guidelines (EBCPG); Alberta Ambassador Program; GRADE-ADOLOPMET; Making GRADE the Irresistible Choice (MAGIC); RAPADAPTE; Royal College of Nursing; Systematic Guideline Review Method (74).

O método ADAPTE foi criado em em 2005, pela Colaboração ADAPTE. Esse grupo de trabalho se formou a partir da junção de dois grupos distintos, o grupo ADAPTE e o grupo Practice Guideline Evaluation and Adaptation Cycle (PGEAC), e foi criado com o intuito de promover o desenvolvimento e uso de GPC, por meio da adaptação de GPC existentes, e obter a similaridade nos conceitos e princípios (26).

$O$ método The Adapted ADAPTE by the Alexandria Center for EBCPG foi elaborado por um grupo de pesquisadores do Centro de Prática Clínica Baseada em Evidências, em Alexandria, por meio de uma adaptação do método ADAPTE original. Este método foi desenvolvido gradualmente durante a adaptação de onze GPC reais, os quais foram produzidos entre 2010 e 2015. Essa adaptação foi criada a fim de dar mais clareza, simplicidade e praticidade na utilização do intrumento e de reduzir recursos e tempo para o processo de adaptação desses GPC. Esse método, como o Adapte, compreende 24 passos, realizados em três fases, porém com algumas alterações em alguns passos; o acréscimo de uma lista com base em GPC reconhecidas, criação de tópicos em pediatria e medicina de emergência econsiderações em relação a divulgação e implementação dos GPC adaptados (75).

O Alberta Ambassador Program, publicado em 2006, foi elaborado por meio de um processo colaborativo, envolvendo diversas parcerias Esse método compreende 11 passos em três fases: Configuração, Adaptação e Finalização. A fase de Configuração é baseada na avaliação do conhecimento dos profissionais e identificação das lacunas nesse conhecimento, para assim formular as questões de pesquisa e definição do público-alvo. A fase de Adaptação é baseada na identificação de GPC relevantes, elaboração de tabelas e matrizes de evidências e versão rascunho do GPC para revisão. A fase de finalização é baseada na revisão e aperfeiçoamento do GPC adaptado e, criação um plano para divulgação e implementação da mesma. Esse método foi elaborado com o objetivo de adaptar GPC para uso local para prevenção, diagnóstico e tratamento de adultos com dor lombar, afim de reduzir o uso de tratamentos ineficazes e auxiliar todos os profissionais da atenção primária responsáveis pelo tratamento da dor lombar (76). 
O GRADE-ADOLOPMENT foi desenvolvido pelo grupo de trabalho GRADE, da Universidade McMaster, Canadá, pensando-se em um modelo eficiente para guiar a produção de GPC, o qual combinou a adoção, adaptação e elaboração de novas recomendações, conforme necessário, utilizando para avaliação das evidências o GRADE evidence to decision (77). Essa ferramenta foi aplicada em um programa de GPC nacionais, o qual deu origem a 22 GPC em um período de 18 meses pelo Ministério da Saúde na Arábia Saudita $(77,78)$. Esse método permite o uso combinado de recomendações adotadas, adaptadas e de um novo e consiste de oito passos: organização geral e planejamento; identificação de possíveis participantes e treinamento; seleção de tópicos de orientação; priorização das questões a serem abordadas; aplicação da ferramenta GRADE, atualização ou revisão sistemática sobre os efeitos em saúde e identificação de dados locais; utilização da tabela GRADE; preparação das tabelas e quadros de evidências para tomada de decisão; formulação e avaliação da força das recomendações (77). Diferentemente dos demais métodos de adaptação, este método não usa a recomendação dos GPC com alta qualidade metodológica avaliados previamente com o instrumento AGREE II para adaptação de um GPC, e sim a evidência que gerou a recomendação e demais evidências localizadas na literatura para elaborar novas recomendações (77).

O MAGIC foi desenvolvido em 2014 visando facilitar a atualização e adaptação de GPC de forma estruturada e sistemática, baseando-se no método ADAPTE e padrões da metodologia GRADE. Este compreende 5 passos: planejamento, avaliação inicial das recomendações, modificação, publicação e avaliação; e foi utilizado inicialmente para adaptação da $9^{\circ}$ edição do GPC para terapêutica antitrombótica e prevenção de trombose, para a realidade norueguesa (79).

A ferramenta RADAPTE foi criada baseando-se na experiência de elaboração de um GPC com 90 recomendações para tratamento do câncer de mama, a qual foi desenvolvida em apenas 6 meses, mesmo com resursos limitados na Costa Rica. Essa ferramenta foi baseada inicialmente no método ADAPTE, porém utilizou também evidências de bancos de dados, as quais foram avaliadas utilizando 0 GRADE (80). Foi elaborada para acelerar o processo de desenvolvimento de GPC sem comprometer a validade e a relevância das recomendações resultantes; e 
compreende 12 passos: identificação e seleção do grupo de trabalho e alocação dos recursos; treinamento do grupo de trabalho; definição das questões clínicas; identificação de GPC relevantes; seleção dos GPC; identificação de evidências nos GPC para cada questão clínica pré definida; busca de novas evidências para questões clinicas não respondidas adequadamente; classificação da qualidade de evidências selecionadas previamente; elaboração das recomendações, levando- se em conta os benefícios, riscos, preferências e custos; fornecimento de versão rascunho para revisão; modificação das recomendações conforme necessário, baseado na revisão de especialistas e; elaboração da versão final (80).

A estratégia criada pelo Royal College of Nursing foi desenvolvida em 2000 para possibilitar o processo de adaptação de GPC sobre a gestão de pacientes com úlceras venosas na perna e avaliação e prevenção de risco de úlcera de pressão para uso local (81). Foi baseado em um quadro composto por 5 passos: identificação de um tópico prioritário; localização de GPC sobre o tópico escolhido; avaliação da qualidade do GPC encontrado; avaliação da aplicabilidade do GPC e; adaptação para o uso local (81).

O Systematic Guideline Review Method, que foi desenvolvido em 2006 para produção de um GPC para insuficiência cardíaca crônica para médicos de família na Alemanha, compreende 9 passos: busca sistemática de GPC, seleção de GPC de acordo com critérios pré-definidos, avaliação da qualidade dos GPC, desenvolvimento de uma estrutura, extração de dados, análises de consistência, síntese de informações, validação e formulação de rascunho de GPC (82).

\subsection{O MÉTODO ADAPTE}

O método ADAPTE, compreende 24 passos em três fases: Configuração, Adaptação e Finalização, como resumido na Figura $2(26,83)$. 
Figura 2 - Etapas do método ADAPTE.

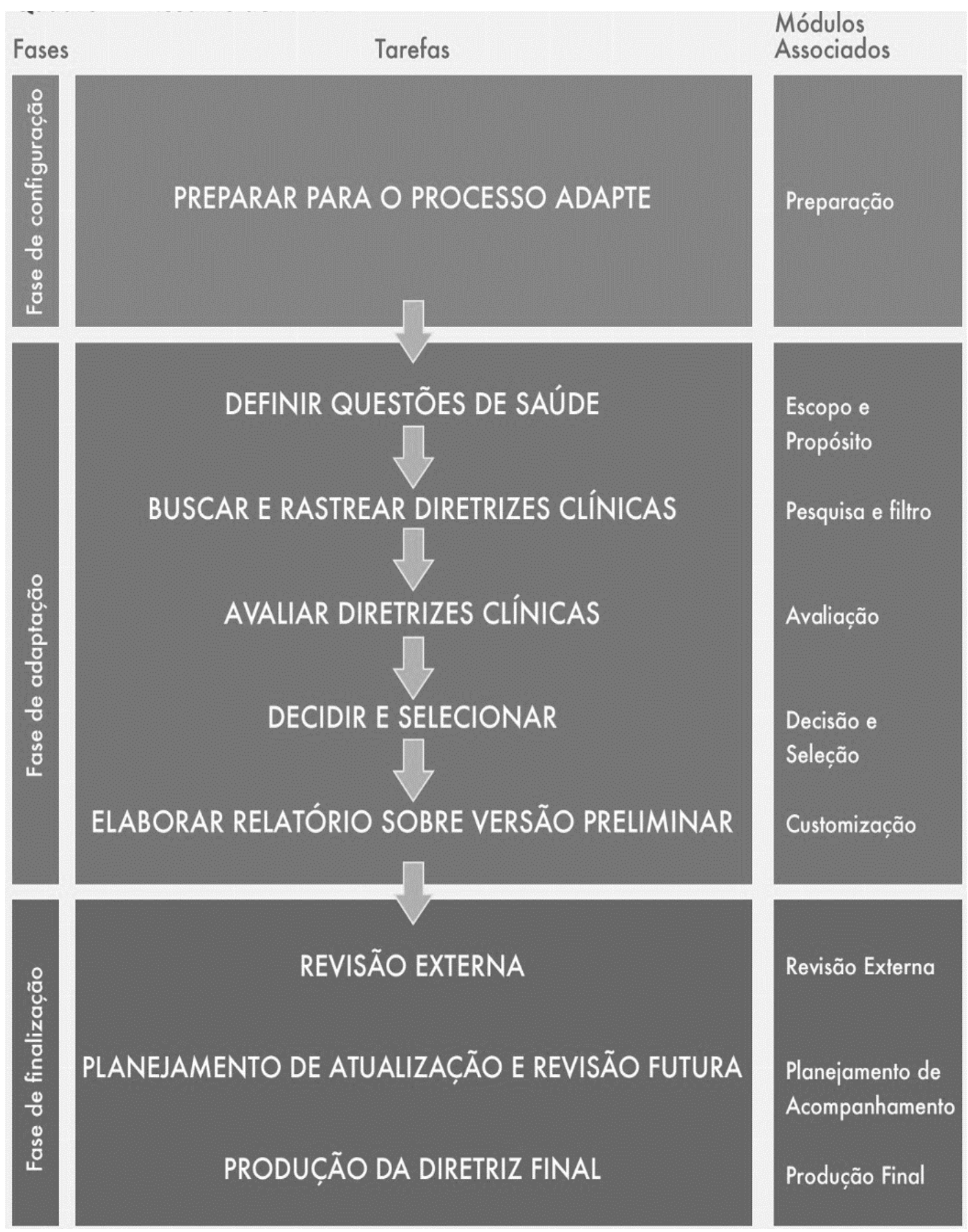

Fonte: Brasil (2014).

A fase de Configuração inclui atividades de preparação e planejamento e as tarefas necessárias que devem ser concluídas antes do início do processo de adaptação do GPC. Para tal, verifica-se a possibilidade de adaptação, realiza-se a 
seleção do tópico à ser abordado; identifica-se recursos e habilidades; estabelecemse comitês de organização e elaboração do documento; e redige-se o protocolo (26).

A fase de Adaptação consiste na etapa de determinação das questões de saúde: População, Intervenção, Profissionais, Desfechos e Sistemas de saúde, denominada ferramenta PIPDS. Nesta, também estão incluídas as etapas de elaboração técnica de levantamento dos GPC e de outros documentos relevantes; seleção dos documentos a serem considerados; avaliação da qualidade metodológica, com base no instrumento AGREE; redução do número de GPC, por meio do estabelecimento de um ponto de corte; e extração das recomendações em matrizes, ou seja, a matriz das recomendações a partir dos GPC de melhor qualidade (26).

A fase de Finalização traduz-se em processos de discussão e decisões sobre o documento que foi elaborado durante a etapa de adaptação (matriz das recomendações). Deve ser realizada com a participação de representantes do público alvo, de agências de aprovação e desenvolvedores de diretrizes. Após, realiza-se o planejamento do acompanhamento do GPC adaptado, no qual se estabelece o prazo de revisão e atualização para esse documento e a produção do documento de orientação final de alta qualidade (26).

A fase de Adaptação engloba 0 uso do AGREE para a avaliação da qualidade metodológica dos GPC e seleção dos mesmos. O ADAPTE não traz um ponto de corte para um GPC ser considerado aceitável ou inaceitável, segundo as porcentagens dos escores dos domínios, porém o instrumento propõe que o grupo avaliador estabeleça um ponto de corte superior ao escore mediano, ou, superior a $60 \%$ no domínio 3, rigor de desenvolvimento (26). Esse método foi traduzido e adotado pelo Ministério da Saúde em 2014, tornando-se parte das suas diretrizes metodológicas, por esse motivo esse método foi escolhido para elaboração desse trabalho (83).

Na Nova Zelândia até o ano de 2012 existia um programa de elaboração de GPC de alta qualidade respeitado internacionalmente por meio do New Zealand Guidelines Group, porém esse grupo foi desfeito e a partir de então o Ministério da Saúde da Nova Zelândia criou uma nova organização, afim de criar novos GPC por meio da adaptação de GPC do National Institute for Health and Care Excellence (NICE) para o contexto local utilizando o método ADAPTE (71). 
Em 2018, na região do Mediterrâneo Oriental, foi elaborado um modelo para adaptação de GPC, no qual vinte e duas equipes elaboraram GPC para uso local em hospitais universitários, por meio do método ADAPTE, com algumas modificações. Por meio desse processo 35 GPC foram desenvolvidos e aprovados para implementação. Os autores relataram que esse método foi rápido, prático e econômico (73).

\subsection{MATRIZ DE RECOMENDAÇÕES}

Apesar dos diferentes métodos existentes para adaptação de GPC, a maioria deles tem duas etapas em comum: a avaliação da qualidade metodológica dos GPC encontrados e a elaboração da matriz das recomendações a partir dos GPC com alta qualidade (74). A exceção seria o GRADE-ADOLOPMENT, que propõe que a evidência que foi usada para formular as recomendações dos GPC de alta qualidade seja revista pelo grupo responsável pelo desenvolvimento do novo GPC (77).

Para a avaliação da qualidade, o método mais amplamente utilizado é o AGREE (19), já em relação a matriz de recomendações, não há na literatura uma única maneira de elaboração. Assim, as recomendações podem ser apresentadas por similaridade ou separadas por GPC. Além disso, as informações podem ser ordenadas por data da publicação do GPC ou pelo escore da avaliação da qualidade do AGREE $(26,62,84)$. Vários autores tem publicado essas matrizes, denominandoas como sínteses de recomendações, com a finalidade de subsidiar o processo de adaptação ou apenas comparar as recomendações contidas em diferentes GPC (70,85-92). Além da possibilidade de análise da consistência das recomendações, o principal objetivo da matriz é facilitar processos locais de adaptação de GPC, reduzindo o uso de recursos humanos e financeiros pelas instituições de saúde.

Matriz de recomendações é definida na literatura como tabelas ou quadros que contém as recomendações extraídas dos GPC selecionados anteriormente após avaliação da qualidade, e pode ainda conter recomendações de outros estudos como revisões sistemáticas e avaliações de tecnologias em saúde $(26,62,84)$. As matrizes de recomendações permitem comparar as similaridades e discrepâncias encontradas nas recomendações de diversos GPC, assim como os níveis das 
evidências usados na formulação das recomendações (26). O método ADAPTE recomenda ainda que a matriz seja revisada por um clínico especialista para que nenhuma recomendação esteja fora de contexto (26).

\subsection{GUIAS DE PRÁTICA CLÍNICA DA HIPERTENSÃO}

Al-Ansary et al (2013) fizeram uma revisão sistemática, na qual avaliaram a qualidade e compararam as recomendações dos GPC da HAS. Constataram que somente 2 de 11 GPC tinha alta qualidade metodológica (49). Outras duas revisões sistemáticas, publicadas em 2015 e 2016, as quais avaliaram a qualidade metodológica empregadas em 17 e 41 GPC da HAS, respectivamente, também concluiram que os GPC precisam melhorar a qualidade metodológica em seu desenvolvimento (93,94). Molino et al (2016) avaliaram a qualidade metodológica de 26 GPC para DCNT publicados no Brasil e reportaram que nenhum GPC foi considerado de alta qualidade, dentre os GPC dois eram para manejo da HAS e obtiveram escores de 18 e $20 \%$ no domínio "rigor de desenvolvimento" (16).

Em relação às recomendações, Al-Ansary et al (2013) relataram consistência entre aquelas sobre diagnóstico e cuidados não farmacológicos, mas disparidades nas recomendações referentes à farmacoterapia. As principais diferenças entre os GPC eram a respeito da seleção da primeira linha de tratamento, ajustes de dose e associação de medicamentos (49). Em 2015, outra revisão sistemática sobre avaliação comparativa do conteúdo dos GPC da HAS, dessa vez no que dizia respeito a população idosa, reportou também disparidades nas recomendações referentes a famacoterapia (95). 


\section{MATERIAL E MÉTODOS}

\subsection{ESTUDO}

Este estudo compõe a linha de pesquisa do Grupo Chronic Diseases and Informed Decisions (CHRONIDE), composto por docentes e alunos da Universidade Federal de São Paulo e da Universidade de São Paulo, incluindo a autora desta dissertação de mestrado (96).

Para o desenvolvimento do estudo foram realizadas a fase de Configuração e a fase de Adaptação, até a extração das recomendações e elaboração das matrizes de evidências para o tratamento farmacológico da HAS do método ADAPTE. Portanto, somente a fase de Finalização não foi realizada neste trabalho.

$\mathrm{Na}$ fase de Configuração, as atividades de preparação, planejamento e elaboração do protocolo, cadastrado na plataforma PRÓSPERO sob o registro 2016:CRD42016043364, foi desenvolvida e publicada pelo grupo CHRONIDE (97).

$\mathrm{Na}$ fase de Adaptação foi realizado o levantamento dos GPC para o tratamento da HAS. Para este trabalho, GPC foi considerado como qualquer documento que contivesse recomendações para o tratamento farmacológico da HAS na atenção primária. Para a avaliação da qualidade metodológica dos GPC, foi aplicado o instrumento AGREE II.

O método para a obtenção da seleção dos GPC, até a matriz das recomendações, apresenta-se descrito a seguir. Todas as etapas foram realizadas por no mínimo dois avaliadores, de forma independente. As discrepâncias, encontradas em quaisquer estágios, foram resolvidas por meio de consenso entre os avaliadores. Quando não houve um consenso, um terceiro avaliador foi incluído.

\subsection{SELEÇÃO DOS GUIAS DE PRÁTICA CLÍNICA}

Para a realização da busca sistematizada da literatura, elaborou-se uma pergunta com base no acrônimo Paciente; Intervenção; Profissional, Desfecho e Serviço de saúde (PIPDS), como apresentado no Quadro 2. 
Quadro 2 - Descrição do acrônimo PIPDS para a seleção dos guias de pratica clínica para tratamento farmacológico da hipertensão arterial sistêmica.

\begin{tabular}{|l|l|}
\hline P & Pacientes adultos ou idosos com HAS \\
\hline I & Tratamento farmacológico \\
\hline P & Profissionais da saúde em geral \\
\hline D & Controle da doença \\
\hline S & Atenção primária \\
\hline
\end{tabular}

Fonte: Elaboração própria.

Todavia, para que a busca fosse mais abrangente e não se excluisse GPC, os descritores foram combinados como apresentados em Quadro 3. Os outros itens do acrônimo foram incluídos como critérios de elegibilidade.

Quadro 3 - Estratégia de busca por guias de prática clinica para tratamento farmacológico da hipertensão arterial sistêmica, realizada em 22/01/2017.

\begin{tabular}{|c|c|}
\hline Base de dados & Estratégia de busca \\
\hline $\begin{array}{l}\text { Medline (via } \\
\text { Pubmed) }\end{array}$ & $\begin{array}{l}((((" G u i d e l i n e " \text { [Publication Type] OR "Guidelines as Topic"[Mesh] OR } \\
\text { "Practice Guideline" [Publication Type] OR "Health Planning } \\
\text { Guidelines"[Mesh]) OR "Clinical Protocols"[Mesh])) OR ("Consensus } \\
\text { Development Conference, NIH" [Publication Type] OR "Consensus } \\
\text { Development Conference" [Publication Type] OR "Consensus"[Mesh]))) } \\
\text { OR "Standard of Care"[Mesh])) "Guideline" [Publication Type] OR } \\
\text { "Guidelines as Topic"[Mesh] OR "Practice Guideline" [Publication Type] } \\
\text { OR "Health Planning Guidelines"[Mesh]) OR "Clinical Protocols"[Mesh])) } \\
\text { OR ("Consensus Development Conference, NIH" [Publication Type] OR } \\
\text { "Consensus Development Conference" [Publication Type] OR } \\
\text { "Consensus"[Mesh]))) OR "Standard of Care"[Mesh]))) AND } \\
\text { ("Hypertension"[Mesh] OR Blood Pressure, High OR Blood Pressures, } \\
\text { High OR High Blood Pressure OR High Blood Pressures)) }\end{array}$ \\
\hline Embase & $\begin{array}{l}\text { ('practice guideline'/mj OR 'consensus development'/exp/mj OR 'clinical } \\
\text { protocol'/mj AND 'hypertension'/exp AND (2011:py OR 2012:py } \\
\text { OR 2013:py OR 2014:py OR 2015:py OR 2016:py) AND [embase]/lim) }\end{array}$ \\
\hline Cochrane Library & $\begin{array}{l}\text { \#1 MeSH descriptor: [Guideline] explode all trees } \\
\text { \#2 MeSH descriptor: [Consensus] explode all trees } \\
\text { \#3 MeSH descriptor: [Clinical Protocols] explode all trees } \\
\text { \#4 \#1 OR \#2 OR \#3 } \\
\text { \#5 MeSH descriptor: [Hypertension] explode all trees }\end{array}$ \\
\hline
\end{tabular}

Fonte: Elaboração própria.

A seleção dos GPC abrangeu as bases de dados do Medline (via Pubmed), Embase e Cochrane Library e 12 bases específicas para o período de 01/2011 a 
12/2016. As bases específicas de GPC consultadas foram: Australian Clinical Practice Guidelines (clinicalguidelines.gov.au), Brazilian Ministry of Health (saude.gov.br), Canadian Agency for Drugs and Technologies in Health (cadth.ca), Canadian Medical Association (cma.ca), Chilean Ministry of Health (bibliotecaminsal.cl/guias-clinicas-auge/), Colombian Ministry of Health and Social Protection (http://gpc.minsalud.gov.co/gpc/SitePages/default_gpc.aspx), Guidelines International Network (g-i-n.net), Institute for Clinical Systems Improvement (icsi.org), National Guideline Clearinghouse (guidelines.gov), Portal GuíaSalud (guiasalud.es), Scottish Intercollegiate Guidelines Network (sign.ac.uk), e the National Institute for Health and Care Excellence (nice.org.uk)).

Pesquisa manual também foi realizada nas revistas e sites responsáveis pela publicação de GPC, a fim de localizar a versão mais recente de GPC selecionados e todos os documentos relacionados, como, por exemplo: documentos suplementares, sumário das recomendações, documentos e aplicativos para pacientes e profissionais da saúde e outros. Os documentos obtidos nas bases de dados foram anexados ao Mendeley ${ }^{\circledR}$ (98), que se trata de uma base de referências bibliográficas. Por meio desse, foram excluídas os documentos repetidos. Em seguida, realizou-se a seleção dos GPC.

Para a seleção dos GPC, foram considerados os seguintes critérios de elegibilidade: GPC para HAS com texto completo, incluindo recomendações para o tratamento farmacológico, com ou sem outras comorbidades, publicadas em inglês, espanhol ou português, com recomendações para assistência primária, para a população adulta ou idosa.

Posteriormente à exclusão dos documentos repetidos, os títulos e os resumos de cada documento foram lidos, e os GPC que não atendiam aos critérios de elegibilidade foram excluídos. Na etapa seguinte, os avaliadores fizeram a leitura completa dos GPC e aplicaram, novamente, os critérios de elegibilidade. Em 11/2017, foi realizada nova busca para identificar versões atualizadas de GPC incluídos no estudo. 


\subsection{EXTRAÇÃO DAS CARACTERÍSTICAS GERAIS DOS GUIAS DE PRÁTICA CLÍNICA}

A caracterização geral dos GPC selecionados para avaliação da qualidade foi extraída por meio de um formulário Google®, a fim de realizar análise descritiva dos documentos utilizados. Esse formulário foi testado e validado anteriormente por meio da extração de dados de trinta GPC, que continham tratamento farmacológico para osteoporose.

Os dados extraídos foram:

- número de autores;

- ano de publicação;

- continente em que o GPC foi elaborado;

- tipo do GPC: Elaborado ou Atualizado;

- tipo de instituição/organização responsável pela elaboração: Governo, sempre que qualquer instância governamental estivesse envolvida ou a instituição, mesmo que independente, tenha elaborado GPC para o governo; Sociedade, quando o GPC teve como autores uma ou mais sociedades; ou Universidade ou pesquisador, para pesquisadores independentes ou GPC em nome da universidade ou de hospital universitário;

- período previsto para atualização: Menciona ou Não menciona;

- método de desenvolvimento do GPC: Revisão sistemática; Adaptação, ou outros métodos;

- método para formular as recomendações: Consenso formal, quando o método para o consenso foi descrito detalhadamente; ou Consenso sem detalhes do processo, quando a explicação foi sucinta ou somente mencionada a utilização de consenso;

- sistema de classificação de evidências: GRADE, para o GRADE ou GRADE adaptado; outros métodos de classificação; ou não classificou as evidências; e

- órgão financiador: Governo, Sociedade, Indústria, ou Universidade ou pesquisador. 


\subsection{AVALIAÇÃO DE QUALIDADE DOS GUIAS DE PRÁTICA CLÍNICA}

Para a avaliação da qualidade e do rigor metodológico dos GPC foi empregado o instrumento AGREE ॥ (64). A análise da qualidade dos GPC foi realizada por três avaliadores independentes, que passaram por um treinamento prévio, constituído pelas seguintes etapas:

- leitura do manual do AGREE II e de dois artigos que usaram esse instrumento $(18,56,99)$, registro de conta na plataforma AGREE, disponível em: http://www.agreetrust.org/resource-centre/agreeplus/ e treinamento online disponível em: http://www.agreetrust.org/resource-centre/agree-ii-training-tools/.

- avaliação de três GPC e discussão com demais integrantes do grupo CHRONIDE: Protocolo clínico e diretrizes terapêuticas (PCDT) para dor crônica (100), PCDT para doença de Gaucher (101) e GPC para tratamento da Obesidade (Obesity - NICE) (102).

- avaliação de dois GPC e discussão com demais integrantes do grupo CHRONIDE: Hipertireoidismo (103) e Infecção do trato urinário - NGC (104).

A porcentagem total de cada domínio de GPC foi determinada conforme escala do tipo Likert de sete pontos, no qual o 1 corresponde a discordo totalmente (quando não há informação relevante ou a mesma está mal escrita), e 07 a condordo totalmente (quando a qualidade da informação é excelente e todos os critérios estão descritos) (64). Cada um dos três avaliadores pontuou cada item para cada GPC na plataforma do AGREE (site: https://www.agreetrust.org/). Posteriormente, o trio de avaliadores recebeu relatório da avaliação. Discrepâncias com dois pontos ou mais foram discutidas pelos avaliadores até obter consenso.

O cálculo da nota para cada um dos seis domínios do AGREE II foi realizado de acordo com a fórmula proposta no manual, de forma automática pela plataforma. A nota do domínio é dada em porcentagem, ou seja, a nota representa em qual proporção o GPC cumpriu os critérios de qualidade do AGREE II referentes ao : escopo e finalidade; envolvimento das partes interessadas; rigor do 
desenvolvimento; clareza e apresentação; aplicabilidade; ou independência editorial (18).

Para esse estudo, tal qual sugerido pelo ADAPTE e outros estudos, a qualidade do GPC foi classificada com base na pontuação do domínio 3 (rigor do desenvolvimento), sendo considerado de alta qualidade todos os GPC com escore igual ou superior a $60 \%(26,105-108)$. Este domínio foi escolhido por ser considerado o mais relevante para a confiabilidade das recomendações listadas nos GPC, uma vez que avalia a qualidade do processo de revisão das evidências e da formulação das recomendações $(50,54)$.

\subsection{MATRIZES DE RECOMENDAÇÕES PARA FARMACOTERAPIA DA HIPERTENSÃO ARTERIAL SISTÊMICA}

As recomendações referentes à farmacoterapia foram extraídas e transcritas para uma planilha de Excel $\AA$, por dois pesquisadores de forma independente. $A$ classificação de qualidade da evidência e/ou força das recomendações também foram extraídos.

Em seguida, essas recomendações foram agrupadas em tópicos mais amplos, de acordo as semelhanças de assuntos, por meio de um processo interativo com um terceiro pesquisador e, na sequência, discutidas com um clínico geral e dois nefrologistas, sendo um especialista em HAS.

As recomendações foram agrupadas em relação:

$\checkmark \quad$ ao público e condição clínica, a saber: adultos, populações especiais (hipertensão sistólica isolada, idosos, negros) e pacientes com outras comorbidades.

$\checkmark$ ao tipo de recomendação: início de tratamento (indicação de farmacoterapia, meta, farmacoterapia) ou alternativas terapêuticas. 


\subsection{CONSIDERAÇÕES ÉTICAS}

Trata-se de pesquisa em bases de dados da literatura, portanto foi dispensada da avaliação de Comitê de Ética em Pesquisa da Faculdade de Ciências Farmacêuticas da Universidade de São Paulo, de acordo com a Resolução 466/12 do Conselho Nacional de Saúde. 


\section{RESULTADOS}

\subsection{BUSCA E SELEÇÃO DOS GUIAS DE PRÁTICA CLÍNICA}

Foram localizados 3.795 documentos nas bases Pubmed, Embase e Cochrane; e 33 nas bases específicas. Desses, 287 foram selecionados para leitura dos textos. Após aplicação dos critérios de elegibilidade, 37 documentos, foram incluídos na avaliação de qualidade por meio do instrumento AGREE II, conforme apresentado em Figura 3.

Figura 3 - Fluxograma de seleção de guias de prática clínica para tratamento farmacológico da hipertensão arterial sistêmica para avaliação da qualidade metodológica com instrumento AGREE II.

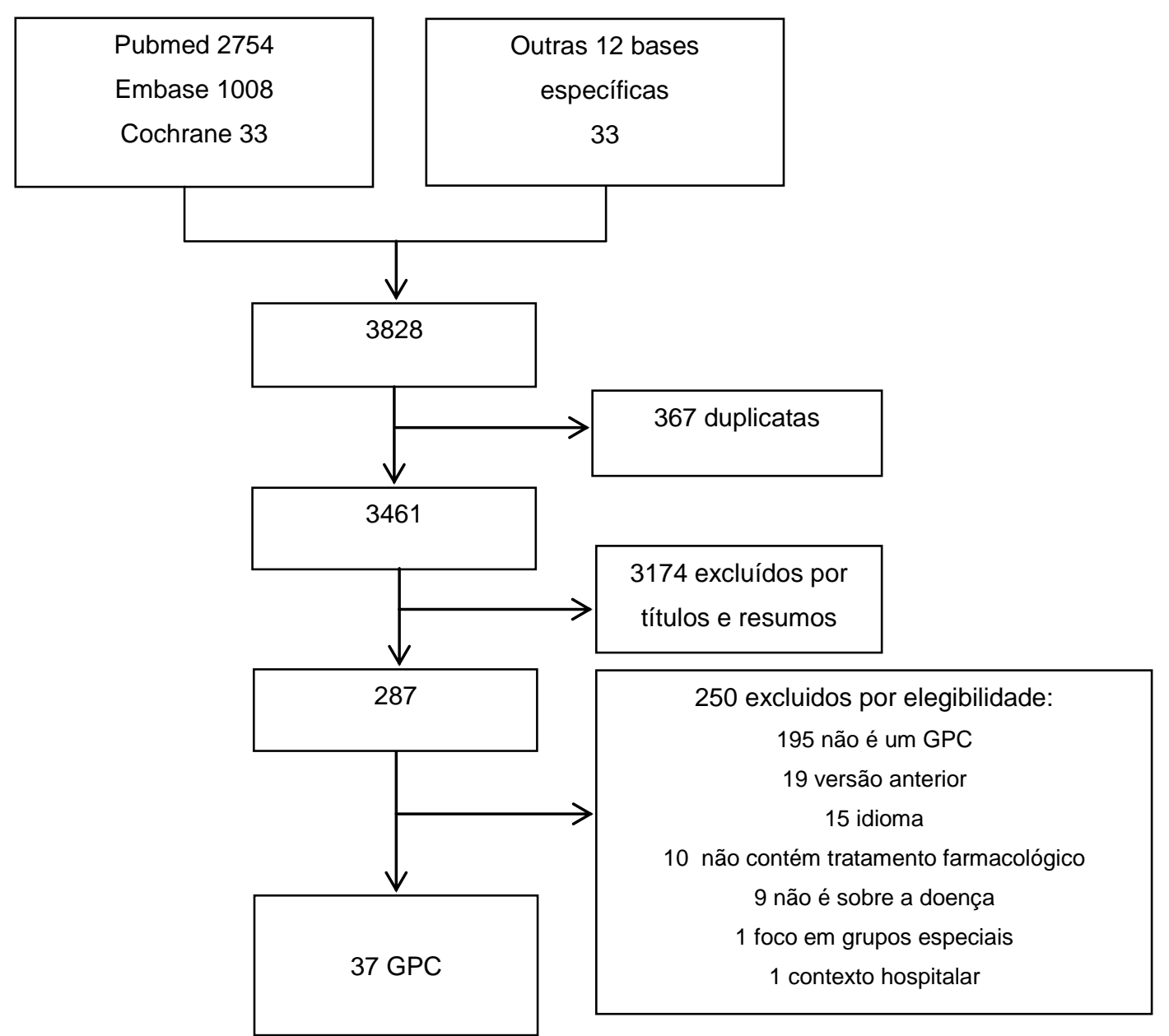

Fonte: Elaboração própria. 
Os 37 GPC incluídos estão descritos no Apêndice 1 e os documentos excluídos, com base nos critérios de elegibilidade, após a leitura do texto na íntegra, estão em Apêndice 2.

\subsection{EXTRAÇÃO DAS CARACTERÍSTICAS GERAIS DOS GUIAS DE PRÁTICA CLÍNICA}

Como pode ser observado na Tabela 1, dos 37 GPC incluídos, somente 7 apresentaram período previsto para atualização; 27,1\% (10/37) foram elaborados na América do Norte; mais da metade foram elaborados por sociedades profissionais. Além disso, somente 27,1\% (10/37) foram desenvolvidos por meio de revisão sistemática e mais de um terço $(35,1 \%)$ não mencionaram como foram desenvolvidos. Chama a atenção que 56,8\% (21/37) não mencionaram se o GPC foi ou não financiado. O detalhamento dos dados coletados para cada GPC estão dispostos no Apêndice 3.

Tabela 1 - Características gerais dos guias de prática clinica (GPC) para tratamento farmacológico da hipertensão arterial sistêmica, obtido por meio de revisão sistemática no período de 01/2011 a 12/2016, atualizado os GPC incluídos até $11 / 2017$.

\begin{tabular}{lccc}
\hline Caracteristicas & & N de GPC & \\
Número de autores & Não mencionado & & $\%$ \\
\hline & $\leq 5$ & 2 & $5,4 \%$ \\
& 6 a 10 & 10 & $27,1 \%$ \\
Ano de publicação & 11 a 20 & 7 & $18,9 \%$ \\
& $>20$ & 5 & $13,5 \%$ \\
& 2011 & 13 & $35,1 \%$ \\
& 2013 & 3 & $8,1 \%$ \\
& 2014 & 9 & $24,3 \%$ \\
& 2015 & 14 & $37,9 \%$ \\
& 2016 & 4 & $10,8 \%$ \\
& 2017 & 5 & $13,5 \%$ \\
\hline
\end{tabular}


Conclusão

\begin{tabular}{|c|c|c|}
\hline Caracteristicas & $\begin{array}{c}\mathrm{N} \text { de GPC } \\
(\mathrm{n}=37)\end{array}$ & $\%$ \\
\hline \multicolumn{3}{|l|}{ Continente } \\
\hline América do Norte & 10 & $27,1 \%$ \\
\hline Ásia & 8 & $21,6 \%$ \\
\hline Europa & 8 & $21,6 \%$ \\
\hline América do Sul & 7 & $18,9 \%$ \\
\hline Africa & 2 & $5,4 \%$ \\
\hline Oceania & 1 & $2,7 \%$ \\
\hline Intercontinental & 1 & $2,7 \%$ \\
\hline \multicolumn{3}{|l|}{ Tipo de GPC } \\
\hline Elaborado & 20 & $54,1 \%$ \\
\hline Atualizado & 17 & $45,9 \%$ \\
\hline \multicolumn{3}{|c|}{ Tipo da instituição responsável pela elaboração } \\
\hline Sociedade & 19 & $51,4 \%$ \\
\hline Governo & 9 & $24,3 \%$ \\
\hline Universidade ou pesquisador & 9 & $24,3 \%$ \\
\hline \multicolumn{3}{|l|}{ Periodo para atualização } \\
\hline Não menciona & 29 & $78,4 \%$ \\
\hline Menciona & 8 & $21,6 \%$ \\
\hline \multicolumn{3}{|l|}{ Método de desenvolvimento } \\
\hline Não menciona & 13 & $35,1 \%$ \\
\hline Outro & 12 & $32,4 \%$ \\
\hline Revisão sistemática & 10 & $27,1 \%$ \\
\hline Adaptado & 2 & $5,4 \%$ \\
\hline \multicolumn{3}{|l|}{ Método para formular as recomendações } \\
\hline Consenso sem detalhes & 16 & $43,2 \%$ \\
\hline Não menciona & 15 & $40,6 \%$ \\
\hline Consenso formal & 6 & $16,2 \%$ \\
\hline \multicolumn{3}{|l|}{ Sistema de classificação de evidências } \\
\hline Não classifica & 18 & $48,7 \%$ \\
\hline Outro & 12 & $32,4 \%$ \\
\hline GRADE & 7 & $18,9 \%$ \\
\hline \multicolumn{3}{|l|}{ Financiamento } \\
\hline Não menciona & 21 & $56,8 \%$ \\
\hline Sociedade & 8 & $21,6 \%$ \\
\hline Governo & 5 & $13,5 \%$ \\
\hline Indústria & 2 & $5,4 \%$ \\
\hline Universidade ou pesquisador & 1 & $2,7 \%$ \\
\hline
\end{tabular}

Fonte: Elaboração própria. 


\subsection{AVALIAÇÃO E SELEÇÃO DOS GUIAS DE PRÁTICA CLÍNICA COM ALTA QUALIDADE}

As notas de cada domínio, atribuídas aos 37 GPC para tratamento da HAS, em ordem decrescente de valor para o domínio 3, são apresentadas no Quadro 4. Observa-se que, somente, os 6 primeiros GPC apresentaram nota de $60 \%$ ou mais para o domínio em questão, ou seja, 16\% (6/37) apresentaram alta qualidade. As notas atribuídas por cada avaliador estão disponíveis no Apêndice 4.

Quadro 4 - Notas do AGREE II por domínio para cada guia de prática clinica (GPC) para tratamento farmacológico da hipertensão arterial sistêmica, obtido por meio de revisão sistemática no período de 01/2011 a 12/2016, atualizado os GPC incluídos até 11/2017.

\begin{tabular}{|c|c|c|c|c|c|c|}
\hline & $\begin{array}{c}\text { Domínio } \\
1\end{array}$ & $\begin{array}{l}\text { Domínio } \\
2\end{array}$ & $\begin{array}{l}\text { Domínio } \\
3\end{array}$ & $\begin{array}{l}\text { Domínio } \\
4\end{array}$ & $\begin{array}{l}\text { Domínio } \\
5\end{array}$ & $\begin{array}{l}\text { Domínio } \\
6\end{array}$ \\
\hline Guia de Prática Clínica & $\begin{array}{l}\text { Escopo e } \\
\text { finalidade }\end{array}$ & $\begin{array}{l}\text { Envolvi- } \\
\text { mento das } \\
\text { partes } \\
\text { interessa- } \\
\text { das }\end{array}$ & $\begin{array}{l}\text { Rigor do } \\
\text { desenvolvi- } \\
\text { mento }\end{array}$ & $\begin{array}{l}\text { Clareza da } \\
\text { apresenta- } \\
\text { ção }\end{array}$ & $\begin{array}{l}\text { Aplicabili- } \\
\text { dade }\end{array}$ & $\begin{array}{l}\text { Indepen- } \\
\text { dência } \\
\text { editorial }\end{array}$ \\
\hline $\begin{array}{l}\text { Guia de Prática Clínica para } \\
\text { Hipertensão Arterial Primaria- } \\
\text { Colômbia (109) }\end{array}$ & $91 \%$ & $59 \%$ & $92 \%$ & $89 \%$ & $94 \%$ & $67 \%$ \\
\hline $\begin{array}{l}\text { Hypertension in adults: diagnosis and } \\
\text { management - NICE }(110)\end{array}$ & $100 \%$ & $85 \%$ & $83 \%$ & $98 \%$ & $71 \%$ & $78 \%$ \\
\hline $\begin{array}{c}2017 \\
\text { ACC/AHA/AAPA/ABC/ACPM/AGS/AP } \\
\text { hA/ASH/ASPC/NMA/PCNA Guideline } \\
\text { for the Prevention, Detection, } \\
\text { Evaluation, and Management of High } \\
\text { Blood Pressure in Adults - } \underline{\mathbf{2 0 1 7}} \\
\text { ACC/AHA (111) }\end{array}$ & $78 \%$ & $72 \%$ & $81 \%$ & $89 \%$ & $50 \%$ & $78 \%$ \\
\hline $\begin{array}{l}\text { VA/DoD clinical practice guideline for } \\
\text { the diagnosis and management of } \\
\text { hypertension in the primary care } \\
\text { setting - VADOD (112) }\end{array}$ & $91 \%$ & $76 \%$ & $72 \%$ & $100 \%$ & $49 \%$ & $58 \%$ \\
\hline $\begin{array}{c}\text { Hypertension Canada's } 2017 \\
\text { Guidelines for Diagnosis, Risk } \\
\text { Assessment, Prevention, and } \\
\text { Treatment of Hypertension in Adults- } \\
\text { Canadá (113) }\end{array}$ & $70 \%$ & $52 \%$ & $63 \%$ & $80 \%$ & $26 \%$ & $81 \%$ \\
\hline $\begin{array}{c}\text { Diagnóstico y Tratamiento de la } \\
\text { HIPERTENSIÓN ARTERIAL en el } \\
\text { Primer Nivel de Atención - México } \\
\text { (114) }\end{array}$ & $76 \%$ & $44 \%$ & $63 \%$ & $83 \%$ & $19 \%$ & $69 \%$ \\
\hline
\end{tabular}

Continua 


\section{Continuação}

\begin{tabular}{|c|c|c|c|c|c|c|}
\hline & $\begin{array}{c}\text { Domínio } \\
1\end{array}$ & $\begin{array}{c}\text { Domínio } \\
2\end{array}$ & $\begin{array}{c}\text { Domínio } \\
3\end{array}$ & $\begin{array}{c}\text { Domínio } \\
4\end{array}$ & $\begin{array}{c}\text { Domínio } \\
5\end{array}$ & $\begin{array}{c}\text { Domínio } \\
6 \\
\end{array}$ \\
\hline Guia de Prática Clínica & $\begin{array}{l}\text { Escopo e } \\
\text { finalidade }\end{array}$ & $\begin{array}{l}\text { Envolvi- } \\
\text { mento das } \\
\text { partes } \\
\text { interessa- } \\
\text { das }\end{array}$ & $\begin{array}{l}\text { Rigor do } \\
\text { desenvolvi- } \\
\text { mento }\end{array}$ & $\begin{array}{l}\text { Clareza da } \\
\text { apresenta- } \\
\quad \text { ção }\end{array}$ & $\begin{array}{l}\text { Aplicabili- } \\
\text { dade }\end{array}$ & $\begin{array}{l}\text { Indepen- } \\
\text { dência } \\
\text { editorial }\end{array}$ \\
\hline Heart Foundation - HAS 2016 (115) & $78 \%$ & $50 \%$ & $58 \%$ & $76 \%$ & $42 \%$ & $47 \%$ \\
\hline $\begin{array}{l}\text { Clinical practice guidelines on arterial } \\
\text { hypertension - NGC: } 015712(116)\end{array}$ & $70 \%$ & $48 \%$ & $56 \%$ & $72 \%$ & $35 \%$ & $53 \%$ \\
\hline $\begin{array}{c}\text { The Japanese Society of Hypertension } \\
\text { Guidelines for the Management of } \\
\text { Hypertension (117) }\end{array}$ & $46 \%$ & $33 \%$ & $54 \%$ & $78 \%$ & $19 \%$ & $47 \%$ \\
\hline $\begin{array}{c}\text { Essential hypertension - NGC:010401 } \\
(118)\end{array}$ & $81 \%$ & $41 \%$ & $51 \%$ & $93 \%$ & $49 \%$ & $33 \%$ \\
\hline $\begin{array}{c}\text { ACCF/AHA } 2011 \text { Expert Consensus } \\
\text { Document on Hypertension in the } \\
\text { Elderly (119) }\end{array}$ & $54 \%$ & $44 \%$ & $49 \%$ & $69 \%$ & $33 \%$ & $50 \%$ \\
\hline $\begin{array}{l}\text { Management of Hypertension (4th } \\
\text { Edition) - Malaysia (120) }\end{array}$ & $80 \%$ & $48 \%$ & $43 \%$ & $85 \%$ & $24 \%$ & $64 \%$ \\
\hline $\begin{array}{l}\text { Treatment of hypertension in patients } \\
\text { with coronary artery disease }(121)\end{array}$ & $54 \%$ & $6 \%$ & $42 \%$ & $67 \%$ & $8 \%$ & $47 \%$ \\
\hline $\begin{array}{l}\text { Management of resistant hypertension: } \\
\text { expert consensus statement from the } \\
\text { French Society of Hypertension (122) }\end{array}$ & $50 \%$ & $17 \%$ & $41 \%$ & $57 \%$ & $13 \%$ & $53 \%$ \\
\hline $\begin{array}{l}\text { Hypertension- Diagnosis and } \\
\text { Management - British Columbia (123) }\end{array}$ & $70 \%$ & $22 \%$ & $38 \%$ & $72 \%$ & $31 \%$ & $33 \%$ \\
\hline $\begin{array}{c}\text { 7a Diretriz Brasileira de Hipertensão } \\
\text { Arterial (124) }\end{array}$ & $81 \%$ & $26 \%$ & $35 \%$ & $81 \%$ & $17 \%$ & $42 \%$ \\
\hline $\begin{array}{c}2013 \mathrm{ESH} / \mathrm{ESC} \text { Guidelines for the } \\
\text { management of arterial hypertension } \\
(125)\end{array}$ & $52 \%$ & $31 \%$ & $31 \%$ & $87 \%$ & $28 \%$ & $42 \%$ \\
\hline $\begin{array}{c}\text { Expert consensus on blood pressure } \\
\text { management of diabetic patients in } \\
\text { China (126) } \\
\end{array}$ & $54 \%$ & $19 \%$ & $27 \%$ & $59 \%$ & $7 \%$ & $17 \%$ \\
\hline $\begin{array}{l}\text { The Egyptian hypertension society: } \\
\text { Egyptian hypertension guidelines (127) }\end{array}$ & $44 \%$ & $37 \%$ & $25 \%$ & $83 \%$ & $51 \%$ & $86 \%$ \\
\hline $\begin{array}{l}\text { Hypertension in the elderly: how to } \\
\text { treat patients in } 2013 ? \text { The essential } \\
\text { recommendations of the Polish } \\
\text { guidelines (128) }\end{array}$ & $59 \%$ & $22 \%$ & $24 \%$ & $65 \%$ & $4 \%$ & $25 \%$ \\
\hline $\begin{array}{c}\text { Guía de Práctica Clínica para el } \\
\text { Diagnóstico, Tratamiento y Control de } \\
\text { la Enfermedad Hipertensiva (129) }\end{array}$ & $56 \%$ & $15 \%$ & $23 \%$ & $74 \%$ & $21 \%$ & $17 \%$ \\
\hline $\begin{array}{c}\text { Hypertension in diverse populations: A } \\
\text { New York State Medicaid clinical } \\
\text { guidance document (130) }\end{array}$ & $44 \%$ & $19 \%$ & $22 \%$ & $56 \%$ & $25 \%$ & $8 \%$ \\
\hline $\begin{array}{l}\text { Indian guidelines on hypertension } \\
\text { (I.G.H.) - III (131) }\end{array}$ & $59 \%$ & $31 \%$ & $22 \%$ & $57 \%$ & $8 \%$ & $17 \%$ \\
\hline $\begin{array}{c}\text { Management of hypertension in adults: } \\
\text { the } 2013 \text { French Society of } \\
\text { Hypertension guidelines (132) }\end{array}$ & $54 \%$ & $44 \%$ & $17 \%$ & $61 \%$ & $10 \%$ & $50 \%$ \\
\hline
\end{tabular}

\section{Continua}




\section{Conclusão}

\begin{tabular}{|c|c|c|c|c|c|c|}
\hline & $\begin{array}{c}\text { Domínio } \\
1\end{array}$ & $\begin{array}{l}\text { Domínio } \\
2\end{array}$ & $\begin{array}{l}\text { Domínio } \\
3\end{array}$ & $\begin{array}{c}\text { Domínio } \\
4\end{array}$ & $\begin{array}{l}\text { Domínio } \\
5\end{array}$ & $\begin{array}{c}\text { Domínio } \\
6\end{array}$ \\
\hline Guia de Prática Clínica & $\begin{array}{l}\text { Escopo e } \\
\text { finalidade }\end{array}$ & $\begin{array}{c}\text { Envolvi- } \\
\text { mento das } \\
\text { partes } \\
\text { interessa- } \\
\text { das } \\
\end{array}$ & $\begin{array}{l}\text { Rigor do } \\
\text { desenvolvi- } \\
\text { mento }\end{array}$ & $\begin{array}{l}\text { Clareza da } \\
\text { apresenta- } \\
\quad \text { ção }\end{array}$ & $\begin{array}{l}\text { Aplicabili- } \\
\text { dade }\end{array}$ & $\begin{array}{l}\text { Indepen- } \\
\text { dência } \\
\text { editorial }\end{array}$ \\
\hline $\begin{array}{l}\text { Abordaje de la hipertension arterial en } \\
\text { el paciente anciano (133) }\end{array}$ & $52 \%$ & $0 \%$ & $13 \%$ & $50 \%$ & $4 \%$ & $42 \%$ \\
\hline $\begin{array}{l}\text { Combination therapy in hypertension: } \\
\text { an Asia-Pacific consensus viewpoint } \\
(134)\end{array}$ & $59 \%$ & $20 \%$ & $12 \%$ & $63 \%$ & $6 \%$ & $31 \%$ \\
\hline $\begin{array}{c}2015 \text { Oman Heart Association } \\
\text { Guidelines for the Management of } \\
\text { Hypertension (135) }\end{array}$ & $48 \%$ & $22 \%$ & $10 \%$ & $70 \%$ & $13 \%$ & $6 \%$ \\
\hline $\begin{array}{l}\text { Latin American consensus on } \\
\text { hypertension in patients with diabetes } \\
\text { type } 2 \text { and metabolic syndrome (136) }\end{array}$ & $59 \%$ & $31 \%$ & $10 \%$ & $50 \%$ & $18 \%$ & $28 \%$ \\
\hline $\begin{array}{c}\text { South African hypertension practice } \\
\text { guideline } 2014(137)\end{array}$ & $44 \%$ & $24 \%$ & $9 \%$ & $61 \%$ & $21 \%$ & $0 \%$ \\
\hline $\begin{array}{c}\text { Consensus of Chinese Specialists on } \\
\text { Diagnosis and Treatment of Resistant } \\
\text { Hypertension (138) }\end{array}$ & $28 \%$ & $11 \%$ & $8 \%$ & $39 \%$ & $13 \%$ & $0 \%$ \\
\hline $\begin{array}{c}\text { Clinical management of resistant } \\
\text { hypertension: recommendations from } \\
\text { the ISH (139) }\end{array}$ & $43 \%$ & $28 \%$ & $8 \%$ & $52 \%$ & $4 \%$ & $0 \%$ \\
\hline $\begin{array}{l}\text { Clinical Practice Guidelines for the } \\
\text { Management of Hypertension in the } \\
\text { Community (140) }\end{array}$ & $37 \%$ & $39 \%$ & $8 \%$ & $63 \%$ & $29 \%$ & $58 \%$ \\
\hline $\begin{array}{c}\text { I brazilian position paper on } \\
\text { antihypertensive drug combination } \\
\text { (141) }\end{array}$ & $39 \%$ & $9 \%$ & $8 \%$ & $57 \%$ & $7 \%$ & $3 \%$ \\
\hline $\begin{array}{l}\text { I Brazilian Position Paper on } \\
\text { Prehypertension, White Coat } \\
\text { Hypertension and Masked } \\
\text { Hypertension: Diagnosis and } \\
\text { Management (142) }\end{array}$ & $59 \%$ & $15 \%$ & $6 \%$ & $54 \%$ & $3 \%$ & $67 \%$ \\
\hline $\begin{array}{l}\text { Hypertension in the elderly: new blood } \\
\text { pressure targets and prescribing tips } \\
(143)\end{array}$ & $46 \%$ & $24 \%$ & $5 \%$ & $56 \%$ & $3 \%$ & $53 \%$ \\
\hline $\begin{array}{l}\text { Hipertension Arterial em pacientes con } \\
\text { diabetes mellitus tipo } 2(144)\end{array}$ & $48 \%$ & $6 \%$ & $4 \%$ & $50 \%$ & $3 \%$ & $0 \%$ \\
\hline $\begin{array}{l}\text { Hypertension management in diabetic } \\
\text { patients (145) }\end{array}$ & $48 \%$ & $11 \%$ & $4 \%$ & $52 \%$ & $1 \%$ & $0 \%$ \\
\hline
\end{tabular}

Fonte: Elaboração própria.

No geral, os 37 GPC apresentaram escores baixos nos domínios do AGREE II, sendo os domínios 4 (clareza da apresentação) e 1 (escopo e finalidade) os que apresentaram pontuação média mais alta, $68,9 \% \pm 15,3$ e $59,5 \% \pm 16,9$, respectivamente. O domínio 5 (aplicabilidade) foi o pior avaliado, com pontuação média de apenas $23,2 \% \pm 20,8$. O domínio 3 (rigor do desenvolvimento) foi o terceiro 
com menor pontuação média, $32,9 \% \pm 25,3 \%$. A variabilidade dos escores dos domínios do AGREE II para os 37 GPC incluídos estão descritas na Tabela 2.

Tabela 2 - Variação dos escores dos domínios do AGREE II para os trinta e sete guias de prática clinica (GPC) para tratamento farmacológico da hipertensão arterial sistêmica, obtido por meio de revisão sistemática no período de 01/2011 a 12/2016, atualizado os GPC incluídos até 11/2017.

\begin{tabular}{|c|c|c|c|c|c|c|c|}
\hline & Média & Mediana & $\begin{array}{l}\text { Desvio } \\
\text { Padrão }\end{array}$ & $\begin{array}{l}\text { Primeiro } \\
\text { quartil } \\
\text { (Q1) }\end{array}$ & $\begin{array}{l}\text { Terceiro } \\
\text { quartil } \\
\text { (Q3) }\end{array}$ & Mínimo & Máximo \\
\hline $\begin{array}{c}\text { Escopo e finalidade } \\
\text { (Domínio 1) } \\
\text { Envolvimento das partes } \\
\text { interessadas }\end{array}$ & 59,5 & 54 & 16,9 & 47 & 73 & 28 & 100 \\
\hline (Domínio 2) & 31,9 & 28 & 20 & 18 & 44 & 0 & 76 \\
\hline $\begin{array}{l}\text { Rigor do desenvolvimento } \\
\text { (Domínio 3) }\end{array}$ & 32,9 & 25 & 25,3 & 9,5 & 52,5 & 4 & 92 \\
\hline $\begin{array}{c}\text { Clareza da apresentação } \\
\text { (Domínio 4) }\end{array}$ & 68,9 & 67 & 15,3 & 56,5 & 82 & 39 & 100 \\
\hline $\begin{array}{l}\text { Aplicabilidade } \\
\text { (Domínio 5) }\end{array}$ & 23,2 & 19 & 20,8 & 7 & 32 & 1 & 51 \\
\hline $\begin{array}{l}\text { Independência editorial } \\
\text { (Domínio 6) }\end{array}$ & 39,2 & 42 & 26,2 & 17 & 58 & 0 & 86 \\
\hline
\end{tabular}

Fonte: Elaboração própria.

Os 6 GPC com alta qualidade metodológica, assim como os demais GPC, também apresentaram maior pontuação média nos domínios 4 - 89,8\% $\pm 7,9$ (clareza da apresentação) e no domínio $1-84,3 \% \pm 11,4$ (escopo e finalidade). A menor pontuação média foi observada para o domínio 5 -23,2\% \pm 27,9 (aplicabilidade), porém as médias obtidas nos escores foram muito superiores, quando comparadas aos demais GPC. A variabilidade dos escores dos domínios do AGREE II para os GPC com alta qualidade estão descritas na Tabela 3. 
Tabela 3 - Variação dos escores dos domínios do AGREE II para os seis guias de prática clinica (GPC) para tratamento farmacológico da hipertensão arterial sistêmica com alta qualidade $(60 \%$ ou mais no domínio 3$)$, obtido por meio de revisão sistemática no período de 01/2011 a 12/2016, atualizado os GPC incluídos até $11 / 2017$.

\begin{tabular}{|c|c|c|c|c|c|c|c|}
\hline & Média & Mediana & $\begin{array}{l}\text { Desvio } \\
\text { Padrão }\end{array}$ & $\begin{array}{l}\text { Primeiro } \\
\text { quartil } \\
\text { (Q1) }\end{array}$ & $\begin{array}{c}\text { Terceiro } \\
\text { quartil } \\
\text { (Q3) }\end{array}$ & Mínimo & Máximo \\
\hline $\begin{array}{l}\text { Escopo e finalidade } \\
\text { (Domínio 1) } \\
\text { Envolvimento das partes } \\
\text { interessadas }\end{array}$ & 84,3 & 84,5 & 11,4 & 74,5 & 93,3 & 70 & 100 \\
\hline (Domínio 2) & 64,7 & 65,5 & 15,6 & 50 & 78,3 & 44 & 85 \\
\hline $\begin{array}{l}\text { Rigor do desenvolvimento } \\
\text { (Domínio 3) }\end{array}$ & 75,7 & 76,5 & 11,7 & 63 & 85,3 & 63 & 92 \\
\hline $\begin{array}{l}\text { Clareza da apresentação } \\
\text { (Domínio 4) }\end{array}$ & 89,8 & 89 & 7,9 & 82,3 & 98,5 & 80 & 100 \\
\hline $\begin{array}{l}\text { Aplicabilidade } \\
\text { (Domínio 5) }\end{array}$ & 51,5 & 49,5 & 27,9 & 24,3 & 76,8 & 19 & 94 \\
\hline $\begin{array}{l}\text { Independência editorial } \\
\text { (Domínio 6) }\end{array}$ & 71,8 & 73,5 & 8,8 & 64,8 & 78,8 & 94 & 81 \\
\hline
\end{tabular}

Os 31 GPC com baixa qualidade metodológica, assim como os demais GPC, também apresentaram maior pontuação média no domínio 4 - 64,8\% $\pm 12,9$ (clareza da apresentação). Este foi o único domínio com pontuação média superior a $60 \%$. A menor pontuação média foi obtida no domínio $5-17,7 \% \pm 14,0$ (aplicabilidade). A variabilidade dos escores dos domínios do AGREE II para os GPC com alta qualidade estão descritas na Tabela 4. 
Tabela 4 - Variação dos escores dos domínios do AGREE II para os trinta e um guias de prática clinica (GPC) para tratamento farmacológico da hipertensão arterial sistêmica com baixa qualidade (menos de $60 \%$ no domínio 3), obtido por meio de revisão sistemática no período de 01/2011 a 12/2016, atualizado os GPC incluídos até 11/2017.

\begin{tabular}{|c|c|c|c|c|c|c|c|}
\hline & Média & Mediana & $\begin{array}{l}\text { Desvio } \\
\text { Padrão }\end{array}$ & $\begin{array}{l}\text { Primeiro } \\
\text { quartil } \\
\text { (Q1) }\end{array}$ & $\begin{array}{l}\text { Terceiro } \\
\text { quartil } \\
\text { (Q3) }\end{array}$ & Mínimo & Máximo \\
\hline $\begin{array}{l}\text { Escopo e finalidade } \\
\text { (Domínio 1) }\end{array}$ & 54,7 & 54 & 13,2 & 46 & 59 & 28 & 78 \\
\hline $\begin{array}{l}\text { Envolvimento das partes } \\
\text { interessadas } \\
\text { (Domínio 2) }\end{array}$ & 25,6 & 24 & 13,6 & 15 & 37 & 0 & 50 \\
\hline $\begin{array}{l}\text { Rigor do desenvolvimento } \\
\text { (Domínio 3) }\end{array}$ & 24,6 & 22 & 17,5 & 8 & 41 & 4 & 58 \\
\hline $\begin{array}{l}\text { Clareza da apresentação } \\
\text { (Domínio 4) }\end{array}$ & 64,8 & 63 & 12,9 & 56 & 74 & 39 & 93 \\
\hline $\begin{array}{l}\text { Aplicabilidade } \\
\text { (Domínio 5) }\end{array}$ & 17,7 & 13 & 14 & 6 & 28 & 1 & 51 \\
\hline $\begin{array}{c}\text { Independência editorial } \\
\text { (Domínio 6) }\end{array}$ & 32,9 & 33 & 23,6 & 8 & 50 & 0 & 86 \\
\hline
\end{tabular}

Fonte: Elaboração própria.

A comparação das médias dos escores obtidos para cada domínio dos GPC para farmacoterapia da hipertensão arterial sistêmica está apresentada na Figura 4. 
Figura 4 - Médias dos escores obtidos por domínio do AGREE II, dos guias de prática clínica para farmacoterapia da hipertensão arterial sistêmica, obtido por revisão sistemática no período de 01/2011 a 12/2016, atualizado os GPC incluídos até 11/2017.

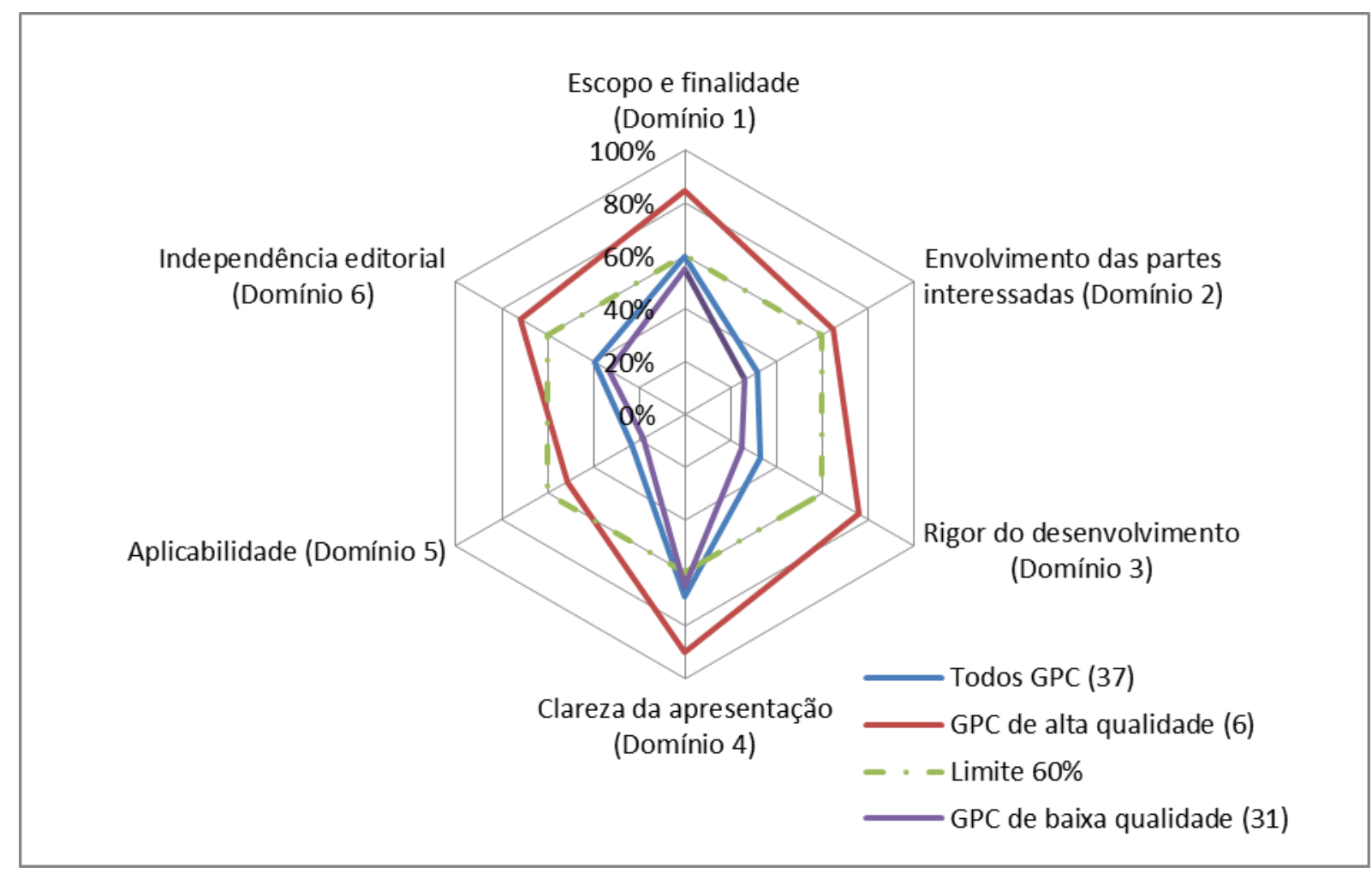

Fonte: Elaboração própria.

Dentre os 6 GPC de alta qualidade metodológica, os da Colômbia e do México são adaptações de outros GPC. Uma descrição dos GPC que foram usados na adaptação está disponível no Quadro 5. 
Quadro 5 - Características dos guias de prática clínica (GPC) adaptados para farmacoterapia da hipertensão arterial sistêmica com nota de $60 \%$ ou mais no domínio 3 do AGREE II, obtido por revisão sistemática no período de 01/2011 a 12/2016, atualizado os GPC incluídos até 11/2017.

\begin{tabular}{|c|c|c|}
\hline $\begin{array}{l}\text { GPC incluídos nas } \\
\text { matrizes de } \\
\text { recomendações }\end{array}$ & $\begin{array}{l}\text { GPC usados nas } \\
\text { adaptações }\end{array}$ & Observações \\
\hline $\begin{array}{l}\text { Guia de Prática Clínica } \\
\text { para Hipertensão Arterial } \\
\text { Primaria- Colômbia (109) }\end{array}$ & \multirow[b]{2}{*}{$\begin{array}{c}\text { Hypertension in adults: } \\
\text { diagnosis and management. } \\
\text { NICE } 2011 \text { (146) }\end{array}$} & \multirow[b]{2}{*}{$\begin{array}{c}\text { É uma versão anterior do GPC incluído } \\
\text { NICE (110), o qual foi atualizado em } \\
2016 \text { e obteve escore igual a } 83 \% \text { no } \\
\text { domínio } 3 \text { do AGREE II. }\end{array}$} \\
\hline $\begin{array}{c}\text { Diagnóstico y Tratamiento } \\
\text { de la HIPERTENSIÓN } \\
\text { ARTERIAL en el Primer } \\
\text { Nivel de Atención - México } \\
\text { (114) }\end{array}$ & & \\
\hline $\begin{array}{c}\text { Diagnóstico y Tratamiento } \\
\text { de la HIPERTENSIÓN } \\
\text { ARTERIAL en el Primer } \\
\text { Nivel de Atención - México } \\
\text { (114) }\end{array}$ & JNC-8 (147) & \multirow{2}{*}{$\begin{array}{l}\text { É uma versão anterior do GPC incluído } \\
2017 \text { ACC/AHA (111), o qual foi } \\
\text { atualizado em } 2017 \text { e obteve escore } \\
\text { igual a } 81 \% \text { no domínio } 3 \text { do AGREE II. }\end{array}$} \\
\hline $\begin{array}{c}\text { Diagnóstico y Tratamiento } \\
\text { de la HIPERTENSIÓN } \\
\text { ARTERIAL en el Primer } \\
\text { Nivel de Atención - México } \\
\text { (114) }\end{array}$ & JNC-7 (148) & \\
\hline $\begin{array}{c}\text { Diagnóstico y Tratamiento } \\
\text { de la HIPERTENSIÓN } \\
\text { ARTERIAL en el Primer } \\
\text { Nivel de Atención - México } \\
\text { (114) }\end{array}$ & $\begin{array}{c}\text { The } 2013 \text { Canadian } \\
\text { Hypertension Education } \\
\text { Program Recommendations } \\
\text { for Blood Pressure } \\
\text { Measurement, Diagnosis, } \\
\text { Assessment of Risk, } \\
\text { Prevention, and Treatment of } \\
\text { Hypertension (149) }\end{array}$ & $\begin{array}{c}\text { É uma versão anterior do GPC incluído } \\
\text { Canada (113), o qual foi atualizado em } \\
2017 \text { e obteve escore igual a } 63 \% \text { no } \\
\text { domínio } 3 \text { do AGREE II. }\end{array}$ \\
\hline $\begin{array}{c}\text { Diagnóstico y Tratamiento } \\
\text { de la HIPERTENSIÓN } \\
\text { ARTERIAL en el Primer } \\
\text { Nivel de Atención - México } \\
(114)\end{array}$ & $\begin{array}{c}\text { ACCF/AHA } 2011 \text { Expert } \\
\text { Consensus Document on } \\
\text { Hypertension in the Elderly } \\
\text { (119) }\end{array}$ & $\begin{array}{l}\text { Foi avaliado neste estudo e e foi } \\
\text { excluído por ter obtido escore igual a } \\
49 \% \text { no domínio } 3 \text { do AGREE II e por } \\
\text { isso ser considerado com baixa } \\
\text { qualidade. }\end{array}$ \\
\hline $\begin{array}{c}\text { Diagnóstico y Tratamiento } \\
\text { de la HIPERTENSIÓN } \\
\text { ARTERIAL en el Primer } \\
\text { Nivel de Atención - México } \\
\text { (114) }\end{array}$ & $\begin{array}{l}2013 \mathrm{ESH} / \mathrm{ESC} \text { Guidelines } \\
\text { for the management of } \\
\text { arterial hypertension (125) }\end{array}$ & $\begin{array}{c}\text { Foi avaliado neste estudo e e foi } \\
\text { excluído por ter obtido escore igual a } \\
31 \% \text { no domínio } 3 \text { do AGREE II e por } \\
\text { isso ser considerado com baixa } \\
\text { qualidade. }\end{array}$ \\
\hline
\end{tabular}

Fonte: Elaboração própria. 


\subsection{MATRIZ DE RECOMENDAÇÃO PARA FARMACOTERAPIA DA HIPERTENSÃO ARTERIAL SISTÊMICA}

O Quadro 6 descreve a relação dos principais tópicos extraídos de cada GPC para elaboração das matrizes de recomendações. Dos 6 GPC incluídos, 5 continham recomendações sobre quando iniciar a farmacoterapia (110-114), com indicações distintas para pacientes sem antecedentes de doença cardiovascular ou baixo risco cardiovascular e pacientes com estimativa de risco cardiovascular. Quatro continham recomendações referentes as metas de tratamento (110-113). 
Quadro 6 - Principais tópicos abordados nos guias de prática clinica (GPC) para farmacoterapia da hipertensão arterial sistêmica, obtidos por meio de revisão sistemática no período de 01/2011 a 12/2016, atualizado os GPC incluídos até $11 / 2017$.

\begin{tabular}{|c|c|c|c|c|c|c|}
\hline & $\begin{array}{c}2017 \text { ACC/AHA } \\
(111)\end{array}$ & Colombia (109) & NICE (110) & VADOD (112) & Canadá (113) & México (114) \\
\hline $\begin{array}{l}\text { Prevencão primária } \\
\text { de eventos } \\
\text { cardiovasculares }\end{array}$ & $x_{1}=1$ & - & $\sqrt{ }$ & $\sqrt{ }$ & $\sqrt{ }$ & $\sqrt{ }$ \\
\hline $\begin{array}{c}\text { Indicação de } \\
\text { farmacoterapia }\end{array}$ & $\sqrt{ }$ & - & $\sqrt{ }$ & $\sqrt{ }$ & $\sqrt{ }$ & $\sqrt{ }$ \\
\hline $\begin{array}{c}\text { Sem considerar risco } \\
\text { cardiovascular }\end{array}$ & - & - & - & $\sqrt{ }$ & - & - \\
\hline $\begin{array}{c}\text { Baixo risco } \\
\text { cardiovascular }\end{array}$ & $\sqrt{ }$ & - & $\sqrt{ }$ & - & $\sqrt{ }$ & $\sqrt{ }$ \\
\hline $\begin{array}{c}\text { Alto risco } \\
\text { cardiovascular }\end{array}$ & $\sqrt{ }$ & - & $\sqrt{ }$ & - & $\sqrt{ }$ & $\sqrt{ }$ \\
\hline $\begin{array}{c}\text { Metas } \\
\text { terapêuticas }\end{array}$ & $\sqrt{ }$ & - & $\sqrt{ }$ & $\sqrt{ }$ & $\sqrt{ }$ & $\sqrt{ }$ \\
\hline $\begin{array}{c}\text { Sem considerar risco } \\
\text { cardiovascular }\end{array}$ & - & - & - & $\sqrt{ }$ & - & - \\
\hline $\begin{array}{c}\text { Baixo risco } \\
\text { cardiovascular }\end{array}$ & $\sqrt{ }$ & - & $\sqrt{ }$ & - & $\sqrt{ }$ & $\sqrt{ }$ \\
\hline $\begin{array}{c}\text { Alto risco } \\
\text { cardiovascular }\end{array}$ & $\sqrt{ }$ & - & $\sqrt{ }$ & - & $\sqrt{ }$ & $\sqrt{ }$ \\
\hline $\begin{array}{l}\frac{\text { Prevencão }}{\text { secundária de }} \\
\text { eventos } \\
\text { cardiovasculares } \\
\text { recorrentes }\end{array}$ & $\sqrt{ }$ & - & - & - & - & $\sqrt{ }$ \\
\hline $\begin{array}{c}\text { Indicação de } \\
\text { farmacoterapia }\end{array}$ & $\sqrt{ }$ & - & - & - & - & $\sqrt{ }$ \\
\hline $\begin{array}{c}\text { Metas } \\
\text { terapêuticas }\end{array}$ & $\sqrt{ }$ & - & - & - & - & - \\
\hline
\end{tabular}

Continua 
Continuação

\begin{tabular}{|c|c|c|c|c|c|c|}
\hline & 2017 ACC/AHA & Colombia (109) & NICE (110) & VADOD (112) & Canadá (113) & México (114) \\
\hline Farmacoterapia & $\sqrt{ }$ & $\sqrt{ }$ & $\sqrt{ }$ & $\sqrt{ }$ & $\sqrt{ }$ & $\sqrt{ }$ \\
\hline $\begin{array}{l}\text { Primeira linha de } \\
\text { tratamento }\end{array}$ & $\sqrt{ }$ & $\sqrt{ }$ & $\sqrt{ }$ & $\sqrt{ }$ & $\sqrt{ }$ & $\sqrt{ }$ \\
\hline $\begin{array}{l}\text { Segunda linha de } \\
\text { tratamento }\end{array}$ & - & $\sqrt{ }$ & $\sqrt{ }$ & $\sqrt{ }$ & $\sqrt{ }$ & $\sqrt{ }$ \\
\hline $\begin{array}{l}\text { Quarta linha de } \\
\text { tratamento }\end{array}$ & - & - & $\sqrt{ }$ & $\sqrt{ }$ & $\sqrt{ }$ & $\sqrt{ }$ \\
\hline Negros & $\sqrt{ }$ & - & $\sqrt{ }$ & $\sqrt{ }$ & $\sqrt{ }$ & $\sqrt{ }$ \\
\hline Idosos & $\sqrt{ }$ & $\sqrt{ }$ & $\sqrt{ }$ & $\sqrt{ }$ & $\sqrt{ }$ & $\sqrt{ }$ \\
\hline $\begin{array}{l}\text { Hipertensão sistólica } \\
\text { isolada }\end{array}$ & - & - & - & - & $\sqrt{ }$ & - \\
\hline Mulheres & - & $\sqrt{ }$ & - & - & - & - \\
\hline Adultos jovens & - & - & $\sqrt{ }$ & - & - & - \\
\hline
\end{tabular}

Continua 
Conclusão

\begin{tabular}{|c|c|c|c|c|c|c|}
\hline & $\begin{array}{c}2017 \text { ACC/AHA } \\
(111)\end{array}$ & Colombia (109) & NICE (110) & VADOD (112) & Canadá (113) & México (114) \\
\hline $\begin{array}{c}\text { Doença } \\
\text { cardiovascular }\end{array}$ & - & - & - & - & - & $\sqrt{ }$ \\
\hline $\begin{array}{l}\text { Doença cardíaca } \\
\text { isquêmica estável }\end{array}$ & $\sqrt{ }$ & - & - & - & - & $\sqrt{ }$ \\
\hline $\begin{array}{l}\text { Insuficiência } \\
\text { cardíaca }\end{array}$ & $\sqrt{ }$ & - & - & - & $\sqrt{ }$ & $\sqrt{ }$ \\
\hline $\begin{array}{c}\text { Doença } \\
\text { cerebrovascular }\end{array}$ & $\sqrt{ }$ & - & - & $\sqrt{ }$ & $\sqrt{ }$ & $\sqrt{ }$ \\
\hline Diabetes Mellitus & $\sqrt{ }$ & - & - & $\sqrt{ }$ & $\sqrt{ }$ & $\sqrt{ }$ \\
\hline $\begin{array}{l}\text { Doença arterial } \\
\text { periférica }\end{array}$ & $\sqrt{ }$ & - & - & - & - & - \\
\hline Fibrilação atrial & $\sqrt{ }$ & - & - & - & - & - \\
\hline $\begin{array}{c}\text { Doença cardiaca } \\
\text { valvular }\end{array}$ & $\sqrt{ }$ & - & - & - & - & - \\
\hline Após infarto & - & - & - & - & $\sqrt{ }$ & $\sqrt{ }$ \\
\hline $\begin{array}{c}\text { Hipertrofia } \\
\text { Ventricular Esquerda }\end{array}$ & - & - & - & - & $\sqrt{ }$ & - \\
\hline $\begin{array}{c}\text { Declínio cognitivo e } \\
\text { demência }\end{array}$ & $\sqrt{ }$ & - & - & - & - & - \\
\hline
\end{tabular}

Fonte: Elaboração própria. 
$\mathrm{Na}$ matriz, apresentada no Quadro 7, estão descritas as indicações de farmacoterapia e metas terapêuticas para tratamento farmacológico da HAS. Nessa matriz é possível observar que as recomendações do GPC 2017 ACC/AHA para início da farmacoterapia e meta terapêutica são as que mais discordam dos demais GPC (111). 
Quadro 7- Matriz das recomendações para indicação de farmacoterapia da hipertensão arterial sistêmica, de guias de prática clinica (GPC) com nota de $60 \%$ ou mais no domínio 3 do AGREE II, obtido por revisão sistemática no período de 01/2011 a 12/2016, atualizado os GPC incluídos até 11/2017.

\begin{tabular}{|c|c|c|c|}
\hline Recomendação & $\begin{array}{l}\text { Método de } \\
\text { classificação } \\
\text { das evidências }\end{array}$ & $\begin{array}{l}\text { Nível da evidência ou Força da } \\
\text { recomendação }\end{array}$ & GPC \\
\hline \multicolumn{4}{|c|}{ PREVENÇÃO PRIMÁRIA DE DOENÇA CARDIOVASCULAR } \\
\hline $\begin{array}{c}\text { Pressão arterial sistólica } \geq 160 \mathrm{mmHg} \text { para adultos }<60 \text { anos, } \\
\text { independente da pressão arterial diastólica. }\end{array}$ & Grade & Fraca a favor & \multirow[b]{2}{*}{$\begin{array}{l}\text { VADOD } \\
(112)\end{array}$} \\
\hline $\begin{array}{c}\text { Pressão arterial diastólica } \begin{array}{l}\geq 90 \mathrm{mmHg} \text { para adultos de } 18 \text { a } 29 \\
\text { anos. }\end{array} \\
\end{array}$ & Grade & Fraca a favor & \\
\hline \multicolumn{4}{|c|}{ Sem antecedentes de doença cardiovascular ou baixo risco cardiovascular } \\
\hline $\begin{array}{c}\text { Pressão arterial sistólica } \geq 140 \mathrm{mmHg} \text { ou pressão arterial } \\
\text { diastólica } \geq 90 \mathrm{mmHg} \text { sem antecedentes de doença } \\
\text { cardiovascular e estimativa de risco }<10 \% \text { para doença } \\
\text { cardiovascular aterosclerótica em } 10 \text { anos. }\end{array}$ & Outros & \begin{tabular}{|c|} 
Forte / Estudos observacionais ou de \\
registro randomizados ou não randomizados \\
com limitações de projeto ou execução; ou \\
meta-análises desses estudos; ou estudos \\
fisiológicos ou mecanicistas em seres \\
humanos. \\
\end{tabular} & $\begin{array}{c}2017 \\
\mathrm{ACC} / \mathrm{AHA} \\
(111)\end{array}$ \\
\hline $\begin{array}{c}\text { Pressão arterial sistólica } \geq 160 \mathrm{mmHg} \text { ou pressão arterial } \\
\text { diastólica } \geq 100 \mathrm{mmHg} \text {. }\end{array}$ & Grade & & $\begin{array}{l}\text { NICE } \\
(110)\end{array}$ \\
\hline
\end{tabular}

Continua 
Continuação

\begin{tabular}{|c|c|c|c|}
\hline Recomendação & $\begin{array}{c}\text { Método de } \\
\text { classificação } \\
\text { das evidências }\end{array}$ & $\begin{array}{l}\text { Nível da evidência ou Força da } \\
\text { recomendação }\end{array}$ & GPC \\
\hline \multicolumn{4}{|c|}{ PREVENÇÃO PRIMÁRIA DE DOENÇA CARDIOVASCULAR } \\
\hline \multicolumn{4}{|c|}{ Sem antecedentes de doença cardiovascular ou baixo risco cardiovascular } \\
\hline $\begin{array}{l}\text { Pressão arterial sistólica } \geq 140 \mathrm{mmHg} \text { e/ou pressão arterial } \\
\text { diastólica } \geq 90 \mathrm{mmHg} \text {. }\end{array}$ & Outros & $\begin{array}{c}\text { *lla, ESH/ESC: O peso da evidência ou } \\
\text { opinião é a favor de sua eficácia ou utilidade } \\
\text { (considerar). }\end{array}$ & $\begin{array}{l}\text { México } \\
(114)\end{array}$ \\
\hline \multirow{3}{*}{$\begin{array}{l}\text { Pressão arterial sistólica } \geq 180 \mathrm{mmHg} \text { ou pressão arterial } \\
\text { diastólica } \geq 110 \mathrm{mmHg} \text {, com qualquer nível de risco } \\
\text { cardiovascular (início imediato da farmacoterapia). }\end{array}$} & Outros & $\begin{array}{c}\text { Forte / Evidência de qualidade moderada de } \\
\text { um ou mais ECR }{ }^{\star} \text { s; ou meta-análises de } \\
\text { ECRs de qualidade moderada. }\end{array}$ & $\begin{array}{c}2017 \\
\mathrm{ACC} / \mathrm{AHA} \\
(111) \\
\end{array}$ \\
\hline & \multirow{2}{*}{ Outros } & $\begin{array}{l}{ }^{*} \mathrm{C}, \mathrm{ESH} / \mathrm{ESC} \text { : Opinião de opinião de } \\
\text { especialistas e/ou pequenos estudos } \\
\text { retrospectivos. }\end{array}$ & \multirow{2}{*}{$\begin{array}{l}\text { México } \\
(114)\end{array}$} \\
\hline & & $\begin{array}{c}{ }^{*} \mathrm{D}, \mathrm{CHEP}: \text { baseiam-se em opiniões de } \\
\text { especialistas. }\end{array}$ & \\
\hline \multicolumn{4}{|c|}{ Com estimativa de risco cardiovascular } \\
\hline $\begin{array}{l}\text { Pressão arterial sistólica } \geq 130 \mathrm{mmHg} \text { e estimativa de risco }>10 \\
\% \text { para doença cardiovascular aterosclerótica em } 10 \text { anos. }\end{array}$ & Outros & $\begin{array}{c}\text { Forte / Evidência de alta qualidade de mais } \\
\text { de um ECR*; ou meta-análises de ECRs de } \\
\text { alta qualidade; ou um ou mais ECR } \\
\text { corroborados por estudos de registro de alta } \\
\text { qualidade. }\end{array}$ & \multirow[t]{2}{*}{$\begin{array}{l}2017 \\
\mathrm{ACC} / \mathrm{AHA} \\
(111)\end{array}$} \\
\hline $\begin{array}{c}\text { Pressão arterial diastólica } \geq 80 \text { mmHg e estimativa de risco }>10 \\
\% \text { para doença cardiovascular aterosclerótica em } 10 \text { anos. }\end{array}$ & Outros & $\begin{array}{c}\text { Forte / Consenso da opinião de especialistas } \\
\text { com base na experiência clínica. }\end{array}$ & \\
\hline $\begin{array}{c}\text { Pressão arterial sistólica } 130-139 \text { mmHg ou pressão arterial } \\
\text { diastólica } 80-89 \mathrm{mmHg} \text {, com estimativa de risco de doença } \\
\text { cardiovascular aterosclerótica }>10 \% \text { em } 10 \text { anos, iniciar } \\
\text { tratamento com terapia não farmacológica e farmacológica. } \\
\text { Reavaliar em } 1 \text { mês. }\end{array}$ & Outros & $\begin{array}{l}\text { Forte / Evidência de qualidade moderada de } \\
\text { um ou mais ECR*s; ou meta-análises de } \\
\text { ECRs de qualidade moderada. }\end{array}$ & $\begin{array}{c}2017 \\
\mathrm{ACC} / \mathrm{AHA} \\
(111)\end{array}$ \\
\hline
\end{tabular}

Continua 
Continuação

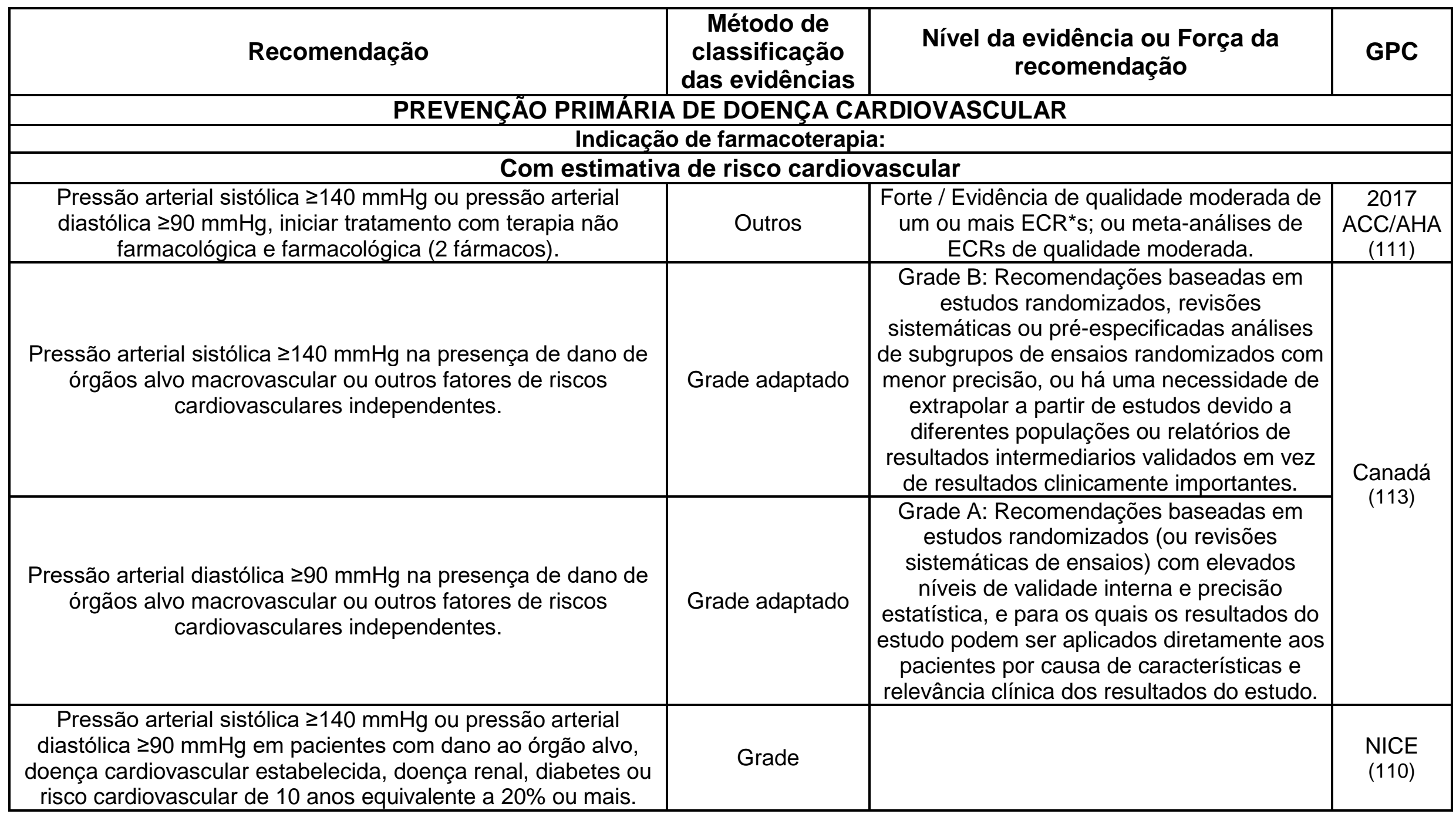

Continua 
Continuação

\begin{tabular}{|c|c|c|c|}
\hline Recomendação & $\begin{array}{c}\text { Método de } \\
\text { classificação } \\
\text { das evidências }\end{array}$ & $\begin{array}{l}\text { Nível da evidência ou Força da } \\
\text { recomendação }\end{array}$ & GPC \\
\hline \multicolumn{4}{|c|}{ PREVENÇÃO PRIMÁRIA DE DOENÇA CARDIOVASCULAR } \\
\hline Pressão arterial sistólica $<150 \mathrm{mmHg}$ para adultos $<60$ anos. & Grade & Fraca a favor & \multirow{2}{*}{$\begin{array}{l}\text { VADOD } \\
(112)\end{array}$} \\
\hline Pressão arterial diastólica $<90 \mathrm{mmHg}$ para adultos $\geq 30$ anos. & Grade & Forte a favor & \\
\hline \multicolumn{4}{|c|}{ Sem antecedentes de doença cardiovascular ou baixo risco cardiovascular } \\
\hline Pressão arterial sistólica $<130$ mmHg. & Outros & $\begin{array}{c}\text { Fraca / Evidência de qualidade moderada de } \\
\text { um ou mais estudos não randomizados bem } \\
\text { desenhados e bem executados, estudos } \\
\text { observacionais ou estudos de registro; ou } \\
\text { meta-análises desses estudos. }\end{array}$ & $\begin{array}{c}2017 \\
\mathrm{ACC} / \mathrm{AHA} \\
(111)\end{array}$ \\
\hline Pressão arterial sistólica $<140$ mmHg. & Grade adaptado & $\begin{array}{c}\text { Grade C: Recomendações baseadas em } \\
\text { ensaios com níveis inferiores de validade } \\
\text { interna e/ou precisão, ou ensaios relatando } \\
\text { resultados substitutos não validados, ou } \\
\text { resultados de estudos observacionais não } \\
\text { randomizados. }\end{array}$ & $\begin{array}{c}\text { Canadá } \\
(113)\end{array}$ \\
\hline
\end{tabular}


Continuação

\begin{tabular}{|c|c|c|c|}
\hline Recomendação & $\begin{array}{c}\text { Método de } \\
\text { classificação } \\
\text { das evidências }\end{array}$ & $\begin{array}{l}\text { Nível da evidência ou Força da } \\
\text { recomendação }\end{array}$ & GPC \\
\hline \multicolumn{4}{|c|}{ PREVENÇÃO PRIMÁRIA DE DOENÇA CARDIOVASCULAR } \\
\hline \multicolumn{4}{|c|}{ Sem antecedentes de doença cardiovascular ou baixo risco cardiovascular } \\
\hline Pressão arterial diastólica $<90$ mmHg. & Grade adaptado & $\begin{array}{c}\text { Grade A: Recomendações baseadas em } \\
\text { estudos randomizados (ou revisões } \\
\text { sistemáticas de ensaios) com elevados níveis } \\
\text { de validade interna e precisão estatística, e } \\
\text { para os quais os resultados do estudo podem } \\
\text { ser aplicados diretamente aos pacientes por } \\
\text { causa de características e relevância clínica } \\
\text { dos resultados do estudo. }\end{array}$ & $\begin{array}{c}\text { Canadá } \\
(113)\end{array}$ \\
\hline Pressão arterial <140/90 mmHg. & Grade & & $\begin{array}{l}\text { NICE } \\
(110)\end{array}$ \\
\hline Pressão arterial diastólica <80mmHg. & Outros & $\begin{array}{l}\text { Forte / Consenso da opinião de especialistas } \\
\text { com base na experiência clínica. }\end{array}$ & $\begin{array}{c}2017 \\
\mathrm{ACC} / \mathrm{AHA} \\
(111)\end{array}$ \\
\hline Pressão arterial sistólica <140mmHg. & Grade adaptado & $\begin{array}{c}\text { Grade C: Recomendações baseadas em } \\
\text { ensaios com níveis inferiores de validade } \\
\text { interna e/ou precisão, ou ensaios relatando } \\
\text { resultados substitutos não validados, ou } \\
\text { resultados de estudos observacionais não } \\
\text { randomizados. }\end{array}$ & $\begin{array}{c}\text { Canadá } \\
(113)\end{array}$ \\
\hline
\end{tabular}


Continuação

\begin{tabular}{|c|c|c|c|}
\hline Recomendação & $\begin{array}{l}\text { Método de } \\
\text { classificação } \\
\text { das evidências }\end{array}$ & $\begin{array}{l}\text { Nível da evidência ou Força da } \\
\text { recomendação }\end{array}$ & GPC \\
\hline \multicolumn{4}{|c|}{ PREVENÇÃO PRIMÁRIA DE DOENÇA CARDIOVASCULAR } \\
\hline \multicolumn{4}{|c|}{ Com estimativa de risco cardiovascular } \\
\hline Pressão arterial diastólica <90 mmHg. & Grade adaptado & \begin{tabular}{|} 
Grade A: Recomendações baseadas em \\
estudos randomizados (ou revisões \\
sistemáticas de ensaios) com elevados \\
níveis de validade interna e precisão \\
estatística, e para os quais os resultados do \\
estudo podem ser aplicados diretamente aos \\
pacientes por causa de características e \\
relevância clínica dos resultados do estudo. \\
\end{tabular} & $\begin{array}{c}\text { Canadá } \\
(113)\end{array}$ \\
\hline Pressão arterial < $140 / 90$ mmHg. & Grade & & $\begin{array}{l}\text { NICE } \\
(110)\end{array}$ \\
\hline \multicolumn{4}{|c|}{ PREVENÇÃO SECUNDÁRIA DE EVENTOS CARDIOVASCULARES RECORRENTES } \\
\hline $\begin{array}{c}\text { Doença cardiovascular clínica e pressão arterial diastólica } \geq 80 \\
\text { mmHg. }\end{array}$ & Outros & $\begin{array}{c}\text { Forte / Consenso da opinião de especialistas } \\
\text { com base na experiência clínica. }\end{array}$ & $\begin{array}{c}2017 \\
\text { ACC/AHA } \\
(111)\end{array}$ \\
\hline $\begin{array}{l}\text { Pressão arterial sistólica } \geq 140 \mathrm{mmHg} \text { e/ou pressão arterial } \\
\text { diastólica } \geq 90 \mathrm{~mm} \mathrm{Hg} \text {, com alto risco cardiovascular, diabetes } \\
\text { mellitus, doença cardiovascular ou doença renal crônica. }\end{array}$ & Outros & $\begin{array}{l}\text { *I, ESH/ESC: Evidência e/ou concordância } \\
\text { geral sobre o benefício, eficácia e utilidade } \\
\text { de realizar um procedimento ou dar um } \\
\text { tratamento específico (recomendado). } \\
\end{array}$ & $\begin{array}{l}\text { México } \\
(114)\end{array}$ \\
\hline
\end{tabular}

Continua 
Conclusão

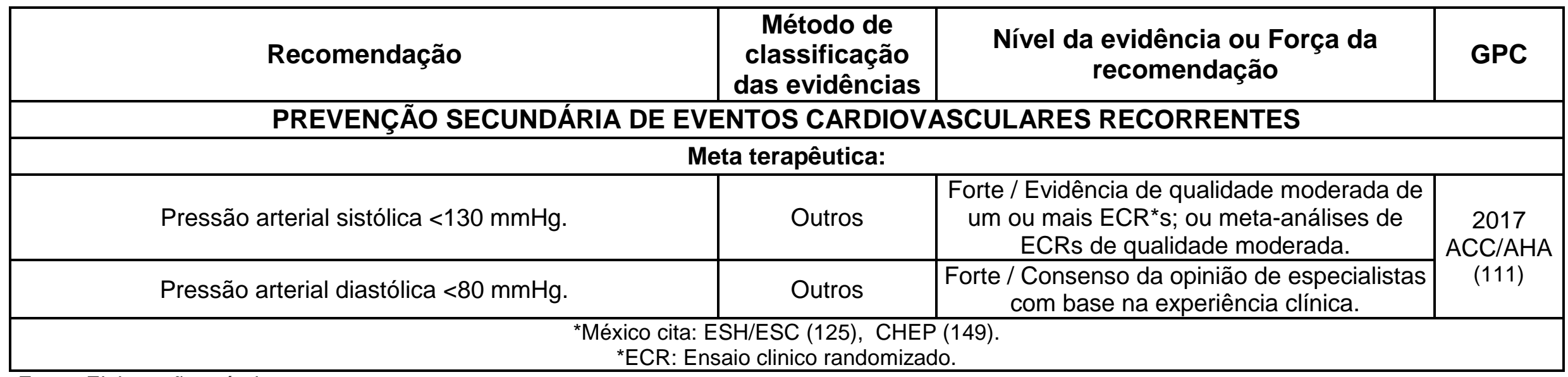

Fonte: Elaboração própria.

*ECR: Ensaio clinico randomizado. 
Na matriz, apresentada no Quadro 8, estão descritas as recomendações referentes a farmacoterapia da HAS, sendo classificadas em primeira, segunda, terceira e quarta linhas de tratamento e contraindicações. Dos 6 GPC incluídos, 5 continham recomendações a respeito de contraindicações dos fármacos, todas concordantes (110-114).

Não há consenso entre os GPC sobre os medicamentos a serem utilizados em cada linha de tratamento. As seguintes classes de fármacos estão na primeira linha de tratamento: diuréticos tiazídicos, inibidores da enzima conversora de angiotensina, bloqueadores do receptor de angiotensina II, bloqueadores de canal de cálcio e apenas um os betabloqueadores (113), sendo que 3 GPC trazem como primeira opção os diuréticos tiazidicos $(109,112,114)$. 
Quadro 8 - Matriz das recomendações para farmacoterapia em adultos com hipertensão arterial sistêmica, de guias de prática clinica (GPC) com nota de $60 \%$ ou mais no domínio 3 do AGREE II, obtido por revisão sistemática no período de 01/2011 a 12/2016, atualizado os GPC incluídos até 11/2017.

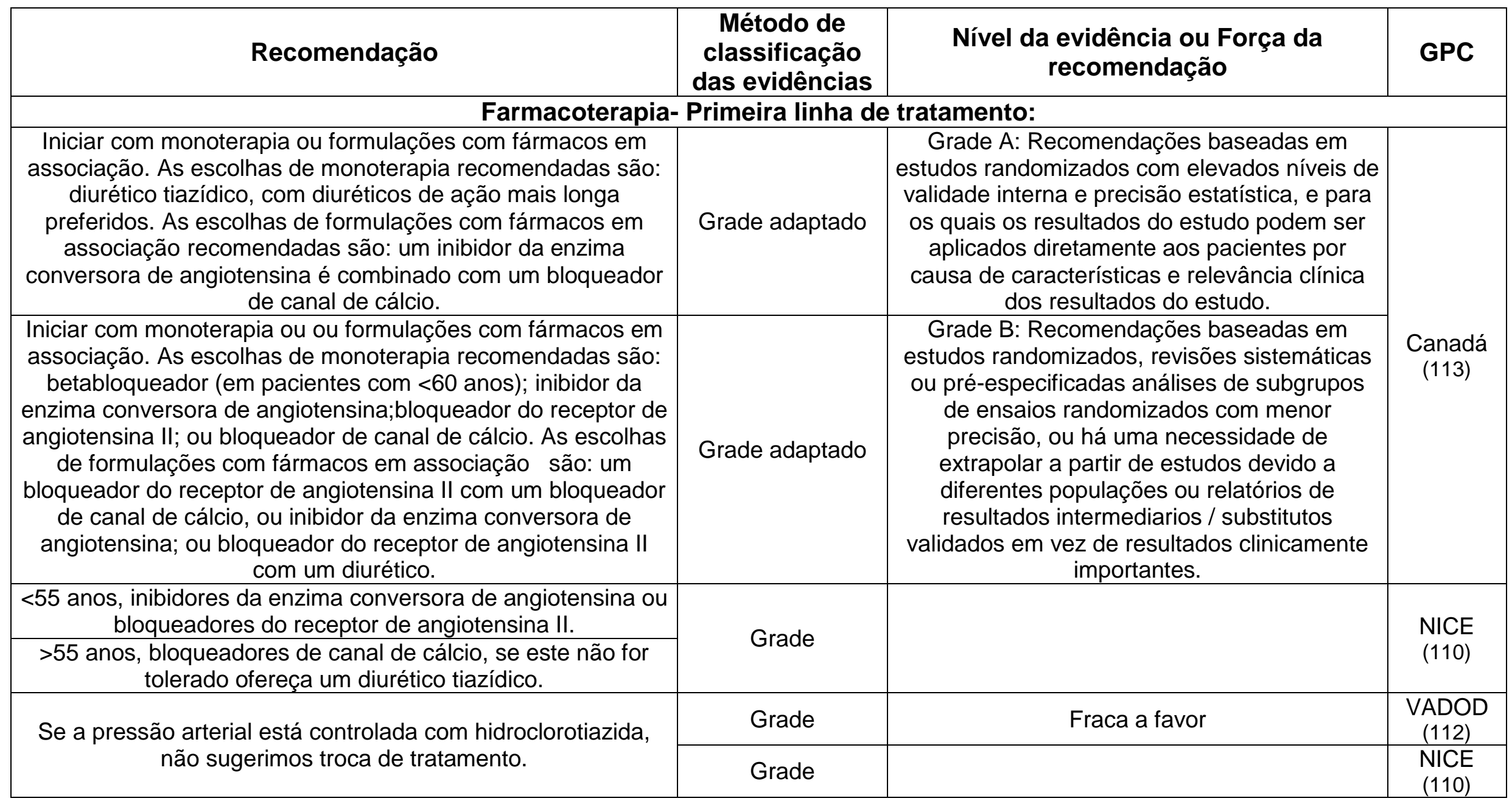

Continua 


\begin{tabular}{|c|c|c|c|}
\hline Recomendação & $\begin{array}{l}\text { Método de } \\
\text { classificação } \\
\text { das evidências }\end{array}$ & $\begin{array}{l}\text { Nível da evidência ou Força da } \\
\text { recomendação }\end{array}$ & GPC \\
\hline \multicolumn{4}{|c|}{ Farmacoterapia- Primeira linha de tratamento: } \\
\hline \multirow[t]{2}{*}{ Diuréticos tiazídicos em monoterapia. } & Grade & Forte a favor & $\begin{array}{l}\text { VADOD } \\
(112)\end{array}$ \\
\hline & Outros & $\begin{array}{c}\text { *A, CHEP: Baseados em estudos com altos } \\
\text { níveis de validade interna, precisão estatística } \\
\text { e generalização com relevância clínica. }\end{array}$ & $\begin{array}{l}\text { México } \\
(114)\end{array}$ \\
\hline Diuréticos tiazídicos em combinação com outros fármacos. & Grade & Fraca a favor & $\begin{array}{l}\text { VADOD } \\
(112)\end{array}$ \\
\hline $\begin{array}{l}\text { Recomendamos o uso das seguintes terapias alternativas em } \\
\text { pacientes que não toleram diuréticos tiazidicos, ou como } \\
\text { terapia suplementar para pacientes que não atingem as metas } \\
\text { terapêuticas, ou para inicio com terapia combinada: inibidor da } \\
\text { enzima conversora de angiotensina ou bloqueador do receptor } \\
\text { de angiotensina II (mas não juntos) e bloqueador de canal de } \\
\text { cálcio dihidropiridínico de ação prolongada. }\end{array}$ & Grade & Forte a favor & $\begin{array}{l}\text { VADOD } \\
(112)\end{array}$ \\
\hline \multirow{2}{*}{$\begin{array}{l}\text { Terapia combinada se pressão arterial sistólica }>20 \mathrm{mmHg} \text { ou } \\
\text { pressão arterial diastólica }>10 \mathrm{mmHg} \text { acima da meta do } \\
\text { paciente. }\end{array}$} & Grade & Fraca a favor & $\begin{array}{c}\text { VADOD } \\
(112)\end{array}$ \\
\hline & Outros & $\begin{array}{l}\text { Forte / Consenso da opinião de especialistas } \\
\text { com base na experiência clínica. }\end{array}$ & $\begin{array}{c}2017 \\
\mathrm{ACC} / \mathrm{AHA} \\
(111) \\
\end{array}$ \\
\hline $\begin{array}{l}\text { Monoterapia para pressão arterial sistólica } 130-139 \mathrm{mmHg} \text { ou } \\
\text { pressão arterial diastólica } 80-89 \mathrm{mmHg} \text {. }\end{array}$ & Outros & $\begin{array}{l}\text { Moderada / Consenso da opinião de } \\
\text { especialistas com base na experiência clínica. }\end{array}$ & \multirow{2}{*}{$\begin{array}{c}2017 \\
\mathrm{ACC} / \mathrm{AHA} \\
(111)\end{array}$} \\
\hline $\begin{array}{l}\text { Dois fármacos de primeira linha para pressão arterial sistólica } \\
\geq 140 \mathrm{mmHg} \text { ou pressão arterial diastólica } \geq 90 \mathrm{mmHg} \text {. }\end{array}$ & Outros & $\begin{array}{c}\text { Forte / Consenso da opinião de especialistas } \\
\text { com base na experiência clínica. }\end{array}$ & \\
\hline
\end{tabular}

Continua 
Continuação

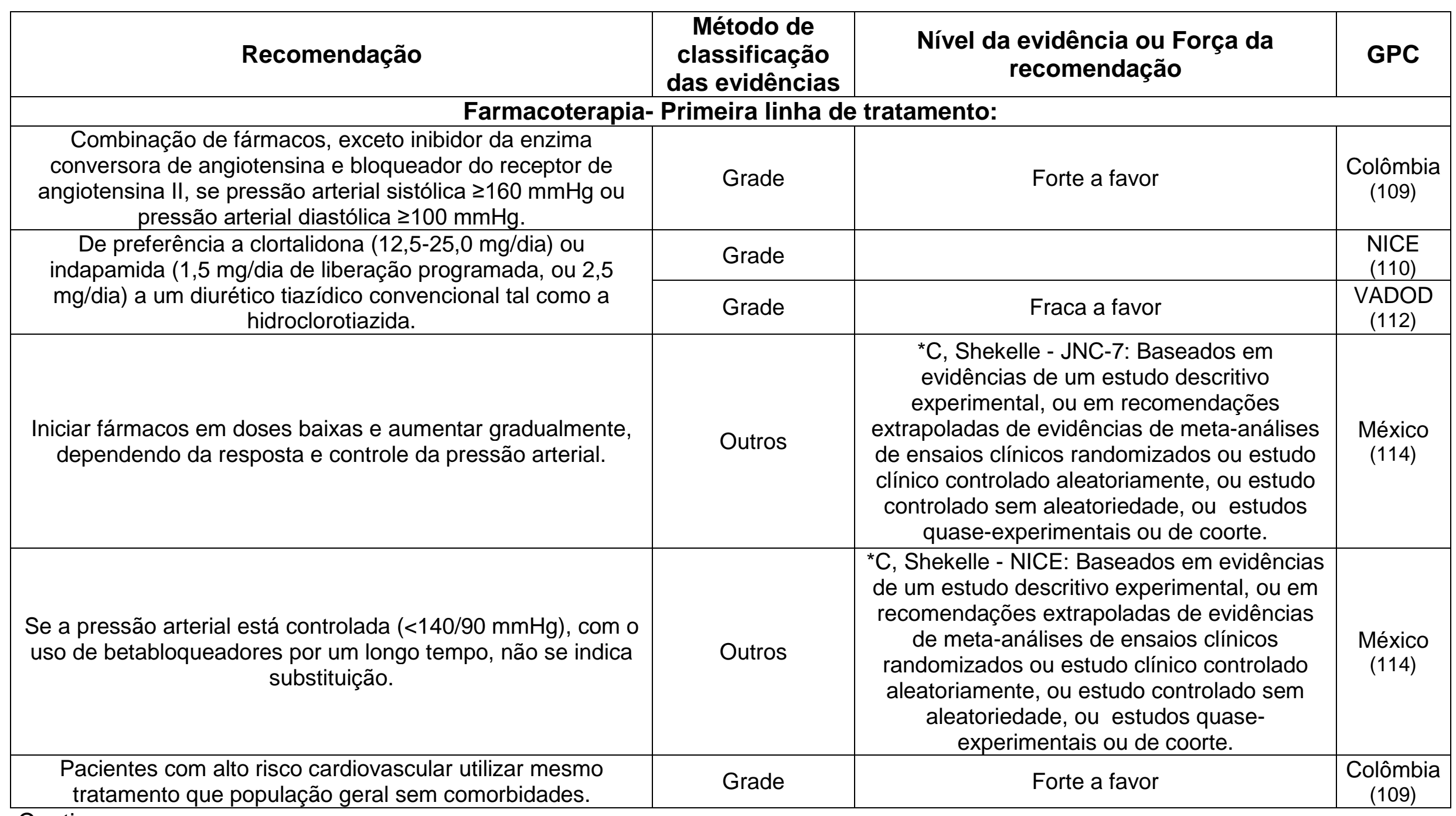


Continuação

\begin{tabular}{|c|c|c|c|}
\hline Recomendação & $\begin{array}{l}\text { Método de } \\
\text { classificação } \\
\text { das evidências }\end{array}$ & $\begin{array}{l}\text { Nível da evidência ou Força da } \\
\text { recomendação }\end{array}$ & GPC \\
\hline \multicolumn{4}{|c|}{ Farmacoterapia- Primeira linha de tratamento: } \\
\hline $\begin{array}{c}\text { Diuréticos tiazidicos, inibidores da enzima conversora de } \\
\text { angiotensina, bloqueadores do receptor de angiotensina II, } \\
\text { bloqueadores de canal de cálcio ou betabloqueadores em } \\
\text { monoterapia ou terapia combinada. }\end{array}$ & Outros & $\begin{array}{l}\text { *I, ESH/ESC: Evidência e/ou concordância } \\
\text { geral sobre o benefício, eficácia e utilidade de } \\
\text { realizar um procedimento ou dar um } \\
\text { tratamento específico (recomendado). }\end{array}$ & $\begin{array}{l}\text { México } \\
(114)\end{array}$ \\
\hline \multicolumn{4}{|c|}{ Fármacos de primeira linha } \\
\hline \multirow{2}{*}{ Hidroclorotiazida $25-50 \mathrm{mg} /$ día ou clortalidona $12,5-25 \mathrm{mg} / \mathrm{dia}$. } & Grade & Forte a favor & \begin{tabular}{|c|c|}
$\begin{array}{c}\text { Colômbia } \\
(109)\end{array}$ \\
\end{tabular} \\
\hline & Grade & Forte a favor & $\begin{array}{l}\text { VADOD } \\
(112)\end{array}$ \\
\hline $\begin{array}{l}\text { Diuréticos tiazídicos, bloqueadores de canal de cálcio, } \\
\text { inibidores da enzima conversora de angiotensina ou } \\
\text { bloqueadores do receptor de angiotensina II. }\end{array}$ & Outros & $\begin{array}{l}\text { Forte / Evidência de alta qualidade de mais de } \\
\text { um ECR*; ou meta-análises de ECRs de alta } \\
\text { qualidade; ou um ou mais ECR corroborados } \\
\text { por estudos de registro de alta qualidade. }\end{array}$ & $\begin{array}{l}2017 \\
\mathrm{ACC} / \mathrm{AHA} \\
\quad(111)\end{array}$ \\
\hline
\end{tabular}

Continua 
Continuação

\begin{tabular}{|c|c|c|c|}
\hline Recomendação & $\begin{array}{c}\text { Método de } \\
\text { classificação } \\
\text { das evidências }\end{array}$ & $\begin{array}{l}\text { Nível da evidência ou Força da } \\
\text { recomendação }\end{array}$ & GPC \\
\hline \multicolumn{4}{|c|}{ Farmacoterapia- Primeira linha de tratamento: } \\
\hline \multicolumn{4}{|c|}{ Fármacos de primeira linha } \\
\hline $\begin{array}{l}\text { Iniciar com monoterapia ou formulações com fármacos em } \\
\text { associação. As escolhas de monoterapia recomendadas são: } \\
\text { diurético tiazídico, com diuréticos de ação mais longa } \\
\text { preferidos. As escolhas de formulações com fármacos em } \\
\text { associação recomendadas são: um inibidor da enzima } \\
\text { conversora de angiotensina é combinado com um bloqueador } \\
\text { de canal de cálcio. }\end{array}$ & Grade adaptado & $\begin{array}{l}\text { Grade A: Recomendações baseadas em } \\
\text { estudos randomizados (ou revisões } \\
\text { sistemáticas de ensaios) com elevados níveis } \\
\text { de validade interna e precisão estatística, e } \\
\text { para os quais os resultados do estudo podem } \\
\text { ser aplicados diretamente aos pacientes por } \\
\text { causa de características e relevância clínica } \\
\text { dos resultados do estudo. }\end{array}$ & \multirow[b]{2}{*}{$\begin{array}{c}\text { Canadá } \\
(113)\end{array}$} \\
\hline $\begin{array}{l}\text { Iniciar com monoterapia ou ou formulações com fármacos em } \\
\text { associação. As escolhas de monoterapia recomendadas são: } \\
\text { betabloqueador (em pacientes com <60 anos); inibidor da } \\
\text { enzima conversora de angiotensina;bloqueador do receptor de } \\
\text { angiotensina II; ou bloqueador de canal de cálcio. As escolhas } \\
\text { de formulações com fármacos em associação são: um } \\
\text { bloqueador do receptor de angiotensina II com um bloqueador } \\
\text { de canal de cálcio, ou inibidor da enzima conversora de } \\
\text { angiotensina; ou bloqueador do receptor de angiotensina II } \\
\text { com um diurético. }\end{array}$ & Grade adaptado & $\begin{array}{c}\text { Grade B: Recomendações baseadas em } \\
\text { estudos randomizados, revisões sistemáticas } \\
\text { ou pré-especificadas análises de subgrupos } \\
\text { de ensaios randomizados com menor } \\
\text { precisão, ou há uma necessidade de } \\
\text { extrapolar a partir de estudos devido a } \\
\text { diferentes populações ou relatórios de } \\
\text { resultados intermediarios / substitutos } \\
\text { validados em vez de resultados clinicamente } \\
\text { importantes. }\end{array}$ & \\
\hline $\begin{array}{c}<55 \text { anos, inibidores da enzima conversora de angiotensina ou } \\
\text { bloqueadores do receptor de angiotensina II. }\end{array}$ & \multirow{2}{*}{ Grade } & & \multirow{2}{*}{$\begin{array}{l}\text { NICE } \\
(110)\end{array}$} \\
\hline $\begin{array}{l}>55 \text { anos, bloqueadores de canal de cálcio, se este não for } \\
\text { tolerado ofereça um diurético tiazídico. }\end{array}$ & & & \\
\hline
\end{tabular}

Continua 
Continuação

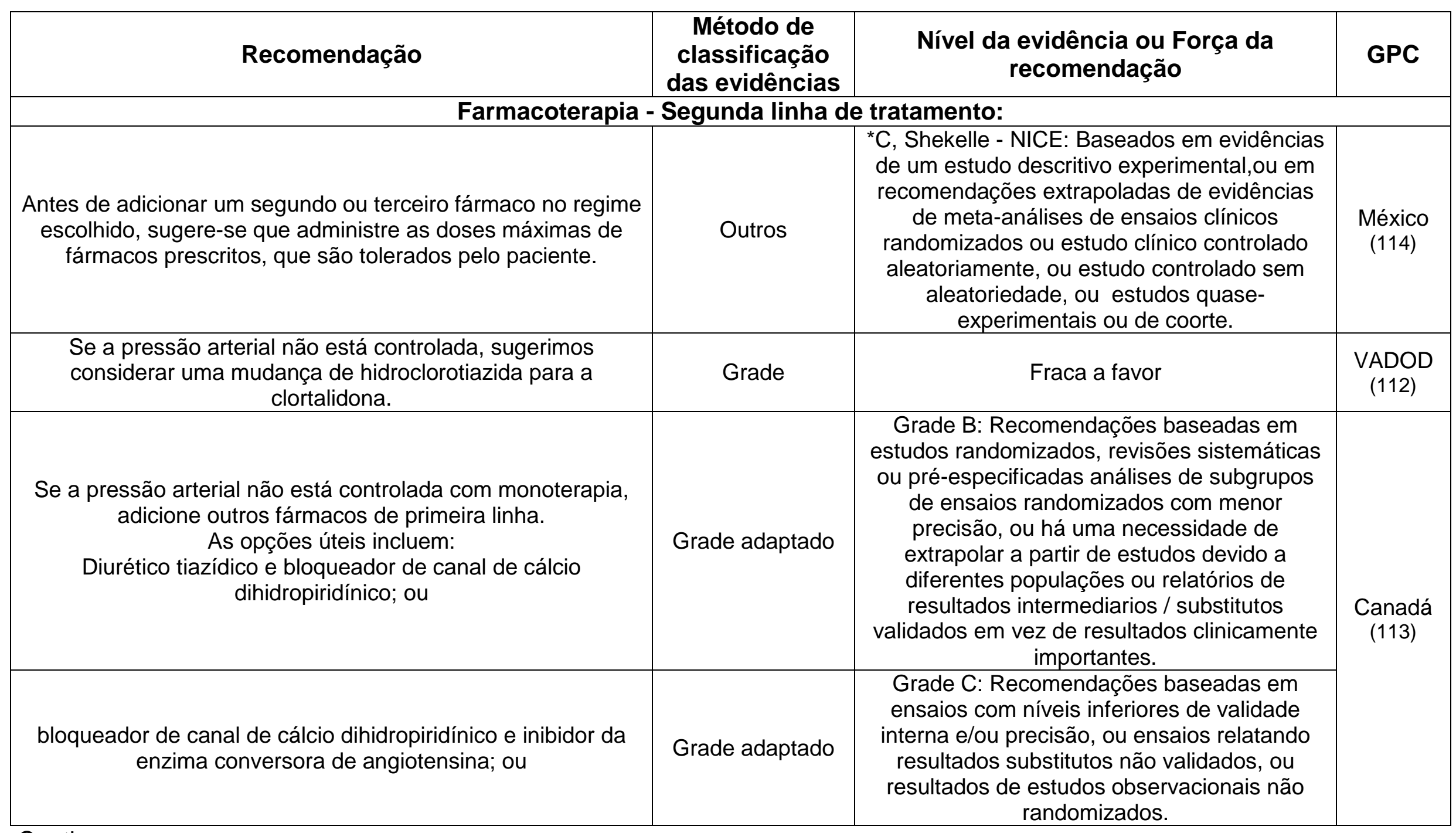


Continuação

\begin{tabular}{|c|c|c|c|}
\hline Recomendação & $\begin{array}{l}\text { Método de } \\
\text { classificação } \\
\text { das evidências }\end{array}$ & $\begin{array}{l}\text { Nível da evidência ou Força da } \\
\text { recomendação }\end{array}$ & GPC \\
\hline \multicolumn{4}{|c|}{ Farmacoterapia - Segunda linha de tratamento: } \\
\hline $\begin{array}{c}\text { Se a pressão arterial não for controlada com monoterapia em } \\
\text { dose padrão, é preferivel o tratamento com combinação de } \\
\text { famílias anti-hipertensivas (exceto a combinação de inibidores } \\
\text { da enzima conversora de angiotensina e bloqueadores do } \\
\text { receptor de angiotensina II), ao invés de aumento da dose de } \\
\text { agente único. } \\
\end{array}$ & Grade & Fraca a favor & $\begin{array}{l}\text { Colômbia } \\
\text { (109) }\end{array}$ \\
\hline $\begin{array}{c}\text { Recomendamos o uso de das seguintes terapias alternativas } \\
\text { para pacientes que não toleram diuréticos tiazidicos, ou como } \\
\text { terapia suplementar para pacientes que não atingem seus } \\
\text { objetivos hipertensivos, ou para aqueles que iniciam com } \\
\text { terapia combinada: } \\
\text { Inibidor da enzima conversora de angiotensina ou bloqueador } \\
\text { do receptor de angiotensina II (mas não juntos) } \\
\text { Bloqueador de canal de cálcio dihidropiridínico de ação } \\
\text { prolongada. }\end{array}$ & Grade & Forte a favor & $\begin{array}{l}\text { VADOD } \\
(112)\end{array}$ \\
\hline $\begin{array}{c}\text { Se a terapia for iniciada com um betabloqueador e um } \\
\text { segundo fármaco for necessário, adicione um bloqueador de } \\
\text { canal de cálcio no lugar de um diurético tiazídico para reduzir o } \\
\text { risco de desenvolver diabetes. }\end{array}$ & Grade & & $\begin{array}{l}\text { NICE } \\
(110)\end{array}$ \\
\hline
\end{tabular}

Continua 
Continuação

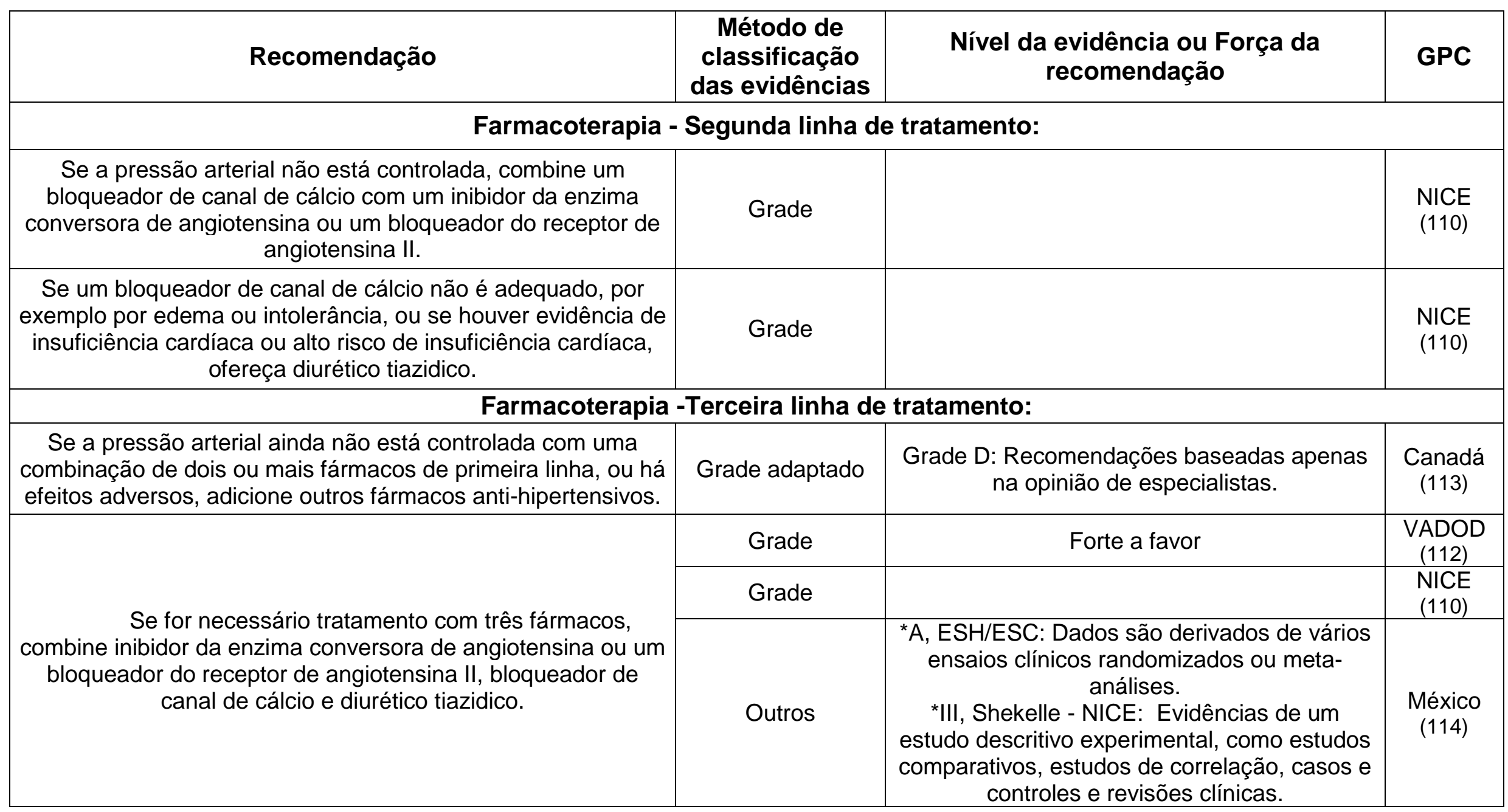

Continua controles e revisões clínicas. 
Continuação

\begin{tabular}{|c|c|c|c|}
\hline Recomendação & $\begin{array}{c}\text { Método de } \\
\text { classificação } \\
\text { das evidências }\end{array}$ & $\begin{array}{l}\text { Nível da evidência ou Força da } \\
\text { recomendação }\end{array}$ & GPC \\
\hline \multicolumn{4}{|c|}{ Farmacoterapia - Quarta linha de tratamento: } \\
\hline
\end{tabular}

Continua quase-experimentais ou de coorte. 
Continuação

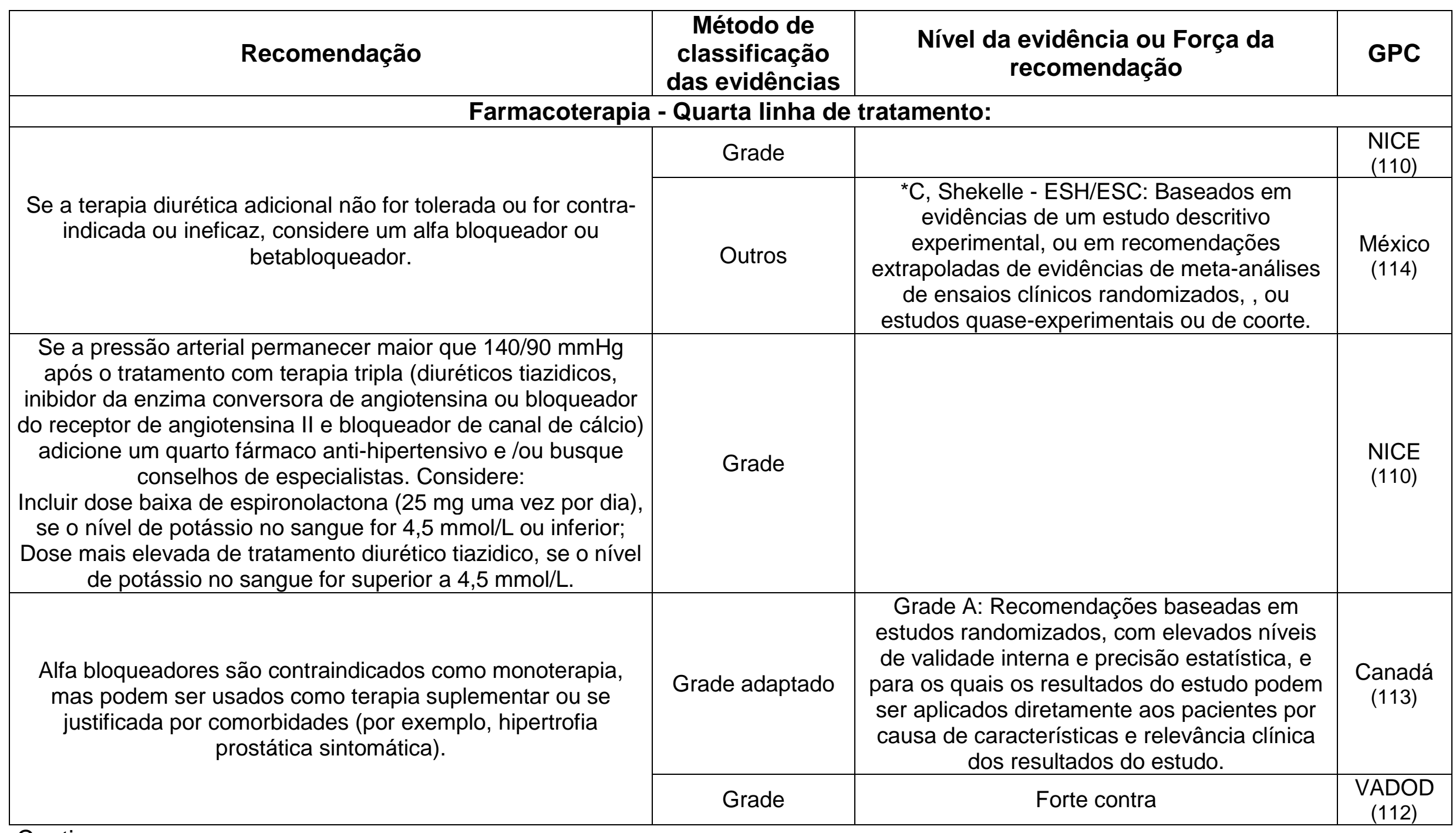

Continua 
Conclusão

\begin{tabular}{|c|c|c|c|}
\hline Recomendação & $\begin{array}{l}\text { Método de } \\
\text { classificação } \\
\text { das evidências }\end{array}$ & $\begin{array}{l}\text { Nível da evidência ou Força da } \\
\text { recomendação }\end{array}$ & GPC \\
\hline \multicolumn{4}{|c|}{ Contraindicaçôes: } \\
\hline \multirow{2}{*}{$\begin{array}{c}\text { Não combinar inibidor da enzima conversora de angiotensina e } \\
\text { bloqueador do receptor de angiotensina II. }\end{array}$} & Outros & $\begin{array}{c}\text { *A, CHEP: Baseados em estudos com altos } \\
\text { níveis de validade interna, precisão estatística } \\
\text { e generalização com relevância clínica. } \\
\text { *III, ESH/ESC: A evidência ou o acordo geral } \\
\text { não considera eficaz ou útil para dar um } \\
\text { procedimento ou tratamento específico e, em } \\
\text { alguns casos, pode causar danos à saúde } \\
\text { (Não recomendado). }\end{array}$ & $\begin{array}{l}\text { México } \\
(114)\end{array}$ \\
\hline & Grade adaptado & $\begin{array}{c}\text { Grade A: Recomendações baseadas em } \\
\text { estudos randomizados (ou revisões } \\
\text { sistemáticas de ensaios) com elevados níveis } \\
\text { de validade interna e precisão estatística, e } \\
\text { para os quais os resultados do estudo podem } \\
\text { ser aplicados diretamente aos pacientes por } \\
\text { causa de características e relevância clínica } \\
\text { dos resultados do estudo. }\end{array}$ & $\begin{array}{c}\text { Canadá } \\
(113)\end{array}$ \\
\hline \multirow[t]{2}{*}{$\begin{array}{l}\text { Não combinar o uso de mais de um dos seguintes três } \\
\text { fármacos: inibidor da enzima conversora de angiotensina, } \\
\text { bloqueador do receptor de angiotensina II e inibidor de renina. }\end{array}$} & Outros & $\begin{array}{l}\text { Forte / Evidência de alta qualidade de mais de } \\
\text { um ECR*; ou meta-análises de ECRs de alta } \\
\text { qualidade; ou um ou mais ECR corroborados } \\
\text { por estudos de registro de alta qualidade. }\end{array}$ & $\begin{array}{c}2017 \\
\text { ACC/AHA } \\
(111)\end{array}$ \\
\hline & Grade & Forte contra & $\begin{array}{l}\text { VADOD } \\
(112)\end{array}$ \\
\hline
\end{tabular}

Fonte: Elaboração própria. 
Na matriz, apresentada no Quadro 9, estão descritas as recomendações referentes a indicação de farmacoterapia, meta terapêutica e farmacoterapia da HAS em populações especificas: negros, idosos, pacientes com hipertensão sistólica isolada, mulheres e adultos mais jovens. Dos 6 GPC incluídos, todos continham recomendações para idosos, 4 traziam recomendações para negros (110-113) e apenas 2 para pacientes com hipertensão sistólica isolada $(113,114)$. 
Quadro 9 - Matriz das recomendações para farmacoterapia em populações/situações especificas com hipertensão arterial sistêmica, de guias de prática clinica (GPC) com nota de $60 \%$ ou mais no domínio 3 do AGREE II, obtido por revisão sistemática no período de 01/2011 a 12/2016, atualizado os GPC incluídos até 11/2017.

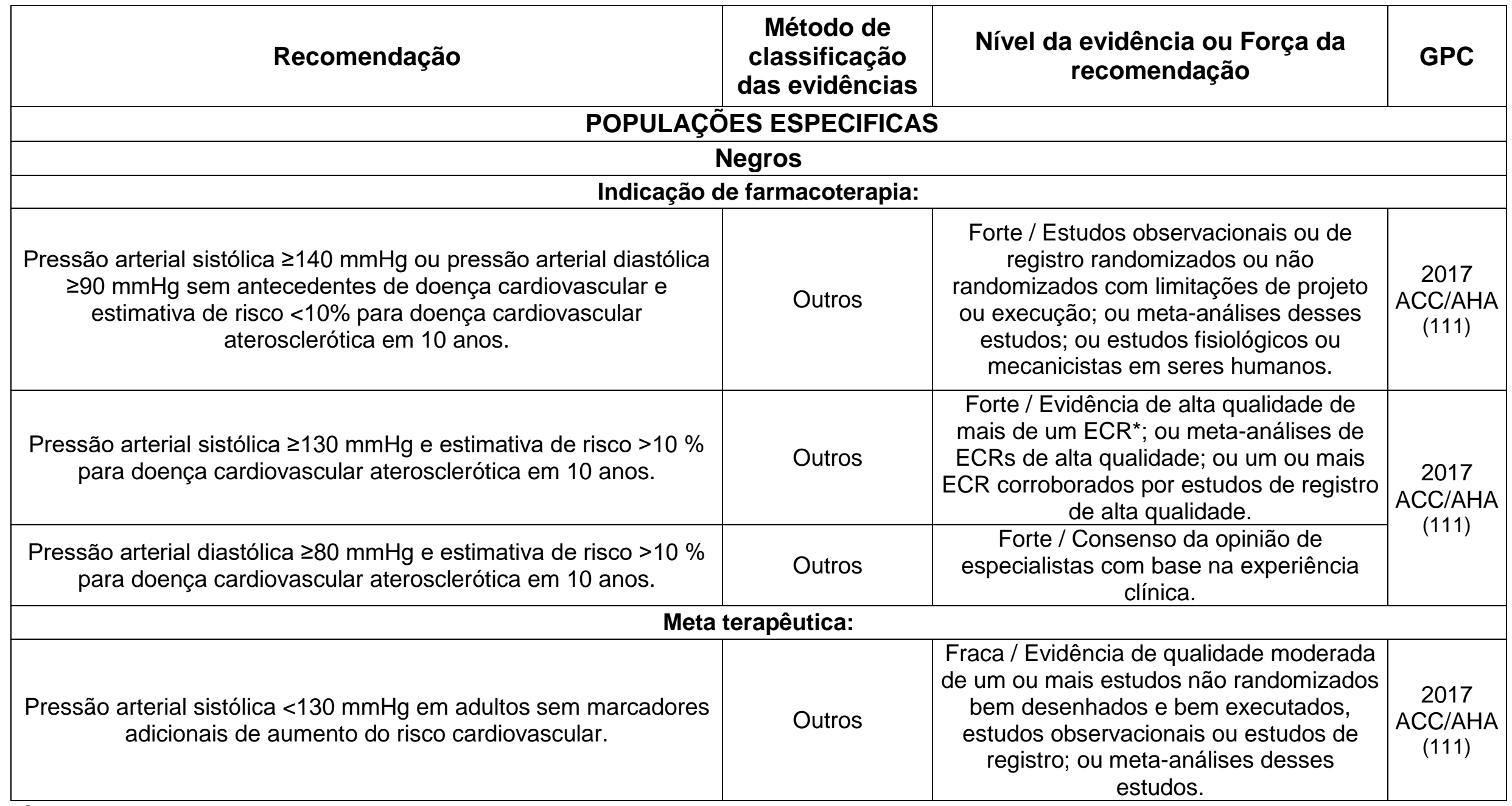


Continuação

\begin{tabular}{|c|c|c|c|}
\hline Recomendação & $\begin{array}{l}\text { Método de } \\
\text { classificação } \\
\text { das evidências }\end{array}$ & $\begin{array}{l}\text { Nível da evidência ou Força da } \\
\text { recomendação }\end{array}$ & GPC \\
\hline \multicolumn{4}{|c|}{ POPULAÇÕES ESPECIFICAS } \\
\hline \multicolumn{4}{|c|}{ Negros } \\
\hline \multicolumn{4}{|c|}{ Meta terapêutica: } \\
\hline $\begin{array}{l}\text { Pressão arterial diastólica }<80 \mathrm{mmHgem} \text { adultos sem marcadores } \\
\text { adicionais de aumento do risco cardiovascular. }\end{array}$ & Outros & $\begin{array}{c}\text { Fraca / Consenso da opinião de } \\
\text { especialistas com base na experiência } \\
\text { clínica. }\end{array}$ & $\begin{array}{c}2017 \\
\mathrm{ACC} / \mathrm{AHA} \\
(111)\end{array}$ \\
\hline $\begin{array}{l}\text { Pressão arterial sistólica }<130 \mathrm{mmHg} \text { em adultos com doença } \\
\text { cardiovascular conhecida ou risco de evento de doença } \\
\text { cardiovascular aterosclerótica }>10 \% \text { em } 10 \text { anos. }\end{array}$ & Outros & $\begin{array}{l}\text { Forte / Evidência de qualidade moderada } \\
\text { de um ou mais ECR }{ }^{\star} \text {; ou meta-análises } \\
\text { de ECRs de qualidade moderada. }\end{array}$ & \multirow{2}{*}{$\begin{array}{c}2017 \\
\mathrm{ACC} / \mathrm{AHA} \\
(111)\end{array}$} \\
\hline $\begin{array}{l}\text { Pressão arterial diastólica }<80 \mathrm{mmHg} \text { em adultos com doença } \\
\text { cardiovascular conhecida ou risco de evento de doença } \\
\text { cardiovascular aterosclerótica }>10 \% \text { em } 10 \text { anos. }\end{array}$ & Outros & $\begin{array}{l}\text { Forte / Consenso da opinião de } \\
\text { especialistas com base na experiência } \\
\text { clínica. }\end{array}$ & \\
\hline $\begin{array}{l}\text { Bloqueador de canal de cálcio, se este não for tolerado (edema, } \\
\text { intolerância ou insuficiência cardiaca) oferecer um diurético } \\
\text { tiazidico. }\end{array}$ & Grade & & $\begin{array}{l}\text { NICE } \\
(110)\end{array}$ \\
\hline $\begin{array}{c}\text { Se necessário, considerar um bloqueador do receptor de } \\
\text { angiotensina II em preferência a um inibidor da enzima conversora } \\
\text { de angiotensina, em combinação com um bloqueador de canal de } \\
\text { cálcio. }\end{array}$ & Grade & & $\begin{array}{l}\text { NICE } \\
(110)\end{array}$ \\
\hline
\end{tabular}

Continua 
Continuação

\begin{tabular}{|c|c|c|c|}
\hline Recomendação & $\begin{array}{c}\text { Método de } \\
\text { classificação } \\
\text { das evidências }\end{array}$ & $\begin{array}{l}\text { Nível da evidência ou Força da } \\
\text { recomendação }\end{array}$ & GPC \\
\hline \multicolumn{4}{|c|}{ POPULAÇÕES ESPECIFICAS } \\
\hline \multicolumn{4}{|c|}{ Farmacoterapia: } \\
\hline $\begin{array}{l}\text { Dois ou mais fármacos anti-hipertensivos são recomendados para } \\
\text { alcançar meta da pressão arterial na maioria dos pacientes. }\end{array}$ & Outros & $\begin{array}{l}\text { Forte / Estudos observacionais ou de } \\
\text { registro randomizados ou não } \\
\text { randomizados com limitações de projeto } \\
\text { ou execução; ou meta-análises desses } \\
\text { estudos; ou estudos fisiológicos ou } \\
\text { mecanicistas em seres humanos. }\end{array}$ & $\begin{array}{c}2017 \\
\mathrm{ACC} / \mathrm{AHA} \\
(111)\end{array}$ \\
\hline \multirow[b]{2}{*}{$\begin{array}{c}\text { É contraindicado o uso de inibidor da enzima conversora de } \\
\text { angiotensina ou bloqueador do receptor de angiotensina II como } \\
\text { monoterapia. }\end{array}$} & Grade & Forte contra & $\begin{array}{l}\text { VADOD } \\
(112)\end{array}$ \\
\hline & Grade adaptado & $\begin{array}{l}\text { Grade A: Recomendações baseadas em } \\
\text { estudos randomizados com elevados } \\
\text { níveis de validade interna e precisão } \\
\text { estatística, e para os quais os resultados } \\
\text { do estudo podem ser aplicados } \\
\text { diretamente aos pacientes por causa de } \\
\text { características e relevância clínica dos } \\
\text { resultados do estudo. }\end{array}$ & $\begin{array}{l}\text { Canadá } \\
(113)\end{array}$ \\
\hline $\begin{array}{l}\text { No entanto, inibidor da enzima conversora de angiotensina pode } \\
\text { ser usado em pacientes com certas comorbidades ou em terapia } \\
\text { combinada. }\end{array}$ & Grade adaptado & $\begin{array}{l}\text { Grade A: Recomendações baseadas em } \\
\text { estudos randomizados com elevados } \\
\text { níveis de validade interna e precisão } \\
\text { estatística, e para os quais os resultados } \\
\text { do estudo podem ser aplicados } \\
\text { diretamente aos pacientes por causa de } \\
\text { características e relevância clínica dos } \\
\text { resultados do estudo. }\end{array}$ & $\begin{array}{l}\text { Canadá } \\
(113)\end{array}$ \\
\hline
\end{tabular}

Continua 
Continuação

\begin{tabular}{|c|c|c|c|}
\hline Recomendação & $\begin{array}{c}\text { Método de } \\
\text { classificação } \\
\text { das evidências }\end{array}$ & $\begin{array}{l}\text { Nível da evidência ou Força da } \\
\text { recomendação }\end{array}$ & GPC \\
\hline \multicolumn{4}{|c|}{ POPULAÇÕES ESPECIFICAS } \\
\hline \multicolumn{4}{|c|}{ Farmacoterapia: } \\
\hline $\begin{array}{l}\text { Se paciente tiver doença renal crônica estágio } 1 \text { a 3, sugerimos } \\
\text { uma combinação de um diurético tiazídico (para proteção } \\
\text { cardiovascular) com um inibidor da enzima conversora de } \\
\text { angiotensina ou bloqueador do receptor de angiotensina II (para } \\
\text { proteção renal). }\end{array}$ & Grade & Fraca a favor & $\begin{array}{l}\text { VADOD } \\
(112)\end{array}$ \\
\hline \multicolumn{4}{|c|}{ Idosos } \\
\hline \multicolumn{4}{|c|}{ Indicação de farmacoterapia: } \\
\hline $\begin{array}{l}\text { Pressão arterial sistólica } \geq 130 \mathrm{mmHg} \text { para a comunidade } \\
\text { ambulatorial não institucionalizada em adultos } \geq 65 \text { anos. }\end{array}$ & Outros & $\begin{array}{c}\text { Forte / Evidência de alta qualidade de } \\
\text { mais de um ECR*; ou meta-análises de } \\
\text { ECRs de alta qualidade; ou um ou mais } \\
\text { ECR corroborados por estudos de registro } \\
\text { de alta qualidade. } \\
\end{array}$ & $\begin{array}{c}2017 \\
\mathrm{ACC} / \mathrm{AHA} \\
(111)\end{array}$ \\
\hline Pressão arterial sistólica $\geq 160 \mathrm{mmHg}$ em adultos $\geq 60$ anos. & Outros & $\begin{array}{l}\text { *I, ESH/ESC: Evidência e/ou } \\
\text { concordância geral sobre o benefício, } \\
\text { eficácia e utilidade de realizar um } \\
\text { procedimento ou dar um tratamento } \\
\text { específico (recomendado). }\end{array}$ & $\begin{array}{l}\text { México } \\
(114)\end{array}$ \\
\hline $\begin{array}{l}\text { Usar um modelo de tomada de decisão compartilhada para } \\
\text { pressão arterial sistólica }<160 \mathrm{mmHg} \text { em adultos } \geq 60 \text { anos. }\end{array}$ & Grade & Fraca a favor & $\begin{array}{l}\text { VADOD } \\
(112)\end{array}$ \\
\hline
\end{tabular}

Continua 
Continuação

\begin{tabular}{|c|c|c|c|}
\hline Recomendação & $\begin{array}{c}\text { Método de } \\
\text { classificação } \\
\text { das evidências }\end{array}$ & $\begin{array}{l}\text { Nível da evidência ou Força da } \\
\text { recomendação }\end{array}$ & GPC \\
\hline \multicolumn{4}{|c|}{ POPULAÇÕES ESPECIFICAS } \\
\hline \multicolumn{4}{|c|}{ Meta terapêutica: } \\
\hline $\begin{array}{l}\text { Pressão arterial sistólica }<130 \mathrm{mmHg} \text { para a comunidade } \\
\text { ambulatorial não institucionalizada em adultos } \geq 65 \text { anos. }\end{array}$ & Outros & $\begin{array}{c}\text { Forte / Evidência de alta qualidade de } \\
\text { mais de um ECR*; ou meta-análises de } \\
\text { ECRs de alta qualidade; ou um ou mais } \\
\text { ECR corroborados por estudos de registro } \\
\text { de alta qualidade. }\end{array}$ & \multirow{2}{*}{$\begin{array}{c}2017 \\
\mathrm{ACC} / \mathrm{AHA} \\
(111)\end{array}$} \\
\hline $\begin{array}{c}\text { Para adultos } \geq 65 \text { anos com hipertensão e uma alta carga de } \\
\text { comorbidade e expectativa de vida limitada, julgamento clínico, } \\
\text { preferência do paciente e uma abordagem baseada em equipe } \\
\text { para avaliar risco/benefício é razoável para decisões relativas à } \\
\text { intensidade da redução da pressão arterial e escolha de fármacos } \\
\text { anti-hipertensivos. }\end{array}$ & Outros & $\begin{array}{l}\text { Moderada / Consenso da opinião de } \\
\text { especialistas com base na experiência } \\
\text { clínica. }\end{array}$ & \\
\hline Pressão arterial $<150 / 90$ mmHg em adultos $\geq 80$ anos. & Grade & & $\begin{array}{l}\text { NICE } \\
(110)\end{array}$ \\
\hline $\begin{array}{l}\text { Pressão arterial sistólica }<140 \mathrm{mmHg} \text { e pressão arterial diastólica } \geq \\
65 \mathrm{mmHg} \mathrm{em} \text { adultos }<80 \text { anos. }\end{array}$ & \multirow{2}{*}{ Outros } & \multirow{2}{*}{$\begin{array}{l}\text { *Ilb, ESC/ESH: Eficiência e utilidade não } \\
\text { são bem definidas por evidências ou } \\
\text { opiniões de especialistas (considerar). }\end{array}$} & \multirow{2}{*}{$\begin{array}{l}\text { México } \\
(114)\end{array}$} \\
\hline $\begin{array}{l}\text { Pressão arterial sistólica entre } 140 \text { e } 150 \mathrm{mmHg} \text { em adultos > } \\
\text { anos com pressão arterial sistólica inicial >160 mmHg. }\end{array}$ & & & \\
\hline
\end{tabular}

Continua 
Continuação

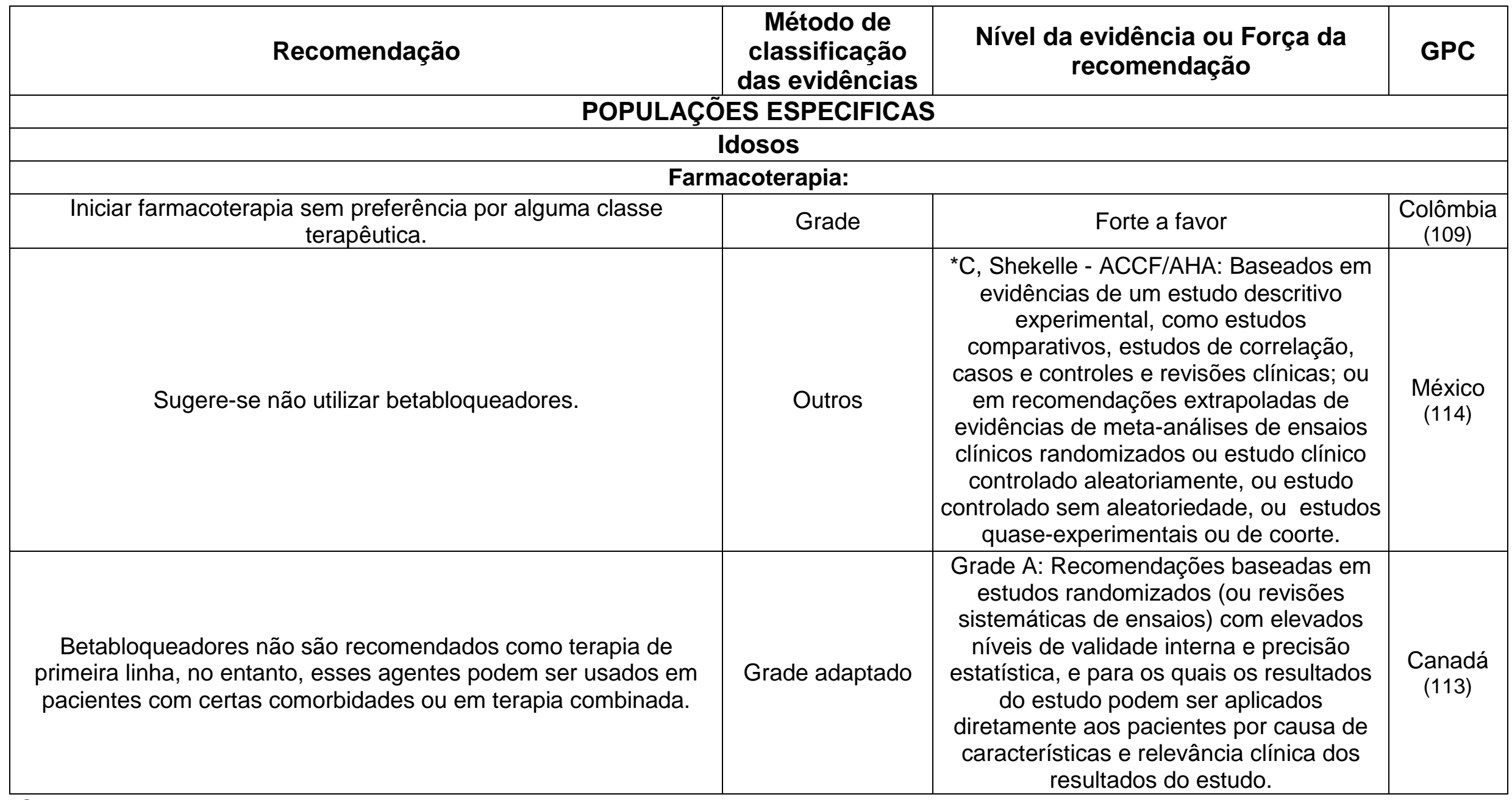


Continuação

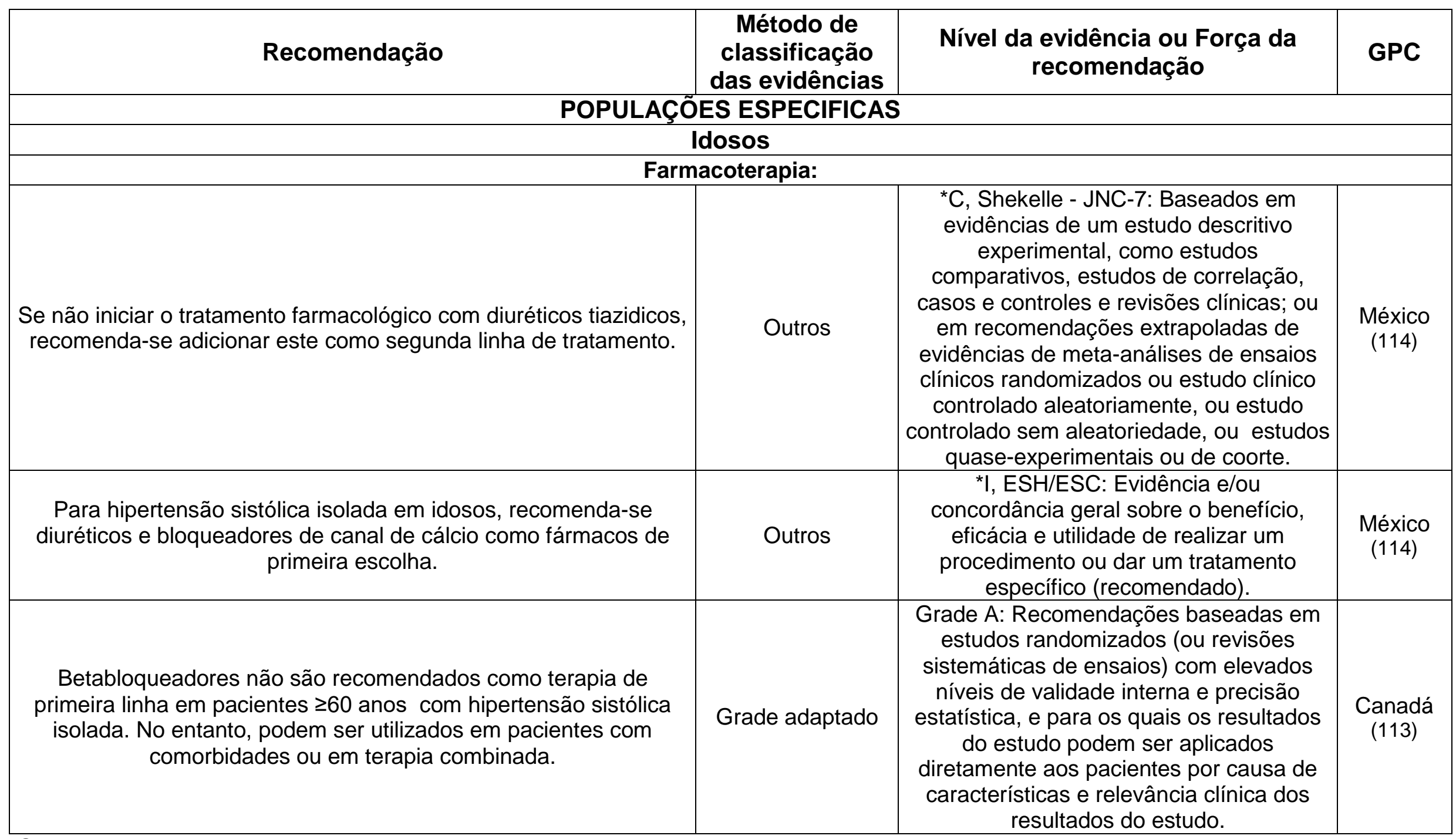

Continua 
Continuação

\begin{tabular}{|c|c|c|c|}
\hline Recomendação & $\begin{array}{l}\text { Método de } \\
\text { classificação } \\
\text { das evidências }\end{array}$ & $\begin{array}{l}\text { Nível da evidência ou Força da } \\
\text { recomendação }\end{array}$ & GPC \\
\hline \multicolumn{4}{|c|}{ POPULAÇÕES ESPECIFICAS } \\
\hline \multicolumn{4}{|c|}{ Idosos } \\
\hline \multicolumn{4}{|c|}{ Farmacoterapia: } \\
\hline $\begin{array}{l}\text { Em um idoso frágil, é recomendado ao médico a decisão da terapia } \\
\text { anti-hipertensiva, tratando e monitorando os efeitos clínicos do } \\
\text { tratamento. }\end{array}$ & Outros & $\begin{array}{l}\text { *I, ESH/ESC: Evidência e/ou } \\
\text { concordância geral sobre o benefício, } \\
\text { eficácia e utilidade de realizar um } \\
\text { procedimento ou dar um tratamento } \\
\text { específico (recomendado). }\end{array}$ & $\begin{array}{l}\text { México } \\
(114)\end{array}$ \\
\hline $\begin{array}{l}\text { Continuar tratamento anti-hipertensivo se este for bem tolerado em } \\
\text { paciente idoso que atinge } 80 \text { anos de idade. }\end{array}$ & Outros & $\begin{array}{l}\text { *Ila, ESH/ESC: O peso da evidência ou } \\
\text { opinião é a favor de sua eficácia ou } \\
\text { utilidade (considerar). }\end{array}$ & $\begin{array}{l}\text { México } \\
(114)\end{array}$ \\
\hline \multicolumn{4}{|c|}{ Pacientes com hipertensão sistólica isolada } \\
\hline
\end{tabular}


Continuação

\begin{tabular}{|c|c|c|c|}
\hline Recomendação & $\begin{array}{l}\text { Método de } \\
\text { classificação } \\
\text { das evidências }\end{array}$ & $\begin{array}{l}\text { Nível da evidência ou Força da } \\
\text { recomendação }\end{array}$ & GPC \\
\hline \multicolumn{4}{|c|}{ POPULAÇÕES ESPECIFICAS } \\
\hline \multicolumn{4}{|c|}{ Indicação de farmacoterapia: } \\
\hline $\begin{array}{c}\text { Pressão arterial sistólica } \geq 140 \mathrm{mmHg} \text { na presença de dano de } \\
\text { órgãos alvo macrovascular ou outros fatores de riscos } \\
\text { cardiovasculares independentes. }\end{array}$ & Grade adaptado & $\begin{array}{l}\text { Grade B: Recomendações baseadas em } \\
\text { estudos randomizados, revisões } \\
\text { sistemáticas ou pré-especificadas } \\
\text { análises de subgrupos de ensaios } \\
\text { randomizados com menor precisão, ou há } \\
\text { uma necessidade de extrapolar a partir de } \\
\text { estudos devido a diferentes populações } \\
\text { ou relatórios de resultados intermediarios / } \\
\text { substitutos validados em vez de } \\
\text { resultados clinicamente importantes. }\end{array}$ & $\begin{array}{c}\text { Canadá } \\
(113)\end{array}$ \\
\hline
\end{tabular}

Continua 
Continuação

\begin{tabular}{|c|c|c|c|}
\hline Recomendação & $\begin{array}{c}\text { Método de } \\
\text { classificação } \\
\text { das evidências }\end{array}$ & $\begin{array}{l}\text { Nível da evidência ou Força da } \\
\text { recomendação }\end{array}$ & GPC \\
\hline \multicolumn{4}{|c|}{ POPULAÇÕES ESPECIFICAS } \\
\hline \multicolumn{4}{|c|}{ Farmacoterapia: } \\
\hline $\begin{array}{l}\text { Diurético tiazídico, ou bloqueador de canal de cálcio } \\
\text { dihidropiridínico de ação prolongada, ou }\end{array}$ & Grade adaptado & $\begin{array}{l}\text { Grade A: Recomendações baseadas em } \\
\text { estudos randomizados (ou revisões } \\
\text { sistemáticas de ensaios) com elevados } \\
\text { níveis de validade interna e precisão } \\
\text { estatística, e para os quais os resultados } \\
\text { do estudo podem ser aplicados } \\
\text { diretamente aos pacientes por causa de } \\
\text { características e relevância clínica dos } \\
\text { resultados do estudo. }\end{array}$ & \multirow{3}{*}{$\begin{array}{c}\text { Canadá } \\
(113)\end{array}$} \\
\hline bloqueador do receptor de angiotensina II. & Grade adaptado & \begin{tabular}{|} 
Grade B: Recomendações baseadas em \\
estudos randomizados, revisões \\
sistemáticas ou pré-especificadas \\
análises de subgrupos de ensaios \\
randomizados com menor precisão, ou há \\
uma necessidade de extrapolar a partir de \\
estudos devido a diferentes populações \\
ou relatórios de resultados intermediarios / \\
substitutos validados em vez de \\
resultados clinicamente importantes.
\end{tabular} & \\
\hline $\begin{array}{l}\text { Se houver efeitos adversos, outro fármaco destes grupos devem } \\
\text { ser usados na substituíção. }\end{array}$ & Grade adaptado & \begin{tabular}{|l|} 
Grade C: Recomendações baseadas em \\
ensaios com níveis inferiores de validade \\
interna e/ou precisão, ou ensaios \\
relatando resultados substitutos não \\
validados, ou resultados de estudos \\
observacionais não randomizados. \\
\end{tabular} & \\
\hline
\end{tabular}


Continuação

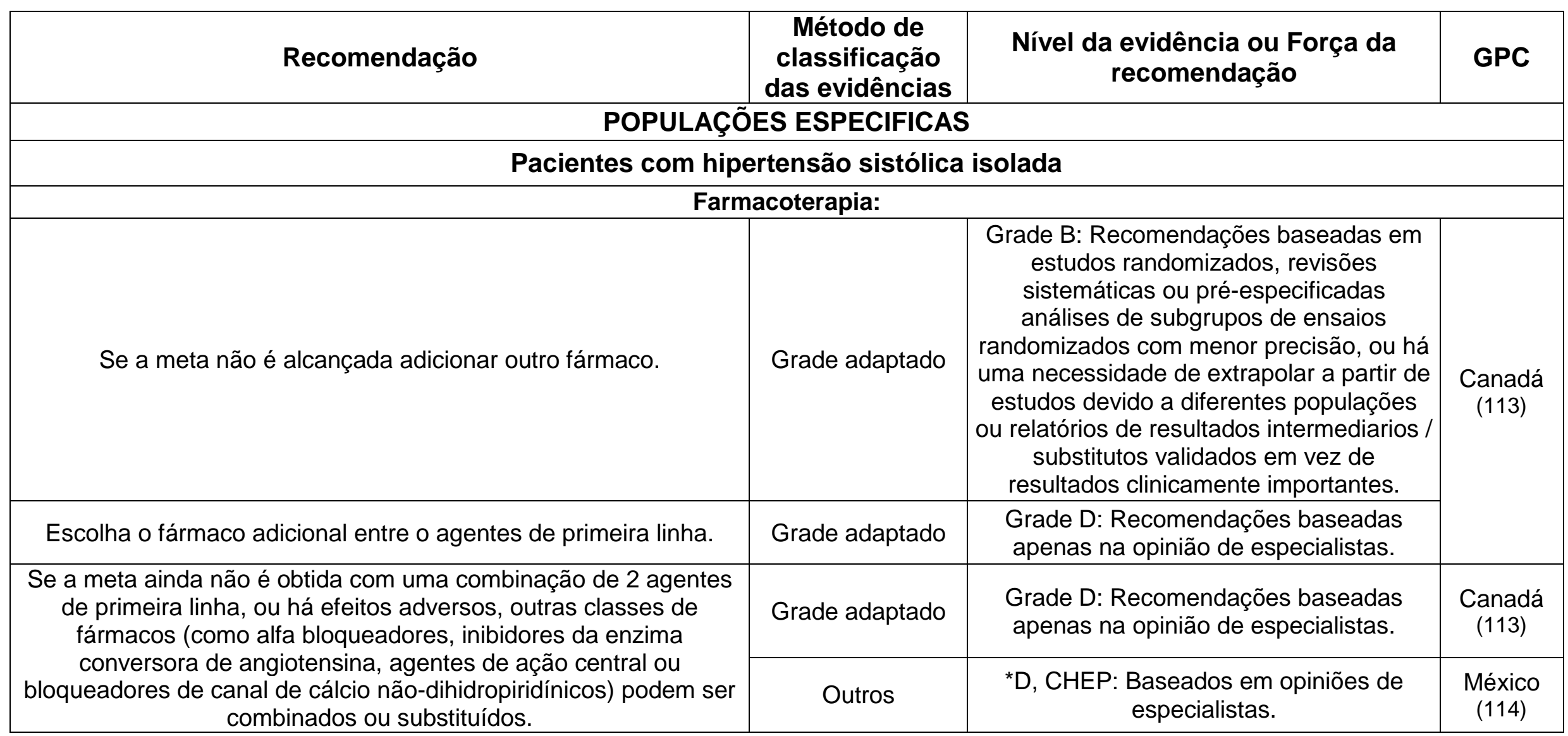

Continua 
Conclusão

\begin{tabular}{|c|c|c|c|}
\hline Recomendação & $\begin{array}{c}\text { Método de } \\
\text { classificação } \\
\text { das evidências }\end{array}$ & $\begin{array}{l}\text { Nível da evidência ou Força da } \\
\text { recomendação }\end{array}$ & GPC \\
\hline \multicolumn{4}{|c|}{ POPULAÇÕES ESPECIFICAS } \\
\hline \multicolumn{4}{|c|}{ Farmacoterapia: } \\
\hline $\begin{array}{l}\text { Alfa bloqueadores não são agentes de primeira linha para } \\
\text { hipertensão sistólica isolada sem complicações e os } \\
\text { betabloqueadores não são recomendados como terapia de } \\
\text { primeira linha em pacientes com } 60 \text { anos ou mais. No entanto, } \\
\text { estes podem ser utilizados em pacientes com comorbidades ou em } \\
\text { terapia combinada. }\end{array}$ & Grade adaptado & $\begin{array}{l}\text { Grade A: Recomendações baseadas em } \\
\text { estudos randomizados com elevados } \\
\text { níveis de validade interna e precisão } \\
\text { estatística, e para os quais os resultados } \\
\text { do estudo podem ser aplicados } \\
\text { diretamente aos pacientes por causa de } \\
\text { características e relevância clínica dos } \\
\text { resultados do estudo. }\end{array}$ & $\begin{array}{c}\text { Canadá } \\
(113)\end{array}$ \\
\hline $\begin{array}{c}\text { Em idosos, recomenda-se diuréticos e bloqueadores de canal de } \\
\text { cálcio como fármacos de primeira escolha. }\end{array}$ & Outros & $\begin{array}{l}\text { *I, ESH/ESC: Evidência e/ou } \\
\text { concordância geral sobre o benefício, } \\
\text { eficácia e utilidade de realizar um } \\
\text { procedimento ou dar um tratamento } \\
\text { específico (recomendado). }\end{array}$ & $\begin{array}{l}\text { México } \\
(114)\end{array}$ \\
\hline \multicolumn{4}{|c|}{ Adultos mais jovens } \\
\hline $\begin{array}{l}\text { Betabloqueadores não são terapia inicial preferida, porém podem } \\
\text { ser considerados em pessoas mais jovens, particularmente } \\
\text { naqueles com intolerância ou contra-indicação aos inibidores da } \\
\text { enzima conversora de angiotensina e bloqueadores do receptor de } \\
\text { angiotensina II, mulheres com potencial para engravidar ou } \\
\text { pessoas com evidência de maior movimentação simpática. }\end{array}$ & Grade & & $\begin{array}{l}\text { NICE } \\
(110)\end{array}$ \\
\hline
\end{tabular}

Fonte: Elaboração própria.

*ECR: Ensaio clínico randomizado. 
Na matriz, apresentada no Quadro 10, estão descritas as recomendações para farmacoterapia da HAS em adultos ou idosos com comorbidades. Não foi feita uma busca por GPC que incluíssem outras comorbidades, porém dos 6 GPC incluídos, 4 continham recomendações para pacientes com HAS e comorbidades (111-114). 
Quadro 10 - Matriz das recomendações para farmacoterapia da hipertensão arterial sistêmica em adultos ou idosos com comorbidades, de guias de prática clinica (GPC) com nota de $60 \%$ ou mais no domínio 3 do AGREE II, obtido por revisão sistemática no período de 01/2011 a 12/2016, atualizado os GPC incluídos até 11/2017.

\begin{tabular}{|c|c|c|c|}
\hline Recomendação & $\begin{array}{l}\text { Método de } \\
\text { classificação } \\
\text { das evidências }\end{array}$ & $\begin{array}{l}\text { Nível da evidência ou Força da } \\
\text { recomendação }\end{array}$ & GPC \\
\hline \multicolumn{4}{|c|}{ COMORBIDADES } \\
\hline $\begin{array}{c}\text { Meta terapêutica: } \\
\text { Pressão arterial sistólica <140 mmHg. }\end{array}$ & Outros & \begin{tabular}{|c|} 
*A, CHEP: Baseados em estudos com altos \\
níveis de validade interna, precisão estatística \\
e generalização com relevância clínica. \\
*C, CHEP: Baseados em estudos que \\
relatam resultados intermediários ou \\
substitutos em vez de resultados clinicamente \\
mais relevantes.
\end{tabular} & $\begin{array}{l}\text { México } \\
(114)\end{array}$ \\
\hline $\begin{array}{c}\text { Farmacoterapia: } \\
\text { Combinar inibidor da enzima conversora de angiotensina ou } \\
\text { bloqueador do receptor de angiotensina II com bloqueador de } \\
\text { canal de cálcio. }\end{array}$ & Outros & $\begin{array}{c}\text { *A, CHEP: Baseados em estudos com altos } \\
\text { níveis de validade interna, precisão estatística } \\
\text { e generalização com relevância clínica. } \\
\text { *C, CHEP: Baseados em estudos que } \\
\text { relatam resultados intermediários ou } \\
\text { substitutos em vez de resultados clinicamente } \\
\text { mais relevantes. }\end{array}$ & $\begin{array}{l}\text { México } \\
(114)\end{array}$ \\
\hline Pressão arterial sistólica $\geq 130$ mmHg. & Outros & $\begin{array}{c}\text { Forte / Evidência de qualidade moderada de } \\
\text { um ou mais ECR*s; ou meta-análises de } \\
\text { ECRs de qualidade moderada. }\end{array}$ & \multirow{2}{*}{$\begin{array}{c}2017 \\
\text { ACC/AHA } \\
(111)\end{array}$} \\
\hline Pressão arterial diastólica $\geq 80$ mmHg. & Outros & $\begin{array}{c}\text { Forte / Consenso da opinião de especialistas } \\
\text { com base na experiência clínica. }\end{array}$ & \\
\hline
\end{tabular}

Continua 
Continuação

\begin{tabular}{|c|c|c|c|}
\hline Recomendação & $\begin{array}{c}\text { Método de } \\
\text { classificação } \\
\text { das evidências }\end{array}$ & $\begin{array}{l}\text { Nível da evidência ou Força da } \\
\text { recomendação }\end{array}$ & GPC \\
\hline \multicolumn{4}{|c|}{ COMORBIDADES } \\
\hline \multicolumn{4}{|c|}{ Meta terapêutica: } \\
\hline Pressão arterial sistólica $<130$ mmHg. & Outros & $\begin{array}{c}\text { Forte / Evidência de qualidade moderada de } \\
\text { um ou mais ECR }{ }^{*} \text {; ; ou meta-análises de } \\
\text { ECRs de qualidade moderada. }\end{array}$ & $\begin{array}{c}2017 \\
\mathrm{ACC} / \mathrm{AHA} \\
(111)\end{array}$ \\
\hline Pressão arterial < $130 / 80$ mmHg. & Outros & $\begin{array}{c}{ }^{*} \mathrm{C} \text {, Shekelle - NICE: Baseados em evidências } \\
\text { de um estudo descritivo experimental, como } \\
\text { estudos comparativos, ou de correlação; ou } \\
\text { em recomendações extrapoladas de } \\
\text { evidências de meta-análises de ensaios } \\
\text { clínicos randomizados ou estudo clínico } \\
\text { controlado aleatoriamente, ou estudo } \\
\text { controlado sem aleatoriedade, ou estudos } \\
\text { quase-experimentais ou de coorte. }\end{array}$ & $\begin{array}{l}\text { México } \\
(114)\end{array}$ \\
\hline
\end{tabular}

Continua 
Continuação

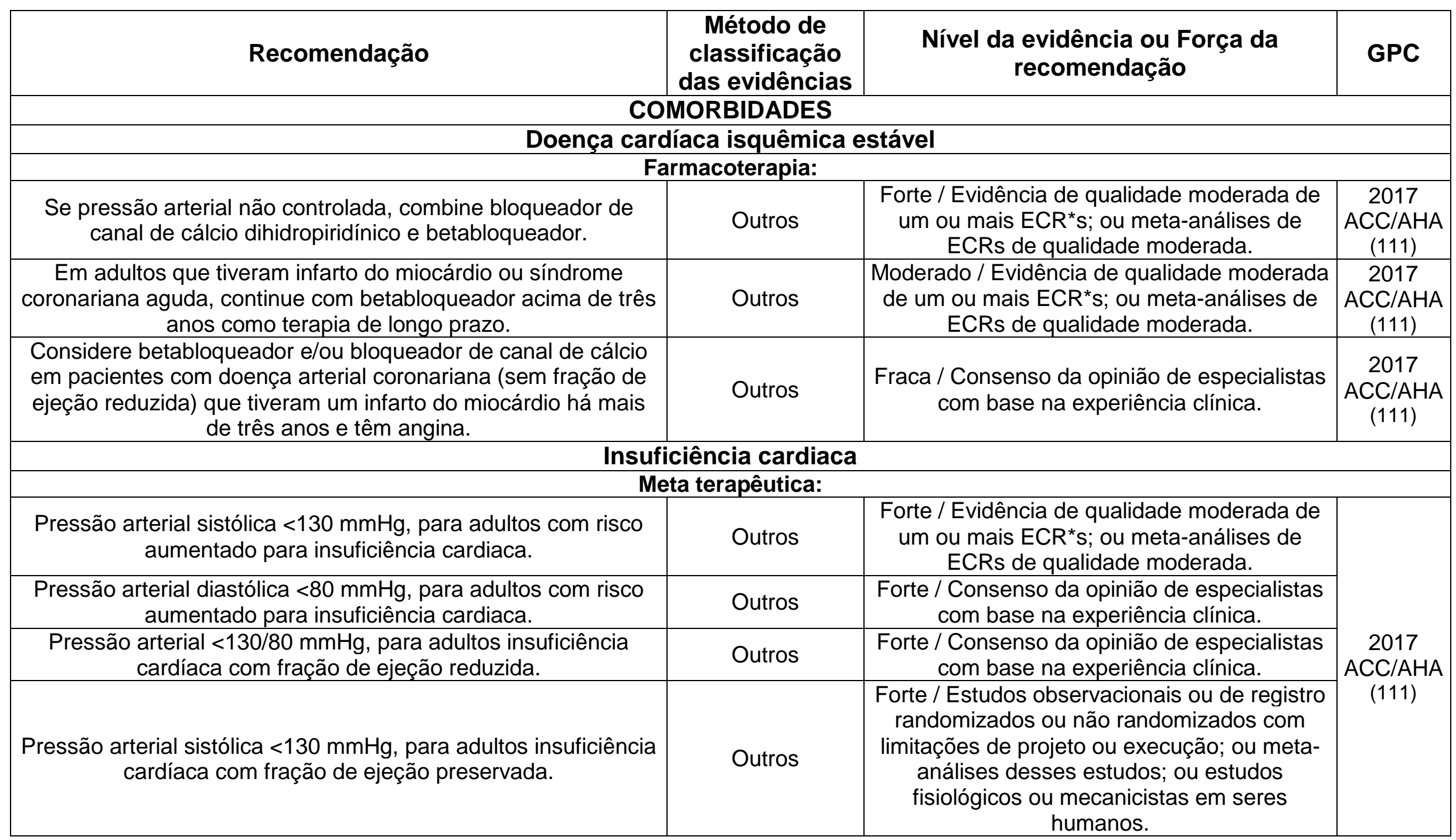

Continua 
Continuação

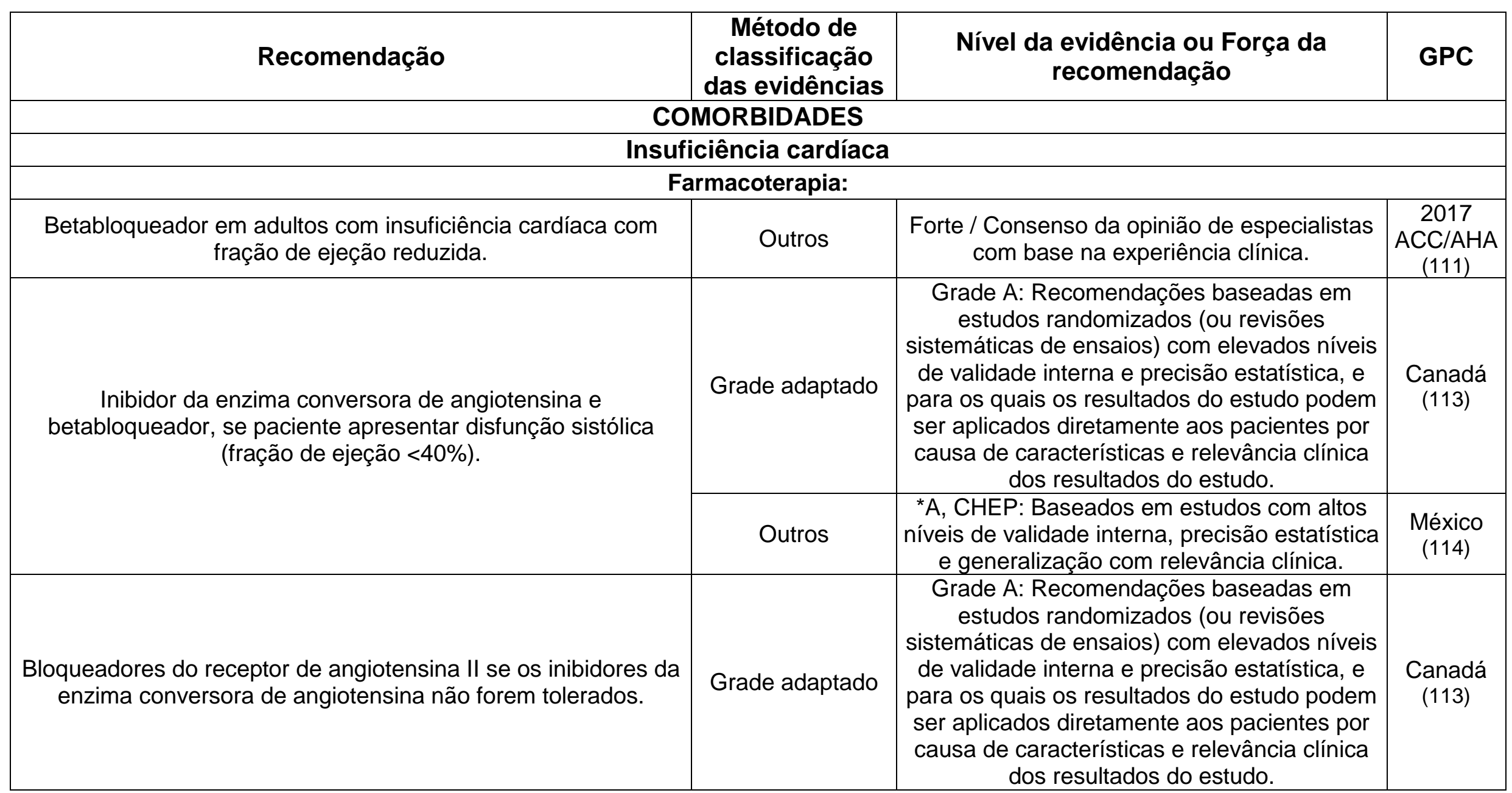

Continua 
Continuação

\begin{tabular}{|c|c|c|c|}
\hline Recomendação & $\begin{array}{l}\text { Método de } \\
\text { classificação } \\
\text { das evidências }\end{array}$ & $\begin{array}{l}\text { Nível da evidência ou Força da } \\
\text { recomendação }\end{array}$ & GPC \\
\hline \multicolumn{4}{|c|}{ COMORBIDADES } \\
\hline \multicolumn{4}{|c|}{ Farmacoterapia: } \\
\hline $\begin{array}{l}\text { Combine hidralazina e dinitrato de isossorbida se os inibidores } \\
\text { da enzima conversora de angiotensina e bloqueadores do } \\
\text { receptor de angiotensina II estiverem contra-indicados ou não } \\
\text { forem tolerados. }\end{array}$ & Grade adaptado & $\begin{array}{c}\text { Grade B: Recomendações baseadas em } \\
\text { estudos randomizados, revisões sistemáticas } \\
\text { ou pré-especificadas análises de subgrupos } \\
\text { de ensaios randomizados com menor } \\
\text { precisão, ou há uma necessidade de } \\
\text { extrapolar a partir de estudos devido a } \\
\text { diferentes populações ou relatórios de } \\
\text { resultados intermediarios / substitutos } \\
\text { validados em vez de resultados clinicamente } \\
\text { importantes. }\end{array}$ & $\begin{array}{c}\text { Canadá } \\
(113)\end{array}$ \\
\hline $\begin{array}{l}\text { Combinar antagonista de aldosterona, se paciente apresentar } \\
\text { hospitalização cardiovascular recente, infarto agudo do } \\
\text { miocárdio, péptido natriurético de tipo B elevado ou nível de } \\
\text { péptido natriurético do tipo N-terminal do tipo B ou sintomas da } \\
\text { Classe II-IV da Associação do Coração de Nova York. }\end{array}$ & Grade adaptado & $\begin{array}{l}\text { Grade A: Recomendações baseadas em } \\
\text { estudos randomizados (ou revisões } \\
\text { sistemáticas de ensaios) com elevados níveis } \\
\text { de validade interna e precisão estatística, e } \\
\text { para os quais os resultados do estudo podem } \\
\text { ser aplicados diretamente aos pacientes por } \\
\text { causa de características e relevância clínica } \\
\text { dos resultados do estudo. }\end{array}$ & $\begin{array}{c}\text { Canadá } \\
(113)\end{array}$ \\
\hline
\end{tabular}

Continua 
Continuação

\begin{tabular}{|c|c|c|c|}
\hline Recomendação & $\begin{array}{c}\text { Método de } \\
\text { classificação } \\
\text { das evidências }\end{array}$ & $\begin{array}{l}\text { Nível da evidência ou Força da } \\
\text { recomendação }\end{array}$ & GPC \\
\hline \multicolumn{4}{|c|}{ COMORBIDADES } \\
\hline \multicolumn{4}{|c|}{ Farmacoterapia: } \\
\hline $\begin{array}{l}\text { Se necessário adicionar diuréticos tiazídicos para controle de } \\
\text { pressão arterial ou }\end{array}$ & Grade adaptado & $\begin{array}{c}\text { Grade B: Recomendações baseadas em } \\
\text { estudos randomizados, revisões sistemáticas } \\
\text { ou pré-especificadas análises de subgrupos } \\
\text { de ensaios randomizados com menor } \\
\text { precisão, ou há uma necessidade de } \\
\text { extrapolar a partir de estudos devido a } \\
\text { diferentes populações ou relatórios de } \\
\text { resultados intermediarios / substitutos } \\
\text { validados em vez de resultados clinicamente } \\
\text { importantes. }\end{array}$ & \multirow[t]{2}{*}{$\begin{array}{c}\text { Canadá } \\
(113)\end{array}$} \\
\hline diuréticos de alça para controle de volume. & Grade adaptado & $\begin{array}{c}\text { Grade D: Recomendações baseadas apenas } \\
\text { na opinião de especialistas. }\end{array}$ & \\
\hline $\begin{array}{l}\text { Bloqueadores de canal de cálcio se betabloqueadores são } \\
\text { contra-indicados ou não são eficazes. }\end{array}$ & Outros & $\begin{array}{l}\text { *A, CHEP: Baseados em estudos com altos } \\
\text { níveis de validade interna, precisão estatística } \\
\text { e generalização com relevância clínica. }\end{array}$ & $\begin{array}{l}\text { México } \\
(114)\end{array}$ \\
\hline
\end{tabular}

Continua 
Continuação

\begin{tabular}{|c|c|c|c|}
\hline Recomendação & $\begin{array}{c}\text { Método de } \\
\text { classificação } \\
\text { das evidências }\end{array}$ & $\begin{array}{l}\text { Nível da evidência ou Força da } \\
\text { recomendação }\end{array}$ & GPC \\
\hline \multicolumn{4}{|c|}{ COMORBIDADES } \\
\hline \multicolumn{4}{|c|}{ Insuficiência cardíaca } \\
\hline \multicolumn{4}{|c|}{ Farmacoterapia: } \\
\hline $\begin{array}{l}\text { Bloqueadores de canal de cálcio não-dihidropiridínicos não são } \\
\text { recomendados em pacientes com insuficiência cardíaca com } \\
\text { fração de ejeção reduzida. }\end{array}$ & Outros & $\begin{array}{c}\text { Moderada / Evidência de qualidade moderada } \\
\text { de um ou mais ECR*s; ou meta-análises de } \\
\text { ECRs de qualidade moderada. }\end{array}$ & $\begin{array}{c}2017 \\
\mathrm{ACC} / \mathrm{AHA} \\
(111)\end{array}$ \\
\hline $\begin{array}{c}\text { Ofereça diuréticos para adultos com insuficiência cardíaca com } \\
\text { fração de ejeção preservada que apresentam sintomas de } \\
\text { sobrecarga de volume. }\end{array}$ & Outros & $\begin{array}{l}\text { Forte / Consenso da opinião de especialistas } \\
\text { com base na experiência clínica. }\end{array}$ & $\begin{array}{c}2017 \\
\mathrm{ACC} / \mathrm{AHA} \\
(111)\end{array}$ \\
\hline $\begin{array}{c}\text { Adicionar inibidores da enzima conversora de angiotensina ou } \\
\text { bloqueadores do receptor de angiotensina II e } \\
\text { betabloqueadores, se pressão arterial não controlada após o } \\
\text { manejo da sobrecarga de volume em adultos com insuficiência } \\
\text { cardíaca com fração de ejeção preservada. }\end{array}$ & Outros & $\begin{array}{l}\text { Forte / Estudos observacionais ou de registro } \\
\text { randomizados ou não randomizados com } \\
\text { limitações de projeto ou execução; ou meta- } \\
\text { análises desses estudos; ou estudos } \\
\text { fisiológicos ou mecanicistas em seres } \\
\text { humanos. }\end{array}$ & $\begin{array}{c}2017 \\
\mathrm{ACC} / \mathrm{AHA} \\
(111)\end{array}$ \\
\hline $\begin{array}{c}\text { Não prescrever bloqueadores de canal de cálcio em presença } \\
\text { de insuficiência cardiaca com evidência de congestão pulmonar } \\
\text { ou radiológica da mesma. }\end{array}$ & Outros & $\begin{array}{l}{ }^{*} \mathrm{D}, \mathrm{CHEP}: \text { Baseados em opiniões de } \\
\text { especialistas. }\end{array}$ & $\begin{array}{l}\text { México } \\
(114)\end{array}$ \\
\hline
\end{tabular}

Continua 
Continuação

\begin{tabular}{|c|c|c|c|}
\hline Recomendação & \begin{tabular}{|c|} 
Método de \\
classificação \\
das evidências
\end{tabular} & $\begin{array}{l}\text { Nível da evidência ou Força da } \\
\text { recomendação }\end{array}$ & GPC \\
\hline \multicolumn{4}{|c|}{ COMORBIDADES } \\
\hline \multicolumn{4}{|c|}{ Meta terapêutica: } \\
\hline Pressão arterial sistólica $<130$ mmHg. & Outros & $\begin{array}{c}\text { Forte / Evidência de qualidade moderada de } \\
\text { um ou mais ECR }{ }^{*} \text {; ou meta-análises de } \\
\text { ECRs de qualidade moderada. }\end{array}$ & $\begin{array}{c}2017 \\
\mathrm{ACC} / \mathrm{AHA} \\
(111)\end{array}$ \\
\hline \multicolumn{4}{|c|}{ Farmacoterapia: } \\
\hline $\begin{array}{c}\text { Inibidor da enzima conversora de angiotensina para retardar a } \\
\text { progressão da doença renal (em doença renal crônica estágio } 3 \\
\text { ou superior ou estágio } 1 \text { ou } 2 \text { com albuminúria } \geq 300 \mathrm{mg} / \mathrm{g}, \text { ou } \geq \\
300 \mathrm{mg} / \mathrm{g} \text { de proporção de albumina-creatinina ou equivalente } \\
\text { na primeira urina da manhã). }\end{array}$ & Outros & $\begin{array}{c}\text { Moderada / Evidência de qualidade moderada } \\
\text { de um ou mais ECR*s; ou meta-análises de } \\
\text { ECRs de qualidade moderada. }\end{array}$ & $\begin{array}{c}2017 \\
\mathrm{ACC} / \mathrm{AHA} \\
(111)\end{array}$ \\
\hline
\end{tabular}

Continua 
Continuação

\begin{tabular}{|c|c|c|c|}
\hline Recomendação & $\begin{array}{c}\text { Método de } \\
\text { classificação } \\
\text { das evidências }\end{array}$ & $\begin{array}{l}\text { Nível da evidência ou Força da } \\
\text { recomendação }\end{array}$ & GPC \\
\hline \multicolumn{4}{|c|}{ COMORBIDADES } \\
\hline \multicolumn{4}{|c|}{ Doença renal crônica } \\
\hline \multicolumn{4}{|c|}{ Farmacoterapia: } \\
\hline $\begin{array}{c}\text { Bloqueador do receptor de angiotensina Il se houver } \\
\text { intolerância à inibidor da enzima conversora de angiotensina em } \\
\text { pacientes com doença renal crônica proteinúrica (proteína } \\
\text { urinária }>500 \mathrm{mg} \text { por } 24 \text { horas ou proporção de albumina para } \\
\text { creatinina }>30 \mathrm{mg} / \mathrm{Mmol}) \text {. }\end{array}$ & Grade adaptado & $\begin{array}{c}\text { Grade B: Recomendações baseadas em } \\
\text { estudos randomizados, revisões sistemáticas } \\
\text { ou pré-especificadas análises de subgrupos } \\
\text { de ensaios randomizados com menor } \\
\text { precisão, ou há uma necessidade de } \\
\text { extrapolar a partir de estudos devido a } \\
\text { diferentes populações ou relatórios de } \\
\text { resultados intermediarios / substitutos } \\
\text { validados em vez de resultados clinicamente } \\
\text { importantes. }\end{array}$ & $\begin{array}{c}\text { Canadá } \\
(113)\end{array}$ \\
\hline $\begin{array}{c}\text { Inibidor da enzima conversora de angiotensina em pacientes } \\
\text { com insuficiência renal não associada a diabetes e na ausência } \\
\text { de estenose da artéria renal. }\end{array}$ & Outros & $\begin{array}{l}\text { *A, CHEP: Baseados em estudos com altos } \\
\text { níveis de validade interna, precisão estatística } \\
\text { e generalização com relevância clínica. }\end{array}$ & $\begin{array}{l}\text { México } \\
(114)\end{array}$ \\
\hline $\begin{array}{c}\text { Adicione diuréticos tiazidicos se o paciente tiver doença renal ou } \\
\text { diuréticos de alça, para sobrecarga de volume. }\end{array}$ & Grade adaptado & $\begin{array}{l}\text { Grade D: Recomendações baseadas apenas } \\
\text { na opinião de especialistas. }\end{array}$ & $\begin{array}{c}\text { Canadá } \\
(113)\end{array}$ \\
\hline
\end{tabular}

Continua 
Continuação

\begin{tabular}{|c|c|c|c|}
\hline Recomendação & \begin{tabular}{|c|} 
Método de \\
classificação \\
das evidências
\end{tabular} & $\begin{array}{l}\text { Nível da evidência ou Força da } \\
\text { recomendação }\end{array}$ & GPC \\
\hline \multicolumn{4}{|c|}{ COMORBIDADES } \\
\hline \multicolumn{4}{|c|}{ Farmacoterapia: } \\
\hline $\begin{array}{c}\text { Em nefropatia diabética ou não diabética, use terapia } \\
\text { combinada com: } \\
\text { Inibidor da enzima conversora de angiotensina ou bloqueador } \\
\text { do receptor de angiotensina II; } \\
\text { Bloqueador de canal de cálcio com efeito prolongado; } \\
\text { Diuréticos, de alça substituem os tiazidicos quando a creatinina } \\
\text { sérica é de } 1,5 \mathrm{mg} / \mathrm{dL} \text { ou a taxa de filtração glomerular é }<30 \mathrm{~mL} \\
/ \mathrm{min} / 1,73 \mathrm{~m} \text {. }\end{array}$ & Outros & $\begin{array}{c}\text { *II, ESH/ESC: Evidências contraditórias e } \\
\text { diferentes opiniões sobre o eficácia e } \\
\text { utilidade de dar um tratamento ou } \\
\text { procedimento. }\end{array}$ & $\begin{array}{l}\text { México } \\
(114)\end{array}$ \\
\hline $\begin{array}{l}\text { Na maioria dos casos, a terapia combinada pode ser } \\
\text { necessária. }\end{array}$ & Grade adaptado & $\begin{array}{l}\text { Grade D: Recomendações baseadas apenas } \\
\text { na opinião de especialistas. }\end{array}$ & \\
\hline
\end{tabular}

Continua 
Continuação

\begin{tabular}{|c|c|c|c|}
\hline Recomendação & $\begin{array}{c}\text { Método de } \\
\text { classificação } \\
\text { das evidências }\end{array}$ & $\begin{array}{l}\text { Nível da evidência ou Força da } \\
\text { recomendação }\end{array}$ & GPC \\
\hline \multicolumn{4}{|c|}{ COMORBIDADES } \\
\hline \multicolumn{4}{|c|}{ Indicação de farmacoterapia: } \\
\hline $\begin{array}{l}\text { Em pacientes com história de doença cerebrovascular e } \\
\text { pressão arterial sistólica } \geq 140 \mathrm{mmHg} \text {. }\end{array}$ & Grade & Fraca a favor & $\begin{array}{l}\text { VADOD } \\
(112)\end{array}$ \\
\hline $\begin{array}{c}\text { Após fase aguda de acidente vascular cerebral ou ataque } \\
\text { isquêmico transitório. }\end{array}$ & Grade adaptado & $\begin{array}{c}\text { Grade A: Recomendações baseadas em } \\
\text { estudos randomizados (ou revisões } \\
\text { sistemáticas de ensaios) com elevados níveis } \\
\text { de validade interna e precisão estatística, e } \\
\text { para os quais os resultados do estudo podem } \\
\text { ser aplicados diretamente aos pacientes por } \\
\text { causa de características e relevância clínica } \\
\text { dos resultados do estudo. }\end{array}$ & $\begin{array}{c}\text { Canadá } \\
(113)\end{array}$ \\
\hline $\begin{array}{c}\text { Se pressão arterial }<140 / 90 \mathrm{mmHg} \text {, em adultos que não foram } \\
\text { previamente tratados e sofreram acidente vascular cerebral ou } \\
\text { ataque isquêmico transitório a utilidade de iniciar farmacoterapia } \\
\text { não é bem estabelecida. }\end{array}$ & Outros & $\begin{array}{l}\text { Fraca / Estudos observacionais ou de registro } \\
\text { randomizados ou não randomizados com } \\
\text { limitações de projeto ou execução; ou meta- } \\
\text { análises desses estudos; ou estudos } \\
\text { fisiológicos ou mecanicistas em seres } \\
\text { humanos. }\end{array}$ & $\begin{array}{c}2017 \\
\text { ACC/AHA } \\
(111)\end{array}$ \\
\hline
\end{tabular}

Continua 
Continuação

\begin{tabular}{|c|c|c|c|}
\hline Recomendação & $\begin{array}{c}\text { Método de } \\
\text { classificação } \\
\text { das evidências }\end{array}$ & $\begin{array}{l}\text { Nível da evidência ou Força da } \\
\text { recomendação }\end{array}$ & GPC \\
\hline \multicolumn{4}{|c|}{ COMORBIDADES } \\
\hline \multicolumn{4}{|c|}{ Meta terapêutica: } \\
\hline $\begin{array}{l}\text { Pressão arterial }<130 / 80 \mathrm{mmHg} \text { para adultos que sofreram um } \\
\text { sofreram acidente vascular cerebral ou ataque isquêmico } \\
\text { transitório; }\end{array}$ & \multirow{2}{*}{ Outros } & \multirow{2}{*}{$\begin{array}{c}\text { Fraca / Evidência de qualidade moderada de } \\
\text { um ou mais ECR*s; ou meta-análises de } \\
\text { ECRs de qualidade moderada. }\end{array}$} & \multirow{2}{*}{$\begin{array}{c}2017 \\
\mathrm{ACC} / \mathrm{AHA} \\
(111)\end{array}$} \\
\hline $\begin{array}{c}\text { Pressão arterial sistólica }<130 \mathrm{mmHg} \text { para adultos com acidente } \\
\text { vascular cerebral lacunar. }\end{array}$ & & & \\
\hline $\begin{array}{c}\text { Pressão arterial }<140 / 90 \mathrm{mmHg} \text { após fase aguda de um } \\
\text { acidente vascular cerebral. }\end{array}$ & Grade adaptado & $\begin{array}{c}\text { Grade C: Recomendações baseadas em } \\
\text { ensaios com níveis inferiores de validade } \\
\text { interna e/ou precisão, ou ensaios relatando } \\
\text { resultados substitutos não validados, ou } \\
\text { resultados de estudos observacionais não } \\
\text { randomizados. }\end{array}$ & $\begin{array}{c}\text { Canadá } \\
(113)\end{array}$ \\
\hline
\end{tabular}

Continua qualidade. 
Continuação

\begin{tabular}{|c|c|c|c|}
\hline Recomendação & \begin{tabular}{|c|} 
Método de \\
classificação \\
das evidências
\end{tabular} & $\begin{array}{l}\text { Nível da evidência ou Força da } \\
\text { recomendação }\end{array}$ & GPC \\
\hline \multicolumn{4}{|c|}{ COMORBIDADES } \\
\hline \multicolumn{4}{|c|}{ Farmacoterapia: } \\
\hline \multirow{2}{*}{$\begin{array}{c}\text { Combinar inibidor da enzima conversora de angiotensina com } \\
\text { diurético tiazidico. }\end{array}$} & Grade adaptado & $\begin{array}{c}\text { Grade B: Recomendações baseadas em } \\
\text { estudos randomizados, revisões sistemáticas } \\
\text { ou pré-especificadas análises de subgrupos } \\
\text { de ensaios randomizados com menor } \\
\text { precisão, ou há uma necessidade de } \\
\text { extrapolar a partir de estudos devido a } \\
\text { diferentes populações ou relatórios de } \\
\text { resultados intermediarios / substitutos } \\
\text { validados em vez de resultados clinicamente } \\
\text { importantes. }\end{array}$ & $\begin{array}{c}\text { Canadá } \\
(113)\end{array}$ \\
\hline & Outros & $\begin{array}{l}\text { *B, CHEP: Derivados de estudos que são } \\
\text { caracterizados por baixa precisão de validade } \\
\text { interna ou generalização limitada. }\end{array}$ & $\begin{array}{l}\text { México } \\
(114)\end{array}$ \\
\hline $\begin{array}{c}\text { Seleção de fármacos deve ser individualizada com base em } \\
\text { comorbidades do paciente e agentes das classes } \\
\text { farmacológicas. }\end{array}$ & Outros & $\begin{array}{l}\text { Forte / Evidência de qualidade moderada de } \\
\text { um ou mais ECR*s; ou meta-análises de } \\
\text { ECRs de qualidade moderada. }\end{array}$ & $\begin{array}{c}2017 \\
\mathrm{ACC} / \mathrm{AHA} \\
(111)\end{array}$ \\
\hline
\end{tabular}

Continua 
Continuação

\begin{tabular}{|c|c|c|c|}
\hline Recomendação & $\begin{array}{c}\text { Método de } \\
\text { classificação } \\
\text { das evidências }\end{array}$ & $\begin{array}{l}\text { Nível da evidência ou Força da } \\
\text { recomendação }\end{array}$ & GPC \\
\hline \multicolumn{4}{|c|}{ COMORBIDADES } \\
\hline \multicolumn{4}{|c|}{ Farmacoterapia: } \\
\hline $\begin{array}{l}\text { É contraindicado combinar inibidor da enzima conversora de } \\
\text { angiotensina em adultos com acidente vascular cerebral. }\end{array}$ & Grade adaptado & $\begin{array}{c}\text { Grade B: Recomendações baseadas em } \\
\text { estudos randomizados, revisões sistemáticas } \\
\text { ou pré-especificadas análises de subgrupos } \\
\text { de ensaios randomizados com menor } \\
\text { precisão, ou há uma necessidade de } \\
\text { extrapolar a partir de estudos devido a } \\
\text { diferentes populações ou relatórios de } \\
\text { resultados intermediarios / substitutos } \\
\text { validados em vez de resultados clinicamente } \\
\text { importantes. }\end{array}$ & $\begin{array}{c}\text { Canadá } \\
(113)\end{array}$ \\
\hline \multicolumn{4}{|c|}{ Doença arterial periférica } \\
\hline \multicolumn{4}{|c|}{ Indicação de farmacoterapia: } \\
\hline Pressão arterial sistólica $\geq 130$ mmHg. & \multirow[t]{2}{*}{ Outros } & $\begin{array}{c}\text { Forte / Evidência de qualidade moderada de } \\
\text { um ou mais ECR*s; ou meta-análises de } \\
\text { ECRs de qualidade moderada. }\end{array}$ & \multirow{2}{*}{$\begin{array}{c}2017 \\
\mathrm{ACC} / \mathrm{AHA} \\
(111)\end{array}$} \\
\hline Pressão arterial diastólica $\geq 80$ mmHg. & & $\begin{array}{l}\text { Forte / Consenso da opinião de especialistas } \\
\text { com base na experiência clínica. }\end{array}$ & \\
\hline
\end{tabular}

Continua 
Continuação

\begin{tabular}{|c|c|c|c|}
\hline Recomendação & $\begin{array}{l}\text { Método de } \\
\text { classificação } \\
\text { das evidências }\end{array}$ & $\begin{array}{l}\text { Nível da evidência ou Força da } \\
\text { recomendação }\end{array}$ & GPC \\
\hline \multicolumn{4}{|c|}{ COMORBIDADES } \\
\hline \multicolumn{4}{|c|}{ Indicação de farmacoterapia: } \\
\hline Pressão arterial sistólica >140mmHg. & Outros & $\begin{array}{l}\text { *I, ESH/ESC: Evidência e/ou concordância } \\
\text { geral sobre o benefício, eficácia e utilidade de } \\
\text { realizar um procedimento ou dar um } \\
\text { tratamento específico (recomendado). }\end{array}$ & $\begin{array}{l}\text { México } \\
(114)\end{array}$ \\
\hline \multicolumn{4}{|c|}{ Meta terapêutica: } \\
\hline Pressão arterial sistólica <130mmHg. & Grade adaptado & $\begin{array}{l}\text { Grade C: Recomendações baseadas em } \\
\text { ensaios com níveis inferiores de validade } \\
\text { interna e/ou precisão, ou ensaios relatando } \\
\text { resultados substitutos não validados, ou } \\
\text { resultados de estudos observacionais não } \\
\text { randomizados. }\end{array}$ & $\begin{array}{c}\text { Canadá } \\
(113)\end{array}$ \\
\hline Pressão arterial diastólica $<80$ mmHg. & Outros & $\begin{array}{l}\text { Forte / Consenso da opinião de especialistas } \\
\text { com base na experiência clínica. }\end{array}$ & $\begin{array}{c}2017 \\
\mathrm{ACC} / \mathrm{AHA} \\
(111)\end{array}$ \\
\hline
\end{tabular}


Continuação

\begin{tabular}{|c|c|c|c|}
\hline Recomendação & $\begin{array}{c}\text { Método de } \\
\text { classificação } \\
\text { das evidências }\end{array}$ & $\begin{array}{l}\text { Nível da evidência ou Força da } \\
\text { recomendação }\end{array}$ & GPC \\
\hline \multicolumn{4}{|c|}{ COMORBIDADES } \\
\hline \multicolumn{4}{|c|}{ Meta terapêutica: } \\
\hline $\begin{array}{c}\text { Pressão arterial sistólica }<150 \mathrm{mmHg} \text { e pressão arterial } \\
\text { diastólica }<85 \mathrm{mmHg} .\end{array}$ & Grade & Forte a favor & $\begin{array}{l}\text { VADOD } \\
(112)\end{array}$ \\
\hline \multicolumn{4}{|c|}{ Farmacoterapia: } \\
\hline \multirow{2}{*}{$\begin{array}{l}\text { Diuréticos tiazídicos, inibidor da enzima conversora de } \\
\text { angiotensina, bloqueador do receptor de angiotensina II ou } \\
\text { bloqueador de canal de cálcio. }\end{array}$} & Outros & $\begin{array}{c}\text { Forte / Evidência de alta qualidade de mais } \\
\text { de um ECR*; ou meta-análises de ECRs de } \\
\text { alta qualidade; ou um ou mais ECR } \\
\text { corroborados por estudos de registro de alta } \\
\text { qualidade. }\end{array}$ & $\begin{array}{c}2017 \\
\text { ACC/AHA } \\
(111)\end{array}$ \\
\hline & Outros & $\begin{array}{c}\text { *A, CHEP: Baseados em estudos com altos } \\
\text { níveis de validade interna, precisão estatística } \\
\text { e generalização com relevância clínica. }\end{array}$ & $\begin{array}{l}\text { México } \\
(114)\end{array}$ \\
\hline
\end{tabular}


Continuação

\begin{tabular}{|c|c|c|c|}
\hline Recomendação & $\begin{array}{c}\text { Método de } \\
\text { classificação } \\
\text { das evidências }\end{array}$ & $\begin{array}{l}\text { Nível da evidência ou Força da } \\
\text { recomendação }\end{array}$ & GPC \\
\hline \multicolumn{4}{|c|}{ COMORBIDADES } \\
\hline \multicolumn{4}{|c|}{ Farmacoterapia: } \\
\hline bloqueador do receptor de angiotensina II. & Grade adaptado & $\begin{array}{l}\text { Grade B: Recomendações baseadas em } \\
\text { estudos randomizados, revisões sistemáticas } \\
\text { ou pré-especificadas análises de subgrupos } \\
\text { de ensaios randomizados com menor } \\
\text { precisão, ou há uma necessidade de } \\
\text { extrapolar a partir de estudos devido a } \\
\text { diferentes populações ou relatórios de } \\
\text { resultados intermediarios / substitutos } \\
\text { validados em vez de resultados clinicamente } \\
\text { importantes. }\end{array}$ & $\begin{array}{c}\text { Canadá } \\
(113)\end{array}$ \\
\hline $\begin{array}{c}\text { Considerar inibidor da enzima conversora de angiotensina ou } \\
\text { bloqueador do receptor de angiotensina II na presença de } \\
\text { albuminúria. }\end{array}$ & Outros & $\begin{array}{c}\text { Fraca / Evidência de qualidade moderada de } \\
\text { um ou mais ECR*s; ou meta-análises de } \\
\text { ECRs de qualidade moderada. }\end{array}$ & $\begin{array}{c}2017 \\
\mathrm{ACC} / \mathrm{AHA} \\
(111) \\
\end{array}$ \\
\hline $\begin{array}{l}\text { Inibidor da enzima conversora de angiotensina ou bloqueador } \\
\text { do receptor de angiotensina II, se paciente apresentar doença } \\
\text { cardiovascular ou doença renal. }\end{array}$ & Grade adaptado & $\begin{array}{c}\text { Grade A: Recomendações baseadas em } \\
\text { estudos randomizados (ou revisões } \\
\text { sistemáticas de ensaios) com elevados níveis } \\
\text { de validade interna e precisão estatística, e } \\
\text { para os quais os resultados do estudo podem } \\
\text { ser aplicados diretamente aos pacientes por } \\
\text { causa de características e relevância clínica } \\
\text { dos resultados do estudo. }\end{array}$ & $\begin{array}{c}\text { Canadá } \\
(113)\end{array}$ \\
\hline
\end{tabular}

Continua 
Continuação

\begin{tabular}{|c|c|c|c|}
\hline Recomendação & $\begin{array}{c}\text { Método de } \\
\text { classificação } \\
\text { das evidências }\end{array}$ & $\begin{array}{l}\text { Nível da evidência ou Força da } \\
\text { recomendação }\end{array}$ & GPC \\
\hline \multicolumn{4}{|c|}{ COMORBIDADES } \\
\hline \multicolumn{4}{|c|}{ Farmacoterapia: } \\
\hline $\begin{array}{l}\text { Se a meta de pressão arterial não for alcançada com a } \\
\text { monoterapia, adicione fármacos. Se a terapia combinada com } \\
\text { um inibidor da enzima conversora de angiotensina for } \\
\text { considerada, um de bloqueador de canal de cálcio } \\
\text { dihidropiridínico é preferível a um diurético tiazidico. }\end{array}$ & Grade adaptado & $\begin{array}{c}\text { Grade A: Recomendações baseadas em } \\
\text { estudos randomizados (ou revisões } \\
\text { sistemáticas de ensaios) com elevados níveis } \\
\text { de validade interna e precisão estatística, e } \\
\text { para os quais os resultados do estudo podem } \\
\text { ser aplicados diretamente aos pacientes por } \\
\text { causa de características e relevância clínica } \\
\text { dos resultados do estudo. }\end{array}$ & $\begin{array}{c}\text { Canadá } \\
(113)\end{array}$ \\
\hline $\begin{array}{l}\text { Para terapia combinada use inibidor da enzima conversora de } \\
\text { angiotensina ou bloqueador do receptor de angiotensina II com } \\
\text { bloqueador de canal de cálcio de ação prolongada. }\end{array}$ & Outros & $\begin{array}{l}\text { *A, CHEP: Baseados em estudos com altos } \\
\text { níveis de validade interna, precisão estatística } \\
\text { e generalização com relevância clínica. }\end{array}$ & $\begin{array}{l}\text { México } \\
(114)\end{array}$ \\
\hline
\end{tabular}

Continua importantes. 
Continuação

\begin{tabular}{|c|c|c|c|}
\hline Recomendação & $\begin{array}{c}\text { Método de } \\
\text { classificação } \\
\text { das evidências }\end{array}$ & $\begin{array}{l}\text { Nível da evidência ou Força da } \\
\text { recomendação }\end{array}$ & GPC \\
\hline \multicolumn{4}{|c|}{ COMORBIDADES } \\
\hline $\begin{array}{c}\text { Farmacoterapia: } \\
\text { Bloqueador do receptor de angiotensina II para prevenção de } \\
\text { recorrência. }\end{array}$ & Outros & \begin{tabular}{|c|} 
Moderada / Evidência de qualidade moderada \\
de um ou mais ECR*s; ou meta-análises de \\
ECRs de qualidade moderada.
\end{tabular} & $\begin{array}{c}2017 \\
\mathrm{ACC} / \mathrm{AHA} \\
(111)\end{array}$ \\
\hline \multicolumn{4}{|c|}{ Doença cardiaca valvular } \\
\hline \multicolumn{4}{|c|}{ Farmacoterapia: } \\
\hline $\begin{array}{c}\text { Em adultos com estenose aórtica assintomática, inicie } \\
\text { farmacoterapia com uma dose baixa e aumento gradual } \\
\text { conforme necessidade. }\end{array}$ & Outros & $\begin{array}{c}\text { Forte / Evidência de qualidade moderada de } \\
\text { um ou mais ECR*s; ou meta-análises de } \\
\text { ECRs de qualidade moderada. }\end{array}$ & $\begin{array}{c}2017 \\
\mathrm{ACC} / \mathrm{AHA} \\
(111)\end{array}$ \\
\hline $\begin{array}{l}\text { Em pacientes com insuficiência aórtica crônica, evite } \\
\text { betabloqueadores para tratar hipertensão sistólica isolada. }\end{array}$ & Outros & $\begin{array}{c}\text { Moderada / Estudos observacionais ou de } \\
\text { registro randomizados ou não randomizados } \\
\text { com limitações de projeto ou execução; ou } \\
\text { meta-análises desses estudos; ou estudos } \\
\text { fisiológicos ou mecanicistas em seres } \\
\text { humanos. }\end{array}$ & $\begin{array}{c}2017 \\
\mathrm{ACC} / \mathrm{AHA} \\
(111)\end{array}$ \\
\hline $\begin{array}{c}\text { Farmacoterapia: } \\
\text { Betabloqueadores são preferidos. }\end{array}$ & Outros & $\begin{array}{c}\text { Forte / Consenso da opinião de especialistas } \\
\text { com base na experiência clínica. }\end{array}$ & $\begin{array}{c}2017 \\
\mathrm{ACC} / \mathrm{AHA} \\
(111)\end{array}$ \\
\hline
\end{tabular}

Continua 
Continuação

\begin{tabular}{|c|c|c|c|}
\hline Recomendação & \begin{tabular}{|c|} 
Método de \\
classificação \\
das evidências
\end{tabular} & $\begin{array}{l}\text { Nível da evidência ou Força da } \\
\text { recomendação }\end{array}$ & GPC \\
\hline \multicolumn{4}{|c|}{ COMORBIDADES } \\
\hline \multicolumn{4}{|c|}{ Farmacoterapia: } \\
\hline $\begin{array}{c}\text { Para a maioria dos pacientes recomenda-se inibidor da enzima } \\
\text { conversora de angiotensina ou bloqueador do receptor de } \\
\text { angiotensina II. }\end{array}$ & Grade adaptado & $\begin{array}{c}\text { Grade A: Recomendações baseadas em } \\
\text { estudos randomizados (ou revisões } \\
\text { sistemáticas de ensaios) com elevados níveis } \\
\text { de validade interna e precisão estatística, e } \\
\text { para os quais os resultados do estudo podem } \\
\text { ser aplicados diretamente aos pacientes por } \\
\text { causa de características e relevância clínica } \\
\text { dos resultados do estudo. }\end{array}$ & $\begin{array}{c}\text { Canadá } \\
(113)\end{array}$ \\
\hline $\begin{array}{c}\text { Não combinar inibidor da enzima conversora de angiotensina ou } \\
\text { bloqueador do receptor de angiotensina II em pacientes sem } \\
\text { insuficiência cardíaca sistólica coexistente. }\end{array}$ & Grade adaptado & $\begin{array}{l}\text { Grade B: Recomendações baseadas em } \\
\text { estudos randomizados, revisões sistemáticas } \\
\text { ou pré-especificadas análises de subgrupos } \\
\text { de ensaios randomizados com menor } \\
\text { precisão, ou há uma necessidade de } \\
\text { extrapolar a partir de estudos devido a } \\
\text { diferentes populações ou relatórios de } \\
\text { resultados intermediarios validados em vez } \\
\text { de resultados clinicamente importantes. }\end{array}$ & $\begin{array}{c}\text { Canadá } \\
(113)\end{array}$ \\
\hline $\begin{array}{l}\text { Para pacientes hipertensos de alto risco, utilizando terapia } \\
\text { combinada, as escolhas devem ser individualizadas. } \\
\text { É preferível combinar com um inibidor da enzima conversora de } \\
\text { angiotensina um bloqueador de canal de cálcio dihidropiridínico } \\
\text { que um diurético tiazidico. }\end{array}$ & Grade adaptado & $\begin{array}{c}\text { Grade A: Recomendações baseadas em } \\
\text { estudos randomizados (ou revisões } \\
\text { sistemáticas de ensaios) com elevados níveis } \\
\text { de validade interna e precisão estatística, e } \\
\text { para os quais os resultados do estudo podem } \\
\text { ser aplicados diretamente aos pacientes por } \\
\text { causa de características e relevância clínica } \\
\text { dos resultados do estudo. }\end{array}$ & $\begin{array}{c}\text { Canadá } \\
(113)\end{array}$ \\
\hline
\end{tabular}

Continua 
Continuação

\begin{tabular}{|c|c|c|c|}
\hline Recomendação & $\begin{array}{c}\text { Método de } \\
\text { classificação } \\
\text { das evidências }\end{array}$ & $\begin{array}{l}\text { Nível da evidência ou Força da } \\
\text { recomendação }\end{array}$ & GPC \\
\hline \multicolumn{4}{|c|}{ COMORBIDADES } \\
\hline \multicolumn{4}{|c|}{ Farmacoterapia: } \\
\hline $\begin{array}{l}\text { Betabloqueadores ou bloqueadores de canal de cálcio em } \\
\text { pacientes com angina estável. }\end{array}$ & Grade adaptado & $\begin{array}{c}\text { Grade B: Recomendações baseadas em } \\
\text { estudos randomizados, revisões sistemáticas } \\
\text { ou pré-especificadas análises de subgrupos } \\
\text { de ensaios randomizados com menor } \\
\text { precisão, ou há uma necessidade de } \\
\text { extrapolar a partir de estudos devido a } \\
\text { diferentes populações ou relatórios de } \\
\text { resultados intermediarios / substitutos } \\
\text { validados em vez de resultados clinicamente } \\
\text { importantes. }\end{array}$ & $\begin{array}{c}\text { Canadá } \\
(113)\end{array}$ \\
\hline
\end{tabular}

Continua 
Continuação

\begin{tabular}{|c|c|c|c|}
\hline Recomendação & \begin{tabular}{|c|} 
Método de \\
classificação \\
das evidências
\end{tabular} & $\begin{array}{l}\text { Nível da evidência ou Força da } \\
\text { recomendação }\end{array}$ & GPC \\
\hline \multicolumn{4}{|c|}{ COMORBIDADES } \\
\hline \multicolumn{4}{|c|}{ Após infarto } \\
\hline \multicolumn{4}{|c|}{ Farmacoterapia: } \\
\hline $\begin{array}{l}\text { Betabloqueador e inibidor da enzima conversora de } \\
\text { angiotensina. }\end{array}$ & Grade adaptado & $\begin{array}{c}\text { Grade A: Recomendações baseadas em } \\
\text { estudos randomizados (ou revisões } \\
\text { sistemáticas de ensaios) com elevados níveis } \\
\text { de validade interna e precisão estatística, e } \\
\text { para os quais os resultados do estudo podem } \\
\text { ser aplicados diretamente aos pacientes por } \\
\text { causa de características e relevância clínica } \\
\text { dos resultados do estudo. }\end{array}$ & $\begin{array}{c}\text { Canadá } \\
(113)\end{array}$ \\
\hline $\begin{array}{c}\text { Bloqueador do receptor de angiotensina II se o paciente com } \\
\text { disfunção sistólica do ventrículo esquerdo é intolerante a um } \\
\text { inibidor da enzima conversora de angiotensina. }\end{array}$ & Grade adaptado & $\begin{array}{c}\text { Grade A: Recomendações baseadas em } \\
\text { estudos randomizados (ou revisões } \\
\text { sistemáticas de ensaios) com elevados níveis } \\
\text { de validade interna e precisão estatística, e } \\
\text { para os quais os resultados do estudo podem } \\
\text { ser aplicados diretamente aos pacientes por } \\
\text { causa de características e relevância clínica } \\
\text { dos resultados do estudo. }\end{array}$ & $\begin{array}{c}\text { Canadá } \\
(113)\end{array}$ \\
\hline Betabloqueadores em pacientes com infarto recente. & Outros & $\begin{array}{c}\text { *Ila, ESH/ESC: O peso da evidência ou } \\
\text { opinião é a favor de sua eficácia ou utilidade } \\
\text { (considerar). }\end{array}$ & $\begin{array}{l}\text { México } \\
(114)\end{array}$ \\
\hline $\begin{array}{l}\text { Bloqueadores de canal de cálcio se betabloqueadores são } \\
\text { contra-indicados ou não são eficazes. Bloqueadores de canal } \\
\text { de cálcio não-dihidropiridínicos não devem ser usados quando } \\
\text { há insuficiência cardiaca, evidenciada pela congestão pulmonar } \\
\text { no exame ou na radiografia. }\end{array}$ & Grade adaptado & $\begin{array}{l}\text { Grade D: Recomendações baseadas apenas } \\
\text { na opinião de especialistas. }\end{array}$ & $\begin{array}{c}\text { Canadá } \\
(113)\end{array}$ \\
\hline
\end{tabular}

Continua 
Conclusão

\begin{tabular}{|c|c|c|c|}
\hline Recomendação & $\begin{array}{c}\text { Método de } \\
\text { classificação } \\
\text { das evidências }\end{array}$ & $\begin{array}{l}\text { Nível da evidência ou Força da } \\
\text { recomendação }\end{array}$ & GPC \\
\hline \multicolumn{4}{|c|}{ COMORBIDADES } \\
\hline $\begin{array}{c}\text { Farmacoterapia: } \\
\text { Inibidor da enzima conversora de angiotensina, bloqueador do } \\
\text { receptor de angiotensina II, bloqueador de canal de cálcio de } \\
\text { ação prolongada ou diurético tiazidico. Não utilizar } \\
\text { vasodilatadores arteriais diretos tais como a hidralazina ou o } \\
\text { minoxidil. }\end{array}$ & Grade adaptado & $\begin{array}{l}\text { Grade D: Recomendações baseadas apenas } \\
\text { na opinião de especialistas. }\end{array}$ & $\begin{array}{c}\text { Canadá } \\
(113)\end{array}$ \\
\hline \multicolumn{4}{|c|}{ Declínio cognitivo e demência } \\
\hline $\begin{array}{l}\text { Em adultos com hipertensão, reduza a pressão arterial para } \\
\text { prevenir declínio cognitivo e demência. }\end{array}$ & Outros & $\begin{array}{c}\text { Moderada / Evidência de qualidade moderada } \\
\text { de um ou mais ECR }{ }^{\star} \text {; ou meta-análises de } \\
\text { ECRs de qualidade moderada. }\end{array}$ & $\begin{array}{c}2017 \\
\mathrm{ACC} / \mathrm{AHA} \\
(111)\end{array}$ \\
\hline *México cita: $\mathrm{CHE}$ & $\begin{array}{l}\text { 49), NICE (146), } \\
\text { io clínico random }\end{array}$ & ESC (125). & \\
\hline
\end{tabular}

Fonte: Elaboração própria. 


\section{DISCUSSÃO}

\subsection{GUIAS DE PRATICA CLÍNICA}

Neste estudo, foi avaliada a qualidade de 37 GPC, número superior à média de outras revisões similares. Em duas overviews, publicadas em 2010 e 2017, respectivamente, que incluíram estudos que avaliaram a qualidade de GPC, a média foi de 25 e 17 GPC avaliados por estudo, respectivamente $(14,15)$. Em uma revisão que avaliou GPC para diagnóstico, avaliação e tratamento da HAS, publicada em 2013, foram avaliados 11 GPC (49).

Tal qual reportado em outros estudos, a maioria (56,8\%; 21/37) dos GPC não informou financiamento. Na revisão conduzida por Al-Ansary et al (2013), avaliando 11 GPC da HAS, 45,5\% (5/11) também não traziam essa informação (49). Esse número foi ainda maior em revisão que avaliou a qualidade de 41 GPC para prevenção e tratamento da HAS, na qual 85,4\% (35/41) também não traziam essa informação (94). Chama a atenção, que entre os GPC de alta qualidade, todos relataram o financiamento. De fato, em uma revisão sistemática, que avaliou a qualidade de 421 GPC para tratamento de DCNT, o relato do financiamento foi um dos fatores associados à alta qualidade metodológica dos GPC, aumentando em dez vezes a chance de o GPC ter alta qualidade (150).

Foram identificados vários desvios no método de desenvolvimento dos GPC: menos de um terço foi elaborado por meio de revisão sistemática e mais de um terço nem descreveu como ocorreu a busca das informações na literatura científica. Além disso, poucos GPC empregaram método de consenso formal ao formular suas recomendações e mais de $40 \%$ não mencionou como foi o processo decisório sobre o que recomendar. A maioria dos GPC não mencionou o período ou método para atualizações. Essas mesmas deficiências foram relatadas nos estudos de Al-Ansary et al (2013), Alonso-Coello et al (2010) e Armstrong et al (2017) $(14,15,49)$. Esses achados estão diretamente relacionados à baixa qualidade metodológica encontrada nos GPC já que fazem parte dos quesitos avaliados nesse domínio. Portanto, é coerente que menos de um quinto $(16,2 \% ; 6 / 37)$ dos GPC tenham sido classificados como de alta qualidade metodológica. 
Sabendo que os GPC são documentos destinados a disseminar a prática clínica baseada em evidências $(12,40,41)$, justamente o domínio "rigor de desenvolvimento" é o que asseguraria confiança, por essa razão este é considerado o mais relevante para a adaptação de GPC (151). De modo geral, os escores do domínio "rigor de desenvolvimento" variaram bastante para os 37 GPC e a pontuação média foi baixa $(32,9 \% \pm 25,3 \%)$, com grande desvio padrão. Outros estudos que avaliaram GPC, não só para HAS, também reportaram a necessidade de melhora desse domínio $(14,15,49,56,150)$.

É particularmente preocupante que os domínios "envolvimento das partes interessadas" e "aplicabilidade" tenham recebido notas tão baixas na avaliação. É importante que ao elaborar GPC incluam equipe multiprofissional, assim como representantes de pacientes, pois estudos sugerem que a inclusão de outros profissionais da saúde assim como a inclusão de representantes de pacientes na elaboração dos GPC melhoram a adesão a esses documentos (152-154). No caso do domínio "envolvimento das partes interessadas", a pontuação média geral foi mais baixa do que a reportada em outros estudos $(15,49,150)$. Esse achado pode ter sido influenciado pela definição abrangente de GPC que foi adotada nesse estudo, incluindo-se não apenas GPC institucionais como também aqueles elaborados por autores independentes. O escore baixo nesse domínio reflete deficiências em relação a inclusão das opiniões e preferências de pacientes, definição de usuárioalvo, e/ou a falta de uma equipe multiprofissional na elaboração dos GPC (18). Chama a atenção que apenas 3 GPC obtiveram escore $60 \%$ ou mais (110-112), sendo todos eles institucionais. Nestes 3 GPC há informação de que foram elaborados por uma equipe multiprofissional, incluindo, dentre outros profissionais, médicos com formações em diferentes especialidades, farmacêuticos e enfermeiros. Além disso, 2 GPC reportaram a inclusão de representantes de pacientes no grupo elaborador $(110,111)$.

Da mesma forma que em outros estudos, o domínio com menor escore foi "aplicabilidade", seguido por "envolvimento das partes interessadas" $(14,15,150)$. O escore médio para esse domínio foi $23,2 \% \pm 20,8 \%$. Também em outros estudos a aplicabilidade foi mal avaliada, com escore médio variando entre $22 \%$ e $38 \%$ $(14,15,49,150)$. Esse achado expressa a falta de planejamento para implementação, como o levantamento de facilitadores e barreiras, ferramentas e estratégias que 
facilitem a utilização desses documentos, e planejamento de recursos necessários (18).

Já foi demonstrado que há muitas barreiras que prejudicam a adesão de médicos aos GPC, e que ferramentas como fluxogramas e sumários podem auxiliar na disseminação desses documentos (155,156). Somente 5,4\% (2/37) GPC apresentaram escore igual ou superior a 60\% nesse domínio $(109,110)$. Esses 2 GPC apresentaram estratégia de implementação, identificando barreiras e facilitadores para aplicação do GPC, além de análise de custo e estratégia para o monitoramento da adesão ao GPC. Fatores que, também, podem facilitar a acessibilidade ao tratamento.

Dois domínios para os quais tem aumentado o escore médio ao longo dos anos são "clareza da apresentação" e "escopo e finalidade" $(14,15)$. De fato essa era uma barreira relatada pelos profissionais para o emprego dos GPC há alguns anos atrás (14). Nesse trabalho, a maior parte dos GPC 64,9\% (24/37) apresentou escore igual ou superior a $60 \%$ para "clareza da apresentação" e 32,4\% (12/37) para "escopo e finalidade". Esses dados demonstram que as recomendações tem sido apresentadas de forma clara e concisa mas, que ainda, há o que melhorar, principalmente ao explicitar para quem o GPC está direcionado e qual seu objetivo, o que também facilita que o GPC seja posto em prática (157).

Sobre a "independência editorial", somente 21,6\% (8/37) GPC obtiveram escore de $60 \%$ ou mais. Mesmo entre os GPC que relataram o financiamento e/ou os conflitos de interesse, muitos não esclareceram se o financiador influenciou no desenvolvimento do GPC ou como os conflitos presentes foram solucionados, o que contribuiu para redução do escore. Esses achados também são concordantes aos encontrados em outros estudos $(55,158,159)$, ainda que Armstrong et al (2017) tenham relatado melhora desse aspecto ao longo do tempo (15).

Sabendo que poucos GPC descreveram de forma satisfatória como formularam suas recomendações, esse domínio ganha importância. Uma vez que espera-se que um GPC traduza o conhecimento científico, para que seja empregado na clínica, é essencial que o processo de sua elaboração seja realizado com base na melhor evidência disponível e de forma transparente $(12,40,41)$. A transparência em relação ao processo de formulação das recomendações e o manejo de conflitos 
de interesses é, particularmente, importante quando há pouca ou nenhuma evidência científica sobre o assunto a ser discutido (160).

Vale ainda ressaltar que o AGREE II avalia apenas se há relato dos conflitos de interesses dos autores do GPC e o manejo desses conflitos, assim como se houve declaração em relação ao financiamento e se o órgão financiador exerceu influência no conteúdo do GPC. Porém, de modo geral conflitos econômicos são declarados, mas tem sido discutido a existência de outros tipos de conflito que são muito mais difíceis de avaliar, como o intelectual, por exemplo (160-163). Dentre os GPC de alta qualidade, todos declararam os conflitos de interesse e apenas os GPC Colômbia e VADOD não descreveram como foi realizado o manejo desses conflitos.

Fatores associados com alta qualidade de GPC como número de autores superior a 20 , relato de financiamento e participação de instituições governamentais na elaboração do documento, também, foram identificados nos GPC de alta qualidade deste trabalho (150). Todos GPC de alta qualidade descreveram os autores (109-114) - sendo 66,7\% (4/6) com um número de autores superior a 20 $(109,111-113)$ e os outros dois com 10 e 17 , respectivamente $(110,114) ; 66,7 \%$ (4/6) foram elaborados por instituições governamentais $(109,110,112,114)$ e todos reportaram financiamento. Esses GPC também classificaram a força da recomendação e/ou o nível da evidência (109-114), e somente um deixou de mencionar o método para formulação das recomendações (114).

\subsection{RECOMENDAÇÕES PARA FARMACOTERAPIA DA HIPERTENSÃO ARTERIAL SISTÊMICA}

\subsubsection{Indicação de farmacoterapia e metas}

Em geral, os GPC incluídos nas matrizes abordaram os mesmos tópicos, mas divergiram em relação aos níveis pressóricos a serem considerados para início da farmacoterapia, assim como para metas de tratamento. As principais discordâncias envolveram o GPC 2017 ACC/AHA (111).

O GPC 2017 ACC/AHA (111), que atualizou os GPC do Joint National Committee (JNC), divergiu da maior parte dos GPC de alta qualidade, ao ser mais 
rigoroso em relação aos parâmetro da HAS. Parte de suas recomendações baseiamse no ensaio clinico Systolic Blood Pressure Intervention Trial (SPRINT), concluído em 2015. Trata-se de um estudo que incluiu 9.361 adultos com idade 50 anos ou mais, pressão arterial sistólica (PAS) igual ou maior que $130 \mathrm{mmHg}$ e pelo menos um fator de risco alto adicional de doença cardiovascular (164). O SPRINT concluiu que tratar os pacientes para atingir metas de PAS $\leq 120 \mathrm{mmHg}$ em comparação com $\leq 140 \mathrm{mmHg}$ diminuiria em $25 \%$ as taxas de ataque cardíaco, insuficiência cardíaca e acidente vascular cerebral, e em $27 \%$ o risco de morte por qualquer causa. Entretanto, também relatou que para alcançar essa meta os pacientes precisariam receber mais medicamentos e apresentariam mais eventos adversos como, por exemplo: desmaios causados por hipotensão, síncope, anormalidades eletrolíticas e lesão renal aguda. Porém cita também que esses fatores não prejudicariam a adesão dos pacientes $(164,165)$.

Os pacientes com doença renal crônica; incluídos no SPRINT foram tratados para alcançar uma meta menor (PAS $\leq 120 \mathrm{mmHg}$ em comparação com $\leq 140$ $\mathrm{mmHg}$ ), apesar de apresentarem melhora de desfechos cardiovasculares e maior sobrevivência; apresentaram também mais episódios de lesão renal aguda, que, em sua maioria, foi revertida; declínio mais rápido na taxa de filtração glomerular e falha na prevenção da progressão da insuficiência renal, o que indicou falta de proteção renal $(164,165)$. Além disso, foi necessário tratar 61 pacientes para cada beneficio observado (164).

Dois autores do SPRINT colaboraram na elaboração do GPC 2017 ACC/AHA e esse conflito de interesse foi devidamente declarado. Assim, eles foram excluídos da elaboração das recomendações diretamente ligadas ao SPRINT. De fato, a pontuação no domínio independência editorial deste GPC foi alta (78\%), refletindo um processo cuidadoso de lidar com conflitos de interesses (111). Porém, há receio de que conflitos de interesse, financeiros ou intelectuais, possam gerar recomendações divergentes em diferentes GPC para uma mesma doença e população, pois podem influenciar desenvolvedores de GPC a interpretarem de forma distinta uma mesma evidência (160).

É interessante notar que os GPC do NICE e do Canadá também foram desenvolvidos depois da publicação do SPRINT, porém optaram por não alterar suas metas terapêuticas e de níveis pressóricos para indicação da farmacoterapia 
(110,113). Em dezembro de 2017, a American Academy of Family Physicians (AAFP) publicou posicionamento no qual relatou algumas falhas no GPC 2017 ACC/AHA, como o fato de que a maior parte das recomendações não foi baseada em uma revisão sistemática das evidências; que grande peso foi dado para o SPRINT, e outros estudos foram minimizados; e a falta de uma avaliação dos custos. Todos esses motivos levaram à decisão da AAFP de não endossar esse GPC (166).

Chama a atenção ainda que, embora o SPRINT tenha incluído apenas adultos com idade de 50 anos ou mais e pelo menos um fator de alto risco para doença cardiovascular, seus resultados também foram empregados para subsidiar a recomendação de meta para pacientes com baixo risco cardiovascular, ainda que a evidência tenha sido considerada de menor qualidade (111).

Sabe-se que no desenvolvimento de GPC para atenção primária muitas vezes evidências indiretas, evidências de pacientes de cuidados secundários ou de maior risco, são utilizadas para embasar as recomendações por não haver evidências direcionadas a pacientes de atenção primária ou de baixo risco $(167,168)$. Nesses casos, as evidências podem ter relevância limitada e resultar em danos que superam os benefícios (169), ou, induzir o sobretratamento (170). Revisão publicada em 2014, analisou 22 GPC do NICE aplicáveis a atenção primária para avaliar se as recomendações de GPC para cuidados primários foram baseadas em pesquisas relevantes. Concluiu que $62 \%$ das evidências citadas para apoiar as recomendações de cuidados primários eram de relevância incerta para os pacientes na atenção primária (170). Nessas situações, que as evidências não são conclusivas, a colaboração GRADE sugere que a recomendação seja classificada como fraca (condicional) e que se discuta o tratamento com o paciente para uma tomada de decisão compartilhada, ou seja, a escolha do tratamento deve ser discutida entre médico e paciente, levando-se em conta as melhores evidências científicas disponíveis, riscos, beneficios, bem como os valores e preferências do paciente (171).

De fato, tem havido muita discussão sobre o GPC 2017 ACC/AHA, pois sua adoção acarreta em aumento do número de adultos classificados como hipertensos, impactando nos índices de prevalência da doença (172-174), no uso de medicamentos e seu acesso pelo paciente. Estima-se que nos Estados Unidos e na 
China, o aumento de prevalência nos adultos de 45 a 75 anos seria de $26,8 \%$ e $45,1 \%$, respectivamente. Isto corresponderia a tratar 8,1 milhões e 74,5 milhões de pessoas a mais, respectivamente, seguindo esses critérios (172). O aumento na prevalência da HAS e no uso da farmacoterapia pode gerar outros contratempos, por exemplo, países sem cobertura de saúde, pessoas diagnosticadas com HAS podem ter dificuldades para obter cobertura de seguro devido a condição "preexistente". Além disso, pacientes tratados com farmacoterapia para uma meta menor podem apresentar mais eventos adversos graves, ou, descontinuar permanentemente o uso de fármacos $(164,175,176)$.

Em 2018, foi publicada uma revisão sistemática Cochrane, considerando 6 ensaios clínicos, inclusive o SPRINT, que buscava determinar se metas de pressão arterial $(P A) \leq 135 / 85 \mathrm{mmHg}$ estavam associadas a redução de mortalidade e morbidade em pacientes com HAS e história de doença cardiovascular, comparada as metas encontradas em GPC para pacientes sem antecedentes de doença cardiovascular ou baixo risco cardiovascular (PA $\leq 140$ a 160/90 a $100 \mathrm{mmHg}$ ). Essa revisão concluiu que não haviam evidências de diferença na mortalidade total e de eventos adversos graves entre os pacientes do grupo para o qual foi determinada meta de PA $\leq 135 / 85 \mathrm{mmHg}$ e relatou risco de viés na ocultação de alocação, no cegando dos participantes e do pessoal, e outros vieses sem especificá-los no SPRINT (177).

Também em 2018, foi publicado um estudo que visava avaliar a associação entre as taxas de mortalidade, doença cardiovascular, e eventos adversos relacionados ao tratamento farmacológico de pacientes com HAS leve (140 / 90-159 ( $99 \mathrm{mmHg}$ ). Nesse estudo foram analisados dados de 38.286 pacientes, com idade entre 18 e 74 anos, acompanhados por um período médio de 5,8 anos, com HAS leve e sem fator de risco aumentado para eventos cardiovasculares no período de 1995 a 2015. Esse estudo concluiu que não haviam evidências para associação entre o tratamento anti-hipertensivo e as taxas de mortalidade ou de doença cardiovascular, porém o tratamento farmacológico foi associado a um aumento de risco para eventos adversos, incluindo lesão renal aguda. Com base nesses achados, foi recomendado que os médicos tivessem cautela na adoção de recomendações de GPC quando estas são elaboradas a partir de evidências 
extrapoladas de estudos realizados em pacientes com alto risco cardiovascular para todos os pacientes (178).

Também um estudo publicado em 2017, que analisou dados de pacientes de alto risco para eventos cardiovasculares com idade $\geq 55$ anos de estudos anteriores (ONTARGET e TRANSCEND), relatou que metas mais baixas de PAS $(<120 \mathrm{mmHg})$ foram associadas há aumento no risco de desfechos cardiovasculares, exceto infarto do miocárdio e acidente vascular cerebral, assim como para pressão arterial diastólica (PAD) $<70 \mathrm{mmHg}$, na qual incluiu também aumento do risco de infarto do miocárdio e hospitalização por insuficiência cardíaca (179).

Por outro lado, mesmo que exista uma preocupação de que a adoção dos parâmetros defendidos no GPC 2017 ACC/AHA possam levar a sobretratamento, é sabido que o melhor gerenciamento da HAS diminui o risco de morte por eventos cardiovasculares $(49,180)$. Uma metanálise incluindo um milhão de indivíduos, identificou que o risco desses eventos aumenta constantemente a partir dos níveis pressóricos 115/75 mmHg, e dobra a cada aumento de $20 \mathrm{mmHg}$ na PAS e 10 $\mathrm{mmHg}$ na $\mathrm{PAD}$, dessa forma pode-se concluir que mesmo não atingindo as metas terapêuticas, qualquer diminuição na PA já traz benefícios para os pacientes (180).

Todos os GPC salientam a importância do tratamento não farmacológico, como redução no consumo de sódio e álcool, e prática de atividade física antes do início da farmacoterapia, ou combinado com a mesma, tanto como antecessor a farmacoterapia, como coadjuvante a ela. Alguns GPC inclusive classificam os pacientes em pré-hipertensos e nesses casos a indicação do tratamento não farmacológico é essencial para prevenir o surgimento da HAS $(109,112)$.

É importante ressaltar que os GPC focam nos valores de PA para determinar quem precisa ou não de tratamento farmacológico, no entanto, estudos relataram falhas na mensuração da PA (181-184). Estudo. que analisou se estudantes de medicina cumpriam as etapas previstas para uma correta medição de PA no consultório baseada nas recomendações do GPC 2017 ACC/AHA, relatou que apenas 1 em cada 159 estudantes de medicina cumpriram todas as etapas propostas no documento. Foram identificadas algumas falhas em relação a procedimentos como verificar se o paciente estava com os pés no chão, fazer a medida em ambos os braços e principalmente solicitar para o paciente descansar por 5 minutos em uma cadeira antes da medição (182). 
Para ajudar a solucionar esses problemas algumas sugestões são encontradas na literatura, como medir a PA duas vezes com intervalo de ao menos um minuto entre as medições na mesma consulta relatada em um estudo que avaliou em mais de 38 mil pacientes com diagnóstico da HAS seguidos na atenção primária essa sugestão feita pela American Heart Association e concluiu que uma segunda medição levava a uma diminuição média de $8 \mathrm{mmHg}$ na PAS (183). Outro estudo, que sugeriu a monitorização automatizada da PA durante 30 minutos com intervalo de 5 minutos, relatou que essa medida diminuiu em média $22,8 \mathrm{mmHg}$ na PAS e $11,6 \mathrm{mmHg}$ na PAD. Esses resultados diminuiriam a iniciação ou intensificação do tratamento da HAS de 79,1\% para apenas 24,9\% (184).

\subsubsection{Opções de farmacoterapia}

Em relação as classes de fármacos recomendadas para o tratamento da HAS, houve variabilidade entre os seis GPC incluídos nas matrizes de recomendações. Três GPC recomendaram o uso de diuréticos tiazídicos como primeira escolha, principalmente a clortalidona $(109,112,114)$. Em dois, houve a recomendação dessa classe de medicamentos associada à outras classes farmacológicas: inibidores da enzima conversora de angiotensina (IECA), bloqueadores do receptor de angiotensina II (BRA), bloqueadores de canal de cálcio (BCC) $(111,113)$ ou betabloqueadores (111). No GPC do NICE, por sua vez, não houve menção do uso dos diuréticos tiazídicos para tratamento da HAS, mas do uso de IECA ou BRA para pacientes com até 55 anos e BCC para pacientes com idade superior a 55 anos (110). No GPC NICE e VADOD houve a recomendação de manter o diurético tiazídico se este for iniciado, desde que não fosse a hidroclorotiazida (110,112). Os achados encontrados por Al-Ansary et al (2013), em revisão sistemática, que comparou as recomendações de GPC para tratamento da HAS de 2006 a 2011, mostraram que a maioria das recomendações fazia referência ao uso das seguintes classes de anti-hipertensivos como primeira opção de tratamento: IECA, BRA, betabloqueador, BCC ou diuréticos. Apenas o GPC da África do Sul (2006) (185) havia recomendado o uso exclusivo de diuréticos (49). 
Em 2018, foi publicada revisão sistemática Cochrane, que incluiu 24 ECR com 58.040 participantes. Essa revisão comparou a eficácia de diferentes classes farmacológicas de anti-hipertensivos (diuréticos tiazidicos, betabloqueadores, BCC, IECA, BRA e alfabloqueadores), no tratamento da HAS, concluindo que diuréticos tiazidicos em baixas doses são a melhor escolha para início de tratamento da HAS. Os medicamentos da referida classe reduziram todos os desfechos de morbidade e mortalidade em pacientes hipertensos. Outras classes farmacológicas, como, por exemplo, IECA e BRA parecem apresentar eficácia semelhante. No entanto, a qualidade da evidência foi considerada menor (186).

Dentre os diuréticos tiazídicos, alguns estudos sugerem preferência a clortalidona e/ou indapamida em relação a hidroclorotiazida (187-189). Assim, a metanálise publicada por Ernst et al em 2010, que comparou os efeitos da hidroclorotiazida e clortalidona na PAS, incluindo 108 ECR com 6.063 participantes, que utilizaram a hidroclorotiazida, e 29 ECR com 4.380 participantes, que utilizaram a clortalidona, concluiu que baixas doses de clortalidona tem maior efeito hipotensor que a hidroclorotiazida (187). Uma outra revisão sistemática, publicada em 2015 por Roush et al, analisou 14 ECR e concluiu que a indapamida, assim como a clortalidona, tem maior efeito hipotensor que a hidroclorotiazida (188).

Roush e colaboradores (2012) realizaram uma revisão sistemática com metanálise para comparar os efeitos da hidroclorotiazida e clortalidona na prevenção de evento cardiovasculares, na qual foram incluídos 9 ECR para tratamento da HAS, sendo que 3 utilizaram hidroclorotiazida e 6, clortalidona. Os pesquisadores concluíram a clortalidona apresentou melhor efeito hipotensor e foi mais eficaz na prevenção de eventos cardiovasculares quando comparada a hidrocloriotiazida. Sugeriram que essa maior eficácia pode estar relacionada ao curto tempo de ação da hidroclorotiazida (189).

Em 2018, foi publicado um estudo visando investigar a associação entre o uso de hidroclorotiazida e o desenvolvimento de carcinoma basocelular e carcinoma de células escamosas. Este estudo dinamarquês analisou o banco de dados do Danish Cancer Registry e identificou 71.533 pacientes diagnosticados com carcinoma basocelular e 8629 com carcinoma de células escamosas. Esses achados foram comparados com 1.430 .883 e 172.462 controles populacionais, respectivamente. Concluiu-se que o uso de hidroclorotiazida em doses maiores que $50 \mathrm{mg}$ por dia foi 
relacionado com aumento de 1,29 vezes na chance de desenvolver carcinoma basocelular e 3,98 vezes para carcinoma de células escamosas. A referida relação aumenta de acordo com o valor da dosagem acumulada. Porém este estudo relatou que não foram obtidas informações sobre dois principais fatores de risco para carcinoma basocelular e carcinoma de células escamosas: a exposição à radiação ultravioleta e fenótipo de pele (190). Porém, este achado foi específico para doses maiores que $50 \mathrm{mg}$ por dia, dessa forma o futuro para este medicamento no tratamento da HAS é incerto.

Assim como para primeira linha de tratamento, algumas outras divergências foram encontradas nas demais linhas de tratamento. Para segunda linha, 4 GPC recomendam adicionar IECA, BRA ou BCC $(110,112-114)$, e para terceira linha de tratamento, dos 4 GPC que trazem recomendações, 3 indicam a combinação de IECA ou BRA com diurético tiazídico e BCC $(110,112,114)$. Não é frequente que os GPC recomendem medicamentos específicos. Em geral, trazem recomendações de classes farmacológicas.

Sabe-se que muitos pacientes precisam combinar 2 ou mais fármacos antihipertensivos para alcançar as metas de PA, a fim de reduzir eventos cardiovasculares e diminuir os eventos adversos (191-197). Em metanálise, que incluiu 42 estudos com 10.968 participantes, com o objetivo de comparar a monoterapia com terapia combinada, observou-se que a combinação de dois fármacos reduz, em média, em 5 vezes a PA quando comparada a duplicação de dose de um único fármaco (194).

Outra metanálise, que incluiu 354 ECR com 56.000 participantes, para comparar a diminuição média na PA e prevalência de eventos adversos, usando monoterapia ou terapia combinada, concluiu que o tratamento com combinações de fármacos em baixas doses promovem um melhor efeito na diminuição e controle da PA, assim como diminui os eventos adversos (195). Entretanto, estudos sugerem que deve-se evitar a combinação de fármacos da mesma classe ou fármacos que atuam em um mesmo sistema, com algumas exceções, como a combinação de diuréticos tiazídicos com diuréticos de alça ou BCC não dihidropiridínico, com BCC não dihidropiridínico (191-193). Pelo menos três ECR demonstraram que a administração simultânea de dois fármacos da mesma classe farmacológica de antihipertensivos do sistema renina angiotensina (IECA, BRA ou inibidor direto da 
renina), aumenta os riscos cardiovasculares e renais (198-200). De fato, cinco dos seis GPC contraindica o uso combinado de IECA e BRA para um mesmo paciente (110-114). Dois CPG recomendam que não se combine IECA ou BRA com um inibidor de renina $(111,112)$.

Outro ponto sobre a combinação de dois ou mais medicamentos é que o GPC do Canadá é o único que recomenda explicitamente o uso de formulações com fármacos em associação, como forma de favorecer a adesão ao tratamento quando o paciente necessita da terapia combinada $(113,201)$. Porém em instituições ou países que utilizam GPC para atualizar a lista de medicamentos fornecidos, essa recomendação pode não ser viável. Por exemplo, a OMS não recomendou a adição de formulações com fármacos em associação para doenças cardiovasculares em sua lista de medicamentos essenciais, embora reconheça as vantagens dessas apresentações (202). Além disso, o uso dessas formulações possuem algumas desvantagens: essas formulações geralmente são mais caras que os fármacos equivalentes separados; a posologia dos fármacos usados na combinação podem não ser equivalentes, podendo ser necessário mais de uma dose diária, não simplificando a terapia e; as formulações com fármacos em associação diminuem a flexibilidade no ajuste de doses e pode expor o paciente a terapia desnecessária (203). Outro ponto a ser discutido é o fato de que nessas associações, é importante que se evitem medicamentos que possuam o mesmo perfil de reações adversas, pois embora não seja frequente, esta somatória de efeitos pode acarretar em reações graves ou letais (204)

\subsubsection{Particularidades no processo de cuidado da hipertensão}

Uma crítica comum em relação a GPC é que eles são elaborados para doenças e não para pacientes $(205,206)$. Em geral, dois em cada três pacientes hipertensos tem ao menos uma comorbidade (207), por essa razão as recomendações para pacientes com comorbidades também foram extraídas e sintetizadas.

Quatro GPC trouxeram recomendações para pacientes hipertensos com outras comorbidades (111-114). Dentre eles, o GPC 2017 ACC/AHA trouxe trinta e 
cinco recomendações destinadas a 10 comorbidades, número maior que os demais GPC (111).

A doença renal crônica, como comorbidade, foi citada pelos 4 GPC (111-114) e merece atenção, pois a HAS é uma das principais causas para o surgimento da doença renal crônica, por essa razão, estima-se que mais da metade das pessoas com doença renal crônica apresentam HAS (208). Além disso, sabe-se que estas doenças tem associação interdependente (209).

Todos os GPC recomendaram iniciar a farmacoterapia com IECA ou BRA para pacientes com doença renal (111-114), pois essas classes de antihipertensivos apresentam efeito renoprotetor, ou seja, interrompem ou lentificam a progressão da doença renal (210-213). Porém, mesmo não sendo comum, alguns pacientes apresentam declínio súbito da função renal ao iniciar o tratamento com as referidas classes farmacológicas (214).

Schmidt e colaboradores (2017), publicaram estudo coorte, no qual analisaram registros de 122.363 pacientes no Reino Unido, com o objetivo de associar desfechos cardiorrenais a farmacoterapia com IECA ou BRA. Os autores descreveram que quando houve um aumento na creatinina sérica do paciente após o início da farmacoterapia com alguma dessas classes de fármacos, houve também um aumento nos riscos cardiorrenais dos pacientes numa relação dose-resposta (215). Os resultados deste estudo sugeriram que ao se iniciar a farmacoterapia com IECA ou BRA, deve-se acompanhar os níveis de creatinina sérica do paciente, e quando houver aumento significativo nos seus valores (sem um ponto de corte distinto a $30 \%$ como sugerido anteriormente em outros estudos), deve-se avaliar os benefícios e riscos potenciais da continuação da farmacoterapia (215).

Todos os GPC abordaram o tratamento farmacológico para populações especiais. No entanto, com pouquíssimas recomendações. Todos GPC abordaram recomendações para metas terapêuticas, indicação de farmacoterapia ou tratamento farmacológico para idosos, e para negros apenas 4 GPC (110-113).

Além disso, 2 GPC continham recomendações específicas, referente à farmacoterapia para mulheres (109) ou adultos mais jovens (110). Vale ainda ressaltar que o GPC VADOD (112) também considerou a idade dos pacientes ao recomendar a indicação para início da farmacoterapia e as metas terapêuticas. Porém a recomendação é a mesma, alterando apenas a força da recomendação. 
Dos 4 GPC, que abordaram recomendações específicas para a população negra, (110-113), somente o GPC 2017 ACC/AHA e do NICE recomendaram fármacos de primeira escolha: BCC ou diurético tiazídico, com a ressalva que 0 NICE só recomenda diuréticos tiazídicos se o BCC não for tolerado $(110,111)$. Os GPC do NICE, do Canadá e do VADOD ainda salientaram que os IECA ou BRA não são recomendados em monoterapia, mas podem ser usados como terapia complementar, se necessário $(110,112,113)$.

Assim como para a população adulta em geral, o GPC 2017 ACC/AHA foi o mais rigoroso, ao recomendar o início da farmacoterapia e metas terapêuticas para níveis pressóricos mais baixos na população idosa. Enquanto, o GPC do VADOD e do México recomendaram início da farmacoterapia quando PAS $\geq 160 \mathrm{mmHg}$ $(112,114)$, o GPC 2017 ACC/AHA recomendou início quando PAS $\geq 130 \mathrm{mmHg}$ (111) e nenhum dos GPC recomendou início de farmacoterapia baseando-se em valores da PAD. Em relação a metas terapêuticas, todos trouxeram metas semelhantes a população adulta $(110-112,114)$. Para escolha da farmacoterapia somente o GPC da Colômbia (109) abordou primeira linha de tratamento, porém sugere que não há nenhuma classe farmacológica de preferência, cabendo ao médico essa escolha (109). O GPC do México aconselhou que quando o tratamento farmacológico não foi iniciado com diuréticos tiazídicos, este deve ser utilizado como terapia complementar (114), e os GPC do México e do Canadá orientaram não utilizar betabloqueadores como fármacos de primeira linha para essa população $(113,114)$.

A apresentação de recomendações destinadas a pacientes com comorbidades é um desafio para desenvolvedores de GPC. Por exemplo, embora o GPC NICE não tenha trazido recomendações para pacientes com comorbidades, houve recomendações para o hipertensos em outros CPG elaborados pelo NICE: CG182 (doença renal crônica), CG108 (insuficiência cardíaca crônica), CG87 (diabetes tipo 2), NG17 (diabetes tipo 1), CG180 (fibrilação atrial) (110). 


\subsection{LIMITAÇÕES E FORÇAS DO ESTUDO}

Entre as limitações do estudo pode-se citar a restrição de idioma, uma vez que foram incluídos apenas documentos em inglês, espanhol, ou português. Apesar disso, foi possível avaliar GPC de diferentes regiões do mundo, como Ásia, Europa e América do Sul. Ainda que tenha sido incluído apenas GPC que continham recomendações para tratamento farmacológico da HAS, grande parte dos GPC apresentaram um escopo amplo, o que reduziu o impacto dessa restrição. Pode ser citada ainda a limitação intrínseca presente em qualquer ferramenta de avaliação de qualidade de GPC. No entanto, a subjetividade da avaliação foi manejada ao realizar a análise com 3 avaliadores e discutir todas as notas com 2 pontos ou mais de discordância.

Este estudo também apresenta pontos fortes. Primeiro, a definição mais ampla de GPC, considerando, dessa forma, o maior número possível de documentos disponíveis, que podem ser usados por médicos da atenção primária e, dessa forma, afetar $\mathrm{O}$ atendimento de pacientes em todo mundo. Além disso, houve a preocupação em atualizar os GPC selecionados. Segundo, o instrumento AGREE II, que foi escolhido para avaliação da qualidade dos GPC, é amplamente utilizado (19). Dessa forma, esta revisão pode ser comparada ou combinada com outros estudos que avaliaram GPC usando esse mesmo instrumento. Terceiro, os avaliadores passaram antecipadamente por um treinamento prévio rigoroso (97). Quarto, a busca sistemática nesse estudo foi bastante abrangente, além da busca em bases de dados gerais (EMBASE, Medline e Cochrane), realizamos a busca em doze websites específicos de GPC. Quinto, esse estudo teve seu protocolo

publicado antecipadamente na plataforma PROSPERO e também como artigo científico (97). 


\section{CONCLUSÃO}

A elaboração das matrizes de recomendações de GPC de alta qualidade propiciou a análise e comparação de forma a identificar similaridades e controvérsias, o que pode contribuir para processos de adaptação local de GPC para tratamento da HAS. Somente uma pequena parcela dos GPC avaliados foram classificados como de alta qualidade, o que ainda estão disponíveis para consulta muitos documentos elaborados sem o rigor metodológico recomendado para análise e síntese de evidências.

Embora os GPC de alta qualidade tenham apresentados recomendações a respeito dos mesmos tópicos, na maioria das vezes, foram identificadas algumas divergências em seus conteúdos. As controvérsias mais relevantes foram as recomendações muito mais rigorosas do GPC 2017 ACC/AHA tanto para início do tratamento quanto para as metas terapêuticas, mesmo para pacientes com baixo risco cardiovascular. Também não há consenso entre quais classes farmacológicas ou fármacos recomendar. Entre os seis GPC incluídos três concordam ao recomendar iniciar o tratamento farmacológico com diuréticos tiazídicos, especialmente a clortalidona (Colômbia, VADOD e México) e outros dois, recomendam essa classe de medicamentos como uma das opções para iniciar a farmacoterapia (2017 ACC/AHA e Canadá), tal qual outras classes de antihipertensivos (inibidores da enzima conversora de angiotensina, bloqueadores fos receptores de angiotensina II e bloqueadores dos canais de cálcio).

Sabendo-se que o desenvolvimento de um novo GPC demanda muito tempo e recursos, e que a adaptação local de GPC de alta qualidade é uma opção mais viável e realista, as matrizes elaboradas nesse trabalho resumem as recomendações de GPC de alta qualidade e, portanto, podem servir como base para instituições, desenvolvedores de GPC e formuladores de políticas na adaptação local de GPC, evitando a duplicação de esforços. Nesse caso, um dos pontos principais na discussão para adaptação local de recomendações, além de se levar em conta a questão do acesso aos medicamentos, seria adotar ou não os parâmetros mais rigorosos do GPC 2017 ACC/AHA. Para todos os casos controversos, uma adaptação deveria gerar recomendações condicionais, ou seja, aquelas nas quais a 
tomada de decisão deva ser compartilhada com o paciente, o que facilitaria, também, a adesão ao tratamento e o acesso do medicamento pelo paciente. 


\section{REFERÊNCIAS BIBLIOGRÁFICAS}

1. World Health Organization. Global Health and Aging [Internet]. Global Health and Aging. 2011 [cited 2018 Dec 21]. Disponível em: https://www.who.int/ageing/publications/global_health.pdf

2. World Health Organization. Ageing and health [Internet]. 2018 [cited 2019 Jan 18]. Disponível em: https://www.who.int/news-room/fact-sheets/detail/ageingand-health

3. Marengoni A, Angleman S, Melis R, Mangialasche F, Karp A, Garmen A, et al. Aging with multimorbidity: A systematic review of the literature. Ageing Res Rev. 2011;10(4):430-9.

4. Porter T, Sanders T, Richardson J, Grime J, Ong BN. Living with multimorbidity: Medical and lay healthcare approaches. Int $\mathrm{J}$ Clin Rheumtol. 2015;10(2):111-9.

5. World Health Organization. Global status report on noncommunicable diseases. [Internet]. 2010 [cited 2019 Jan 21]. Disponível em: http://www.who.int/about/licensing/copyright_form/en/index.html

6. Pan American Health Organization. Health in the Americas. 2012 [cited 2019 Jan 22]; Disponível em: https://www.paho.org/salud-en-las-americas2012/index.php?option=com_docman\&view=download\&category_slug=saudenas-americas-edicao-2012-8\&alias=61-sau-nas-ame-ricas-edic-a-o-2012panorama-regional-e-perfis-paises- 1 \&ltemid $=231$ \&lang=pt

7. World Health Organization. World Health Statistics 2018: Monitoring health for the SDGs. WHO [Internet]. 2018 [cited 2018 Dec 21]; Disponível em: https://www.who.int/gho/publications/world_health_statistics/2018/en/

8. Muka T, Imo D, Jaspers L, Colpani V, Chaker L, Lee SJVD, et al. The global impact of non-communicable diseases on healthcare spending and national income: a systematic review. Eur J Epidemiol [Internet]. 2015 Apr 18 [cited 2019 Jan 17];30(4):251-77. Disponível em: http://link.springer.com/10.1007/s10654-014-9984-2

9. Chaker L, Falla A, Lee SJVD, Muka T, Imo D, Jaspers L, et al. The global impact of non-communicable diseases on macro-economic productivity: a systematic review. Eur J Epidemiol [Internet]. 2015 May 3 [cited 2019 Jan 17];30(5):357-95. Disponível em: http://www.ncbi.nlm.nih.gov/pubmed/25837965

10. Pan American Health Organization. The economic burden of noncommunicable diseases in the Americas. 2010 [cited 2019 Jan 17]; Disponível em: http://www.diabetesatlas.org/sites/default/files/Economic impact of Diabetes_101123.pdf

11. Kearney PM, Whelton M, Reynolds K, Muntner P, Whelton PK, He J. Global 
burden of hypertension: analysis of worldwide data. Lancet [Internet]. 2005 Jan [cited 2018 Sep 3];365(9455):217-23. Disponível em: http://www.ncbi.nlm.nih.gov/pubmed/15652604

12. Turner T, Misso M, Harris C, Green S. Development of evidence-based clinical practice guidelines (CPGs): comparing approaches. Implement Sci. 2008 Jan;3:45.

13. Upshur REG. Do clinical guidelines still make sense? No. Ann Fam Med. 2014 Jan;12(3):202-3.

14. Alonso-Coello P, Irfan A, Sola I, Gich I, Delgado-Noguera M, Rigau D, et al. The quality of clinical practice guidelines over the last two decades: a systematic review of guideline appraisal studies. BMJ Qual Saf [Internet]. 2010 Dec;19(6):e58-e58. http://www.ncbi.nlm.nih.gov/pubmed/21127089

15. Armstrong JJ, Goldfarb AM, Instrum RS, MacDermid JC. Improvement evident but still necessary in clinical practice guideline quality: a systematic review. J Clin Epidemiol. 2017 Jan;81:13-21.

16. Molino CGRC, Romano-Lieber NS, Ribeiro E, Melo DO. Non-Communicable Disease Clinical Practice Guidelines in Brazil: A Systematic Assessment of Methodological Quality and Transparency. Gan SH, editor. PLoS One [Internet]. 2016 Nov 15 [cited 2018 Apr 6];11(11):e0166367. Disponível em: http://dx.plos.org/10.1371/journal.pone.0166367

17. MacDermid JC, Brooks D, Solway S, Switzer-McIntyre S, Brosseau L, Graham ID. Reliability and validity of the AGREE instrument used by physical therapists in assessment of clinical practice guidelines. BMC Health Serv Res. 2005 Mar;5(1):18.

18. Brouwers MC, Browman G, Cluzeau F, Davis D, Feder G, Graham I, et al. Instrumento para avaliação de diretrizes clinicas - Appraisal of Guidelines Research \& Evaluation. 2009; Disponível em: https://www.agreetrust.org/wpcontent/uploads/2013/06/AGREE_II_Brazilian_Portuguese.pdf

19. Makarski J, Brouwers MC. The AGREE Enterprise: a decade of advancing clinical practice guidelines. Implement Sci. 2014 Aug;9:103.

20. Harrison MB, Graham ID, Hoek JVD, Dogherty EJ, Carley ME, Angus V. Guideline adaptation and implementation planning: a prospective observational study. Implement Sci. 2013 Jan;8(1):49.

21. Shekelle PG, Woolf SH, Eccles M, Grimshaw J. Clinical guidelines: developing guidelines. BMJ. 1999 Mar;318(7183):593-6.

22. Schieir O, Hazlewood G, Akhavan P, Bykerk V, Bombardier C. Adapting ADAPTE: A novel methodology for the development of national clinical practice guidelines. J Rheumatol. 2010;37(6):1315. 
23. Misso ML, Pitt VJ, Jones KM, Barnes HN, Piterman L, Green SE. Quality and consistency of clinical practice guidelines for diagnosis and management of osteoarthritis of the hip and knee: a descriptive overview of published guidelines. Med J Aust [Internet]. 2008 Oct 6 [cited 2018 Sep 25];189(7):3949. Disponível em: http://www.ncbi.nlm.nih.gov/pubmed/18837684

24. Fervers B, Burgers JS, Haugh MC, Latreille J, Mlika-Cabanne N, Paquet L, et al. Adaptation of clinical guidelines: Literature review and proposition for a framework and procedure. Int J Qual Heal Care. 2006;18(3):167-76.

25. Harrison MB, Légaré F, Graham ID, Fervers B. Adapting clinical practice guidelines to local context and assessing barriers to their use. CMAJ. 2010 Feb;182(2):E78-84.

26. The ADAPTE Collaboration. The ADAPTE process: resource toolkit for guideline adaptation. Version 2.0. 2009. Disponível em: http://www.g-i-n.net.

27. Law MR, Morris JK, Wald NJ. Use of blood pressure lowering drugs in the prevention of cardiovascular disease: meta-analysis of 147 randomised trials in the context of expectations from prospective epidemiological studies. BMJ. 2009 Jan;338(may19_1):b1665-b1665.

28. World Health Organization. A global brief on hypertension. [Internet]. World Health Organization; 2013.40 p. Disponível em: http://apps.who.int/iris/bitstream/handle/10665/79059/WHO_DCO_WHD_2013. 2_eng.pdf?sequence $=1$

29. Zhou B, Bentham J, Di Cesare M, Bixby H, Danaei G, Cowan MJ, et al. Worldwide trends in blood pressure from 1975 to 2015: a pooled analysis of 1479 population-based measurement studies with 19.1 million participants. Lancet [Internet]. 2017 Jan 7 [cited 2018 Dec 21];389(10064):37-55. Disponível em: http://www.ncbi.nlm.nih.gov/pubmed/27863813

30. Alsuwaida A, Alghonaim M. Gender disparities in the awareness and control of hypertension. Clin Exp Hypertens. 2011 Jan;33(5):354-7.

31. Whelton PK. Epidemiology and the Prevention of Hypertension. J Clin Hypertens. 2004 Nov;6(11):636-42.

32. Cai L, Liu A, Zhang L, Li S, Wang P. Prevalence, awareness, treatment, and control of hypertension among adults in Beijing, China. Clin Exp Hypertens. 2012 Jan;34(1):45-52.

33. Rothwell PM, Howard SC, Dolan E, O'Brien E, Dobson JE, Dahlöf B, et al. Effects of $\beta$ blockers and calcium-channel blockers on within-individual variability in blood pressure and risk of stroke. Lancet Neurol [Internet]. 2010 May [cited 2019 Jan 17];9(5):469-80. Disponível em: http://www.ncbi.nlm.nih.gov/pubmed/20227347

34. Muntner P, Whittle J, Lynch AI, Colantonio LD, Simpson LM, Einhorn PT, et al. Visit-to-Visit Variability of Blood Pressure and Coronary Heart Disease, Stroke, 
Heart Failure, and Mortality. Ann Intern Med [Internet]. 2015 Sep 1 [cited 2019 Jan 17];163(5):329. Disponível em: http://www.ncbi.nlm.nih.gov/pubmed/26215765

35. Rothwell PM, Howard SC, Dolan E, O'Brien E, Dobson JE, Dahlöf B, et al. Prognostic significance of visit-to-visit variability, maximum systolic blood pressure, and episodic hypertension. Lancet [Internet]. 2010 Mar 13 [cited 2019 Jan 17];375(9718):895-905. Disponível em: http://www.ncbi.nlm.nih.gov/pubmed/20226988

36. Santos C, Pimenta C, Nobre M. The PICO strategy for the research question construction and evidence search. Rev Lat Am Enfermagem [Internet]. 2007 Jun;15(3):508-11. Disponível em: http://www.scielo.br/scielo.php?script=sci_arttext\&pid=S0104$11692007000300023 \&$ Ing=en\&tlng=en

37. Magarey JM. Elements of a systematic review. Int J Nurs Pract [Internet]. 2001 Dec;7(6):376-82. Disponível

em: http://www.ncbi.nlm.nih.gov/pubmed/11785440

38. Sackett DL, Rosenberg WM, Gray JA, Haynes RB, Richardson WS. Evidence based medicine: what it is and what it isn't. BMJ [Internet]. 1996 Jan;312(7023):71-2. http://www.ncbi.nlm.nih.gov/pubmed/8555924

39. Titler MG. The Evidence for Evidence-Based Practice Implementation [Internet]. Patient Safety and Quality: An Evidence-Based Handbook for Nurses. 2008 [cited 2018 Feb 15]. Disponível em: http://www.ncbi.nlm.nih.gov/pubmed/21328760

40. Hochman B, Nahas F, Oliveira-Filho R, Ferreira L. Research designs. Acta Cir

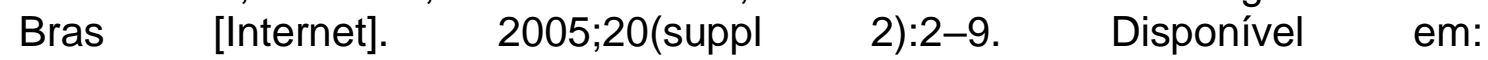
http://www.scielo.br/scielo.php?script=sci_arttext\&pid=S0102$86502005000800002 \& \operatorname{lng}=$ pt\&tlng=pt

41. Evans D. Hierarchy of evidence: a framework for ranking evidence evaluating healthcare interventions. J Clin Nurs [Internet]. 2003 Jan;12(1):77-84. Disponível em: http://doi.wiley.com/10.1046/j.1365-2702.2003.00662.x

42. Burns PB, Rohrich RJ, Chung KC. The levels of evidence and their role in evidence-based medicine. Plast Reconstr Surg [Internet]. 2011 Jul [cited 2018 Apr 9];128(1):305-10. http://www.ncbi.nlm.nih.gov/pubmed/21701348 Disponível em:

43. Sadowsky $\mathrm{CH}$, Galvin JE. Guidelines for the management of cognitive and behavioral problems in dementia. J Am Board Fam Med [Internet]. 2012 May;25(3):350-66. Disponível http://www.ncbi.nlm.nih.gov/pubmed/22570399

44. Atkins D, Best D, Briss PA, Eccles M, Falck-Ytter Y, Flottorp S, et al. Grading quality of evidence and strength of recommendations. BMJ [Internet]. 2004 Jun 
19 [cited 2018 Dec 18];328(7454):1490. Disponível em: http://www.ncbi.nlm.nih.gov/pubmed/15205295

45. Ellis C. Evidence-based practice: a personal journey from scepticism to pragmatism. J Psychiatr Ment Health Nurs [Internet]. 2005 Dec [cited 2018 Feb 15];12(6):739-44. Disponível em: http://www.ncbi.nlm.nih.gov/pubmed/16336600

46. Oxman $A D$, Fretheim $A$, Schünemann $H J$, SURE. Improving the use of research evidence in guideline development: introduction. Heal Res Policy Syst [Internet]. 2006 Dec 20 [cited 2018 Feb 15];4(1):12. Disponível em: http://www.ncbi.nlm.nih.gov/pubmed/17116254

47. Institute of Medicine. Clinical Practice Guidelines: We Can Trust. 2011.

48. Burgers JS, Grol R, Klazinga NS, Mäkelä M, Zaat J. Towards evidence-based clinical practice: an international survey of 18 clinical guideline programs. Int $\mathrm{J}$ Qual Health Care. 2003 Feb;15(1):31-45.

49. Al-Ansary LA, Tricco AC, Adi Y, Bawazeer G, Perrier L, Al-Ghonaim M, et al. A Systematic Review of Recent Clinical Practice Guidelines on the Diagnosis, Assessment and Management of Hypertension. LoGerfo J, editor. PLoS One [Internet]. 2013 Jan 17 [cited 2018 Aug 31];8(1):e53744. Disponível em: http://www.ncbi.nlm.nih.gov/pubmed/23349738

50. Bancos I, Cheng T, Prokop LJ, Montori VM, Murad MH. Endocrine clinical practice guidelines in North America. A systematic assessment of quality. J Clin Epidemiol. 2012 May;65(5):520-5.

51. Shaneyfelt TM, Mayo-Smith MF, Rothwangl J. Are guidelines following guidelines? The methodological quality of clinical practice guidelines in the peer-reviewed medical literature. JAMA [Internet]. 1999 May;281(20):1900. Disponível http://jama.jamanetwork.com/article.aspx?doi=10.1001/jama.281.20.1900

52. Kryworuchko J, Stacey D, Bai N, Graham ID. Twelve years of clinical practice guideline development, dissemination and evaluation in Canada (1994 to 2005). Implement Sci [Internet]. 2009 Dec;4(1):49. Disponível em: http://implementationscience.biomedcentral.com/articles/10.1186/1748-5908-449

53. Kung J, Miller RR, Mackowiak PA. Failure of Clinical Practice Guidelines to Meet Institute of Medicine Standards. Arch Intern Med [Internet]. 2012 Nov;172(21):1628. Disponível em: http://archinte.jamanetwork.com/article.aspx?doi=10.1001/2013.jamainternmed .56

54. Smith CAM, Toupin-April K, Jutai JW, Duffy CMCM, Rahman P, Cavallo S, et al. A Systematic Critical Appraisal of Clinical Practice Guidelines in Juvenile Idiopathic Arthritis Using the Appraisal of Guidelines for Research and Evaluation II (AGREE II) Instrument. PLoS One [Internet]. 2015 
Jan;10(9):e0137180-e0137180.

Disponível

em:

http://www.pubmedcentral.nih.gov/articlerender.fcgi?artid=4565560\&tool=pmce ntrez\&rendertype $=$ abstract

55. Knai C, Brusamento S, Legido-Quigley H, Saliba V, Panteli D, Turk E, et al. Systematic review of the methodological quality of clinical guideline development for the management of chronic disease in Europe. Health Policy [Internet]. 2012 Oct;107(2-3):157-67. Disponível em: http://www.ncbi.nlm.nih.gov/pubmed/22795610

56. Ronsoni RM, Pereira CC, Stein AT, Osanai MH, Machado CJ, Pereira CCA, et al. Avaliação de oito Protocolos Clínicos e Diretrizes Terapêuticas (PCDT) do Ministério da Saúde por meio do instrumento AGREE II: um estudo piloto. Cad Saude Publica [Internet]. 2015 Jun;31(6):1157-62. Disponível em: http://www.scielo.br/scielo.php?script=sci_arttext\&pid=S0102-

311X2015000601157\&lng=pt\&tlng=pt

57. Vlayen J, Aertgeerts B, Hannes K, Sermeus W, Ramaekers D. A systematic review of appraisal tools for clinical practice guidelines: multiple similarities and one common deficit. Int J Qual Heal Care [Internet]. 2005 Jun 1 [cited 2018 Feb 15];17(3):235-42. Disponível em: http://www.ncbi.nlm.nih.gov/pubmed/15743883

58. Siering U, Eikermann M, Hausner E, Hoffmann-Eßer W, Neugebauer EA. Appraisal Tools for Clinical Practice Guidelines: A Systematic Review. Tu Y-K, editor. PLoS One [Internet]. 2013 Dec;8(12):e82915-e82915. Disponível em: http://dx.plos.org/10.1371/journal.pone.0082915

59. Lohr KN, Field MJ. A provisional instrument for assessing clinical practice guidelines. In Guidelines for Clinical Practice: From Development to Use. Washingt DC Natl Acad Press [Internet]. 1992. Disponível em: https://www.ncbi.nlm.nih.gov/books/NBK234505/

60. Lohr KN. Guidelines for Clinical Practice: What They are and Why They Count. J Law, Med Ethics [Internet]. 1995 Mar 24 [cited 2018 Feb 15];23(1):49-56. Disponivel em: http://journals.sagepub.com/doi/10.1111/j.1748720X.1995.tb01330.x

61. AGREE Collaboration. Development and validation of an international appraisal instrument for assessing the quality of clinical practice guidelines: the AGREE project. Qual Saf Health Care [Internet]. 2003 Feb;12(1):18-23. Disponível em: http://www.ncbi.nlm.nih.gov/pubmed/12571340

62. Graham ID, Harrison MB, Brouwers MC, Davies BL, Dunn S. Facilitating the use of evidence in practice: evaluating and adapting clinical practice guidelines for local use by health care organizations. J Obstet Gynecol neonatal Nurs JOGNN [Internet]. [cited 2018 Aug 31];31(5):599-611. Disponível em: http://www.ncbi.nlm.nih.gov/pubmed/12353740

63. Khan GSC, Stein AT. Adaptação transcultural do instrumento Appraisal of 
Guidelines for Research \& Evaluation II (AGREE II) para avaliação de diretrizes clínicas. Cad Saude Publica [Internet]. 2014 May;30(5):1111-4. Disponível em: http://www.scielo.br/scielo.php?script=sci_arttext\&pid=S0102311 X2014000501111\&lng=pt\&tlng=pt

64. Brouwers MC, Kho ME, Browman GP, Burgers JS, Cluzeau F, Feder G, et al. AGREE II: advancing guideline development, reporting and evaluation in health care. CMAJ. 2010 Dec;182(18):E839-42.

65. Burgers JS, Anzueto A, Black PN, Cruz AA, Fervers B, Graham ID, et al. Adaptation, evaluation, and updating of guidelines: article 14 in Integrating and coordinating efforts in COPD guideline development. An official ATS/ERS workshop report. Proc Am Thorac Soc [Internet]. 2012 Dec;9(5):304-10. Disponível em: http://www.ncbi.nlm.nih.gov/pubmed/23256175

66. Kristiansen A, Brandt L, Agoritsas T, Akl EA, Berge E, Flem Jacobsen A, et al. Applying new strategies for the national adaptation, updating, and dissemination of trustworthy guidelines: results from the Norwegian adaptation of the Antithrombotic Therapy and the Prevention of Thrombosis, 9th Ed: American College of Chest Physicians . Chest [Internet]. 2014 Sep;146(3):73561. Disponível em: http://www.ncbi.nlm.nih.gov/pubmed/25180724

67. Turner TJ. Developing evidence-based clinical practice guidelines in hospitals in Australia, Indonesia, Malaysia, the Philippines and Thailand: values, requirements and barriers. BMC Health Serv Res [Internet]. 2009 Dec 15 [cited 2018 Aug 14];9(1):235. Disponível em: http://bmchealthservres.biomedcentral.com/articles/10.1186/1472-6963-9-235

68. Schünemann HJ, Fretheim $A$, Oxman $A D$. Improving the use of research evidence in guideline development: 13. Applicability, transferability and adaptation. Heal Res policy Syst [Internet]. 2006 Dec;4:25. Disponível em: http://www.ncbi.nlm.nih.gov/pubmed/17156457

69. Grimshaw JM, Russell IT. Achieving health gain through clinical guidelines II: Ensuring guidelines change medical practice. Qual Health Care [Internet]. 1994 Mar [cited 2018 Aug 14];3(1):45-52. Disponível em: http://www.ncbi.nlm.nih.gov/pubmed/10136260

70. Wainberg SK, Santos NCL, Gabriel FC, Vasconcelos LP, Nascimento JS, Molino CGRC, et al. Clinical practice guidelines for surgical antimicrobial prophylaxis: Qualitative appraisals and synthesis of recommendations. J Eval Clin Pract [Internet]. 2018 Jul 19 [cited 2018 Dec 17]. Disponível em: http://www.ncbi.nlm.nih.gov/pubmed/30024082

71. Wang Z, Norris SL, Bero L. The advantages and limitations of guideline adaptation frameworks. Implement Sci. 2018 Dec;13(1):72.

72. Colombia. Ministerio de Salud y Protección Social. Guía Metodológica, Adopción Adaptación de Guías de Práctica Clínica Basadas en Evidencia. Guía metodológica en Internet. Edición 1ª. Bogotá DC. 2017. Disponível em: 
gpc.minsalud.gov.com.

73. Amer YS, Wahabi HA, Abou Elkheir MM, Bawazeer GA, lqbal SM, Titi MA, et al. Adapting evidence-based clinical practice guidelines at university teaching hospitals: A model for the Eastern Mediterranean Region. J Eval Clin Pract [Internet]. 2018 Apr 24 [cited 2018 Oct 2]; Disponível em: http://doi.wiley.com/10.1111/jep.12927

74. Darzi A, Abou-Jaoude EA, Agarwal A, Lakis C, Wiercioch W, Santesso N, et al. A methodological survey identified eight proposed frameworks for the adaptation of health related guidelines. J Clin Epidemiol [Internet]. 2017 Jun;86:3-10. Disponível em: http://www.ncbi.nlm.nih.gov/pubmed/28412463

75. Amer YS, Elzalabany MM, Omar TI, Ibrahim AG, Dowidar NL. The 'Adapted ADAPTE': an approach to improve utilization of the ADAPTE guideline adaptation resource toolkit in the Alexandria Center for Evidence-Based Clinical Practice Guidelines. J Eval Clin Pract [Internet]. 2015 Dec;21(6):1095106. Disponível em: http://doi.wiley.com/10.1111/jep.12479

76. Harstall C, Taenzer P, Angus DK, Moga C, Schuller T, Scott NA. Creating a multidisciplinary low back pain guideline: anatomy of a guideline adaptation process. J Eval Clin Pract [Internet]. 2011 Aug;17(4):693-704. Disponível em: http://www.ncbi.nlm.nih.gov/pubmed/20846284

77. Schünemann HJ, Wiercioch W, Brozek J, Etxeandia-Ikobaltzeta I, Mustafa RA, Manja V, et al. GRADE Evidence to Decision (EtD) frameworks for adoption, adaptation, and de novo development of trustworthy recommendations: GRADE-ADOLOPMENT. J Clin Epidemiol [Internet]. 2017 Jan [cited 2018 Aug 10];81:101-10. Disponível em: http://www.ncbi.nlm.nih.gov/pubmed/27713072

78. World Health Organization. Estonian Handbook for Guidelines Development. 2016; Disponível em: https://www.ravijuhend.ee/uploads/userfiles/file/3_mai_2016/RJ_kasiraamat_3 _5_2016.pdf

79. Kristiansen A, Brandt L, Agoritsas T, Akl EA, Berge E, Bondi J, et al. Adaptation of Trustworthy Guidelines Developed Using the GRADE Methodology. Chest [Internet]. 2014 Sep;146(3):727-34. Disponível em: http://www.ncbi.nlm.nih.gov/pubmed/25180723

80. Alper BS, Tristan M, Ramirez-Morera A, Vreugdenhil MMT, Van Zuuren EJ, Fedorowicz Z. RAPADAPTE for rapid guideline development: high-quality clinical guidelines can be rapidly developed with limited resources. Int J Qual Heal Care [Internet]. 2016 Jun;28(3):268-74. Disponível em: http://www.ncbi.nlm.nih.gov/pubmed/27097885

81. Rycroft-Malone J, Duff L. Developing clinical guidelines: issues and challenges. J Tissue Viability [Internet]. 2000 Oct;10(4):144-149,152-153. Disponível em: http://www.ncbi.nlm.nih.gov/pubmed/11949302

82. Muth C, Gensichen J, Beyer M, Hutchinson A, Gerlach FM. The Systematic 
Guideline Review: Method, rationale, and test on chronic heart failure. BMC Health Serv Res [Internet]. 2009 Dec;9(1):74. Disponível em: $\mathrm{http} / / / \mathrm{bmchealthservres.biomedcentral.com/articles/10.1186/1472-6963-9-74}$

83. Brasil. Ministério da Saúde. Secretaria de Ciência, Tecnologia e Insumos Estratégicos. Departamento de Ciência e Tecnologia. Diretrizes metodológicas: ferramentas para adaptação de diretrizes clínicas. 2014; Disponível

em: http://bvsms.saude.gov.br/bvs/publicacoes/diretrizes_metodologicas_adaptaca o_diretrizes_clinicas.pdf

84. Graham ID. Evaluation and adaptation of clinical practice guidelines. Evid Based Nurs. $2005 \mathrm{Jul} ; 8(3): 68-72$.

85. Dagenais S, Tricco AC, Haldeman S. Synthesis of recommendations for the assessment and management of low back pain from recent clinical practice guidelines. Spine J [Internet]. 2010 Jun [cited 2018 Aug 31];10(6):514-29. Disponível em: http://www.ncbi.nlm.nih.gov/pubmed/20494814

86. Tirotta D, Marchetti A, Di Lillo M, Pomero F, Re R, Meschi M, et al. Abdominal pain: a synthesis of recommendations for its correct management. Ital $\mathrm{J}$ Med [Internet]. 2015 May 8 [cited 2018 Aug 10];9(2):193. Disponível em: http://www.italjmed.org/index.php/ijm/article/view/itjm.2015.515

87. Koumans EH, Markowitz LE, Hogan V. Indications for Therapy and Treatment Recommendations for Bacterial Vaginosis in Nonpregnant and Pregnant Women: A Synthesis of Data. Clin Infect Dis [Internet]. 2002 Oct 15 [cited 2018 Aug 31];35(s2):S152-72. Disponível em: https://academic.oup.com/cid/articlelookup/doi/10.1086/342103

88. Kroenke K, Krebs EE, Bair MJ. Psychiatric-Medical Comorbidity Pharmacotherapy of chronic pain: a synthesis of recommendations from systematic reviews. Gen Hosp Psychiatry [Internet]. 2009 [cited 2018 Aug 31];31:206-19. Disponível em: www.sciencedirect.com

89. World Health Organization. Antibiotic resistance: synthesis of recommendations by expert policy groups Alliance for the Prudent Use of Antibiotics [Internet]. 2001 [cited 2018 Aug 31]. Disponível em: http://www.who.int/emc

90. Bird L, Cross-Bardell L, Ward D, Kai J. Synthesis of UK evidence based recommendations for adult obesity prevention and treatment for service improvement and implementation: why weight? East Midlands Academic Health Science Network Obesity Programme. 2015 [cited 2018 Aug 31]; Disponível em: http://eprints.nottingham.ac.uk/29881/

91. Jolliffe L, Lannin NA, Cadilhac DA, Hoffmann T. Systematic review of clinical practice guidelines to identify recommendations for rehabilitation after stroke and other acquired brain injuries. BMJ Open [Internet]. 2018 Feb 28 [cited 2018 Aug 
http://www.ncbi.nlm.nih.gov/pubmed/29490958

92. Ángel García D, Martínez Nicolás I, Saturno Hernández PJ. Abordaje clínico de la fibromialgia: síntesis de recomendaciones basadas en la evidencia, una revisión sistemática. Reumatol Clínica [Internet]. 2016 Mar [cited 2018 Aug 31];12(2):65-71. http://www.ncbi.nlm.nih.gov/pubmed/26481494

93. Chen $Y$, Hu S, Wu L, Fang X, Xu W, Shen G. Clinical practice guidelines for hypertension in China: a systematic review of the methodological quality. BMJ Open [Internet]. 2015 Jul 15 [cited 2018 Apr 9];5(7):e008099. Disponível em: http://www.ncbi.nlm.nih.gov/pubmed/26179649

94. Zhang X, Zhao K, Bai Z, Yu J, Bai F. Clinical Practice Guidelines for Hypertension: Evaluation of Quality Using the AGREE II Instrument. Am J Cardiovasc Drugs [Internet]. 2016 Dec 31 [cited 2018 Apr 9];16(6):439-51 Disponível em: http://www.ncbi.nlm.nih.gov/pubmed/27580999

95. Alhawassi TM, Krass I, Pont LG. Hypertension in Older Persons: A Systematic Review of National and International Treatment Guidelines. J Clin Hypertens [Internet]. 2015 [cited 2018 Apr 9];17:486-92. Disponível em: https://onlinelibrary.wiley.com/doi/pdf/10.1111/jch.12536

96. CHRONIDE. Chronic Diseases and Informed Decisions [Internet]. [cited 2018 Apr 2]. Disponível em: http://chronidebrazil.wixsite.com/chronide

97. Molino CGRC, Ribeiro E, Romano-Lieber NS, Stein AT, Melo DO. Methodological quality and transparency of clinical practice guidelines for the pharmacological treatment of non-communicable diseases using the AGREE II instrument: a systematic review protocol. Syst Rev [Internet]. 2017 Nov 2 [cited 2018 Feb 1];6(1):220. Disponível em: http://www.ncbi.nlm.nih.gov/pubmed/29096721

98. Mendeley. Editora Elsevier Brasil [Internet]. [cited 2018 Apr 2]. Disponível em: https://www.elsevier.com/americalatina/pt-br/mendeley

99. Khan GSC, Stein AT, Khan GSC, Stein AT. Adaptação transcultural do instrumento Appraisal of Guidelines for Research \& Evaluation II (AGREE II) para avaliação de diretrizes clínicas. Cad Saude Publica. 2014 May;30(5):1111-4.

100. Brasil. Ministério da Saúde. Secretaria de Atenção a Saúde. Portaria $n^{0} 1.083$, de 02 de outubro de 2012. Protocolo Clínico e Diretrizes Terapêuticas da Dor Crônica. [Internet]. [cited 2019 Jan 22]. Disponível em: http://portalarquivos2.saude.gov.br/images/pdf/2014/abril/02/pcdt-dor-cronica2012.pdf

101. Brasil. Ministério da Saúde. Secretaria de Atenção a Saúde. Portaria $n^{0} 1.266$, de 14 de novembro de 2014. Protocolo Clínico e Diretrizes Terapêuticas da Doença de Gaucher. Disponível em: http://conitec.gov.br/images/DoencaGaucher.pdf 
102. National Institute for Health and Care Excellence. Obesity: identification, assessment and management. NICE guideline (CG189). 2014. Disponível em: https://www.nice.org.uk/guidance/cg189

103. Bahn RS, Burch HB, Cooper DS, Garber JR, Carol Greenlee M, Klein I, et al. Hyperthyroidism and Other Causes of Thyrotoxicosis: Management Guidelines of the American Thyroid Association and American Association of Clinical Endocrinologists. Endocr Pract Endocr Pr. 1717(3).

104. Gradwohl SE, Greenberg GM, Van Harrison MR. Guidelines for Clinical Care Ambulatory Urinary Tract Infection- Michigan. 1999. Disponível em: https://www.uofmhealth.org/provider/clinical-care-guidelines

105. Hoffmann-Eßer W, Siering U, Neugebauer EAM, Lampert U, Eikermann M. Systematic review of current guideline appraisals performed with the Appraisal of Guidelines for Research \& Evaluation II instrument-a third of AGREE II users apply a cut-off for guideline quality. J Clin Epidemiol [Internet]. $2018 \mathrm{Mar}$ [cited 2019 Jan 17];95:120-7. Disponível em: http://www.ncbi.nlm.nih.gov/pubmed/29288133

106. Acuña-Izcaray A, Sánchez-Angarita E, Plaza V, Rodrigo G, De Oca MM, Gich I, et al. Quality assessment of asthma clinical practice guidelines: A systematic appraisal. Chest. 2013 Aug;144(2):390-7.

107. Arevalo-Rodriguez I, Pedraza OL, Rodriguez A, Sanchez E, Gich I, Sola I, et al. Alzheimer's disease dementia guidelines for diagnostic testing: a systematic review. Am J Alzheimers Dis Other Demen. 2013 Mar;28(2):111-9.

108. Watine J, Friedberg B, Nagy E, Onody R, Oosterhuis W, Bunting PS, et al. Conflict between guideline methodologic quality and recommendation validity: A potential problem for practitioners. Clin Chem. 2006;52(1):65-72.

109. Centeno JCV, Granados CE, Ardila GFT, Pérez JG, Valencia L, Vélez CM, et al. Guía de Práctica Clínica - Hipertensión arterial primaria (hta) - Colombia. 2013; Disponível em: https://www.medicosgeneralescolombianos.com/images/Guias_2013/gpc_18pr of_sal_hta.pdf

110. National Institute for Health and Care Excellence (2011- updated 2016). Hypertension in adults: diagnosis and management. NICE guideline (CG 127). 2016. Disponível em: https://www.nice.org.uk/guidance/cg127

111. Whelton PK, Carey RM, Aronow WS, Casey DE, Collins KJ, Dennison Himmelfarb C, et al. 2017 ACC/AHA/AAPA/ABC/ACPM/AGS/APhA/ASH/ASPC/NMA/PCNA Guideline for the Prevention, Detection, Evaluation, and Management of High Blood Pressure in Adults: Executive Summary. Hypertension [Internet]. 2017 Nov;HYP.0000000000000066-HYP.0000000000000066. Disponível em: http://www.ncbi.nlm.nih.gov/pubmed/29133354

112. Cushman W, Harrell T, Berlowitz D, Abbott J, Furmaga E, Allerman A, et al. 
VA/DoD clinical practice guideline for the diagnosis and management of hypertension in the primary care setting [Internet]. 2014. Disponível em: https://www.healthquality.va.gov/guidelines/cd/htn/

113. Leung A, Daskalopoulou S, Dasgupta K, McBrien K, Butalia S, Zarnke KB, et al. Hypertension Canada's 2017 Guidelines for Diagnosis, Risk Assessment, Prevention, and Treatment of Hypertension in Adults. Can J Cardiol [Internet]. 2017 May;33(5):557-76. Disponível em: http://www.sciencedirect.com/science/article/pii/S0828282X17301101?via\%3Di hub

114. Montero JPA, López JAC, Rodríguez DÁE, Zarate JHG, Flores EM, Vargas RAM, et al. Diagnóstico y Tratamiento de la Hipertensión Arterial en el Primer Nivel de Atención. 2014. Disponível em: http://www.cenetec.salud.gob.mx

115. Anderson C, Arnolda L, Cowley D, Dowden J, Gabb G, Golledge J, et al. Guideline for the diagnosis and management of hypertension in adults - Heart Foundation. 2016;

Disponível

em: https://www.heartfoundation.org.au/images/uploads/publications/PRO167_Hypertension-guideline-2016_WEB.pdf

116. Rotaeche R Balagué L, Gorroñogoitia A, Idarreta I, Mariñelarena E, Mozo C, Ruiz de Velasco E, Torcal J. AJ. Clinical practice guidelines on arterial hypertension. National Guideline Clearinghouse [Internet]. Disponível em: https:/guideline.gov/summaries/summary/15712/clinical-practice-guidelineson-arterial-hypertension-2007-update? $\mathrm{q}=$ coronary

117. The Japanese Society of Hypertension Guidelines for the Management of Hypertension (JSH 2014) [Internet]. Disponível em: http://www.nature.com/hr/journal/v37/n4/index.html

118. Dorsch MP, Ealovega MW, Harrison R Van, Jamerson KA. Essential hypertension. University of Michigan Health System. National Guideline Clearinghouse [Internet]. 2014. Disponível em: https://www.guideline.gov/summaries/summary/48196

119. Aronow WS, Harrington RA, Fleg JL, Pepine CJ, Artinian NT, Bakris G, et al. ACCF/AHA 2011 Expert Consensus Document on Hypertension in the Elderly. Circulation [Internet]. 2011;123(21). Disponível em: http://circ.ahajournals.org/content/123/21/2434.short

120. Bavanandan S, Chin CY, Ahmad G, Ming KE, Yusoff K, Zambahari R, et al. Management of Hypertension (4th Edition) - Malaysia. [Internet]. 2013. Disponível em: http://www.acadmed.org.my/index.cfm?\&menuid=67

121. Rosendorff C, Lackland DT, Allison M, Aronow WS, Black HR, Blumenthal RS, et al. Treatment of Hypertension in Patients With Coronary Artery Disease. Hypertension [Internet]. 2015;65(6). Disponível em: http://hyper.ahajournals.org/content/65/6/1372.full

122. Denolle T, Chamontin B, Doll G, Fauvel J-P, Girerd X, Herpin D, et al. 
Management of resistant hypertension: expert consensus statement from the French Society of Hypertension, an affiliate of the French Society of Cardiology. J Hum Hypertens [Internet]. 2016 Nov;30(11):657-63. Disponível em: http://www.nature.com/doifinder/10.1038/jhh.2015.122

123. Hypertension- Diagnosis and Management - British Columbia. 2016 Jun; Disponível em: http://www2.gov.bc.ca/gov/content/health/practitionerprofessional-resources/bc-guidelines/hypertension

124. Malachias MVB, Póvoa RMS, Nogueira AR, Souza D, Costa LS, Magalhães ME. $7^{\text {a }}$ Diretriz Brasileira de Hipertensão Arterial. 2016;107(3). Disponível em: http://www.arquivosonline.com.br

125. Mancia G, Fagard R, Narkiewicz K, Redón J, Zanchetti A, Böhm M, et al. 2013 $\mathrm{ESH} / \mathrm{ESC}$ Guidelines for the management of arterial hypertension. J Hypertens [Internet]. 2013;31(7):1281-357. Disponível em: http://www.ncbi.nlm.nih.gov/pubmed/23817082

126. Peng Y. Expert consensus on blood pressure management of diabetic patients in China. J Diabetes [Internet]. 2014 May;6(3):202-11. Disponível em: http://doi.wiley.com/10.1111/1753-0407.12103

127. The Egyptian Hypertension Society: Egyptian Hypertension Guidelines. Egypt Hear J [Internet]. 2014;66(2):79-132. Disponível em: http://www.sciencedirect.com/science/article/pii/S1110260814000349

128. Tomasik T, Gryglewska B, Windak A, Grodzicki T. Hypertension in the elderly: how to treat patients in 2013? The essential recommendations of the Polish guidelines. Pol Arch Med Wewn [Internet]. 2013;123(7-8):409-16. Disponível em: http://www.ncbi.nlm.nih.gov/pubmed/23828034

129. Ministerio de Salud- Republica Del Peru. Enfermedad Hipertensiva. Resolución Ministerial $\quad \mathrm{N}^{\circ} \quad$ 031-2015. 2015. Disponível em: http://www.minsa.gob.pe/dgsp/documentos/Guias/RM031-2015-MINSA.pdf

130. Wrobel MJ, Figge JJ, Izzo JL. Hypertension in diverse populations: a New York State Medicaid clinical guidance document. J Am Soc Hypertens [Internet]. 2011 Jul;5(4):208-29. Disponível em: http://www.ncbi.nlm.nih.gov/pubmed/21771564

131. Association of Physicians of India. Indian guidelines on hypertension (I.G.H.) III. 2013. J Assoc Physicians India. 2013 Feb;61(2 Suppl):6-36.

132. Blacher J, Halimi J-M, Hanon O, Mourad J-J, Pathak A, Schnebert B, et al. Management of hypertension in adults: the 2013 French Society of Hypertension guidelines. Fundam Clin Pharmacol [Internet]. 2014 Feb;28(1):19. Disponível em: http://doi.wiley.com/10.1111/fcp.12044

133. Roca FV. Abordaje de la hipertensión arterial en el paciente anciano. Semer Med Fam [Internet]. 2014 May;40:3-9. Disponível em: http://linkinghub.elsevier.com/retrieve/pii/S1138359314743813 
134. Abdul Rahman AR, Reyes EB, Sritara P, Pancholia A, Phuoc D Van, Tomlinson B. Combination therapy in hypertension: an Asia-Pacific consensus viewpoint. Curr Med Res Opin [Internet]. 2015 May;31(5):865-74. Disponível em: http://www.tandfonline.com/doi/full/10.1185/03007995.2015.1020368

135. El-Deeb MH, Sulaiman KJ, Al-Riyami AA, Mohsin N, Al-Mukhaini M, Al-Lamki $M$, et al. 2015 Oman Heart Association Guidelines for the Management of Hypertension. High Blood Press Cardiovasc Prev [Internet]. 2015 Mar;22(1):83-97. Disponível em: http://link.springer.com/10.1007/s40292-0140074-z

136. López-Jaramillo P, Sánchez RA, Diaz M, Cobos L, Bryce A, Parra Carrillo JZ, et al. Latin American consensus on hypertension in patients with diabetes type 2 and metabolic syndrome. J Hypertens [Internet]. 2013 Feb;31(2):223-38. Disponível em: http://www.ncbi.nlm.nih.gov/pubmed/23282894

137. Seedat YK, Rayner BL, Veriava Y. South African hypertension practice guideline 2014. Cardiovasc J Afr [Internet]. 2014;25(6):288-94. Disponível em: http://www.ncbi.nlm.nih.gov/pubmed/25629715

138. Sun N-L, Huo Y, Wang J-G, Li N-F, Tao J, Li Y, et al. Consensus of Chinese Specialists on Diagnosis and Treatment of Resistant Hypertension. Chin Med J (Engl) [Internet]. 2015 Aug;128(15):2102-8. Disponível em: http://www.ncbi.nlm.nih.gov/pubmed/26228226

139. Veglio F, Grassi G, Mancia G, Volpe M, Hypertension IS of. Clinical management of resistant hypertension: practical recommendations from the Italian Society of Hypertension (SIIA). High Blood Press Cardiovasc Prev [Internet]. $2013 \quad$ Dec;20(4):251-6. Disponível em: http://www.ncbi.nlm.nih.gov/pubmed/23949949

140. Weber MA, Schiffrin EL, White WB, Mann S, Lindholm LH, Kenerson JG, et al. Clinical Practice Guidelines for the Management of Hypertension in the Community. J Clin Hypertens [Internet]. 2014 Jan;16(1):14-26. Disponível em: http://www.ncbi.nlm.nih.gov/pubmed/24341872

141. Póvoa R, Barroso WS, Brandão AA, Jardim PCV, Barroso O, Passarelli O, et al. I brazilian position paper on antihypertensive drug combination. Arq Bras Cardiol. 2014 Mar;102(3):203-10.

142. Alessi A, Brandão AA, Paiva AMG de, Nogueira A da R, Feitosa A, Gonzaga C de $C$, et al. I Brazilian Position Paper on Prehypertension, White Coat Hypertension and Masked Hypertension: Diagnosis and Management. Arq Bras Cardiol [Internet]. 2014;102(2):110-9. Disponível em: http://www.gnresearch.org/doi/10.5935/abc.20140011

143. Laubscher T, Regier L, Stone S. Hypertension in the elderly: new blood pressure targets and prescribing tips. Can Fam Physician [Internet]. 2014 May;60(5):453-6. 
144. Bendersky M, Sánchez R. Hipertensión arterial en pacientes con diabetes mellitus tipo 2. Rev Fac Cienc Med [Internet]. 2013. Disponível em: http://www.revista2.fcm.unc.edu.ar/2013.70.2/Revision/revision.pdf

145. Anwer Z, Sharma PK, Garg VK, Kumar N, Kumari A. Hypertension management in diabetic patients. Eur Rev Med Pharmacol Sci [Internet]. 2011. Disponível em: http://www.europeanreview.org/wp/wpcontent/uploads/1067.pdf

146. National Institute for Health and Care Excellence. Hypertension in adults: diagnosis and management. NICE guideline (CG 127). 2011 [cited 2018 Aug 9]; Disponível em: https://www.nice.org.uk/guidance/cg127

147. James PA, Oparil S, Carter BL, Cushman WC, Dennison-Himmelfarb C, Handler J, et al. 2014 Evidence-Based Guideline for the Management of High Blood Pressure in Adults Report From the Panel Members Appointed to the Eighth Joint National Committee (JNC 8). JAMA [Internet]. 2014 Feb 5 [cited 2018 Oct 3];311(5):507. Disponível em: http://jama.jamanetwork.com/article.aspx?doi=10.1001/jama.2013.284427

148. Chobanian A V., Bakris GL, Black HR, Cushman WC, Green LA, Izzo JL, et al. The Seventh Report of the Joint National Committee on Prevention, Detection, Evaluation, and Treatment of High Blood Pressure. JNC 7 Report. JAMA [Internet]. 2003 May 21 [cited 2018 Aug 9];289(19):2560. Disponível em: http://www.ncbi.nlm.nih.gov/pubmed/12748199

149. Hackam DG, Quinn RR, Ravani P, Rabi DM, Dasgupta K, Daskalopoulou SS, et al. The 2013 Canadian Hypertension Education Program Recommendations for Blood Pressure Measurement, Diagnosis, Assessment of Risk, Prevention, and Treatment of Hypertension. Can J Cardiol [Internet]. 2013 May [cited 2018 Aug 9];29(5):528-42. Disponível em: http://www.ncbi.nlm.nih.gov/pubmed/23541660

150. Molino CGRC, Leite-Santos NC, Gabriel FC, Wainberg SK, Vasconcelos LP, Mantovani-Silva RA, et al. Factors Associated With High-Quality Guidelines for the Pharmacologic Management of Chronic Diseases in Primary Care: A Systematic Review. JAMA Intern Med. 2019. No prelo.

151. Hoffmann-eßer W, Siering U, Neugebauer EAM, Brockhaus C, Lampert U, Eikermann M. Guideline appraisal with AGREE II: Systematic review of the current evidence on how users handle the 2 overall assessments. PLoS One. 2017;3:1-15.

152. Kunz R, Fretheim A, Cluzeau F, Wilt TJ, Qaseem A, Lelgemann M, et al. Guideline Group Composition and Group Processes. Proc Am Thorac Soc [Internet]. 2012 Dec 15 [cited 2018 Apr 11];9(5):229-33. Disponível em: http://www.ncbi.nlm.nih.gov/pubmed/23256164

153. Fretheim $A$, Schünemann $H J$, Oxman $A D$. Improving the use of research evidence in guideline development: 3. Group composition and consultation 
process. Heal Res policy Syst. 2006 Nov;4:15.

154. Hudon C, Fortin M, Haggerty J, Loignon C, Lambert M, Poitras M-E. Patientcentered care in chronic disease management: A thematic analysis of the literature in family medicine. Patient Educ Couns [Internet]. 2012 Aug [cited 2018 Apr 11];88(2):170-6. Disponível em: http://www.ncbi.nlm.nih.gov/pubmed/22360841

155. Murthy L, Shepperd S, Clarke MJ, Garner SE, Lavis JN, Perrier L, et al. Interventions to improve the use of systematic reviews in decision-making by health system managers, policy makers and clinicians. Cochrane Database Syst Rev. 2012 Sep;(9):CD009401.

156. Cabana MD, Rand CS, Powe NR, Wu AW, Wilson MH, Abboud PA, et al. Why don't physicians follow clinical practice guidelines? A framework for improvement. JAMA [Internet]. 1999 Oct 20 [cited 2018 Apr 11];282(15):145865. Disponível em: http://www.ncbi.nlm.nih.gov/pubmed/10535437

157. Gagliardi AR, Brouwers MC. Do guidelines offer implementation advice to target users? A systematic review of guideline applicability. BMJ Open [Internet]. 2015 Feb 18 [cited 2018 Nov 19];5(2):e007047. Disponível em: http://www.ncbi.nlm.nih.gov/pubmed/25694459

158. Norris SL, Holmer HK, Ogden LA, Selph SS, Fu R. Conflict of Interest Disclosures for Clinical Practice Guidelines in the National Guideline Clearinghouse. Ross JS, editor. PLoS One [Internet]. 2012 Nov 7 [cited 2018 Apr 11];7(11):e47343. Disponível em: http://dx.plos.org/10.1371/journal.pone.0047343

159. Chen $Y, H u S, W u L$, Fang $X, X u$ W, Shen $G$. Clinical practice guidelines for hypertension in China: a systematic review of the methodological quality. BMJ Open [Internet]. 2015 Jul 15 [cited 2018 Apr 11];5(7):e008099. Disponível em: http://www.ncbi.nlm.nih.gov/pubmed/26179649

160. Greenfield S, Kaplan SH. When Clinical Practice Guidelines Collide: Finding a Way Forward. Ann Intern Med [Internet]. 2017 Nov 7 [cited 2018 Dec 5];167(9):677. Disponível em: http://annals.org/article.aspx?doi=10.7326/M172665

161. Akl EA, El-Hachem P, Abou-Haidar H, Neumann I, Schünemann HJ, Guyatt $\mathrm{GH}$. Considering intellectual, in addition to financial, conflicts of interest proved important in a clinical practice guideline: a descriptive study. J Clin Epidemiol. 2014 Nov;67(11):1222-8.

162. Alhazzani W, Lewis K, Jaeschke R, Rochwerg B, Møller MH, Evans L, et al. Conflicts of interest disclosure forms and management in critical care clinical practice guidelines. Intensive Care Med. 2018 Oct;44(10):1691-8.

163. Schünemann HJ, Al-Ansary LA, Forland F, Kersten S, Komulainen J, Kopp IB, et al. Guidelines International Network: Principles for Disclosure of Interests and Management of Conflicts in Guidelines. Ann Intern Med. 2015 
Oct;163(7):548.

164. SPRINT Research Group, Wright JT, Williamson JD, Whelton PK, Snyder JK, Sink KM, et al. A Randomized Trial of Intensive versus Standard BloodPressure Control. N Engl J Med [Internet]. 2015 Nov 26 [cited 2018 Sep 12];373(22):2103-16.

http://www.ncbi.nlm.nih.gov/pubmed/26551272

165. Taler SJ. More From SPRINT (Systolic Blood Pressure Intervention Trial): A Closer Look at the Price of Intensive Blood Pressure Control. Am J Kidney Dis [Internet]. 2018 May [cited 2018 Sep 25];71(5):611-4. Disponível em: http://www.ncbi.nlm.nih.gov/pubmed/29352606

166. AAFP Decides to Not Endorse AHA/ACC Hypertension Guideline [Internet]. [cited 2018 Oct 1]. Disponível em: https://www.aafp.org/news/health-of-thepublic/20171212notendorseaha-accgdlne.html

167. Morris AH, loannidis JPA. Limitations of Medical Research and Evidence at the Patient-Clinician Encounter Scale. Chest [Internet]. 2013 Apr [cited 2018 Sep 17];143(4):1127-35. http://www.ncbi.nlm.nih.gov/pubmed/23546485

168. Lenzer J, Hoffman JR, Furberg CD, loannidis JPA, Guideline Panel Review Working Group. Ensuring the integrity of clinical practice guidelines: a tool for protecting patients. BMJ [Internet]. 2013 Sep 17 [cited 2018 Sep 17];347:f5535. Disponível em: http://www.ncbi.nlm.nih.gov/pubmed/24046286

169. Mant J, McManus RJ, Hare R. Applicability to primary care of national clinical guidelines on blood pressure lowering for people with stroke: cross sectional study. BMJ [Internet]. 2006 Mar 18 [cited 2018 Sep 17];332(7542):635-7. Disponível em: http://www.ncbi.nlm.nih.gov/pubmed/16500926

170. Steel N, Abdelhamid A, Stokes T, Edwards H, Fleetcroft R, Howe A, et al. A review of clinical practice guidelines found that they were often based on evidence of uncertain relevance to primary care patients. J Clin Epidemiol [Internet]. 2014 Nov [cited 2018 Sep 17];67(11):1251-7. Disponível em: http://www.ncbi.nlm.nih.gov/pubmed/25199598

171. Andrews J, Guyatt G, Oxman AD, Alderson P, Dahm P, Falck-Ytter Y, et al. GRADE guidelines: 14. Going from evidence to recommendations: the significance and presentation of recommendations. J Clin Epidemiol. 2013 Jul;66(7):719-25.

172. Khera R, Lu Y, Lu J, Saxena A, Nasir K, Jiang L, et al. Impact of 2017 ACC/AHA guidelines on prevalence of hypertension and eligibility for antihypertensive treatment in United States and China: nationally representative cross sectional study. BMJ [Internet]. 2018 Jul 11 [cited 2018 Sep 18];362:k2357. Disponível em: http://www.ncbi.nlm.nih.gov/pubmed/29997129

173. Schiffrin EL. Global Impact of the 2017 American College of 
Cardiology/American Heart Association Hypertension Guidelines. A Perspective From Canada. Circulation [Internet]. 2018 Feb 27 [cited 2018 Sep 20];137(9):883-5. Disponível em: https://www.ahajournals.org/doi/10.1161/CIRCULATIONAHA.117.032849

174. Wander GS, Ram CVS. Global Impact of 2017 American Heart Association/American College of Cardiology Hypertension Guidelines. A Perspective From India. Circulation [Internet]. 2018 Feb 6 [cited 2018 Sep 20];137(6):549-50. Disponível em: https://www.ahajournals.org/doi/10.1161/CIRCULATIONAHA.117.032877

175. Lonn EM, Bosch J, López-Jaramillo P, Zhu J, Liu L, Pais P, et al. BloodPressure Lowering in Intermediate-Risk Persons without Cardiovascular Disease. N Engl J Med [Internet]. 2016 May 26 [cited 2018 Sep 24];374(21):2009-20. Disponível em: http://www.nejm.org/doi/10.1056/NEJMoa1600175

176. Bell KJL, Doust J, Glasziou P. Incremental Benefits and Harms of the 2017 American College of Cardiology/American Heart Association High Blood Pressure Guideline. JAMA Intern Med [Internet]. 2018 Jun 1 [cited 2018 Sep 18];178(6):755. Disponível em: http://archinte.jamanetwork.com/article.aspx?doi=10.1001/jamainternmed.2018 .0310

177. Saiz LC, Gorricho J, Garjón J, Celaya MC, Erviti J, Leache L. Blood pressure targets for the treatment of people with hypertension and cardiovascular disease. Cochrane Database Syst Rev [Internet]. 2018 Jul 20 [cited 2018 Sep 17];(7). Disponível em: http://doi.wiley.com/10.1002/14651858.CD010315.pub3

178. Sheppard JP, Stevens S, Stevens R, Martin U, Mant J, Hobbs FDR, et al. Benefits and Harms of Antihypertensive Treatment in Low-Risk Patients With Mild Hypertension. JAMA Intern Med [Internet]. 2018 Dec 1 [cited 2018 Dec 6];178(12):1626. Disponível em: http://archinte.jamanetwork.com/article.aspx?doi=10.1001/jamainternmed.2018 .4684

179. Böhm M, Schumacher H, Teo KK, Lonn EM, Mahfoud F, Mann JFE, et al. Achieved blood pressure and cardiovascular outcomes in high-risk patients: results from ONTARGET and TRANSCEND trials. Lancet (London, England). 2017 Jun;389(10085):2226-37.

180. Lewington S, Clarke R, Qizilbash N, Peto R, Collins R, Prospective Studies Collaboration. Age-specific relevance of usual blood pressure to vascular mortality: a meta-analysis of individual data for one million adults in 61 prospective studies. Lancet (London, England) [Internet]. 2002 Dec 14 [cited 2018 Mar 20];360(9349):1903-13. Disponível em: http://www.ncbi.nlm.nih.gov/pubmed/12493255

181. Pickering TG, Hall JE, Appel LJ, Falkner BE, Graves JW, Hill MN, et al. Recommendations for blood pressure measurement in humans: an AHA 
scientific statement from the Council on High Blood Pressure Research Professional and Public Education Subcommittee. J Clin Hypertens (Greenwich) [Internet]. 2005 Feb [cited 2018 Sep 18];7(2):102-9. Disponível em: http://www.ncbi.nlm.nih.gov/pubmed/15722655

182. Abbasi J. Medical Students Fall Short on Blood Pressure Check Challenge. JAMA [Internet]. 2017 Sep 19 [cited 2018 Sep 25];318(11):991. Disponível em: http://jama.jamanetwork.com/article.aspx?doi=10.1001/jama.2017.11255

183. Einstadter D, Bolen SD, Misak JE, Bar-Shain DS, Cebul RD. Association of Repeated Measurements With Blood Pressure Control in Primary Care. JAMA Intern Med [Internet]. 2018 Jun 1 [cited 2018 Sep 18];178(6):858. Disponível em: http://www.ncbi.nlm.nih.gov/pubmed/29710186

184. Mayor S. Monitoring blood pressure for 30 minutes reduces unnecessary hypertension treatment, finds study. BMJ [Internet]. 2017 Mar 16 [cited 2018 Sep 18];356:j1302. Disponível em: https://www.bmj.com/content/356/bmj.j1302

185. Seedat YK, Croasdale MA, Milne FJ, Opie LH, Pinkney-Atkinson V, Rayner BL, et al. South African Hypertension Guideline 2006. S Afr Med J [Internet]. 2006 [cited 2018 Dec 27];96:337-362. Disponível em: https://open.uct.ac.za/handle/11427/24701

186. Wright JM, Musini VM, Gill R. First-line drugs for hypertension. Cochrane Database Syst Rev [Internet]. 2018 Apr 18 [cited 2018 Sep 14];(4). Disponível em: http://doi.wiley.com/10.1002/14651858.CD001841.pub3

187. Ernst ME, Carter BL, Zheng S, Grimm RH. Meta-Analysis of Dose-Response Characteristics of Hydrochlorothiazide and Chlorthalidone: Effects on Systolic Blood Pressure and Potassium. Am J Hypertens [Internet]. 2010 Apr 1 [cited 2018 Oct 11];23(4):440-6. Disponível em: http://www.ncbi.nlm.nih.gov/pubmed/20111008

188. Roush GC, Ernst ME, Kostis JB, Tandon S, Sica DA. Head-to-Head Comparisons of Hydrochlorothiazide With Indapamide and Chlorthalidone. Hypertension [Internet]. 2015 May [cited 2018 Oct 11];65(5):1041-6. Disponível em: http://www.ncbi.nlm.nih.gov/pubmed/25733245

189. Roush GC, Holford TR, Guddati AK. Chlorthalidone Compared With Hydrochlorothiazide in Reducing Cardiovascular Events. Hypertension [Internet]. 2012 Jun [cited 2018 Oct 11];59(6):1110-7. Disponível em: http://www.ncbi.nlm.nih.gov/pubmed/22526259

190. Pedersen SA, Gaist D, Schmidt SAJ, Hölmich LR, Friis S, Pottegård A. Hydrochlorothiazide use and risk of nonmelanoma skin cancer: A nationwide case-control study from Denmark. J Am Acad Dermatol [Internet]. 2018 Apr 1 [cited 2018 Dec 5];78(4):673-681.e9. Disponível em: http://www.ncbi.nlm.nih.gov/pubmed/29217346

191. Gradman AH, Basile JN, Carter BL, Bakris GL, American Society of Hypertension Writing Group. Combination Therapy in Hypertension. J Clin 
Hypertens [Internet]. 2011 Mar [cited 2018 Sep 25];13(3):146-54. Disponível em: http://www.ncbi.nlm.nih.gov/pubmed/21366845

192. The ACCORD Study Group. Effects of Intensive Blood-Pressure Control in Type 2 Diabetes Mellitus. N Engl J Med [Internet]. 2010 Apr 29 [cited 2018 Sep 25];362(17):1575-85. Disponível http://www.nejm.org/doi/abs/10.1056/NEJMoa1001286

193. Cushman WC, Ford CE, Cutler JA, Margolis KL, Davis BR, Grimm RH, et al. Success and predictors of blood pressure control in diverse North American settings: the antihypertensive and lipid-lowering treatment to prevent heart attack trial (ALLHAT). J Clin Hypertens (Greenwich) [Internet]. [cited 2018 Sep 25];4(6):393-404. Disponível

em: http://www.ncbi.nlm.nih.gov/pubmed/12461301

194. Wald DS, Law M, Morris JK, Bestwick JP, Wald NJ. Combination Therapy Versus Monotherapy in Reducing Blood Pressure: Meta-analysis on 11,000 Participants from 42 Trials. Am J Med [Internet]. 2009 Mar [cited 2018 Sep 26];122(3):290-300. Disponível http://www.ncbi.nlm.nih.gov/pubmed/19272490

195. Law MR, Wald NJ, Morris JK, Jordan RE. Value of low dose combination treatment with blood pressure lowering drugs: analysis of 354 randomised trials. BMJ [Internet]. 2003 Jun 26 [cited 2018 Sep 26];326(7404):1427-0. Disponível em: http://www.ncbi.nlm.nih.gov/pubmed/12829555

196. Corrao G, Nicotra F, Parodi A, Zambon A, Heiman F, Merlino L, et al. Cardiovascular Protection by Initial and Subsequent Combination of Antihypertensive Drugs in Daily Life Practice. Hypertension [Internet]. 2011 Oct 1 [cited 2018 Sep 26];58(4):566-72. Disponível em: http://www.ncbi.nlm.nih.gov/pubmed/21825231

197. Gradman $A H$, Parise $H$, Lefebvre $P$, Falvey $H$, Lafeuille $M-H$, Duh MS. Initial Combination Therapy Reduces the Risk of Cardiovascular Events in Hypertensive Patients: A Matched Cohort Study. Hypertension [Internet]. 2013 Feb 1 [cited 2018 Sep 26];61(2):309-18. Disponível em: http://www.ncbi.nlm.nih.gov/pubmed/23184383

198. ONTARGET Investigators, Yusuf S, Teo KK, Pogue J, Dyal L, Copland I, et al. Telmisartan, Ramipril, or Both in Patients at High Risk for Vascular Events. N Engl J Med [Internet]. 2008 Apr 10 [cited 2018 Sep 25];358(15):1547-59. Disponível em: http://www.ncbi.nlm.nih.gov/pubmed/18378520

199. Parving $\mathrm{H}-\mathrm{H}$, Brenner BM, McMurray JJV, de Zeeuw D, Haffner SM, Solomon SD, et al. Cardiorenal End Points in a Trial of Aliskiren for Type 2 Diabetes. N Engl J Med [Internet]. 2012 Dec 6 [cited 2018 Sep 25];367(23):2204-13. Disponível em: http://www.ncbi.nlm.nih.gov/pubmed/23121378

200. Fried LF, Emanuele N, Zhang JH, Brophy M, Conner TA, Duckworth W, et al. Combined Angiotensin Inhibition for the Treatment of Diabetic Nephropathy. N 
Engl J Med [Internet]. 2013 Nov 14 [cited 2018 Sep 25];369(20):1892-903. Disponível em: http://www.ncbi.nlm.nih.gov/pubmed/24206457

201. Sherrill B, Halpern M, Khan S, Zhang J, Panjabi S. Single-Pill vs FreeEquivalent Combination Therapies for Hypertension: A Meta-Analysis of Health Care Costs and Adherence. J Clin Hypertens [Internet]. 2011 Dec 1 [cited 2018 Sep 26];13(12):898-909. Disponível em: http://doi.wiley.com/10.1111/j.17517176.2011.00550.x

202. World Health Organization. The selection and use of essential medicines: report of the WHO Expert Committee, 2017 (including the 20th WHO Model List of Essential Medicines and the 6th WHO Model List of Essential Medicines for Children). Geneva: World Health Organization; 2017.

203. Angeli F, Reboldi G, Mazzotta G, Garofoli M, Ramundo E, Poltronieri C, et al. Fixed-Dose Combination Therapy in Hypertension. High Blood Press Cardiovasc Prev [Internet]. 2012 Jun 1 [cited 2018 Sep 26];19(2):51-4. Disponível em: http://www.ncbi.nlm.nih.gov/pubmed/22867089

204. Lenita Wannmacher, Rogério Hoefler. Combinações em doses fixas: comentários farmacológicos, clínicos e comerciais [Internet]. Vol. 4. 2007 [cited 2019 Jan 12]. Disponível em: https://www.paho.org/bra/index.php?option=com_docman\&view=download\&ali as=513-combinacoes-em-doses-fixas-v-4-n-7-2006-3\&category_slug=usoracional-medicamentos-685\&ltemid $=965$

205. Upshur REG, Tracy S. Chronicity and complexity: is what's good for the diseases always good for the patients? Can Fam Physician [Internet]. 2008 Dec [cited 2018 Dec 14];54(12):1655-8. Disponível em: http://www.ncbi.nlm.nih.gov/pubmed/19074692

206. Tinetti ME, Bogardus ST, Agostini J V. Potential Pitfalls of Disease-Specific Guidelines for Patients with Multiple Conditions. N Engl J Med [Internet]. 2004 Dec 30 [cited 2018 Dec 14];351(27):2870-4. Disponível em: http://www.ncbi.nlm.nih.gov/pubmed/15625341

207. Kennard L, O'Shaughnessy KM. Treating hypertension in patients with medical comorbidities. BMJ [Internet]. 2016 Feb 16 [cited 2018 Sep 24];352:i101. Disponível em: http://www.ncbi.nlm.nih.gov/pubmed/26884124

208. National Kidney Foundation. High Blood Pressure and Chronic Kidney Disease [Internet]. 2010 [cited 2018 Sep 27]. Disponível em: www.kidney.org

209. Judd E, Calhoun DA. Management of hypertension in CKD: beyond the guidelines. Adv Chronic Kidney Dis [Internet]. 2015 Mar [cited 2018 Sep 27];22(2):116-22. http://www.ncbi.nlm.nih.gov/pubmed/25704348

210. Lewis EJ, Hunsicker LG, Clarke WR, Berl T, Pohl MA, Lewis JB, et al. Renoprotective Effect of the Angiotensin-Receptor Antagonist Irbesartan in Patients with Nephropathy Due to Type 2 Diabetes. N Engl J Med [Internet]. 
2001 Sep 20 [cited 2018 Sep 27];345(12):851-60. Disponível em: http://www.nejm.org/doi/abs/10.1056/NEJMoa011303

211. Esnault V, Brown E, Apetrei E, Bagon J, Calvo C, Dechatel R, et al. The effects of amlodipine and enalapril on renal function in adults with hypertension and nondiabetic nephropathies: A 3-year, randomized, multicenter, double-blind, placebo-controlled study. Clin Ther [Internet]. 2008 Mar [cited 2018 Sep 27];30(3):482-98. Disponível http://www.ncbi.nlm.nih.gov/pubmed/18405787

212. Wright JT, Bakris G, Greene T, Agodoa LY, Appel LJ, Charleston J, et al. Effect of blood pressure lowering and antihypertensive drug class on progression of hypertensive kidney disease: results from the AASK trial. JAMA [Internet]. 2002 Nov 20 [cited 2018 Sep 27];288(19):2421-31. Disponível em: http://www.ncbi.nlm.nih.gov/pubmed/12435255

213. Hsu F-Y, Lin F-J, Ou H-T, Huang S-H, Wang C-C. Renoprotective Effect of Angiotensin-Converting Enzyme Inhibitors and Angiotensin II Receptor Blockers in Diabetic Patients with Proteinuria. Kidney Blood Press Res [Internet]. 2017 [cited 2018 Sep 27];42(2):358-68. Disponível em: http://www.ncbi.nlm.nih.gov/pubmed/28618426

214. Lesogor A, Cohn JN, Latini R, Tognoni G, Krum H, Massie B, et al. Interaction between baseline and early worsening of renal function and efficacy of reninangiotensin-aldosterone system blockade in patients with heart failure: insights from the Val-HeFT study. Eur J Heart Fail [Internet]. 2013 Nov [cited 2018 Sep 27];15(11):1236-44. Disponível em: http://www.ncbi.nlm.nih.gov/pubmed/23787721

215. Schmidt M, Mansfield KE, Bhaskaran K, Nitsch D, Sørensen HT, Smeeth L, et al. Serum creatinine elevation after renin-angiotensin system blockade and long term cardiorenal risks: cohort study. BMJ [Internet]. 2017 Mar 9 [cited 2018 Sep 27];356:j791. Disponível em: http://www.ncbi.nlm.nih.gov/pubmed/28279964 


\section{APÊNDICES}

\section{APÊNDICE 1- DOCUMENTOS SELECIONADOS PARA AVALIAÇÃO DA QUALIDADE METODOLÓGICA COM} INSTRUMENTO AGREE II.

\begin{tabular}{|c|c|}
\hline $\begin{array}{l}\text { enteno JCV, Granados CE, Ardila GFT, Pérez JG, Valencia L, Vélez CM, et al. Guía de Práctica Clínica - Hipertensión arterial primaria (hta) - } \\
\text { olombia. } 2013 \text { [cited } 2017 \text { Oct 10]; Available from: https://www.medicosgeneralescolombianos.com/images/Guias_2013/gpc_18prof_sal_hta.pdf }\end{array}$ & Incluído \\
\hline $\begin{array}{l}\text { Williams B, Williams H, Northedge J, Crimmins J, Caulfield M, Watts M, et al. Hypertension in adults: diagnosis and management | Guidance and } \\
\text { guidelines | NICE. } 2016 \text { [cited } 2017 \text { Oct 10]; Available from: https://www.nice.org.uk/guidance/cg127 }\end{array}$ & Incluído \\
\hline $\begin{array}{l}2017 \text { ACC/AHA/AAPA/ABC/ACPM/AGS/APhA/ASH/ASPC/NMA/PCNA Guideline for the Prevention, Detection, Evaluation, and Management of } \\
\text { High Blood Pressure in Adults }\end{array}$ & Incluído \\
\hline $\begin{array}{l}\text { Cushman W, Harrell T, Berlowitz D, Abbott J, Furmaga E, Allerman A, et al. Management of Hypertension (HTN) in Primary Care (2014) - VA/DoD } \\
\text { Clinical Practice Guidelines [Internet]. } 2014 \text { [cited } 2017 \text { Oct 10]. Available from: https://www.healthquality.va.gov/guidelines/cd/htn/ }\end{array}$ & Incluído \\
\hline $\begin{array}{l}\text { Leung A, Daskalopoulou S, Dasgupta K, McBrien K, Butalia S, Zarnke KB, et al. Hypertension Canada's 2017 Guidelines for Diagnosis, Risk } \\
\text { Assessment, Prevention, and Treatment of Hypertension in Adults. Can J Cardiol [Internet]. } 2017 \text { May } 1 \text { [cited 2017 Oct 10];33(5):557-76. Available } \\
\text { from: http://www.sciencedirect.com/science/article/pii/S0828282X17301101?via\%3Dihub }\end{array}$ & Incluído \\
\hline Diagnóstico y Tratamiento de la HIPERTENSIÓN ARTERIAL en el Primer Nivel de Atención & Incluído \\
\hline Heart Foundation - HAS 2016 & Incluído \\
\hline $\begin{array}{l}\text { Rotaeche R, Aguirrezabala J, Balagué L, Gorroñogoitia A, Idarreta I, Mariñelarena E, Mozo C, Ruiz de Velasco E TJ. Clinical practice guidelines on } \\
\text { arterial hypertension. | National Guideline Clearinghouse [Internet]. [cited } 2017 \text { Oct 10]. Available from: } \\
\text { https://guideline.gov/summaries/summary/15712/clinical-practice-guidelines-on-arterial-hypertension-2007-update?q=coronary }\end{array}$ & Incluído \\
\hline $\begin{array}{l}\text { Shimamoto K, Ando K, Fujita T, Hasebe N, Higaki J, Horiuchi M, et al. The Japanese Society of Hypertension Guidelines for the Management of } \\
\text { Hypertension (JSH 2014). Hypertens Res [Internet]. } 2014 \text { Apr [cited } 2017 \text { Oct 10];37(4):253-253. Available from: } \\
\text { http://www.ncbi.nlm.nih.gov/pubmed/24705419 }\end{array}$ & Incluído \\
\hline $\begin{array}{l}\text { Dorsch MP, Ealovega MW, Harrison R Van, Jamerson KA. Essential hypertension. University of Michigan Health System | National Guideline } \\
\text { Clearinghouse [Internet]. } 2014 \text { [cited } 2017 \text { Oct 10]. Available from: https://www.guideline.gov/summaries/summary/48196 }\end{array}$ & Incluído \\
\hline $\begin{array}{l}\text { Aronow WS, Fleg JL, Pepine CJ et al. ACCF/AHA } 2011 \text { Expert Consensus Document on Hypertension in the Elderly. Circulation. 123(21):2434- } \\
\text { 506. doi: 10.1161/CIR.0b013e31821daaf6 }\end{array}$ & Incluído \\
\hline $\begin{array}{l}\text { Bavanandan S, Chin CY, Ahmad G, Ming KE, Yusoff K, Zambahari R, et al. Management of Hypertension (4th Edition) - Malaysia. [Internet]. } 2013 \\
\text { [cited } 2017 \text { Oct 10]. Available from: http://www.acadmed.org.my/index.cfm?\&menuid=67 }\end{array}$ & Incluído \\
\hline $\begin{array}{l}\text { Rosendorff C, Lackland DT, Allison M, Aronow WS, Black HR, Blumenthal RS, et al. Treatn } \\
\text { Disease. Hypertension [Internet]. } 2015 \text { [cited } 2017 \text { Mar 29];65(6). Available from: http://hyp }\end{array}$ & Inclu \\
\hline
\end{tabular}


Apêndice 1- Documentos selecionados para avaliação da qualidade metodológica com instrumento AGREE II.

Denolle T, Chamontin B, Doll G, Fauvel J-P, Girerd X, Herpin D, et al. Management of resistant hypertension: expert consensus statement from the French Society of Hypertension, an affiliate of the French Society of Cardiology. J Hum Hypertens [Internet]. 2016 Nov 28 [cited 2017 Mar 29];30(11):657-63. Available from: http://www.nature.com/doifinder/10.1038/jhh.2015.122

Hypertension- Diagnosis and Management - British Columbia. 2016 Jun 22 [cited 2017 Oct 10]; Available from:

http://www2.gov.bc.ca/gov/content/health/practitioner-professional-resources/bc-guidelines/hypertension

Malachias M, Póvoa R, Nogueira A, Souza D, Costa L, Magalhães M. 7a Diretriz Brasileira de Hipertensão Arterial. 2016 [cited 2017 Oct

10];107(3). Available from: www.arquivosonline.com.br

Mancia G, Fagard R, Narkiewicz K, Redón J, Zanchetti A, Böhm M, et al. 2013 ESH/ESC Guidelines for the management of arterial hypertension. J Hypertens [Internet]. $2013 \mathrm{Jul}$ [cited 2017 Oct 10];31(7):1281-357. Available from: http://www.ncbi.nlm.nih.gov/pubmed/23817082

Peng Y. Expert consensus on blood pressure management of diabetic patients in China. J Diabetes [Internet]. 2014 May 1 [cited 2017 Oct

10];6(3):202-11. Available from: http://doi.wiley.com/10.1111/1753-0407.12103

Ibrahim MM. The Egyptian Hypertension Society EGYPTIAN HYPERTENSION GUIDELINES The Egyptian Heart Journal. Egypt Hear J [Internet].

2014 [cited 2017 Oct 10];66:79-132. Available from: www.elsevier.com/locate/ehj

Tomasik T, Gryglewska B, Windak A, Grodzicki T. Hypertension in the elderly: how to treat patients in 2013 ? The essential recommendations of the Polish guidelines. Pol Arch Med Wewn [Internet]. 2013 [cited 2017 Oct 10];123(7-8):409-16. Available from:

http://www.ncbi.nlm.nih.gov/pubmed/23828034

Ministerio de Salud- Republica Del Peru. Guía de Práctica Clínica para el Diagnóstico, Tratamiento y Control de la Enfermedad Hipertensiva. Resolución Ministerial No 031-2015/MINSA. [cited 2017 Oct 10]; Available from: http://www.minsa.gob.pe/dgsp/documentos/Guias/RM031-2015-

MINSA.pdf

Wrobel MJ, Figge JJ, Izzo JL. Hypertension in diverse populations: a New York State Medicaid clinical guidance document. J Am Soc Hypertens [Internet]. $2011 \mathrm{Jul}$ [cited 2017 Oct 10];5(4):208-29. Available from: http://www.ncbi.nlm.nih.gov/pubmed/21771564

Association of Physicians of India. Indian guidelines on hypertension (I.G.H.) - III. 2013. J Assoc Physicians India [Internet]. 2013 Feb [cited 2017

Oct 10];61(2 Suppl):6-36. Available from: http://www.ncbi.nlm.nih.gov/pubmed/24475694

Blacher J, Halimi J-M, Hanon O, Mourad J-J, Pathak A, Schnebert B, et al. Management of hypertension in adults: the 2013 French Society of

Hypertension guidelines. Fundam Clin Pharmacol [Internet]. 2014 Feb [cited 2017 Oct 10];28(1):1-9. Available from:

http://doi.wiley.com/10.1111/fcp.12044

Roca FV. Abordaje de la hipertensión arterial en el paciente anciano. Semer - Med Fam [Internet]. 2014 May [cited 2017 Mar 29];40:3-9. Available from: http://linkinghub.elsevier.com/retrieve/pii/S1138359314743813

Abdul Rahman AR, Reyes EB, Sritara P, Pancholia A, Phuoc D Van, Tomlinson B. Combination therapy in hypertension: an Asia-Pacific consensus viewpoint. Curr Med Res Opin [Internet]. 2015 May 4 [cited 2017 Oct 10];31(5):865-74. Available from:

http://www.tandfonline.com/doi/full/10.1185/03007995.2015.1020368

El-Deeb MH, Sulaiman KJ, Al-Riyami AA, Mohsin N, Al-Mukhaini M, Al-Lamki M, et al. 2015 Oman Heart Association Guidelines for the

Management of Hypertension. High Blood Press Cardiovasc Prev [Internet]. 2015 Mar 18 [cited 2017 Oct 10];22(1):83-97. Available from:

http://link.springer.com/10.1007/s40292-014-0074-z

López-Jaramillo P, Sánchez RA, Diaz M, Cobos L, Bryce A, Parra Carrillo JZ, et al. Latin American consensus on hypertension in patients with diabetes type 2 and metabolic syndrome. J Hypertens [Internet]. 2013 Feb [cited 2017 Oct 10];31(2):223-38. Available from:

http://www.ncbi.nlm.nih.gov/pubmed/23282894

Seedat YK, Rayner BL, Veriava Y. South African hypertension practice guideline 2014. Cardiovasc J Afr [Internet]. 2014 [cited 2017 Oct

10];25(6):288-94. Available from: http://www.ncbi.nlm.nih.gov/pubmed/25629715 


\section{Apêndice 1- Documentos selecionados para avaliação da qualidade metodológica com instrumento AGREE II.}

Sun N-L, Huo Y, Wang J-G, Li N-F, Tao J, Li Y, et al. Consensus of Chinese Specialists on Diagnosis and Treatment of Resistant Hypertension. Chin Med J (Engl) [Internet]. 2015 Aug 5 [cited 2017 Oct 10];128(15):2102-8. Available from: http://www.ncbi.nlm.nih.gov/pubmed/26228226

Veglio F, Grassi G, Mancia G, Volpe M, Italian Society of Hypertension. Clinical management of resistant hypertension: practical recommendations

from the Italian Society of Hypertension (SIIA). High Blood Press Cardiovasc Prev [Internet]. 2013 Dec 15 [cited 2017 Oct 10];20(4):251-6.

Available from: http://www.ncbi.nlm.nih.gov/pubmed/23949949

Weber MA, Schiffrin EL, White WB, Mann S, Lindholm LH, Kenerson JG, et al. Clinical Practice Guidelines for the Management of Hypertension in

the Community. J Clin Hypertens [Internet]. 2014 Jan [cited 2017 Oct 10];16(1):14-26. Available from:

http://www.ncbi.nlm.nih.gov/pubmed/24341872

Póvoa R, Barroso WS, Brandão AA, Jardim PCV, Barroso O, Passarelli O, et al. I brazilian position paper on antihypertensive drug combination.

Arq Bras Cardiol [Internet]. 2014 Mar [cited 2017 Oct 10];102(3):203-10. Available from: http://www.ncbi.nlm.nih.gov/pubmed/24714792

Alessi A, Brandão AA, Paiva AMG de, Nogueira A da R, Feitosa A, Gonzaga C de C, et al. I Brazilian Position Paper on Prehypertension, White

Coat Hypertension and Masked Hypertension: Diagnosis and Management. Arq Bras Cardiol [Internet]. 2014 [cited 2017 Oct 10]:102(2):110-9.

Available from: http://www.gnresearch.org/doi/10.5935/abc.20140011

Laubscher T, Regier L, Stone S. Hypertension in the elderly: new blood pressure targets and prescribing tips. Can Fam Physician [Internet]. 2014

May [cited 2017 Oct 10];60(5):453-6. Available from: http://www.ncbi.nlm.nih.gov/pubmed/24829009

Bendersky M, Sánchez R. HIPERTENSIÓN ARTERIAL EN PACIENTES CON DIABETES MELLITUS TIPO 2 REVISIÓN ARTERIAL

HYPERTENSION IN PATIENTS WITH TYPE 2 DIABETES MELLITUS. Rev la Fac Ciencias Medicas [Internet]. 2013 [cited 2017 Oct 10]; Available

from: http://www.revista2.fcm.unc.edu.ar/2013.70.2/Revision/revision.pdf

Anwer Z, Sharma P, Garg V, Kumar N, Kumari A. Hypertension management in diabetic patients. Eur Rev Med Pharmacol Sci [Internet]. 2011

[cited 2017 Oct 10]; Available from: http://www.europeanreview.org/wp/wp-content/uploads/1067.pdf 


\section{APÊNDICE 2- DOCUMENTOS EXCLUÍDOS APÓS APLICAÇÃO DOS CRITÉRIOS DE ELEGIBILIDADE.}

\begin{tabular}{|c|c|}
\hline $\begin{array}{l}\text { Flynn, J. T. (2011). Management of hypertension in the young: role of antihypertensive medications. Journal of Cardiovascular Pharmacology, 58(2), } \\
\text { 111-120. https://doi.org/10.1097/FJC.0b013e31820d1b89 }\end{array}$ & $\begin{array}{l}\text { foco em grupos } \\
\text { especiais }\end{array}$ \\
\hline $\begin{array}{l}\text { Schmieder, R. E., Redon, J., Grassi, G., Kjeldsen, S. E., Mancia, G., Narkiewicz, K., ... Tsioufis, C. (2013). Updated ESH position paper on } \\
\text { interventional therapy of resistant hypertension. Eurolntervention : Journal of EuroPCR in Collaboration with the Working Group on Interventional } \\
\text { Cardiology of the European Society of Cardiology, } 9 \text { Suppl R, R58-66. https://doi.org/10.4244/EIJV9SRA11 }\end{array}$ & contexto hospitalar \\
\hline $\begin{array}{l}\text { Arici, M., Birdane, A., Guler, K., Yildiz, B. O., Altun, B., Erturk, S., ... Erdem, Y. (2015). [Turkish Hypertension Consensus Report]. Turk Kardiyoloji } \\
\text { Dernegi arsivi : Turk Kardiyoloji Derneginin yayin organidir, 43(4), 402-409. }\end{array}$ & idioma \\
\hline $\begin{array}{l}\text { Arkhipov, M. V, Arutiunov, G. P., Boitsov, S. A., Galiavich, A. S., Karpov, I. A., Kobalava, Z. D., ... Chazova, I. E. (2011). [Novel Russian } \\
\text { recommendations on arterial hypertension priority for combination therapy (Russian Medical Society on arterial hypertension, section of evidence } \\
\text { based hypertensiology)]. Kardiologiia, 51(9), 92-96. }\end{array}$ & idioma \\
\hline Bönner G (2015) The new 2014 guidelines for the treatment of arterial hypertension. Diabetologe 11:373-378 & idioma \\
\hline Chamontin, B., \& Lieber, A. (2012). [Arterial hypertension in the adult]. La Revue du praticien, 62(8), 1143-1163-1166. & idioma \\
\hline Chinese expert consensus on early morning blood pressure. (2014). Zhonghua xin xue guan bing za zhi, 42(9), 721-725. & idioma \\
\hline $\begin{array}{l}\text { Denolle T, Chamontin B, Doll G, Fauvel J-P, Girerd X, Herpin D, Vaisse B, Villeneuve F, Halimi J-M (2014) [Management of resistant hypertension. } \\
\text { Expert consensus statement from the French Society of Hypertension, an affiliate of the French Society of Cardiology]. Presse Med 43:1325-1331 }\end{array}$ & idioma \\
\hline $\begin{array}{l}\text { Ferrer Soler, C., Ehret, G., \& Pechere-Bertschi, A. (2015). [Screening and management of hypertension in elderly]. Revue medicale suisse, 11(485), } \\
1638,1640-1644 .\end{array}$ & idioma \\
\hline $\begin{array}{l}\text { Filipovsky J, Widimsky JJ, Ceral J, et al (2012) [Diagnosis and treatment of arterial hypertension. } 2012 \text { Guidelines of the Czech Hypertension } \\
\text { Society]. Vnitr Lek 58:785-801 }\end{array}$ & idioma \\
\hline Fukao, K., \& Daida, H. (2012). [Treatment of hypertension]. Nihon rinsho. Japanese journal of clinical medicine, 70 Suppl 5, 275-280. & idioma \\
\hline Groha, P., \& Schunkert, H. (2015). [Management of arterial hypertension]. Herz, 40(6), 922-929. https://doi.org/10.1007/s00059-015-4349-5 & idioma \\
\hline Liu, L.-S. (2011). [2010 Chinese guidelines for the management of hypertension]. Zhonghua xin xue guan bing za zhi, 39(7), 579-615. & idioma \\
\hline $\begin{array}{l}\text { Plouin, P.-F., \& Fiessinger, J.-N. (2012). [Recommendations for the management of patients with severe arterial hypertension. Commission IV. } \\
\text { Cardiovascular Diseases]. Bulletin de l'Academie nationale de medecine, 196(7), 1423-1427. }\end{array}$ & idioma \\
\hline Rahn KH (2013) [New hypertension guidelines]. Dtsch Med Wochenschr 138:2471-2473 & idioma \\
\hline $\begin{array}{l}\text { Schernthaner, G., Drexel, H., Rosenkranz, A., Schernthaner, G.-H., \& Watschinger, B. (2016). [Antihypertensive therapy in diabetes mellitus: } \\
\text { Guidelines of the Austrian Diabetes Association 2016]. Wiener klinische Wochenschrift, } 128 \text { Suppl, S62-7. https://doi.org/10.1007/s00508-015-0924-2 }\end{array}$ & idioma \\
\hline $\begin{array}{l}\text { Xhignesse, } \mathrm{P} \\
294-300 .\end{array}$ & idioma \\
\hline
\end{tabular}


Apêndice 2- Documentos excluídos após aplicação dos critérios de elegibilidade.

\begin{tabular}{|c|c|}
\hline Aalbers, J., \& Hardy, G. (2012, April). South African Hypertension Society 2012 congress report. Cardiovascular Journal of & não é um GPC \\
\hline $\begin{array}{l}\text { Abel, N., Contino, K., Jain, N., Grewal, N., Grand, E., Hagans, I., ... Roy, S. (2015). Eighth joint national committee (JNC-8) guidelines and the } \\
\text { outpatient management of hypertension in the African-American population. North American Journal of Medical Sciences, 7(10), 438-445. Retrieved } \\
\text { from http://www.embase.com/search/results?subaction=viewrecord\&from=export\&id=L606741089 }\end{array}$ & não é um GPC \\
\hline $\begin{array}{l}\text { Abman, S. H., Ivy, D. D., Archer, S. L., \& Wilson, K. (2016). Executive summary of the American Heart Association and American thoracic society } \\
\text { joint guidelines for pediatric pulmonary hypertension. American Journal of Respiratory and Critical Care Medicine, 194(7), 898-906. Retrieved from } \\
\text { http://www.embase.com/search/results?subaction=viewrecord\&from=export\&id=L612938339 }\end{array}$ & não é um GPC \\
\hline $\begin{array}{l}\text { Agarwal, R. (2013). Hypertension: KDIGO BP guidelines--more individualized, less prescriptive. Nature Reviews. Nephrology, 9(3), } 131-133 . \\
\text { https://doi.org/10.1038/nrneph.2013.16 }\end{array}$ & não é um GPC \\
\hline $\begin{array}{l}\text { Agbor-Etang, B. B., \& Setaro, J. F. (2015). Management of Hypertension in Patients with Ischemic Heart Disease. Current Cardiology Reports, } \\
17(12), 119 . \text { https://doi.org/10.1007/s11886-015-0662-0 }\end{array}$ & não é um GPC \\
\hline $\begin{array}{l}\text { Al Khaja, K. A. J., Sequeira, R. P., Alkhaja, A. K., \& Damanhori, A. H. H. (2015). Antihypertensive Drugs and Male Sexual Dysfunction: A Review of } \\
\text { Adult Hypertension Guideline Recommendations. Journal of Cardiovascular Pharmacology and Therapeutics, 21(3), 233-244. }\end{array}$ & não é um GPC \\
\hline $\begin{array}{l}\text { Alcocer, L., Meaney, E., \& Hernandez-Hernandez, H. (2015). Applicability of the current hypertension guidelines in Latin America. Therapeutic } \\
\text { Advances in Cardiovascular Disease, 9(4), 118-126. https://doi.org/10.1177/1753944715586172 }\end{array}$ & não é um GPC \\
\hline $\begin{array}{l}\text { Alonso Moreno, F. J. (2013, March). [New indications and recommendations in the antihypertensive treatment]. Semergen. Spain. } \\
\text { https://doi.org/10.1016/j.semerg.2012.12.003 }\end{array}$ & não é um GPC \\
\hline $\begin{array}{l}\text { Anderson, C., Arnolda, L., Cowley, D., Dowden, J., Gabb, G., Golledge, J., ... Branagan, M. (2016). National Heart Foundation hypertension } \\
\text { guideline-2016. Heart Lung and Circulation, 25, S18. Retrieved from } \\
\text { http://www.embase.com/search/results?subaction=viewrecord\&from=export\&id=L612750315 }\end{array}$ & não é um GPC \\
\hline $\begin{array}{l}\text { Angeli, F., Reboldi, G., \& Verdecchia, P. (2015). The } 2014 \text { hypertension guidelines: Implications for patients and practitioners in Asia. Heart Asia, } \\
\text { 7(2), 21-25. Retrieved from http://www.embase.com/search/results?subaction=viewrecord\&from=export\&id=L611512890 }\end{array}$ & não é um GPC \\
\hline Araki, S., \& Maegawa, H. (2015). [Hypertension and diabetes mellitus]. Nihon rinsho. Japanese journal of clinical medicine, 73(11), 1885-1890. & não é um GPC \\
\hline $\begin{array}{l}\text { Arden, C. (2014). The ESH/ESC guidelines for the management of arterial hypertension. Primary Care Cardiovascular Journal, 7(2), 85-88. } \\
\text { Retrieved from http://www.embase.com/search/results?subaction=viewrecord\&from=export\&id=L373398920 }\end{array}$ & não é um GPC \\
\hline Armstrong, C. (2014). JNC8 guidelines for the management of hypertension in adults. American Family Physician, 90(7), 503-504. & não é um GPC \\
\hline $\begin{array}{l}\text { Aronow, W. S. (2011, September). Hypertension guidelines. Hypertension (Dallas, Tex. : 1979). United States. } \\
\text { https://doi.org/10.1161/HYPERTENSIONAHA.111.177147 }\end{array}$ & não é um GPC \\
\hline Aronow, W. S. (2014). Eighth Joint National Committee guidelines. Future Cardiology, 10(4), 461-463. https://doi.org/10.2 & não é um GPC \\
\hline $\begin{array}{l}\text { Aronow, W. S. (2014). Ten key points from the American College of Cardiology Foundation/American Heart Association } 2011 \text { expert cc } \\
\text { document on hypertension in the elderly. American Journal of Therapeutics, 21(5), 436-437. Retrieved from } \\
\text { http://www.embase.com/search/results?subaction=viewrecord\&from=export\&id=L600642416 }\end{array}$ & não é um GPC \\
\hline
\end{tabular}


Apêndice 2- Documentos excluídos após aplicação dos critérios de elegibilidade.

\begin{tabular}{|c|c|}
\hline $\begin{array}{l}\text { Aronow, W. S. (2015). Treatment of hypertension in persons with coronary artery disease: What the guidelines recommend. Consultant, 55(10). } \\
\text { Retrieved from http://www.embase.com/search/results?subaction=viewrecord\&from=export\&id=L606909810 }\end{array}$ & não é um GPC \\
\hline $\begin{array}{l}\text { Aronow, W. S. (2016). Current treatment of hypertension in patients with coronary artery disease recommended by different guidelines. Expert } \\
\text { Opinion on Pharmacotherapy, 17(2), 205-215. https://doi.org/10.1517/14656566.2015.1091881 }\end{array}$ & não é um GPC \\
\hline $\begin{array}{l}\text { Aronow, W. S., Fleg, J. L., Pepine, C. J., Artinian, N. T., Bakris, G., Brown, A. S., ... Wesley, D. J. (2011). ACCF/AHA } 2011 \text { expert consensus } \\
\text { document on hypertension in the elderly: a report of the American College of Cardiology Foundation Task Force on Clinical Expert Consensus } \\
\text { Documents developed in collaboration with the American Academy of Neurology, America. Journal of the American Society of Hypertension: JASH, } \\
5 \text { (4), 259-352. https://doi.org/10.1016/i.jash.2011.06.001 }\end{array}$ & não é um GPC \\
\hline $\begin{array}{l}\text { Banach, M., \& Aronow, W. S. (2011). Should we have any doubts about hypertension therapy in elderly patients?: ACCF/AHA } 2011 \text { expert consensus } \\
\text { document on hypertension in the elderly. Polskie Archiwum Medycyny Wewnetrznej, 121(7-8), 253-258. }\end{array}$ & não é um GPC \\
\hline $\begin{array}{l}\text { Banach, M., \& Aronow, W. S. (2012). Hypertension therapy in the older adults-do we know the answers to all the questions? The status after } \\
\text { publication of the ACCF/AHA 2011 expert consensus document on hypertension in the elderly. Journal of Human Hypertension, 26(11), 641-643. } \\
\text { https://doi.org/10.1038/ihh.2012.3 }\end{array}$ & não é um GPC \\
\hline $\begin{array}{l}\text { Bangalore, S., Gong, Y., Cooper-Dehoff, R. M., Pepine, C. J., \& Messerli, F. H. (2014). } 2014 \text { eighth joint national committee panel recommendation } \\
\text { for blood pressure targets revisited: Results from the invest tudy. Journal of the American College of Cardiology, 64(8), 784-793. Retrieved from } \\
\text { http://www.embase.com/search/results?subaction=viewrecord\&from=export\&id=L373796374 }\end{array}$ & não é um GPC \\
\hline $\begin{array}{l}\text { Barcin, C. (2014, January). [What has changed with the new European Society of Cardiology/European Society of Hypertension guideline?]. Turk } \\
\text { Kardiyoloji Dernegi arsivi : Turk Kardiyoloji Derneginin yayin organidir. Turkey. }\end{array}$ & não é um GPC \\
\hline $\begin{array}{l}\text { Bauchner, H., Fontanarosa, P. B., \& Golub, R. M. (2014). Updated guidelines for management of high blood pressure recommendations, review, and } \\
\text { responsibility. JAMA - Journal of the American Medical Association, 311(5), 477-478. Retrieved from } \\
\text { http://www.embase.com/search/results?subaction=viewrecord\&from=export\&id=L372303290 }\end{array}$ & não é um GPC \\
\hline $\begin{array}{l}\text { Benetos, A., Bulpitt, C. J., Petrovic, M., Ungar, A., Agabiti Rosei, E., Cherubini, A., ... Mancia, G. (2016, May). An Expert Opinion From the European } \\
\text { Society of Hypertension-European Union Geriatric Medicine Society Working Group on the Management of Hypertension in Very Old, Frail Subjects. } \\
\text { Hypertension (Dallas, Tex. : 1979). United States. https://doi.org/10.1161/HYPERTENSIONAHA.115.07020 }\end{array}$ & não é um GPC \\
\hline $\begin{array}{l}\text { Benetos, A., Rossignol, P., Cherubini, A., Joly, L., Grodzicki, T., Rajkumar, C., ... Petrovic, M. (2015). Polypharmacy in the Aging Patient: } \\
\text { Management of Hypertension in Octogenarians. JAMA, 314(2), 170-180. https://doi.org/10.1001/jama.2015.7517 }\end{array}$ & não é um GPC \\
\hline $\begin{array}{l}\text { Blacher, J., Halimi, J.-M., Hanon, O., Mourad, J.-J., Pathak, A., Schnebert, B., \& Girerd, X. (2013). [Management of arterial hypertension in adults: } \\
2013 \text { guidelines of the French Society of Arterial Hypertension]. Presse medicale (Paris, France : 1983), 42(5), 819-825. } \\
\text { https://doi.org/10.1016/.l.pm.2013.01.022 }\end{array}$ & não é um GPC \\
\hline Bonner, G. (2013). [Hypertension new guidelines--new strategies?]. MMW Fortschritte der Medizin, 155(21-22), 45-47. & não é um GPC \\
\hline $\begin{array}{l}\text { Burgner, A., \& Lewis, J. B. (2014). Hypertension: Is it time to reconsider blood pressure guidelines? Nature Reviews Nephrology, 10(11), 620-621. } \\
\text { Retrieved from http://www.embase.com/search/results?subaction=viewrecord\&from=export\&id=L600219697 }\end{array}$ & não é um GPC \\
\hline $\begin{array}{l}\text { Campbell, N., Young, E. R., Drouin, D., Legowski, B., Adams, M. A., Farrell, J., .. Tobe, S. (2012). A framework for discussion on how to improve } \\
\text { prevention, management, and control of hypertension in Canada. The Canadian Journal of Cardiology, 28(3), 262-269. } \\
\text { https://doi.org/10.1016/i.cica.2011.11.008 }\end{array}$ & não é um GPC \\
\hline
\end{tabular}


Apêndice 2- Documentos excluídos após aplicação dos critérios de elegibilidade.

\begin{tabular}{|c|c|}
\hline $\begin{array}{l}\text { Castilla-Guerra, L., \& Fernandez-Moreno, M. D. C. (2012). Update on the management of hypertension for secondary stroke prevention. European } \\
\text { Neurology, 68(1), 1-7. https://doi.org/10.1159/000336836 }\end{array}$ & não é um GPC \\
\hline $\begin{array}{l}\text { Chalkidou, K., Lord, J., Obeidat, N. A., Alabbadi, I. A., Stanley, A. G., Bader, R., ... Cutler, D. (2011). Piloting the development of a cost-effective } \\
\text { evidence-informed clinical pathway: Managing hypertension in Jordanian primary care. International Journal of Technology Assesssment in Health } \\
\text { Care, } 27(2), 151-158 \text {. Retrieved from http://www.embase.com/search/results?subaction=viewrecord\&from=export\&id=L362858381 }\end{array}$ & não é um GPC \\
\hline $\begin{array}{l}\text { Chalmers, J., Arima, H., Harrap, S., Touyz, R. M., \& Park, J. B. (2013). Global survey of current practice in management of hypertension as reported } \\
\text { by societies affiliated with the international society of hypertension. Journal of Hypertension, 31(5), 1043-1048. Retrieved from } \\
\text { http://www.embase.com/search/results?subaction=viewrecord\&from=export\&id=L52456596 }\end{array}$ & não é um GPC \\
\hline $\begin{array}{l}\text { Chan, S. S.-W., Graham, C. A., \& Rainer, T. H. (2012, January). First-line treatment for hypertension. Journal of Clinical Hypertension (Greenwich, } \\
\text { Conn.). United States. https://doi.org/10.1111/j.1751-7176.2011.00557.x }\end{array}$ & não é um GPC \\
\hline Cheung TT, Cheung BM-Y (2012) New NICE guideline on the treatment of hypertension. J Hong Kong Coll Cardiol 20:15-20 & não é um GPC \\
\hline $\begin{array}{l}\text { Cloutier, L. (2015). [Canadian arterial hypertension recommendations: two significant changes for nurses]. Perspective infirmiere : revue officielle de } \\
\text { l'Ordre des infirmieres et infirmiers du Quebec, 12(5), 11-12. }\end{array}$ & não é um GPC \\
\hline $\begin{array}{l}\text { Cloutier, L., Daskalopoulou, S. S., Padwal, R. S., Lamarre-Cliche, M., Bolli, P., McLean, D., ... Gelfer, M. (2015). A New Algorithm for the Diagnosis } \\
\text { of Hypertension in Canada. The Canadian Journal of Cardiology, 31(5), 620-630. https://doi.org/10.1016/j.cjca.2015.02.014 }\end{array}$ & não é um GPC \\
\hline $\begin{array}{l}\text { Comments on the ESC/ESH guidelines for the management of arterial hypertension 2013. A report of the Task Force of the Clinical Practice } \\
\text { Guidelines Committee of the Spanish Society of Cardiology. (2013). Revista Espanola de Cardiologia (English Ed.), 66(11), 842-847. } \\
\text { https://doi.org/10.1016//.rec.2013.08.003 }\end{array}$ & não é um GPC \\
\hline $\begin{array}{l}\text { Cryer, M. J., Horani, T., \& DiPette, D. J. (2016). Diabetes and Hypertension: A Comparative Review of Current Guidelines. Journal of Clinical } \\
\text { Hypertension (Greenwich, Conn.), 18(2), 95-100. https://doi.org/10.1111/jch.12638 }\end{array}$ & não é um GPC \\
\hline $\begin{array}{l}\text { Cundiff, D. K., Gueyffier, F., \& Wright, J. M. (2014). Guidelines for managing high blood pressure. JAMA - Journal of the American Medical } \\
\text { Association, 312(3), 294. Retrieved from http://www.embase.com/search/results?subaction=viewrecord\&from=export\&id=L373524097 }\end{array}$ & não é um GPC \\
\hline $\begin{array}{l}\text { Dasgupta, K., Padwal, R., Poirier, L., Quinn, R. R., Bacon, S., Feldman, R. D., ... Zarnke, K. (2015). Managing hypertension: evidence supporting the } \\
2013 / 2014 \text { recommendations of the Canadian Hypertension Education Program. CMAJ: Canadian Medical Association Journal = Journal de } \\
\text { l'Association Medicale Canadienne, } 187(2), 116-119 . \text { https://doi.org/10.1503/cmaj.131440 }\end{array}$ & não é um GPC \\
\hline $\begin{array}{l}\text { Davis, L. L. (2015). Hypertension guidelines: Evidence-based treatments for maintaining blood pressure control. The Nurse Practitioner, 40(6), 32-38. } \\
\text { https://doi.org/10.1097/01.NPR.0000465116.19783.a7 }\end{array}$ & não é um GPC \\
\hline $\begin{array}{l}\text { De Nicola, L., Borrelli, S., Chiodini, P., Zamboli, P., lodice, C., Gabbai, F. B., ... Minutolo, R. (2011). Hypertension management in chronic kidney } \\
\text { disease: translating guidelines into daily practice. Journal of Nephrology, 24(6), 733-741. https://doi.org/10.5301/JN.2011.6335 }\end{array}$ & não é um GPC \\
\hline $\begin{array}{l}\text { Dennison Himmelfarb, C. R., \& Hayman, L. L. (2014). Recent blood pressure guidelines: making sense of the controversy. The Journal of } \\
\text { Cardiovascular Nursing, 29(4), 285-287. https://doi.org/10.1097/JCN.0000000000000167 }\end{array}$ & não é um GPC \\
\hline $\begin{array}{l}\text { Derer, W. (2013). The new European guidelines for the treatment of arterial hypertension. Diabetes, Stoffwechse/ Und Herz, 22(5), 319-320. } \\
\text { Retrieved from http://www.embase.com/search/results?subaction=viewrecord\&from=export\&id=L370127080 }\end{array}$ & não é um GPC \\
\hline Derer, W., Dechend, R., \& Baberg, H. (2014). Tr & não é um GPC \\
\hline
\end{tabular}


Apêndice 2- Documentos excluídos após aplicação dos critérios de elegibilidade.

\begin{tabular}{|c|c|}
\hline $\begin{array}{l}\text { Duarte, J. H. (2015). Hypertension: Cost-effectiveness of } 2014 \text { guidelines. Nature Reviews. Cardiology, 12(4), } 194 . \\
\text { https://doi.org/10.1038/nrcardio.2015.18 }\end{array}$ & não é um GPC \\
\hline $\begin{array}{l}\text { Dusing, R. (2011). [On the value of diuretics for hypertension treatment]. Deutsche medizinische Wochenschrift (1946), 136(46), 2378-2381. } \\
\text { https://doi.org/10.1055/s-0031-1292057 }\end{array}$ & não é um GPC \\
\hline $\begin{array}{l}\text { Dzudie, A., Ojji, D., Anisiuba, B. C., Abdou, B. A., Cornick, R., Damasceno, A., ... Mayosi, B. (2015). Development of the roadmap and guidelines for } \\
\text { the prevention and management of high blood pressure in Africa: Proceedings of the PASCAR Hypertension Task Force meeting: Nairobi, Kenya, } 27 \\
\text { October 2014. Cardiovascular Journal of Africa. South Africa. }\end{array}$ & não é um GPC \\
\hline $\begin{array}{l}\text { Egan, B. M., Bland, V. J., Brown, A. L., Ferdinand, K. C., Hernandez, G. T., Jamerson, K. A., ... Saunders, E. (2015). Hypertension in african } \\
\text { americans aged } 60 \text { to } 79 \text { years: statement from the international society of hypertension in blacks. Journal of Clinical Hypertension (Greenwich, } \\
\text { Conn.), 17(4), 252-259. https://doi.org/10.1111/jch.12511 }\end{array}$ & não é um GPC \\
\hline $\begin{array}{l}\text { Elliott, W. J. (2015). Treatment: drug therapy of hypertension. Journal of the American Society of Hypertension : JASH, 9(3), 233-239. } \\
\text { https://doi.org/10.1016/j.jash.2015.01.006 }\end{array}$ & não é um GPC \\
\hline $\begin{array}{l}\text { Epstein, B. J., Shah, N. K., \& Borja-Hart, N. L. (2013). Management of hypertension with fixed-dose triple-combination treatments. Therapeutic } \\
\text { Advances in Cardiovascular Disease, 7(5), 246-259. https://doi.org/10.1177/1753944713498638 }\end{array}$ & não é um GPC \\
\hline Faqah, A., \& Jafar, T. H. (2011). Control of blood pressure in chronic kidney disease: how low to go? Nephron. Clinical Practice, 119(4), c324-31-2. & não é um GPC \\
\hline $\begin{array}{l}\text { Farooq, U., \& Ray, S. G. (2015). } 2014 \text { Guideline for the Management of High Blood Pressure (Eighth Joint National Committee): Take-Home } \\
\text { Messages. The Medical Clinics of North America, 99(4), 733-738. https://doi.org/10.1016/j.mcna.2015.02.004 }\end{array}$ & não é um GPC \\
\hline $\begin{array}{l}\text { Ferdinand, K. C., \& Patterson, K. P. (2011). The } 2010 \text { international society of hypertension in blacks consensus statement-is there a role for opinion } \\
\text { in guidelines or consensus reports? A review. US Cardiology, 8(2), 118-122. Retrieved from } \\
\text { http://www.embase.com/search/results?subaction=viewrecord\&from=export\&id=L364163352 }\end{array}$ & não é um GPC \\
\hline $\begin{array}{l}\text { Filipová, S., Dukát, A., \& Škultétyová, D. (2014). What is the benefit of new guidelines for the diagnosis and therapy of hypertension? Comment on } \\
2013 \text { ESH/ESC guidelines for the management of arterial hypertension. Cardiology Letters, 23(1), 5-9. Retrieved from } \\
\text { http://www.embase.com/search/results?subaction=viewrecord\&from=export\&id=L372871156 }\end{array}$ & não é um GPC \\
\hline $\begin{array}{l}\text { Filipovský J, Widimský J, Špinar J (2014) Summary of } 2013 \text { ESH/ESC guidelines for the management of arterial hypertension prepared by the Czech } \\
\text { society of hypertension/Czech society of cardiology. Cor Vasa 56:e494--e518 }\end{array}$ & não é um GPC \\
\hline $\begin{array}{l}\text { Fitzgerald, M. A. (2011). Hypertension treatment update: focus on direct renin inhibition. Journal of the American Academy of Nurse Practitioners, } \\
\text { 23(5), 239-248. https://doi.org/10.1111/j.1745-7599.2010.00589.x }\end{array}$ & não é um GPC \\
\hline $\begin{array}{l}\text { Fomin, V. V, \& Svistunov, A. A. (2014). [Full-dose combinations of antihypertensive drugs: what has changed in experts' guidelines?]. } \\
\text { Terapevticheskii arkhiv, } 86(10), 124-127 .\end{array}$ & não é um GPC \\
\hline $\begin{array}{l}\text { Fontenla, A., Garcia-Donaire, J. A., Hernandez, F., Segura, J., Salgado, R., Cerezo, C., ... Arribas, F. (2013). Management of resistant hypertension } \\
\text { in a multidisciplinary unit of renal denervation: protocol and results. Revista Espanola de Cardiologia (English Ed.), 66(5), 364-370. } \\
\text { https://doi.org/10.1016/j.rec.2012.09.006 }\end{array}$ & não é um GPC \\
\hline Franklin, S. S. (2012, January). What can we learn from the American Heart Association and American College of Cardiology expert con & não é um GPC \\
\hline
\end{tabular}


Apêndice 2- Documentos excluídos após aplicação dos critérios de elegibilidade.

\begin{tabular}{|c|c|}
\hline $\begin{array}{l}\text { Frieden, T. R., King, S. M. C., \& Wright, J. S. (2014). Protocol-based treatment of hypertension: a critical step on the pathway to progress. JAMA, } \\
311(1), 21-22 \text {. https://doi.org/10.1001/jama.2013.282615 }\end{array}$ & não é um GPC \\
\hline $\begin{array}{l}\text { Furberg, C. D., \& Alderman, M. H. (2014, December). JNC 8: shortcomings in process and treatment recommendations. American Journal of } \\
\text { Hypertension. United States. https://doi.org/10.1093/ajh/hpu158 }\end{array}$ & não é um GPC \\
\hline $\begin{array}{l}\text { Gelatic, R. (2014). The } 2014 \text { hypertension guidelines: processing the information. JAAPA : Official Journal of the American Academy of Physician } \\
\text { Assistants, } 27(11), 15-17 . \mathrm{https} / / / \text { doi.org/10.1097/01.JAA.0000455652.34919.4c }\end{array}$ & não é um GPC \\
\hline $\begin{array}{l}\text { Gelfer, M., Dawes, M., Kaczorowski, J., Padwal, R., \& Cloutier, L. (2015). Diagnosing hypertension: Evidence supporting the } 2015 \text { recommendations } \\
\text { of the Canadian Hypertension Education Program. Canadian Family Physician Medecin de Famille Canadien, 61(11), 957-961. }\end{array}$ & não é um GPC \\
\hline $\begin{array}{l}\text { Girerd, X., \& Danchin, N. (2013, June). [High blood pressure in France: change is coming now]. Annales de cardiologie et d'angeiologie. France. } \\
\text { https://doi.org/10.1016/j.ancard.2013.06.001 }\end{array}$ & não é um GPC \\
\hline $\begin{array}{l}\text { Go, A. S., Bauman, M. A., Coleman King, S. M., Fonarow, G. C., Lawrence, W., Williams, K. A., \& Sanchez, E. (2014). An effective approach to high } \\
\text { blood pressure control: a science advisory from the American Heart Association, the American College of Cardiology, and the Centers for Disease } \\
\text { Control and Prevention. Journal of the American College of Cardiology, 63(12), 1230-1238. https://doi.org/10.1016/j.jacc.2013.11.007 }\end{array}$ & não é um GPC \\
\hline $\begin{array}{l}\text { Godlee, F. (2012). Controversies over hypertension guidelines. BMJ (Online), 344(7841). Retrieved from } \\
\text { http://www.embase.com/search/results?subaction=viewrecord\&from=export\&id=L364154051 }\end{array}$ & não é um GPC \\
\hline $\begin{array}{l}\text { Gorostidi, M., \& de la Sierra, A. (2011, June). [Management of hypertension in the very old]. Medicina clinica. Spain. } \\
\text { https://doi.org/10.1016/j.medcli.2011.01.006 }\end{array}$ & não é um GPC \\
\hline $\begin{array}{l}\text { Grassi, G., Seravalle, G., Trevano, F. Q., Dell'Oro, R., \& Mancia, G. (2012). Blood pressure control and antihypertensive treatment. Current Vascular } \\
\text { Pharmacology, 10(4), 506-511. }\end{array}$ & não é um GPC \\
\hline $\begin{array}{l}\text { Grezzana, G. B., Stein, A. T., \& Pellanda, L. C. (2013, October). Impact on Hypertension Reclassification by Ambulatory Blood Pressure Monitoring } \\
\text { (ABPM) according to the V Brazilian Guidelines on ABPM. Arquivos Brasileiros de Cardiologia. Brazil. https://doi.org/10.5935/abc.20130197 }\end{array}$ & não é um GPC \\
\hline $\begin{array}{l}\text { Gulec, S. (2014, May). Diagnosis and treatment of stage } 1 \text { hypertension: which guidelines should we follow? Journal of the American Society of } \\
\text { Hypertension: JASH. United States. https://doi.org/10.1016/j.jash.2014.02.005 }\end{array}$ & não é um GPC \\
\hline $\begin{array}{l}\text { Guo, Y., \& Hu, D. (2014, April). [The interpretation of } 2014 \text { evidence-based guidelines for the management of high blood pressure in adults]. } \\
\text { Zhonghua nei ke za zhi. China. }\end{array}$ & não é um GPC \\
\hline $\begin{array}{l}\text { Guzman, N. J. (2012). Epidemiology and management of hypertension in the Hispanic population: a review of the available literature. American } \\
\text { Journal of Cardiovascular Drugs: Drugs, Devices, and Other Interventions, } 12(3), 165-178 \text {. https://doi.org/10.2165/11631520-000000000-00000 }\end{array}$ & não é um GPC \\
\hline $\begin{array}{l}\text { Halimi, J.-M. (2013, September). [ESH/ESC and French guidelines for the management of hypertension: Similarities and discrepancies]. Presse } \\
\text { medicale (Paris, France: 1983). France. https://doi.org/10.1016/j.lpm.2013.08.001 }\end{array}$ & não é um GPC \\
\hline $\begin{array}{l}\text { Halimi, J.-M. (2014). [Blood pressure control in patient with chronic kidney disease]. Annales de cardiologie et d'angeiologie, 63(3), 209-212. } \\
\text { https://doi.org/10.1016/j.ancard.2014.05.009 }\end{array}$ & não é um GPC \\
\hline $\begin{array}{l}\text { Halimi, J.-M. (2015, January). [Hypertension: the real challenge is to better care]. Presse medicale (Paris, France : 1983). France. } \\
\text { https://doi.org/10.1016/j.Ipm.2014.12.003 }\end{array}$ & não é um GPC \\
\hline Hasebe, N. (2015). [Hypertension]. Nihon rinsho. Japanese journal of clinical medicine, 73(4), 611-616. & não é um GPC \\
\hline
\end{tabular}


Apêndice 2- Documentos excluídos após aplicação dos critérios de elegibilidade.

\begin{tabular}{|c|c|}
\hline $\begin{array}{l}\text { Hayes, W. (2013). } 2013 \text { American Diabetes Association update: treatment of hypertension in patients with diabetes. South Dakota Medicine : The } \\
\text { Journal of the South Dakota State Medical Association, } 66(6), 236-237 .\end{array}$ & não é um GPC \\
\hline $\begin{array}{l}\text { Hedner, T., Kjeldsen, S. E., \& Narkiewicz, K. (2013, September). Combination treatment in hypertension - the latest } 2013 \text { European Guidelines. Blood } \\
\text { Pressure. England. https://doi.org/10.3109/08037051.2013.826471 }\end{array}$ & não é um GPC \\
\hline $\begin{array}{l}\text { Heine, C. H., \& Köhler, H. (2015). Update on guideline-based management of arterial hypertension. Arzneimitteltherapie, 33(7-8), 223-230. } \\
\text { Retrieved from http://www.embase.com/search/results?subaction=viewrecord\&from=export\&id=L605457543 }\end{array}$ & não é um GPC \\
\hline $\begin{array}{l}\text { Hernandez-Vila, E., \& Hernandez-, E. (2015). A review of the jnc } 8 \text { blood pressure guideline. Texas Heart Institute Journal, 42(3), 226-228. } \\
\text { https://doi.org/10.14503/THIJ-15-5067 }\end{array}$ & não é um GPC \\
\hline $\begin{array}{l}\text { Higaki, J., Tsuchihashi, T., Ura, N., Miyakawa, M., \& Kukida, M. (2011). [Discussion meeting on optimization of antihypertensive treatment in the } \\
\text { JSH2009 era]. Nihon Naika Gakkai zasshi. The Journal of the Japanese Society of Internal Medicine, 100(2), 453-470. }\end{array}$ & não é um GPC \\
\hline Holmstrom, A., \& Broman, C. (2015, February). [Large differences in blood pressure treatment in diabetes]. Lakartidningen. Sweden. & não é um GPC \\
\hline $\begin{array}{l}\text { Hunter, A., Holdsworth, D. A., D'Arcy, J., Bailey, K., \& Casadei, B. (2015). Hypertension in the military patient. Journal of the Royal Army Medical } \\
\text { Corps, 161(3), 200-205. https://doi.org/10.1136/iramc-2015-000506 }\end{array}$ & não é um GPC \\
\hline $\begin{array}{l}\text { Hypertension: Guidelines recommend fixed combinations. (2014). MMW-Fortschritte Der Medizin, 156(7), 62-63. Retrieved from } \\
\text { http://www.embase.com/search/results?subaction=viewrecord\&from=export\&id=L373005605 }\end{array}$ & não é um GPC \\
\hline $\begin{array}{l}\text { Imaizumi, Y., Eguchi, K., \& Kario, K. (2016). [Diabetes mellitus with hypertension]. Nihon rinsho. Japanese journal of clinical medicine, } 74 \text { Suppl } 2 \text {, } \\
\text { 375-379. }\end{array}$ & não é um GPC \\
\hline $\begin{array}{l}\text { Ishimitsu, T. (2011). [Basic strategy of antihypertensive therapy indicated by JSH2009 guidelines]. Nihon Naika Gakkai zasshi. The Journal of the } \\
\text { Japanese Society of Internal Medicine, } 100(2), 367-375 .\end{array}$ & não é um GPC \\
\hline $\begin{array}{l}\text { Ishimitsu, T., Ishikawa, Y., \& Honda, T. (2015). [Hypertension: The Points of Management of Hypertension for All Physicians--Based on the JSH } 2014 \\
\text { Hypertension Guidelines--.Topics; III. Key points of antihypertensive treatment-life-style modification and drug therapy]. Nihon Naika Gakkai zasshi. } \\
\text { The Journal of the Japanese Society of Internal Medicine, } 104(2), 218-231 .\end{array}$ & não é um GPC \\
\hline $\begin{array}{l}\text { Izzo, J. L., \& Zion, A. S. (2011). Combined aliskiren-amlodipine treatment for hypertension in African Americans: clinical science and management } \\
\text { issues. Therapeutic Advances in Cardiovascular Disease, 5(3), 169-178. https://doi.org/10.1177/1753944711409615 }\end{array}$ & não é um GPC \\
\hline $\begin{array}{l}\text { James, P. A., Oparil, S., Carter, B. L., Cushman, W. C., Dennison-Himmelfarb, C., Handler, J., ... Ortiz, E. (2014). } 2014 \text { evidence-based guideline for } \\
\text { the management of high blood pressure in adults: report from the panel members appointed to the Eighth Joint National Committee (JNC 8). JAMA, } \\
\text { 311(5), 507-520. https://doi.org/10.1001/jama.2013.284427 }\end{array}$ & não é um GPC \\
\hline $\begin{array}{l}\text { Jennings, G. L. R. (2015, November). A New Guideline on Treatment of Hypertension in Those with Coronary Artery Disease: Scientific Statement } \\
\text { From the American Heart Association, American College of Cardiology, and American Society of Hypertension About Treatment of Hypertension in } \\
\text { Patients. Heart, Lung \& Circulation. Australia. https://doi.org/10.1016/j.hlc.2015.05.022 }\end{array}$ & não é um GPC \\
\hline $\begin{array}{l}\text { Jennings, G. L. R. (2016). Relieving the pressure: New Australian hypertension guideline. Medical Journal of Australia, 205(2), 63-64. Retrieved from } \\
\text { http://www.embase.com/search/results?subaction=viewrecord\&from=export\&id=L611301664 }\end{array}$ & não é um GPC \\
\hline Jin, J. (2014). New guideline for treatment of high blood pressure in adults. JAMA - Journal of the American Medica & não é um GPC \\
\hline
\end{tabular}


Apêndice 2- Documentos excluídos após aplicação dos critérios de elegibilidade.

\begin{tabular}{|c|c|}
\hline $\begin{array}{l}\text { Kai, H. (2015). [Hypertension: The Points of Management of Hypertensions--Based on the JSH } 2014 \text { Hypertension Guidelines--. Topics: IV. } \\
\text { Treatment for hypertension associated with cerebrovascular disease/heart disease]. Nihon Naika Gakkai zasshi. The Journal of the Japanese Society } \\
\text { of Internal Medicine, } 104(2), 232-239 .\end{array}$ & não é um GPC \\
\hline $\begin{array}{l}\text { Kaitanidis, K., Doumas, M., Tziomalos, K., \& Athyros, V. G. (2014). Hypertension guidelines: The } 2014 \text { joint national committee } 8 \text { vs all the rest. we } \\
\text { can do better. Open Hypertension Journal, 6(1), 35-36. Retrieved from } \\
\text { http://www.embase.com/search/results?subaction=viewrecord\&from=export\&id=L604498326 }\end{array}$ & não é um GPC \\
\hline Kario, K. (2015). Key points of the Japanese society of hypertension guidelines for the management of hypertension in 2014. Pulse, 3(1), 35-47. & não é um GPC \\
\hline Karpov, I. A. (2012). [New guidelines for hypertension in Russia--a priority of combined treatment]. Terapevticheskii arkhiv, 84(1), 61-64. & não é um GPC \\
\hline $\begin{array}{l}\text { Kawano, Y. (2015). [Hypertension: The Points of Management of Hypertension for all Physicians--Based on the JSH } 2014 \text { Hypertension Guidelines--. } \\
\text { Topics: VIII. Diagnosis and treatment of secondary hypertension and resistant hypertension]. Nihon Naika Gakkai zasshi. The Journal of the } \\
\text { Japanese Society of Internal Medicine, } 104(2), 260-267 .\end{array}$ & não é um GPC \\
\hline $\begin{array}{l}\text { Kenerson, J. G. (2014). Hypertension in Haiti: the challenge of best possible practice. Journal of Clinical Hypertension (Greenwich, Conn.), 16(2), } \\
\text { 107-114. https://doi.org/10.1111/jch.12242 }\end{array}$ & não é um GPC \\
\hline $\begin{array}{l}\text { Kithas, P. A., \& Supiano, M. A. (2015). Hypertension in the geriatric population: a patient-centered approach. The Medical Clinics of North America, } \\
\text { 99(2), 379-389. https://doi.org/10.1016/j.mcna.2014.11.009 }\end{array}$ & não é um GPC \\
\hline $\begin{array}{l}\text { Kjeldsen, S. E., Narkiewicz, K., Oparil, S., \& Hedner, T. (2013). } 2013 \text { European society of hypertension/European society of cardiology hypertension } \\
\text { guidelines. Blood Pressure, 22(4), 191-192. Retrieved from } \\
\text { http://www.embase.com/search/results?subaction=viewrecord\&from=export\&id=L369341355 }\end{array}$ & não é um GPC \\
\hline $\begin{array}{l}\text { Kjeldsen, S. E., Narkiewicz, K., Oparil, S., \& Hedner, T. (2014). Hypertension Management by Practice Guidelines. Blood Pressure, 23(1), 1-2. } \\
\text { Retrieved from http://www.embase.com/search/results?subaction=viewrecord\&from=export\&id=L372468766 }\end{array}$ & não é um GPC \\
\hline $\begin{array}{l}\text { Klein, W. S., Merz, C. N. B., \& Jenkins, M. R. (2014). Guidelines for managing high blood pressure. JAMA - Journal of the American Medical } \\
\text { Association, 312(3), 294-295. Retrieved from http://www.embase.com/search/results?subaction=viewrecord\&from=export\&id=L373524098 }\end{array}$ & não é um GPC \\
\hline $\begin{array}{l}\text { Kmietowicz, Z. (2015, November). Western blood pressure guidelines may not be appropriate for Asian populations, experts say. BMJ (Clinical } \\
\text { Research Ed.). England. }\end{array}$ & não é um GPC \\
\hline Kobalava, Z. D., \& Kotovskaia, I. V. (2013). [European Guidelines on Hypertension in 2013: unchanging, new, unsolved]. Kardiologiia, 53(12), 83-95. & não é um GPC \\
\hline $\begin{array}{l}\text { Kostka-Jeziorny, K., Świejkowska, K., \& Tykarski, A. (2011). Comparison between British (NICE) and Polish (PTNT) guidelines regarding } \\
\text { management of hypertension in adults. Nadcisnienie Tetnicze, 15(6), 329-334. }\end{array}$ & não é um GPC \\
\hline Kountz, D. S. (2013). Hypertension in black patients: an update. Postgraduate Medicine, 125(3), 127-135. https://doi.org/10.3810/pgm.2013.0 & não é um GPC \\
\hline $\begin{array}{l}\text { Kovell, L. C., Ahmed, H. M., Misra, S., Whelton, S. P., Prokopowicz, G. P., Blumenthal, R. S., \& McEvoy, J. W. (2015). US Hypertension Management } \\
\text { Guidelines: A Review of the Recent Past and Recommendations for the Future. Journal of the American Heart Association, 4(12). } \\
\text { https://doi.org/10.1161/JAHA.115.002315 }\end{array}$ & não é um GPC \\
\hline Koziolova, N. A., \& Shatunova, I. M. (2013). [The strategy, tactical approaches and choice of combination therapy in & não é um GPC \\
\hline
\end{tabular}


Apêndice 2- Documentos excluídos após aplicação dos critérios de elegibilidade.

\begin{tabular}{|c|c|}
\hline Krader, C. G. (2014). JNC 8 uses evidence-based methodology in new guideline on hypertension management. Medical Economics, 91(11), 20. & não é um GPC \\
\hline $\begin{array}{l}\text { Krakoff, L. R., Gillespie, R. L., Ferdinand, K. C., Fergus, I. V, Akinboboye, O., Williams, K. A., ... Pepine, C. J. (2014). 2014 hypertension } \\
\text { recommendations from the eighth joint national committee panel members raise concerns for elderly black and female populations. Journal of the } \\
\text { American College of Cardiology, 64(4), 394-402. https://doi.org/10.1016/j.jacc.2014.06.014 }\end{array}$ & não é um GPC \\
\hline $\begin{array}{l}\text { Lackland, D. T. (2013). How will the growing threat of resistant hypertension impact the future treatment of high blood pressure? Expert Review of } \\
\text { Cardiovascular Therapy, 11(11), 1541-1546. https://doi.org/10.1586/14779072.2013.851002 }\end{array}$ & não é um GPC \\
\hline $\begin{array}{l}\text { Lackland, D. T. (2013). Hypertension: Joint National Committee on Detection, Evaluation, and Treatment of High Blood Pressure guidelines. Current } \\
\text { Opinion in Neurology, 26(1), 8-12. https://doi.org/10.1097/WCO.0b013e32835c4f54 }\end{array}$ & não é um GPC \\
\hline $\begin{array}{l}\text { Lahera Julia, V., Millan Nunez-Cortes, J., \& Vazquez Carrera, M. (2014). [Particularities and new aspects of Latin American guidelines on } \\
\text { hypertension in diabetic patients and with metabolic syndrome]. Clinica e investigacion en arteriosclerosis : publicacion oficial de la } \\
\text { Sociedad Espanola de Arteriosclerosis. Spain. https://doi.org/10.1016/j.arteri.2014.02.001 }\end{array}$ & não é um GPC \\
\hline $\begin{array}{l}\text { Laubscher, T., Regier, L., \& Stone, S. (2014). Hypertension in the elderly: how to treat patients in } 2013 \text { ? The essential recommendations of the Polish } \\
\text { guidelines. Canadian Family Physician Medecin de Famille Canadien, 60(5), 453-456. }\end{array}$ & não é um GPC \\
\hline $\begin{array}{l}\text { Li, S., Kelly, S. C., \& Petrasko, M. (2015). Implementing effective hypertensive management--review of the } 2014 \text { high blood pressure management } \\
\text { guidelines. South Dakota Medicine : The Journal of the South Dakota State Medical Association, Spec No, 33-35. }\end{array}$ & não é um GPC \\
\hline $\begin{array}{l}\text { Liakos, C. I., Grassos, C. A., \& Babalis, D. K. (2015). } 2013 \text { ESH/ESC guidelines for the management of arterial hypertension: what has changed in } \\
\text { daily clinical practice? High Blood Pressure \& Cardiovascular Prevention : The Official Journal of the Italian Society of Hypertension, 22(1), 43-53. } \\
\text { https://doi.org/10.1007/s40292-014-0071-2 }\end{array}$ & não é um GPC \\
\hline $\begin{array}{l}\text { Lindholm, L. H., \& Carlberg, B. (2014). The new Japanese Society of Hypertension guidelines for the management of hypertension (JSH 2014): A } \\
\text { giant undertaking. Hypertension Research, 37(4), 391-392. Retrieved from } \\
\text { http://www.embase.com/search/results?subaction=viewrecord\&from=export\&id=L372784461 }\end{array}$ & não é um GPC \\
\hline $\begin{array}{l}\text { Lonati, C., \& Morganti, A. (2013). Clinical management of renovascular hypertension: practical recommendations from the Italian Society of } \\
\text { Hypertension (SIIA). High Blood Pressure \& Cardiovascular Prevention : The Official Journal of the Italian Society of Hypertension, 20(4), 257-260. } \\
\text { https://doi.org/10.1007/s40292-013-0023-2 }\end{array}$ & não é um GPC \\
\hline $\begin{array}{l}\text { Matunović, R., Samardžić, J., Špirić, Z., Marinković, D., Gudelj, O., Obradović, D., ... Rafajlovski, S. (2011). Pharmacological treatment of stress- } \\
\text { induced hypertension-guidelines and dilemmas. Vojnosanitetski Pregled, 68(12), 1057-1062. }\end{array}$ & não é um GPC \\
\hline McCormack T, Krause T, O'Flynn N (2012) Management of hypertension in adults in primary care: NICE guideline. Br J Gen P & não é um GPC \\
\hline $\begin{array}{l}\text { McManus, R. J., Caulfield, M., \& Williams, B. (2012). NICE hypertension guideline 2011: evidence based evolution. BMJ (Clinical Research Ed.) } \\
\text { e181. }\end{array}$ & não é um GPC \\
\hline Mitchell, A. (2013). [Arterial hypertension and chronic kidney disease]. MMW Fortschritte der Medizin, 155(17), 55-57. & não é um GPC \\
\hline $\begin{array}{l}\text { Mitka, M. (2011, June). New guidance covers ways to prevent and treat hypertension in elderly patients. JAMA. United States. } \\
\text { https://doi.org/10.1001/jama.2011.827 }\end{array}$ & não é um GPC \\
\hline Mitka, M. (2014, February). Groups spar over new hypertension guidelines. JAMA. United States. https://doi.org/10.1001/jam & não é um GPC \\
\hline $\begin{array}{l}\text { Miura, K. (2015). [Hypertension: The Points of Management of Hypertens } \\
\text { Topics: I. Epidemiology of hypertension]. Nihon Naika Gakkai zasshi. The }\end{array}$ & não é um GPC \\
\hline
\end{tabular}


Apêndice 2- Documentos excluídos após aplicação dos critérios de elegibilidade.

\begin{tabular}{|c|c|}
\hline $\begin{array}{l}\text { Musameh, M. D., Tomaszewski, M., \& Williams, B. (2013, April). Hypertension - a clinical update for physicians. Clinical Medicine (London, England). } \\
\text { England. https://doi.org/10.7861/clinmedicine.13-2-182 }\end{array}$ & não é um GPC \\
\hline $\begin{array}{l}\text { Myers, M. G., \& Tobe, S. W. (2014). A Canadian perspective on the Eighth Joint National Committee (JNC 8) hypertension guidelines. Journal of } \\
\text { Clinical Hypertension (Greenwich, Conn.), 16(4), 246-248. https://doi.org/10.1111/jch.12307 }\end{array}$ & não é um GPC \\
\hline $\begin{array}{l}\text { Nagele, M., Sudano, I., Flammer, A., \& Ruschitzka, F. (2015). [New Aspects and Controversies in the Current European and American } \\
\text { Hypertension Guidelines]. Praxis, 104(11), 575-580. https://doi.org/10.1024/1661-8157/a002015 }\end{array}$ & não é um GPC \\
\hline $\begin{array}{l}\text { Neutel, J. M. (2013). Treatment algorithms for hypertension: A practical approach. Clinical Practice, 10(3), 333-344. Retrieved from } \\
\text { http://www.embase.com/search/results?subaction=viewrecord\&from=export\&id=L368867311 }\end{array}$ & não é um GPC \\
\hline New blood pressure guidelines released. (2014, March). Harvard Women's Health Watch. United States. & não é um GPC \\
\hline $\begin{array}{l}\text { New US hypertension guideline. (2014). Drug and Therapeutics Bulletin, 52(3), 27. Retrieved from } \\
\text { http://www.embase.com/search/results?subaction=viewrecord\&from=export\&id=L372602143 }\end{array}$ & não é um GPC \\
\hline $\begin{array}{l}\text { Ogihara, T. (2011). [Characterisitics of Japanese Guidelines for the Management of Hypertension 2009]. Nihon rinsho. Japanese journal of clinical } \\
\text { medicine, } 69(11), 1921-1928 .\end{array}$ & não é um GPC \\
\hline Ohishi, M. (2013). [Blood pressure control in the elderly]. Nihon Ronen Igakkai zasshi. Japanese journal of geriatrics, 50(5), $615-618$. & não é um GPC \\
\hline $\begin{array}{l}\text { Oparil, S. (2014). Update on Clinical Guidelines for Treatment of Hypertension. Current Cardiovascular Risk Reports, 8(11), 1-8. Retrieved from } \\
\text { http://www.embase.com/search/results?subaction=viewrecord\&from=export\&id=L601018111 }\end{array}$ & não é um GPC \\
\hline $\begin{array}{l}\text { Ortiz, E., Oparil, S., James, P. A., Klein, W. S., Merz, C. N. B., Jenkins, M. R., ... Wright, J. M. (2014). Guidelines for managing high blood pressure. } \\
\text { JAMA - Journal of the American Medical Association, 312(3), 295-296. Retrieved from } \\
\text { http://www.embase.com/search/results?subaction=viewrecord\&from=export\&id=L373524097 }\end{array}$ & não é um GPC \\
\hline Ostergren, J. (2012). [Hypertension is a clinical problem ... even though we have tools to solve it]. Lakartidningen, 109(36), 1544-1548. & não é um GPC \\
\hline Page, M. R. (2014, January). The JNC 8 hypertension guidelines: an in-depth guide. The American Journal of Managed Care. United States. & não é um GPC \\
\hline $\begin{array}{l}\text { Palatini, P. (2015). How should we manage a patient with masked hypertension? High Blood Pressure \& Cardiovascular Prevention : The Official } \\
\text { Journal of the Italian Society of Hypertension, 22(1), 11-16. https://doi.org/10.1007/s40292-014-0044-5 }\end{array}$ & não é um GPC \\
\hline $\begin{array}{l}\text { Park, J. B. (2014). Antihypertensive drug therapy: A review based on recent guidelines. Journal of the Korean Medical Association, 57(12), 1034- } \\
\text { 1040. Retrieved from http://www.embase.com/search/results?subaction=viewrecord\&from=export\&id=L601117145 }\end{array}$ & não é um GPC \\
\hline $\begin{array}{l}\text { Park, J. B. (2015). Asian guidelines on hypertension. Pulse, 3(1), 12-13. Retrieved from } \\
\text { http://www.embase.com/search/results?subaction=viewrecord\&from=export\&id=L604529783 }\end{array}$ & não é um GPC \\
\hline $\begin{array}{l}\text { Pearson, T. (2015). Cardiovascular Update: Risk, Guidelines, and Recommendations. Workplace Health \& Safety, 63(9), 376-380. } \\
\text { https://doi.org/10.1177/2165079915593032 }\end{array}$ & não é um GPC \\
\hline $\begin{array}{l}\text { Phillips, R. A. (2015). Current and Future Treatment of Hypertension in the SPRINT Era. Methodist DeBakey Cardiovascular Journal, 11(4), } 206-213 . \\
\text { https://doi.org/10.14797/mdcj-11-4-206 }\end{array}$ & não é um GPC \\
\hline $\begin{array}{l}\text { Poulter, N. R., Prabhakaran, D., \& Caulfield, M. (2015). Hypertension. Lancet (London, England), 386(9995), 801-812. https://doi.org/10.1016/S014 } \\
6736(14) 61468-9\end{array}$ & não é um GPC \\
\hline
\end{tabular}


Apêndice 2- Documentos excluídos após aplicação dos critérios de elegibilidade.

\begin{tabular}{|c|c|}
\hline $\begin{array}{l}\text { Rakugi, H. (2015). [Hypertension: The Points of Management of Hypertension for All Physicians--Based on the JSH } 2014 \text { Hypertension Guidelines--. } \\
\text { Topics: VII. Key points for the management of hypertension in the elderly]. Nihon Naika Gakkai zasshi. The Journal of the Japanese Society of } \\
\text { Internal Medicine, } 104(2), 253-259 \text {. }\end{array}$ & não é um GPC \\
\hline $\begin{array}{l}\text { Rapeport, N., \& Middlemost, S. (2012). Expert report on the 22nd European meeting on hypertension and cardiovascular protection, London, } 26-29 \\
\text { April 2012. Cardiovascular Journal of Africa, 23(4), 232-234. }\end{array}$ & não é um GPC \\
\hline $\begin{array}{l}\text { Redon, J. (2015, July). Different strategies from monotherapies to dual or triple fixed dose combination therapies to achieve blood pressure goals: a } \\
\text { summary of a satellite symposium from the European Society of Hypertension, June 13-16, 2014 Athens, Greece. Introduction. High Blood Pressure } \\
\& \text { Cardiovascular Prevention: The Official Journal of the Italian Society of Hypertension. New Zealand. https://doi.org/10.1007/s40292-015-0095-2 }\end{array}$ & não é um GPC \\
\hline $\begin{array}{l}\text { Reisin, E., Harris, R. C., \& Rahman, M. (2014). Commentary on the } 2014 \text { BP guidelines from the panel appointed to the Eighth Joint National } \\
\text { Committee (JNC 8). Journal of the American Society of Nephrology, 25(11), 2419-2424. Retrieved from } \\
\text { http://www.embase.com/search/results?subaction=viewrecord\&from=export\&id=L602743904 }\end{array}$ & não é um GPC \\
\hline $\begin{array}{l}\text { Ribeiro, J. M. (2014). New hypertension guidelines: a view from Latin America. Journal of Clinical Hypertension (Greenwich, Conn.), 16(4), } 261-262 . \\
\text { https://doi.org/10.1111/jch.12286 }\end{array}$ & não é um GPC \\
\hline $\begin{array}{l}\text { Ripley, T. L., \& Baumert, M. (2016). Controversies Among the Hypertension Guidelines. Journal of Pharmacy Practice, 29(1), 5-14. } \\
\text { https://doi.org/10.1177/0897190015615879 }\end{array}$ & não é um GPC \\
\hline $\begin{array}{l}\text { Ripley, T. L., Brenner, M., Finks, S., Hough, A., McConnell, K. J., Parker, M., \& Dobesh, P. P. (2015). Key articles and guidelines in the management } \\
\text { of hypertension: } 2015 \text { update. Journal of Pharmacy Practice, 28(2), 146-161. https://doi.org/10.1177/0897190014568382 }\end{array}$ & não é um GPC \\
\hline $\begin{array}{l}\text { Ritchie Mackenzie, L. D., Campbell, N. C., Murchie, P., Ritchie, L. D., Campbell, N. C., \& Murchie, P. (2011). New NICE guidelines for hypertension. } \\
\text { BMJ (Online), 343(7822), d5644. Retrieved from http://www.embase.com/search/results?subaction=viewrecord\&from=export\&id=L362533889 }\end{array}$ & não é um GPC \\
\hline $\begin{array}{l}\text { Roca-Cusachs, A. (2012). [Hypertension and health policy in Catalonia, Spain: from theory to practice]. Medicina clinica, 138(15), 678-683. } \\
\text { https://doi.org/10.1016/j.medcli.2011.10.010 }\end{array}$ & não é um GPC \\
\hline $\begin{array}{l}\text { Rodriguez, F., \& Ferdinand, K. C. (2015). Hypertension in minority populations: New guidelines and emerging concepts. Advances in Chronic Kidney } \\
\text { Disease, 22(2), 145-153. Retrieved from http://www.embase.com/search/results?subaction=viewrecord\&from=export\&id=L602673703 }\end{array}$ & não é um GPC \\
\hline $\begin{array}{l}\text { Ruilope, L. M. (2011). Current challenges in the clinical management of hypertension. Nature Reviews. Cardiology, 9(5), } 267-275 . \\
\text { https://doi.org/10.1038/nrcardio.2011.157 }\end{array}$ & não é um GPC \\
\hline $\begin{array}{l}\text { Sakima, A., \& Ohya, Y. (2015). [Hypertension The Points of Management of Hypertension for All Physicians--Based on the JSH } 2014 \text { Hypertension } \\
\text { Guidelines--. Topics: IX. Evaluation and management of hypertensive emergencies]. Nihon Naika Gakkai zasshi. The Journal of the Japanese } \\
\text { Society of Internal Medicine, 104(2), 268-274. }\end{array}$ & não é um GPC \\
\hline $\begin{array}{l}\text { Schäfer, H. H., De Villiers, J. N., Sudano, I., Dischinger, S., Theus, G.-R. R., Zilla, P., ... Dieterle, T. (2012). Recommendations for the treatment of } \\
\text { hypertension in the elderly and very elderly--a scotoma within international guidelines. Swiss Medical Weekly, } 142 \text {, w13574. } \\
\text { https://doi.org/10.4414/smw.2012.13574 }\end{array}$ & não é um GPC \\
\hline $\begin{array}{l}\text { Scordo, K. A., \& Pickett, K. A. (2014). Hypertension in 2014: making sense of the guidelines. The Nurse Practitioner, 39(6), 14-18. } \\
\text { https://doi.org/10.1097/01.NPR.0000446869.87081.9b }\end{array}$ & não é um GPC \\
\hline $\begin{array}{l}\text { Sealy, L., \& Oliva, A. (2014). Hypertension management guidelines update and research on the importance of blood pressure c } \\
\text { Healthcare Nurse, 32(10), 603-609. https://doi.org/10.1097/NHH.0000000000000163 }\end{array}$ & não é um GPC \\
\hline
\end{tabular}


Apêndice 2- Documentos excluídos após aplicação dos critérios de elegibilidade.

\begin{tabular}{|c|c|}
\hline $\begin{array}{l}\text { Shi, N., Han, X., Yu, W., Wang, L., \& Lu, A. (2013). Adoption in China of Clinical Practice Guidelines for hypertension using Traditional Chinese } \\
\text { Medical approaches: a literature review based on clinical studies. Journal of Alternative and Complementary Medicine (New York, N.Y.), 19(1), 1-8. } \\
\text { https://doi.org/10.1089/act.2013.19108 }\end{array}$ & não é um GPC \\
\hline $\begin{array}{l}\text { Shimada, K. (2015). [The criteria for the selection of antihypertensive drugs by JSH2014 guidelines]. Nihon rinsho. Japanese journal of clinical } \\
\text { medicine, } 73(11), 1841-1845 .\end{array}$ & não é um GPC \\
\hline $\begin{array}{l}\text { Shimamoto, K. (2011). [Guideline for the managements of hypertension -blood pressure control for the elderly hypertension]. Nihon Ronen Igakkai } \\
\text { zasshi. Japanese journal of geriatrics, } 48(6), 648-650 \text {. }\end{array}$ & não é um GPC \\
\hline $\begin{array}{l}\text { Shimosawa, T. (2015). [Hypertension: The Points of Management of Hypertension for All Physicians--Based on the JSH } 2014 \text { Hypertension } \\
\text { Guidelines--.Topics: II. Primary examinations for hypertensives]. Nihon Naika Gakkai zasshi. The Journal of the Japanese Society of Internal } \\
\text { Medicine, } 104(2), 211-217 \text {. }\end{array}$ & não é um GPC \\
\hline $\begin{array}{l}\text { Singh, R. B., Hristova, K., Bjørklund, G., Fedacko, J., Chirumbolo, S., \& Pella, D. (2016). Extended consensus on blood pressure variability beyond } \\
\text { blood pressure for management of hypertension. Journal of the American Society of Hypertension. Retrieved from } \\
\text { http://www.embase.com/search/results?subaction=viewrecord\&from=export\&id=L614079930 }\end{array}$ & não é um GPC \\
\hline $\begin{array}{l}\text { Skov Paulsen, M., Christensen, B., \& Sondergaard, J. (2013). [Pharmacotherapy of patients with mild hypertension in primary care]. Ugeskrift for } \\
\text { laeger, 175(35), 1951-1953. }\end{array}$ & não é um GPC \\
\hline $\begin{array}{l}\text { Sleight, P. (2013). Latest European guidelines for the treatment of hypertension. Prescriber, 24(18), 7. Retrieved from } \\
\text { http://www.embase.com/search/results?subaction=viewrecord\&from=export\&id=L369949126 }\end{array}$ & não é um GPC \\
\hline $\begin{array}{l}\text { Smulders, Y. M., Peters, M. J. L., \& Serne, E. H. (2012, January). Comment on summary of the updated Dutch guidelines for the management of } \\
\text { hypertensive crisis. The Netherlands Journal of Medicine. Netherlands. }\end{array}$ & não é um GPC \\
\hline $\begin{array}{l}\text { Snipelisky, D., Waldo, O., \& Burton, M. C. (2015). Clinical Diagnosis and Management of Hypertension Compared With the Joint National Committee } \\
8 \text { Panelists' Recommendations. Clinical Cardiology, 38(6), 333-343. https://doi.org/10.1002/clc.22393 }\end{array}$ & não é um GPC \\
\hline $\begin{array}{l}\text { Sonst, J. (2013). New ESH/ESC guidelines recommend fixed dose combinations for the treatment of hypertension. Perfusion (Germany), 26(4), 138- } \\
\text { 139. Retrieved from http://www.embase.com/search/results?subaction=viewrecord\&from=export\&id=L370237532 }\end{array}$ & não é um GPC \\
\hline $\begin{array}{l}\text { Stern, R. H. (2013). The new hypertension guidelines. Journal of Clinical Hypertension (Greenwich, Conn.), 15(10), 748-751. } \\
\text { https://doi.org/10.1111/jch.12171 }\end{array}$ & não é um GPC \\
\hline s and contention in the field of hvper & não é um GPC \\
\hline & não é um GPC \\
\hline $\begin{array}{l}\text { Tamura, K., Yutoh, J., Matsushita, K., Sakai, M., \& Oshikawa, J. (2015). [Hypertension with chronic kidney disease: anti-hypertensive therapy } \\
\text { recommended for the management of hypertension with CKD in JSN-CKD GL } 2013 \text { and JSH2014]. Nihon rinsho. Japanese journal of clinical } \\
\text { medicine, 73(11), 1876-1884. }\end{array}$ & não é um GPC \\
\hline Tanahashi, N. (2016). [Management of blood pressure for s & não é um GPC \\
\hline
\end{tabular}


Apêndice 2- Documentos excluídos após aplicação dos critérios de elegibilidade.

\begin{tabular}{|c|c|}
\hline $\begin{array}{l}\text { Tanaka, K., \& Minamino, T. (2015). [Anti-hypertensive therapies in patients with heart disease]. Nihon rinsho. Japanese journal of clinical medicine, } \\
73(11), 1871-1875 .\end{array}$ & não é um GPC \\
\hline $\begin{array}{l}\text { Tanaka, M., \& Itoh, H. (2015). [Hypertension: The Points of Management of Hypertension for All Physicians--Based on the JSH } 2014 \text { Hypertension } \\
\text { Guidelines--. Topics: V. Points of hypertension treatment for the patients complicated by kidney diseases and diabetes]. Nihon Naika Gakkai zasshi. } \\
\text { The Journal of the Japanese Society of Internal Medicine, } 104(2), 240-246 \text {. }\end{array}$ & não é um GPC \\
\hline Taylor J (2013) 2013 ESH/ESC guidelines for the management of arterial hypertension. Eur Heart J 34:2108-2109 & não é um GPC \\
\hline Taylor, P. J. R. (2011). Evidence for key recommendation in NICE guidance on hypertension is poor. BMJ (Online), 343(7827). & não é um GPC \\
\hline $\begin{array}{l}\text { Tobe, S. W. (2014). beta-adrenergic receptor blockers in hypertension. The Canadian Journal of Cardiology, 30(5 Suppl), S1-2. } \\
\text { https://doi.org/10.1016/j.cjca.2014.02.015 }\end{array}$ & não é um GPC \\
\hline $\begin{array}{l}\text { Tobe, S. W., Poirier, L., Tremblay, G., Lindsay, P., Reid, D., Campbell, N. R., ... Rabi, D. (2012). Challenges and scientific considerations in } \\
\text { hypertension management reflected in the } 2012 \text { recommendations of the Canadian Hypertension Education Program. Open Medicine : A Peer- } \\
\text { Reviewed, Independent, Open-Access Journal, 6(4), e127-33. }\end{array}$ & não é um GPC \\
\hline $\begin{array}{l}\text { Tofield, A., \& Jaques, H. (2013). NICE Guideline on hypertension. European Heart Journal, 34(6), 406-408. Retrieved from } \\
\text { http://www.embase.com/search/results?subaction=viewrecord\&from=export\&id=L368321697 }\end{array}$ & não é um GPC \\
\hline $\begin{array}{l}\text { Traynor, K. (2014, February). New hypertension guidelines may simplify treatment. American Journal of Health-System Pharmacy: AJHP : Official } \\
\text { Journal of the American Society of Health-System Pharmacists. United States. https://doi.org/10.2146/news } 140014\end{array}$ & não é um GPC \\
\hline $\begin{array}{l}\text { Tykarski, A., Narkiewicz, K., Gaciong, Z., Januszewicz, A., Litwin, M., \& Kostka-Jeziorny, K. (2015). } 2015 \text { guidelines for the management of } \\
\text { hypertension. part 8. Nadcisnienie Tetnicze, 19(4), 153-173. Retrieved from } \\
\text { http://www.embase.com/search/results?subaction=viewrecord\&from=export\&id=L611083880 }\end{array}$ & não é um GPC \\
\hline Van De Borne P (2014) Guidelines for the management of arterial hypertension. Acta Cardiol 69:53-54 & não é um GPC \\
\hline Wang J-G (2015) Chinese hypertension guidelines. Pulse 3:14-20 & não é um GPC \\
\hline $\begin{array}{l}\text { Weber, M. A. (2014, April). Recently published hypertension guidelines of the JNC } 8 \text { panelists, the American Society of Hypertension/International } \\
\text { Society of Hypertension and other major organizations: introduction to a focus issue of the Journal of Clinical Hypertension. Journal of Clinical } \\
\text { Hypertension (Greenwich, Conn.). United States. https://doi.org/10.1111/jch.12308 }\end{array}$ & não é um GPC \\
\hline $\begin{array}{l}\text { Weir, M. R. (2014). Hypertension and kidney disease. Journal of the American Society of Hypertension : JASH, 8(11), 855-859. } \\
\text { https://doi.org/10.1016/j.jash.2014.09.011 }\end{array}$ & não é um GPC \\
\hline Weiss, L. (2013). [Treatment of hypertension in chronic kidney disease]. Lakartidningen, 110(21), 1028-1029. & não é um GPC \\
\hline $\begin{array}{l}\text { Wheeler, D. C., \& Becker, G. J. (2013). Summary of KDIGO guideline. What do we really know about management of blood pressure in patients with } \\
\text { chronic kidney disease? Kidney International, 83(3), 377-383. https://doi.org/10.1038/ki.2012.425 }\end{array}$ & não é um GPC \\
\hline $\begin{array}{l}\text { Williams, H. (2011). Updated hypertension guidance: What pharmacists need to know. Clinical Pharmacist, 3(8), 254-256. R } \\
\text { http://www.embase.com/search/results?subaction=viewrecord\&from=export\&id=L362993612 }\end{array}$ & não é um GPC \\
\hline
\end{tabular}


Apêndice 2- Documentos excluídos após aplicação dos critérios de elegibilidade.

\begin{tabular}{|c|c|}
\hline $\begin{array}{l}\text { Williams, S. K., Ravenell, J., Seyedali, S., Nayef, S., \& Ogedegbe, G. (2016). Hypertension Treatment in Blacks: Discussion of the U.S. Clinical } \\
\text { Practice Guidelines. Progress in Cardiovascular Diseases, 59(3), 282-288. Retrieved from } \\
\text { http://www.embase.com/search/results?subaction=viewrecord\&from=export\&id=L613694577 }\end{array}$ & não é um GPC \\
\hline Xhignesse, P., \& Krzesinski, J. M. (2013). [New guidelines for hypertension management in 2013]. Revue medicale de Liege, 68(10), 511-520. & não é um GPC \\
\hline Yamada, Y., \& Akishita, M. (2015). [Hypertension of old people in frailty]. Nihon rinsho. Japanese journal of clinical medicine, 73(11), & não é um GPC \\
\hline Zidek, W. (2014). [The new EU and US hypertension guidelines. Implication for practice]. MMW Fortschritte der Medizin, 156(20), 48-50. & não é um GPC \\
\hline $\begin{array}{l}\text { Aalbers, J. (2012). South African } 2012 \text { guidelines for hypertension therapy: Therapeutic options in hypertension management: } 2012 \text { Guidelines from } \\
\text { the Southern African Hypertension Society. Cardiovascular Journal of Africa, 23(1), 53-56. Retrieved from } \\
\text { http://www.embase.com/search/results?subaction=viewrecord\&from=export\&id=L364304973 }\end{array}$ & versão anterior \\
\hline $\begin{array}{l}\text { Campbell, N. (2011). 2011 Canadian Hypertension Education Program recommendations: an annual update. Canadian Family Physician Medecin de } \\
\text { Famille Canadien, 57(12), 1393-1397. }\end{array}$ & versão anterior \\
\hline $\begin{array}{l}\text { Cardiometabolic risk management guidelines in primary care. In: National Guideline Clearinghouse (NGC) [Web site]. Rockville (MD): Agency for } \\
\text { Healthcare Research and Quality (AHRQ); 2011 Jan 01. [cited 2017 Jan 19]. Available: https://www.guideline.gov }\end{array}$ & versão anterior \\
\hline $\begin{array}{l}\text { Castaño-Guerra R, Medina-González MC, de la Rosa-Rincón RL, Loría-Castellanos J, Castano-Guerra R, Medina-Gonzalez MDC, de la Rosa- } \\
\text { Rincon RL, Loria-Castellanos J (2011) [Clinical guideline for diagnosis and treatment of high blood pressure]. Rev Med Inst Mex Seguro Soc 49:315- } \\
324\end{array}$ & versão anterior \\
\hline $\begin{array}{l}\text { Dasgupta, K., Padwal, R., Poirier, L., Quinn, R. R., Bacon, S., Feldman, R. D., ... Zarnke, K. (2015). Managing hypertension: evidence supporting the } \\
2013 / 2014 \text { recommendations of the Canadian Hypertension Education Program. CMAJ : Canadian Medical Association Journal = Journal de } \\
\text { l'Association Medicale Canadienne, 187(2), 116-119. https://doi.org/10.1503/cmaj.131440 }\end{array}$ & versão anterior \\
\hline $\begin{array}{l}\text { Daskalopoulou SS, Rabi DM, Zarnke KB, Dasgupta K, Nerenberg K et al. (2015) The } 2015 \text { Canadian Hypertension Education Program } \\
\text { recommendations for blood pressure measurement, diagnosis, assessment of risk, prevention, and treatment of hypertension. Can J Cardiol. } 2015 \\
\text { May;31(5):549-68. DOI: } 10.1016 / j . c j c a .2015 .02 .016\end{array}$ & versão anterior \\
\hline $\begin{array}{l}\text { Hackam DG, Quinn RR, Ravani P, et al (2013) The } 2013 \text { Canadian Hypertension Education Program recommendations for blood pressure } \\
\text { measurement, diagnosis, assessment of risk, prevention, and treatment of hypertension. Can J Cardiol 29:528-542 }\end{array}$ & versão anterior \\
\hline $\begin{array}{l}\text { Houle SKD, Padwal R, Poirier L, Tsuyuki RT (2015) The } 2015 \text { Canadian Hypertension Education Program (CHEP) guidelines for pharmacists: An } \\
\text { update. Can Pharm J 148:180-186 }\end{array}$ & versão anterior \\
\hline $\begin{array}{l}\text { Houle SKD, Padwal R, Tsuyuki RT (2013) The 2012-2013 Canadian Hypertension Education Program (CHEP) guidelines for pharmacists: An update. } \\
\text { Can Pharm J 146:146-150 }\end{array}$ & versão anterior \\
\hline $\begin{array}{l}\text { James PA, Oparil S, Carter BL, Cushman WC, Dennison-Himmelfarb C, Handler J, et al. } 2014 \text { evidence-based guideline for the management of high } \\
\text { blood pressure in adults. Report from the panel members appointed to the Eighth Joint National Committee (JNC 8). | National Guideline } \\
\text { Clearinghouse [Internet]. } 2014 \text { [cited } 2017 \text { Oct 10]. Available from: https://www.guideline.gov/summaries/summary/48192/2014-evidencebased- } \\
\text { guideline-for-the-management-of-high-blood-pressure-in-adults-report-from-the-panel-members-appointed-to-the-eighth-joint-national-committee-jnc- } \\
8\end{array}$ & versão anterior \\
\hline
\end{tabular}


Apêndice 2- Documentos excluídos após aplicação dos critérios de elegibilidade.

\begin{tabular}{|c|c|}
\hline $\begin{array}{l}\text { Krause, T., Lovibond, K., Caulfield, M., McCormack, T., \& Williams, B. (2011). Management of hypertension: summary } \\
\text { (Clinical Research Ed.), 343, d4891. }\end{array}$ & versão anterior \\
\hline $\begin{array}{l}\text { Prieto-Díaz, M. Á. (2014). Guidelines for the management of hypertension. Semergen / Sociedad Española de Medicina Rural Y Generalista, 40, 2- } \\
\text { 10. Retrieved from http://www.embase.com/search/results?subaction=viewrecord\&from=export\&id=L608002987 }\end{array}$ & versão anterior \\
\hline $\begin{array}{l}\text { Rabi DM, Daskalopoulou SS, Padwal RS, et al (2011) The } 2011 \text { Canadian Hypertension Education Program recommendations for the management } \\
\text { of hypertension: blood pressure measurement, diagnosis, assessment of risk, and therapy. Can J Cardiol 27:412-415 }\end{array}$ & versão anterior \\
\hline Seedat YK, Rayner BL (2013) The abridged & versãc \\
\hline $\begin{array}{l}\text { Seedat, Y. K., \& Rayner, B. L. (2011). South African hypertension guideline 2011. South African Medical Journal = Suid-Afrikaanse Tyds } \\
\text { Geneeskunde, 102(1 Pt 2), 57-83. }\end{array}$ & versão anterior \\
\hline $\begin{array}{l}\text { The } 2012 \text { Canadian Hypertension Education Program recommendations for the management of hypertension: Blood pressure measi } \\
\text { diagnosis, assessment of risk, and therapy }\end{array}$ & versão anterior \\
\hline $\begin{array}{l}\text { The } 2013 \text { Canadian Hypertension Education Program Recommendations for blood pressure measurement, diagnosis, assessment of risk, } \\
\text { prevention, and treatment of hypertension }\end{array}$ & versão anterior \\
\hline $\begin{array}{l}\text { The } 2014 \text { Canadian Hypertension Education Program recommendations for blood pressure measurement, diagnosis, assessment of risk, prevention, } \\
\text { and treatment of hypertension }\end{array}$ & versão anterior \\
\hline $\begin{array}{l}2015 \text { Canadian Hypertension Education Program recommendations for blood pressure measurement, diagnosis, assessment of risk, prev } \\
\text { treatment of hypertension }\end{array}$ & versão anterior \\
\hline $\begin{array}{l}\text { Bosch, J., Abraldes, J. G., Albillos, A., Aracil, C., Banares, R., Berzigotti, A., ... Villanueva, C. (2012). [Portal hypertension: recommendations for } \\
\text { evaluation and treatment: consensus document sponsored by the Spanish Association for the Study of the Liver (AEEH) and the Biomedical } \\
\text { Research Network Center for Liver and Digestive Diseases(CIBERehd)]. Gastroenterologia y hepatologia, 35(6), 421-450. } \\
\text { https://doi.org/10.1016/j.gastrohep.2012.02.009 }\end{array}$ & $\begin{array}{l}\text { não é sobre a } \\
\text { doença }\end{array}$ \\
\hline M. (2013). Guidelines updates in the treatment of obesity or metabolic syndrome and hypertension. & $\begin{array}{ll}\text { não é sobre } \\
\text { doença }\end{array}$ \\
\hline $\begin{array}{l}\text { Head, G. A., McGrath, B. P., Mihailidou, A. S., Nelson, M. R., Schlaich, M. P., Stowasser, M., ... Wilson, A. (2012). Ambulatory blood pressure } \\
\text { monitoring in Australia: } 2011 \text { consensus position statement. Journal of Hypertension, 30(2), 253-266. } \\
\text { https://doi.org/10.1097/HJH.0b013e32834de621 }\end{array}$ & $\begin{array}{l}\text { não é sobre a } \\
\text { doença }\end{array}$ \\
\hline $\begin{array}{l}\text { Hermida, R. C., Smolensky, M. H., Ayala, D. E., Portaluppi, F., Crespo, J. J., Fabbian, F., ... Fernandez, J. R. (2013). [2013 Ambulatory blood } \\
\text { pressure monitoring recommendations for the diagnosis of adult hypertension, assessment of cardiovascular and other hypertension-associated risk, } \\
\text { and attainment of therapeutic goals (summary). Joint recommendations from the Internat. Clinica e investigacion en arteriosclerosis : publicacion } \\
\text { oficial de la Sociedad Espanola de Arteriosclerosis, 25(2), 74-82. https://doi.org/10.1016/j.arteri.2013.03.002 }\end{array}$ & $\begin{array}{l}\text { não é sobre } \\
\text { doença }\end{array}$ \\
\hline $\begin{array}{l}\text { Narvaez-Rivera, R. M., Cortez-Hernandez, C. A., Gonzalez-Gonzalez, J. A., Tamayo-de la Cuesta, J. L., Zamarripa-Dorsey, F., Torre-Delga } \\
\ldots \text { Bosques-Padilla, F. J. (2013). [Mexican consensus on portal hypertension]. Revista de gastroenterologia de Mexico, 78(2), } 92-113 . \\
\text { https://doi.org/10.1016/j.rgmx.2013.01.006 }\end{array}$ & $\begin{array}{l}\text { não é sobre a } \\
\text { doença }\end{array}$ \\
\hline Medic & $\begin{array}{l}\text { não é sobre } \\
\text { doença }\end{array}$ \\
\hline
\end{tabular}


Apêndice 2- Documentos excluídos após aplicação dos critérios de elegibilidade.

\begin{tabular}{|c|c|}
\hline $\begin{array}{l}\text { Virdis, A., Ghiadoni, L., \& Taddei, S. (2014). Clinical management of drug-induced hypertension: } 2013 \text { Practical Recommendations of the Italian } \\
\text { Society of Hypertension (SIIA). High Blood Pressure \& Cardiovascular Prevention : The Official Journal of the Italian Society of Hypertension, } 21 \text { (1), } \\
\text { 77-79. https://doi.org/10.1007/s40292-014-0038-3 }\end{array}$ & $\begin{array}{lll}\text { não é sobre a } \\
\text { doença }\end{array}$ \\
\hline $\begin{array}{l}\text { Volpe, M., \& Morganti, A. (2011). } 2010 \text { position paper of the Italian Society of Hypertension (SIIA): angiotensin receptor blockers and risk of cancer. } \\
\text { High Blood Pressure \& Cardiovascular Prevention: The Official Journal of the Italian Society of Hypertension, 18(1), 37-40. } \\
\text { https://doi.org/10.2165/11588060-000000000-00000 }\end{array}$ & $\begin{array}{lll}\text { não é sobre } \\
\text { doença }\end{array}$ \\
\hline $\begin{array}{l}\text { Volpe, M., Trimarco, B., Battistoni, A., \& Mancia, G. (2013). Clinical management of coronary heart disease in hypertension : practical } \\
\text { recommendations from the Italian Society of Hypertension (SIIA). High Blood Pressure \& Cardiovascular Prevention : The Official Journal of the } \\
\text { Italian Society of Hypertension, 20(3), 129-134. https://doi.org/10.1007/s40292-013-0020-5 }\end{array}$ & $\begin{array}{lll}\text { não é sobre a } \\
\text { doença }\end{array}$ \\
\hline $\begin{array}{l}\text { Adler, A. J., Prabhakaran, D., Bovet, P., Kazi, D. S., Mancia, G., Mungal-Singh, V., \& Poulter, N. (2015). Reducing Cardiovascular Mortality Through } \\
\text { Prevention and Management of Raised Blood Pressure: A World Heart Federation Roadmap. Global Heart, 10(2), 111-122. } \\
\text { https://doi.org/10.1016/j.gheart.2015.04.006 }\end{array}$ & $\begin{array}{l}\text { não contém } \\
\text { tratamento } \\
\text { farmacológico }\end{array}$ \\
\hline $\begin{array}{l}\text { Brook, R. D., Appel, L. J., Rubenfire, M., Ogedegbe, G., Bisognano, J. D., Elliott, W. J., ... Rajagopalan, S. (2013). Beyond medications and diet: } \\
\text { alternative approaches to lowering blood pressure: a scientific statement from the american heart association. Hypertension (Dallas, Tex. : 1979), } \\
61(6), 1360-1383 \text {. https://doi.org/10.1161/HYP.0b013e318293645f }\end{array}$ & $\begin{array}{l}\text { não contém } \\
\text { tratamento } \\
\text { farmacológico }\end{array}$ \\
\hline $\begin{array}{l}\text { Eguchi, K. (2015). Blood Pressure Management in Patients with Type } \\
\text { https://doi.org/10.2169/internalmedicine.54.5617 }\end{array}$ & $\begin{array}{l}\text { não contém } \\
\text { tratamento } \\
\text { farmacológico }\end{array}$ \\
\hline $\begin{array}{l}\text { Handler, J. (2015). } 2014 \text { Hypertension Guideline: Recommendation for a Change in Goal Systolic Blood Pressure. The Permanente Jour } \\
\text { 64-68. https://doi.org/10.7812/TPP/14-226 }\end{array}$ & $\begin{array}{l}\text { não } \\
\text { tratamento } \\
\text { farmacológico }\end{array}$ \\
\hline $\begin{array}{l}\text { Hartle, A., McCormack, T., Carlisle, J., Anderson, S., Pichel, A., Beckett, N., ... Heagerty, A. (2016). The measurement of adult blood pr } \\
\text { management of hypertension before elective surgery: Joint Guidelines from the Association of Anaesthetists of Great Britain and Irelanc } \\
\text { British Hypertension Society. Anaesthesia, 71(3), 326-337. https://doi.org/10.1111/anae.13348 }\end{array}$ & $\begin{array}{l}\text { não contém } \\
\text { tratamento } \\
\text { farmacológico }\end{array}$ \\
\hline Hypertension Canada's 2016 Canadian Hypertension Educe & $\begin{array}{l}\text { não contém } \\
\text { tratamento } \\
\text { farmacológico }\end{array}$ \\
\hline $\begin{array}{l}\text { Imai, Y., Kario, K., Shimada, K., Kawano, Y., Hasebe, N., Matsuura, H., ... Miyakawa, M. (2012). The Japanese Society of Hypertension Guidelines } \\
\text { for Self-monitoring of Blood Pressure at Home (Second Edition). Hypertension Research : Official Journal of the Japanese Society of Hypertension, } \\
\text { 35(8), 777-795. https://doi.org/10.1038/hr.2012.56 }\end{array}$ & $\begin{array}{l}\text { não contém } \\
\text { tratamento } \\
\text { farmacológico }\end{array}$ \\
\hline $\begin{array}{l}\text { Khan, N. A., Herman, R. J., Quinn, R. R., Rabkin, S. W., Ravani, P., Tobe, S. W., ... Padwal, R. S. (2014). Renal denervation therapy for the } \\
\text { treatment of resistant hypertension: a position statement by the Canadian Hypertension Education Program. The Canadian Journal of Cardiology, } \\
\text { 30(1), 16-21. https://doi.org/10.1016/j.cjca.2013.07.008 }\end{array}$ & $\begin{array}{l}\text { não contém } \\
\text { tratamento } \\
\text { farmacológico }\end{array}$ \\
\hline $\begin{array}{l}\text { Parati, G., Stergiou, G., O’Brien, E., Asmar, R., Beilin, L., Bilo, G., ... Zhang, Y. (201 } \\
\text { ambulatory blood pressure monitoring. Journal of Hypertension, 32(7), 1359-1366. }\end{array}$ & $\begin{array}{l}\text { não contém } \\
\text { tratamento } \\
\text { farmacológico }\end{array}$ \\
\hline $\begin{array}{l}\text { Team-based care to improve blood pressure control: recommendation of the Community Preventive Services Task Force. In: National Guideline } \\
\text { Clearinghouse (NGC) [Web site]. Rockville (MD): Agency for Healthcare Research and Quality (AHRQ); 2014 Jul 01. [cited 2017 Jan 19]. Available: } \\
\text { https://www.guideline.gov }\end{array}$ & $\begin{array}{l}\text { não } \\
\text { tratamento } \\
\text { farmacológico }\end{array}$ \\
\hline
\end{tabular}


APÊNDICE 3 - CARACTERÍSTICAS GERAIS DOS GUIAS DE PRÁTICA CLÍNICA (GPC) PARA TRATAMENTO FARMACOLÓGICO DA HIPERTENSÃO ARTERIAL SISTÊMICA PUBLICADOS NO PERÍODO DE 01/2011 A 12/2016, ATUALIZADO OS GPC INCLUÍDOS ATÉ 11/2017.

\begin{tabular}{|c|c|c|c|c|c|c|c|c|c|c|c|c|}
\hline $\begin{array}{c}\text { Guia de Prática } \\
\text { Clínica }\end{array}$ & $\begin{array}{l}\text { Número de } \\
\text { autores }\end{array}$ & $\begin{array}{c}\text { Ano de } \\
\text { publicação }\end{array}$ & $\begin{array}{l}\text { Tipo do } \\
\text { GPC }\end{array}$ & $\begin{array}{c}\text { Período } \\
\text { previsto } \\
\text { para } \\
\text { atualiza- } \\
\text { ção (anos) }\end{array}$ & $\begin{array}{c}\text { Pais } \\
\text { (Continen- } \\
\text { te) }\end{array}$ & $\begin{array}{c}\text { Institui- } \\
\text { ção/orga- } \\
\text { nização } \\
\text { responsável } \\
\text { pela } \\
\text { elaboração } \\
\end{array}$ & $\begin{array}{l}\text { Tipo da } \\
\text { institui- } \\
\text { ção/orga- } \\
\text { nização }\end{array}$ & $\begin{array}{c}\text { Método de } \\
\text { desenvol- } \\
\text { vimento do } \\
\text { GPC }\end{array}$ & $\begin{array}{l}\text { Método } \\
\text { para } \\
\text { formular } \\
\text { as } \\
\text { recomen- } \\
\text { dações } \\
\end{array}$ & $\begin{array}{l}\text { Sistema de } \\
\text { classifi- } \\
\text { cação de } \\
\text { evidências }\end{array}$ & $\begin{array}{c}\text { Financia- } \\
\text { mento (Orgão } \\
\text { financiador) }\end{array}$ & $\begin{array}{l}\text { Tipo do } \\
\text { órgão } \\
\text { financiador }\end{array}$ \\
\hline $\begin{array}{l}\text { Guia de Prática } \\
\text { Clínica para } \\
\text { Hipertensão } \\
\text { Arterial Primaria- } \\
\text { Colômbia (109) }\end{array}$ & 32 & 2013 & Elaborado & $2-4$ & $\begin{array}{c}\text { Colômbia } \\
\text { (América do } \\
\text { Sul) }\end{array}$ & $\begin{array}{c}\text { CINETS, la } \\
\text { Asociación } \\
\text { Colombiana de } \\
\text { Medicina } \\
\text { Interna, la } \\
\text { Sociedad } \\
\text { Colombiana de } \\
\text { Cardiología y la } \\
\text { Asociación } \\
\text { Colombiana de } \\
\text { Nefrología e } \\
\text { Hipertensión } \\
\text { Arterial }\end{array}$ & Governo & Adaptado & $\begin{array}{l}\text { Consenso } \\
\text { formal } \\
\text { (método do } \\
\text { consenso } \\
\text { detalhado) }\end{array}$ & GRADE & $\begin{array}{c}\text { Ministério de } \\
\text { Salud y } \\
\text { Protección } \\
\text { social, y el } \\
\text { Departamento } \\
\text { Administrativo } \\
\text { de Ciencia, } \\
\text { Tecnología e } \\
\text { Innovación- } \\
\text { COLCIENCIAS }\end{array}$ & Governo \\
\hline $\begin{array}{l}\text { Hypertension in } \\
\text { adults: diagnosis } \\
\text { and management - } \\
\text { NICE (110) }\end{array}$ & 10 & 2016 & Atualizado & 3 & $\begin{array}{l}\text { Reino } \\
\text { Unido } \\
\text { (Europa) }\end{array}$ & $\begin{array}{l}\text { The National } \\
\text { Institute for } \\
\text { Health and } \\
\text { Care } \\
\text { Excellence } \\
\text { (NICE) }\end{array}$ & Governo & $\begin{array}{c}\text { Revisão } \\
\text { Sistemática }\end{array}$ & $\begin{array}{l}\text { Consenso } \\
\text { formal } \\
\text { (método do } \\
\text { consenso } \\
\text { detalhado) }\end{array}$ & GRADE & NICE & Governo \\
\hline $\begin{array}{c}2017 \\
\text { ACC/AHA/AAPA/A } \\
\text { BC/ACPM/AGS/AP } \\
\text { hA/ASH/ASPC/NM } \\
\text { A/PCNA Guideline } \\
\text { for the Prevention, } \\
\text { Detection, } \\
\text { Evaluation, and } \\
\text { Management of } \\
\text { High Blood } \\
\text { Pressure in Adults } \\
\text { (111) }\end{array}$ & 21 & 2017 & Atualizado & 6 & \begin{tabular}{|c|} 
Estados \\
Unidos \\
(América do \\
Norte)
\end{tabular} & $\begin{array}{c}\text { ACC/AHA/AAP } \\
\text { A/ABC/ACPM/A } \\
\text { GS/APhA/ASH/ } \\
\text { ASPC/NMA/PC } \\
\text { NA }\end{array}$ & Sociedade & $\begin{array}{c}\text { Revisão } \\
\text { Sistemática }\end{array}$ & $\begin{array}{l}\text { Consenso } \\
\text { formal } \\
\text { (método do } \\
\text { consenso } \\
\text { detalhado) }\end{array}$ & Outros & $\mathrm{ACC}$ and $\mathrm{AHA}$ & Sociedade \\
\hline
\end{tabular}


APÊNDICE 3 - Características gerais dos guias de prática clínica (GPC) para tratamento farmacológico da hipertensão arterial sistêmica publicados no período de 01/2011 a 12/2016, atualizado os GPC incluídos até 11/2017.

\begin{tabular}{|c|c|c|c|c|c|c|c|c|c|c|c|c|}
\hline $\begin{array}{l}\text { Guia de Prática } \\
\text { Clínica }\end{array}$ & $\begin{array}{l}\text { Número de } \\
\text { autores }\end{array}$ & $\begin{array}{c}\text { Ano de } \\
\text { publicação }\end{array}$ & $\begin{array}{l}\text { Tipo do } \\
\text { GPC }\end{array}$ & \begin{tabular}{|c|} 
Período \\
previsto \\
para \\
atualização \\
(anos)
\end{tabular} & $\begin{array}{c}\text { Pais } \\
\text { (Continen- } \\
\text { te) }\end{array}$ & $\begin{array}{c}\text { Institui- } \\
\text { ção/orga- } \\
\text { nização } \\
\text { responsável } \\
\text { pela } \\
\text { elaboração } \\
\end{array}$ & $\begin{array}{c}\text { Tipo da } \\
\text { institui- } \\
\text { ção/orga- } \\
\text { nizaçãa }\end{array}$ & $\begin{array}{c}\text { Método de } \\
\text { desenvol- } \\
\text { vimento do } \\
\text { GPC }\end{array}$ & \begin{tabular}{|c|} 
Método \\
para \\
formular \\
as \\
recomen- \\
dações \\
\end{tabular} & $\begin{array}{c}\text { Sistema de } \\
\text { classifi- } \\
\text { cação de } \\
\text { evidências }\end{array}$ & $\begin{array}{c}\text { Financia- } \\
\text { mento (Orgão } \\
\text { financiador) }\end{array}$ & $\begin{array}{c}\text { Tipo do } \\
\text { órgão } \\
\text { financiador }\end{array}$ \\
\hline $\begin{array}{l}\text { VA/DoD clinical } \\
\text { practice guideline } \\
\text { for the diagnosis } \\
\text { and management } \\
\text { of hypertension in } \\
\text { the primary care } \\
\text { setting (112) }\end{array}$ & 26 & 2014 & Atualizado & $\mathrm{NM}^{*}$ & $\begin{array}{c}\text { Estados } \\
\text { Unidos } \\
\text { (América do } \\
\text { Norte) }\end{array}$ & $\begin{array}{l}\text { Department of } \\
\text { Veterans Affairs } \\
\text { (VA) and the } \\
\text { Department of } \\
\text { Defense (DoD) }\end{array}$ & Governo & $\begin{array}{c}\text { Revisão } \\
\text { Sistemática }\end{array}$ & $\begin{array}{l}\text { Consenso } \\
\text { sem } \\
\text { detalhes do } \\
\text { processo }\end{array}$ & GRADE & $\begin{array}{l}\text { United States } \\
\text { Government }\end{array}$ & Governo \\
\hline $\begin{array}{c}\text { Hypertension } \\
\text { Canada's } 2017 \\
\text { Guidelines for } \\
\text { Diagnosis, Risk } \\
\text { Assessment, } \\
\text { Prevention, and } \\
\text { Treatment of } \\
\text { Hypertension in } \\
\text { Adults (113) }\end{array}$ & 74 & 2017 & Atualizado & 1 & $\begin{array}{c}\text { Canadá } \\
\text { (América do } \\
\text { Norte) }\end{array}$ & $\begin{array}{l}\text { Hypertension } \\
\text { Canada }\end{array}$ & Sociedade & $\begin{array}{c}\text { Revisão } \\
\text { Sistemática }\end{array}$ & $\begin{array}{l}\text { Consenso } \\
\text { sem } \\
\text { detalhes do } \\
\text { processo }\end{array}$ & GRADE & $\begin{array}{l}\text { Hypertension } \\
\text { Canada }\end{array}$ & Sociedade \\
\hline $\begin{array}{c}\text { Diagnóstico y } \\
\text { Tratamiento de la } \\
\text { HIPERTENSIÓN } \\
\text { ARTERIAL en el } \\
\text { Primer Nivel de } \\
\text { Atención (114) }\end{array}$ & 17 & 2014 & Atualizado & 3- 5 & $\begin{array}{c}\text { México } \\
\text { (América do } \\
\text { Norte) }\end{array}$ & $\begin{array}{c}\text { Instituto } \\
\text { Mexicano del } \\
\text { Seguro Social }\end{array}$ & Governo & Adaptado & $\mathrm{NM}^{*}$ & Outros & $\begin{array}{c}\text { Instituto } \\
\text { Mexicano del } \\
\text { Seguro Social }\end{array}$ & Governo \\
\hline $\begin{array}{c}\text { Heart Foundation - } \\
\text { HAS } 2016 \text { (115) }\end{array}$ & 15 & 2016 & Atualizado & $\mathrm{NM}^{*}$ & $\begin{array}{l}\text { Austrália } \\
\text { (Oceania) }\end{array}$ & $\begin{array}{l}\text { National Heart } \\
\text { Foundation of } \\
\text { Australia }\end{array}$ & Sociedade & $\begin{array}{c}\text { Revisão } \\
\text { Sistemática }\end{array}$ & $\begin{array}{l}\text { Consenso } \\
\text { sem } \\
\text { detalhes do } \\
\text { processo }\end{array}$ & GRADE & $\begin{array}{l}\text { National Heart } \\
\text { Foundation of } \\
\text { Australia }\end{array}$ & Sociedade \\
\hline
\end{tabular}


APÊNDICE 3 - Características gerais dos guias de prática clínica (GPC) para tratamento farmacológico da hipertensão arterial sistêmica publicados no período de 01/2011 a 12/2016, atualizado os GPC incluídos até 11/2017.

\begin{tabular}{|c|c|c|c|c|c|c|c|c|c|c|c|c|}
\hline $\begin{array}{l}\text { Guia de Prática } \\
\text { Clínica }\end{array}$ & $\begin{array}{l}\text { Número de } \\
\text { autores }\end{array}$ & $\begin{array}{c}\text { Ano de } \\
\text { publicação }\end{array}$ & $\begin{array}{l}\text { Tipo do } \\
\text { GPC }\end{array}$ & \begin{tabular}{|} 
Período \\
previsto \\
para \\
atualização \\
(anos)
\end{tabular} & $\begin{array}{c}\text { Pais } \\
\text { (Continen- } \\
\text { te) }\end{array}$ & $\begin{array}{c}\text { Institui- } \\
\text { ção/orga- } \\
\text { nização } \\
\text { responsável } \\
\text { pela } \\
\text { elaboração } \\
\end{array}$ & $\begin{array}{l}\text { Tipo da } \\
\text { institui- } \\
\text { ção/orga- } \\
\text { nização }\end{array}$ & $\begin{array}{c}\text { Método de } \\
\text { desenvol- } \\
\text { vimento do } \\
\text { GPC }\end{array}$ & \begin{tabular}{|c|} 
Método \\
para \\
formular \\
as \\
recomen- \\
dações \\
\end{tabular} & $\begin{array}{c}\text { Sistema de } \\
\text { classifi- } \\
\text { cação de } \\
\text { evidências }\end{array}$ & $\begin{array}{c}\text { Financia- } \\
\text { mento (Orgão } \\
\text { financiador) }\end{array}$ & $\begin{array}{l}\text { Tipo do } \\
\text { órgão } \\
\text { financiador }\end{array}$ \\
\hline $\begin{array}{l}\text { Clinical practice } \\
\text { guidelines on } \\
\text { arterial } \\
\text { hypertension - } \\
\text { NGC: } 015712 \\
\text { (116) }\end{array}$ & 9 & 2013 & Atualizado & $\mathrm{NM}^{*}$ & $\begin{array}{l}\text { Espanha } \\
\text { (Europa) }\end{array}$ & $\begin{array}{c}\text { Osakidetza and } \\
\text { the Basque } \\
\text { government's } \\
\text { Ministry of } \\
\text { Health }\end{array}$ & Governo & $\begin{array}{l}\text { Outro } \\
\text { método }\end{array}$ & $\begin{array}{c}\text { Consenso } \\
\text { sem } \\
\text { detalhes do } \\
\text { processo }\end{array}$ & Outros & \begin{tabular}{|} 
Osakidetza \\
and the \\
Department of \\
Health of the \\
Basque \\
Government
\end{tabular} & Governo \\
\hline $\begin{array}{l}\text { The Japanese } \\
\text { Society of } \\
\text { Hypertension } \\
\text { Guidelines for the } \\
\text { Management of } \\
\text { Hypertension (117) }\end{array}$ & 40 & 2014 & Atualizado & $\mathrm{NM}^{*}$ & $\begin{array}{l}\text { Japão } \\
\text { (Ásia) }\end{array}$ & $\begin{array}{l}\text { The Japanese } \\
\text { Society of } \\
\text { Hypertension }\end{array}$ & Sociedade & $\begin{array}{c}\text { Revisão } \\
\text { Sistemática }\end{array}$ & $\begin{array}{c}\text { Consenso } \\
\text { formal } \\
\text { (método do } \\
\text { consenso } \\
\text { detalhado) }\end{array}$ & GRADE & $\begin{array}{c}\text { Japanese } \\
\text { Society of } \\
\text { Hypertension }\end{array}$ & Sociedade \\
\hline $\begin{array}{c}\text { Essential } \\
\text { hypertension - } \\
\text { NGC:010401 (118) }\end{array}$ & 5 & 2014 & Atualizado & $\mathrm{NM}^{*}$ & \begin{tabular}{|c|} 
Estados \\
Unidos \\
(América do \\
Norte)
\end{tabular} & $\begin{array}{c}\text { University of } \\
\text { Michigan Health } \\
\text { System }\end{array}$ & $\begin{array}{l}\text { Universida- } \\
\text { de ou } \\
\text { pesquisa- } \\
\text { dor } \\
\end{array}$ & $\begin{array}{c}\text { Revisão } \\
\text { Sistemática }\end{array}$ & \begin{tabular}{|c|} 
Consenso \\
sem \\
detalhes do \\
processo \\
\end{tabular} & Outros & $\begin{array}{c}\text { University of } \\
\text { Michigan } \\
\text { Health System }\end{array}$ & $\begin{array}{l}\text { Universida- } \\
\text { de }\end{array}$ \\
\hline $\begin{array}{l}\text { ACCF/AHA } 2011 \\
\text { Expert Consensus } \\
\text { Document on } \\
\text { Hypertension in the } \\
\text { Elderly (119) }\end{array}$ & 38 & 2011 & Elaborado & $\mathrm{NM}^{*}$ & \begin{tabular}{|c|} 
Estados \\
Unidos \\
(América do \\
Norte)
\end{tabular} & $\mathrm{ACC} / \mathrm{AHA}$ & Sociedade & $\begin{array}{c}\text { Revisão } \\
\text { Sistemática }\end{array}$ & \begin{tabular}{|c|} 
Consenso \\
sem \\
detalhes do \\
processo
\end{tabular} & $\mathrm{NC}^{* *}$ & $\mathrm{NM}^{*}$ & $\mathrm{NM}^{*}$ \\
\hline $\begin{array}{c}\text { Management of } \\
\text { Hypertension (4th } \\
\text { Edition) - Malaysia } \\
(120)\end{array}$ & 17 & 2013 & Atualizado & 5 & $\begin{array}{l}\text { Malásia } \\
\text { (Ásia) }\end{array}$ & $\begin{array}{c}\text { Malaysian } \\
\text { Society of } \\
\text { Hypertension/ } \\
\text { Ministry of } \\
\text { Health } \\
\text { Malaysia/ } \\
\text { Academy of } \\
\text { Medicine of } \\
\text { Malaysia } \\
\end{array}$ & Governo & $\begin{array}{c}\text { Revisão } \\
\text { Sistemática }\end{array}$ & $\begin{array}{l}\text { Consenso } \\
\text { sem } \\
\text { detalhes do } \\
\text { processo }\end{array}$ & Outros & $\begin{array}{c}\text { unrestricted } \\
\text { educational } \\
\text { grant from } \\
\text { Merck Sharp \& } \\
\text { Dohme } \\
\text { (Malaysia) }\end{array}$ & Indústria \\
\hline
\end{tabular}


APÊNDICE 3 - Características gerais dos guias de prática clínica (GPC) para tratamento farmacológico da hipertensão arterial sistêmica publicados no período de 01/2011 a 12/2016, atualizado os GPC incluídos até 11/2017.

\begin{tabular}{|c|c|c|c|c|c|c|c|c|c|c|c|c|}
\hline $\begin{array}{l}\text { Guia de Prática } \\
\text { Clínica }\end{array}$ & $\begin{array}{l}\text { Número de } \\
\text { autores }\end{array}$ & $\begin{array}{c}\text { Ano de } \\
\text { publicação }\end{array}$ & $\begin{array}{l}\text { Tipo do } \\
\text { GPC }\end{array}$ & \begin{tabular}{|} 
Período \\
previsto \\
para \\
atualização \\
(anos)
\end{tabular} & $\begin{array}{c}\text { Pais } \\
\text { (Continen- } \\
\text { te) }\end{array}$ & $\begin{array}{c}\text { Institui- } \\
\text { ção/orga- } \\
\text { nização } \\
\text { responsável } \\
\text { pela } \\
\text { elaboração } \\
\end{array}$ & $\begin{array}{l}\text { Tipo da } \\
\text { institui- } \\
\text { ção/orga- } \\
\text { nização }\end{array}$ & $\begin{array}{c}\text { Método de } \\
\text { desenvol- } \\
\text { vimento do } \\
\text { GPC }\end{array}$ & $\begin{array}{l}\text { Método } \\
\text { para } \\
\text { formular } \\
\text { as } \\
\text { recomen- } \\
\text { dações } \\
\end{array}$ & $\begin{array}{l}\text { Sistema de } \\
\text { classifi- } \\
\text { cação de } \\
\text { evidências }\end{array}$ & $\begin{array}{c}\text { Financia- } \\
\text { mento (Orgão } \\
\text { financiador) }\end{array}$ & $\begin{array}{c}\text { Tipo do } \\
\text { órgão } \\
\text { financiador }\end{array}$ \\
\hline $\begin{array}{l}\text { Treatment of } \\
\text { hypertension in } \\
\text { patients with } \\
\text { coronary artery } \\
\text { disease (121) }\end{array}$ & 19 & 2015 & Atualizado & $\mathrm{NM}^{*}$ & $\begin{array}{c}\text { Estados } \\
\text { Unidos } \\
\text { (América do } \\
\text { Norte) }\end{array}$ & $\begin{array}{l}\text { American Heart } \\
\text { Association, } \\
\text { American } \\
\text { College of } \\
\text { Cardiology, and } \\
\text { American } \\
\text { Society of } \\
\text { Hypertension }\end{array}$ & Sociedade & $\begin{array}{l}\text { Outro } \\
\text { método }\end{array}$ & $\begin{array}{l}\text { Consenso } \\
\text { sem } \\
\text { detalhes do } \\
\text { processo }\end{array}$ & Outros & $\mathrm{NM}^{*}$ & $\mathrm{NM}^{*}$ \\
\hline $\begin{array}{c}\text { Management of } \\
\text { resistant } \\
\text { hypertension: } \\
\text { expert consensus } \\
\text { statement from the } \\
\text { French Society of } \\
\text { Hypertension (122) } \\
\end{array}$ & 9 & 2016 & Elaborado & $\mathrm{NM}^{*}$ & $\begin{array}{l}\text { França } \\
\text { (Europa) }\end{array}$ & $\begin{array}{l}\text { French Society } \\
\text { of Hypertension }\end{array}$ & Sociedade & $\begin{array}{l}\text { Outro } \\
\text { método }\end{array}$ & $\begin{array}{l}\text { Consenso } \\
\text { formal } \\
\text { (método do } \\
\text { consenso } \\
\text { detalhado) }\end{array}$ & GRADE & $\mathrm{NM}^{*}$ & $\mathrm{NM}^{*}$ \\
\hline $\begin{array}{c}\text { Hypertension- } \\
\text { Diagnosis and } \\
\text { Management - } \\
\text { British Columbia } \\
\text { (123) } \\
\end{array}$ & $\mathrm{NM}^{*}$ & 2016 & Atualizado & $3-5$ & $\begin{array}{c}\text { Canadá } \\
\text { (América do } \\
\text { Norte) }\end{array}$ & $\begin{array}{l}\text { British } \\
\text { Columbia and } \\
\text { the Ministry of } \\
\text { Health }\end{array}$ & Governo & $\begin{array}{l}\text { Outro } \\
\text { método }\end{array}$ & $\begin{array}{l}\text { Consenso } \\
\text { sem } \\
\text { detalhes do } \\
\text { processo }\end{array}$ & Outros & $\mathrm{NM}^{*}$ & $\mathrm{NM}^{*}$ \\
\hline $\begin{array}{c}\text { 7a Diretriz } \\
\text { Brasileira de } \\
\text { Hipertensão } \\
\text { Arterial (124) } \\
\end{array}$ & 69 & 2016 & Atualizado & $1-2$ & $\begin{array}{c}\text { Brasil } \\
\text { (América do } \\
\text { Sul) }\end{array}$ & $\begin{array}{l}\text { Sociedade } \\
\text { Brasileira de } \\
\text { Cardiologia }\end{array}$ & Sociedade & $\mathrm{NM}^{*}$ & $\mathrm{NM}^{*}$ & Outros & $\mathrm{NM}^{*}$ & $\mathrm{NM}^{*}$ \\
\hline $\begin{array}{c}2013 \mathrm{ESH} / \mathrm{ESC} \\
\text { Guidelines for the } \\
\text { management of } \\
\text { arterial } \\
\text { hypertension (125) }\end{array}$ & 25 & 2013 & Atualizado & $\mathrm{NM}^{*}$ & $\begin{array}{l}\text { Vários } \\
\text { (Europa) }\end{array}$ & $\begin{array}{l}\text { European } \\
\text { Society of } \\
\text { Hypertension } \\
\text { and European } \\
\text { Society of } \\
\text { Cardiology }\end{array}$ & Sociedade & $\begin{array}{l}\text { Outro } \\
\text { método }\end{array}$ & $\mathrm{NM}^{*}$ & Outros & $\mathrm{NM}^{*}$ & $\mathrm{NM}^{*}$ \\
\hline
\end{tabular}


APÊNDICE 3 - Características gerais dos guias de prática clínica (GPC) para tratamento farmacológico da hipertensão arterial sistêmica publicados no período de 01/2011 a 12/2016, atualizado os GPC incluídos até 11/2017.

\begin{tabular}{|c|c|c|c|c|c|c|c|c|c|c|c|c|}
\hline $\begin{array}{l}\text { Guia de Prática } \\
\text { Clínica }\end{array}$ & $\begin{array}{l}\text { Número de } \\
\text { autores }\end{array}$ & $\begin{array}{c}\text { Ano de } \\
\text { publicação }\end{array}$ & $\begin{array}{l}\text { Tipo do } \\
\text { GPC }\end{array}$ & \begin{tabular}{|} 
Período \\
previsto \\
para \\
atualização \\
(anos)
\end{tabular} & $\begin{array}{c}\text { Pais } \\
\text { (Continen- } \\
\text { te) }\end{array}$ & $\begin{array}{c}\text { Institui- } \\
\text { ção/orga- } \\
\text { nização } \\
\text { responsável } \\
\text { pela } \\
\text { elaboração } \\
\end{array}$ & $\begin{array}{l}\text { Tipo da } \\
\text { institui- } \\
\text { ção/orga- } \\
\text { nização }\end{array}$ & $\begin{array}{c}\text { Método de } \\
\text { desenvol- } \\
\text { vimento do } \\
\text { GPC }\end{array}$ & \begin{tabular}{|c|} 
Método \\
para \\
formular \\
as \\
recomen- \\
dações \\
\end{tabular} & $\begin{array}{c}\text { Sistema de } \\
\text { classifi- } \\
\text { cação de } \\
\text { evidências }\end{array}$ & $\begin{array}{c}\text { Financia- } \\
\text { mento (Orgão } \\
\text { financiador) }\end{array}$ & $\begin{array}{l}\text { Tipo do } \\
\text { órgão } \\
\text { financiador }\end{array}$ \\
\hline $\begin{array}{l}\text { Expert consensus } \\
\text { on blood pressure } \\
\text { management of } \\
\text { diabetic patients in } \\
\text { China (126) }\end{array}$ & 1 & 2014 & Elaborado & $\mathrm{NM}^{*}$ & $\begin{array}{l}\text { China } \\
\text { (Ásia) }\end{array}$ & $\begin{array}{c}\text { Chinese } \\
\text { Society of } \\
\text { Endocrinology } \\
\text { (CSE) }\end{array}$ & Sociedade & $\begin{array}{l}\text { Outro } \\
\text { método }\end{array}$ & $\begin{array}{l}\text { Consenso } \\
\text { sem } \\
\text { detalhes do } \\
\text { processo }\end{array}$ & Outros & $\mathrm{NM}^{*}$ & $\mathrm{NM}^{*}$ \\
\hline $\begin{array}{l}\text { The Egyptian } \\
\text { hypertension } \\
\text { society: Egyptian } \\
\text { hypertension } \\
\text { guidelines (127) } \\
\end{array}$ & 28 & 2014 & Atualizado & $\mathrm{NM}^{*}$ & $\begin{array}{l}\text { Egito } \\
\text { (África) }\end{array}$ & $\begin{array}{l}\text { The Egyptian } \\
\text { Hypertension } \\
\text { Society }\end{array}$ & Sociedade & $\begin{array}{l}\text { Outro } \\
\text { método }\end{array}$ & $\begin{array}{c}\text { Consenso } \\
\text { sem } \\
\text { detalhes do } \\
\text { processo }\end{array}$ & $\mathrm{NC}^{* *}$ & $\mathrm{NM}^{*}$ & $\mathrm{NM}^{*}$ \\
\hline $\begin{array}{l}\text { Hypertension in the } \\
\text { elderly: how to treat } \\
\text { patients in } 2013 ? \\
\text { The essential } \\
\text { recommendations } \\
\text { of the Polish } \\
\text { guidelines (128) } \\
\end{array}$ & 4 & 2013 & Elaborado & $\mathrm{NM}^{*}$ & $\begin{array}{l}\text { Polônia } \\
\text { (Europa) }\end{array}$ & $\begin{array}{c}\text { Autores } \\
\text { independentes }\end{array}$ & $\begin{array}{l}\text { Universida- } \\
\text { de ou } \\
\text { pesquisa- } \\
\text { dor }\end{array}$ & $\mathrm{NM}^{*}$ & $\begin{array}{c}\text { Consenso } \\
\text { formal } \\
\text { (método do } \\
\text { consenso } \\
\text { detalhado) }\end{array}$ & $\mathrm{NC}^{\star *}$ & $\begin{array}{l}\text { European } \\
\text { Commission }\end{array}$ & Sociedade \\
\hline $\begin{array}{l}\text { Guía de Práctica } \\
\text { Clínica para el } \\
\text { Diagnóstico, } \\
\text { Tratamiento y } \\
\text { Control de la } \\
\text { Enfermedad } \\
\text { Hipertensiva (129) }\end{array}$ & $\mathrm{NM}^{*}$ & 2015 & Elaborado & $\mathrm{NM}^{*}$ & $\begin{array}{c}\text { Peru } \\
\text { (América do } \\
\text { Sul) }\end{array}$ & $\begin{array}{l}\text { Ministério da } \\
\text { Saúde }\end{array}$ & Governo & $\mathrm{NM}^{*}$ & $\mathrm{NM}^{*}$ & Outros & $\mathrm{NM}^{*}$ & $\mathrm{NM}^{*}$ \\
\hline $\begin{array}{c}\text { Hypertension in } \\
\text { diverse } \\
\text { populations: A New } \\
\text { York State } \\
\text { Medicaid clinical } \\
\text { guidance document } \\
\text { (130) } \\
\end{array}$ & 3 & 2011 & Elaborado & $\mathrm{NM}^{*}$ & $\begin{array}{c}\text { Estados } \\
\text { Unidos } \\
\text { (América do } \\
\text { Norte) }\end{array}$ & $\begin{array}{l}\text { New York State } \\
\text { Medicaid } \\
\text { Prescriber } \\
\text { Education } \\
\text { Program (PEP) }\end{array}$ & Governo & $\mathrm{NM}^{*}$ & $\begin{array}{c}\text { Consenso } \\
\text { sem } \\
\text { detalhes do } \\
\text { processo }\end{array}$ & $\mathrm{NC}^{\star *}$ & $\mathrm{NM}^{*}$ & $\mathrm{NM}^{*}$ \\
\hline
\end{tabular}


APÊNDICE 3 - Características gerais dos guias de prática clínica (GPC) para tratamento farmacológico da hipertensão arterial sistêmica publicados no período de 01/2011 a 12/2016, atualizado os GPC incluídos até 11/2017.

\begin{tabular}{|c|c|c|c|c|c|c|c|c|c|c|c|c|}
\hline $\begin{array}{l}\text { Guia de Prática } \\
\text { Clínica }\end{array}$ & $\begin{array}{l}\text { Número de } \\
\text { autores }\end{array}$ & $\begin{array}{c}\text { Ano de } \\
\text { publicação }\end{array}$ & $\begin{array}{l}\text { Tipo do } \\
\text { GPC }\end{array}$ & $\begin{array}{c}\text { Período } \\
\text { previsto } \\
\text { para } \\
\text { atualização } \\
\text { (anos) }\end{array}$ & $\begin{array}{c}\text { Pais } \\
\text { (Continen- } \\
\text { te) }\end{array}$ & $\begin{array}{c}\text { Institui- } \\
\text { ção/orga- } \\
\text { nização } \\
\text { responsável } \\
\text { pela } \\
\text { elaboração } \\
\end{array}$ & $\begin{array}{l}\text { Tipo da } \\
\text { institui- } \\
\text { ção/orga- } \\
\text { nização }\end{array}$ & $\begin{array}{c}\text { Método de } \\
\text { desenvol- } \\
\text { vimento do } \\
\text { GPC }\end{array}$ & $\begin{array}{l}\text { Método } \\
\text { para } \\
\text { formular } \\
\text { as } \\
\text { recomen- } \\
\text { dações } \\
\end{array}$ & $\begin{array}{l}\text { Sistema de } \\
\text { classifi- } \\
\text { cação de } \\
\text { evidências }\end{array}$ & $\begin{array}{c}\text { Financia- } \\
\text { mento (Orgão } \\
\text { financiador) }\end{array}$ & $\begin{array}{c}\text { Tipo do } \\
\text { órgão } \\
\text { financiador }\end{array}$ \\
\hline $\begin{array}{l}\text { Indian guidelines } \\
\text { on hypertension } \\
\text { (I.G.H.) - III (131) }\end{array}$ & 8 & 2013 & Atualizado & $\mathrm{NM}^{*}$ & India (Ásia) & $\begin{array}{l}\text { Cardiological } \\
\text { Society of } \\
\text { India,Hypertens } \\
\text { ion Society of } \\
\text { India, Indian } \\
\text { College of } \\
\text { Physicians, } \\
\text { Indian Society } \\
\text { of Nephrology, } \\
\text { Research } \\
\text { Society for } \\
\text { Study of } \\
\text { Diabetes in } \\
\text { India and Indian } \\
\text { Academy of } \\
\text { Diabetes }\end{array}$ & Sociedade & $\begin{array}{c}\text { Revisão } \\
\text { Sistemática }\end{array}$ & $\begin{array}{c}\text { Consenso } \\
\text { sem } \\
\text { detalhes do } \\
\text { processo }\end{array}$ & $\mathrm{NC}^{* *}$ & $\begin{array}{l}\text { Cardiological } \\
\text { Society of } \\
\text { India, } \\
\text { Hypertension } \\
\text { Society of } \\
\text { India, Indian } \\
\text { College of } \\
\text { Physicians, } \\
\text { Indian Society } \\
\text { of Nephrology, } \\
\text { Research } \\
\text { Society for } \\
\text { Study of } \\
\text { Diabetes in } \\
\text { Indian } \\
\text { Academy of } \\
\text { Diabetes }\end{array}$ & Sociedade \\
\hline $\begin{array}{c}\text { Management of } \\
\text { hypertension in } \\
\text { adults: the } 2013 \\
\text { French Society of } \\
\text { Hypertension (132) }\end{array}$ & 7 & 2013 & Elaborado & $\mathrm{NM}^{*}$ & $\begin{array}{l}\text { França } \\
\text { (Europa) }\end{array}$ & $\begin{array}{l}\text { French Society } \\
\text { of Hypertension }\end{array}$ & Sociedade & $\mathrm{NM}^{*}$ & $\mathrm{NM}^{*}$ & $\mathrm{NC}^{* *}$ & $\mathrm{NM}^{*}$ & $\mathrm{NM}^{*}$ \\
\hline $\begin{array}{l}\text { Abordaje de la } \\
\text { hipertension arterial } \\
\text { en el paciente } \\
\text { anciano (133) }\end{array}$ & 1 & 2014 & Elaborado & $\mathrm{NM}^{*}$ & $\begin{array}{l}\text { Espanha } \\
\text { (Europa) }\end{array}$ & $\begin{array}{c}\text { Autor } \\
\text { independente }\end{array}$ & $\begin{array}{l}\text { Universida- } \\
\text { de ou } \\
\text { pesquisa- } \\
\text { dor } \\
\end{array}$ & $\mathrm{NM}^{*}$ & $\mathrm{NM}^{*}$ & Outros & $\mathrm{NM}^{*}$ & $\mathrm{NM}^{*}$ \\
\hline $\begin{array}{c}\text { Combination } \\
\text { therapy in } \\
\text { hypertension: an } \\
\text { Asia-Pacific } \\
\text { consensus (134) }\end{array}$ & 6 & 2014 & Elaborado & $\mathrm{NM}^{*}$ & $\begin{array}{l}\text { Vários } \\
\text { (Ásia) }\end{array}$ & $\begin{array}{c}\text { Autores } \\
\text { independentes }\end{array}$ & $\begin{array}{l}\text { Universida- } \\
\text { de ou } \\
\text { pesquisa- } \\
\text { dor }\end{array}$ & $\begin{array}{l}\text { Outro } \\
\text { método }\end{array}$ & $\begin{array}{c}\text { Consenso } \\
\text { sem } \\
\text { detalhes do } \\
\text { processo }\end{array}$ & $\mathrm{NC}^{* *}$ & $\begin{array}{l}\text { unrestricted } \\
\text { educational } \\
\text { grant from } \\
\text { Merck Pte Ltd. }\end{array}$ & Indústria \\
\hline
\end{tabular}


APÊNDICE 3 - Características gerais dos guias de prática clínica (GPC) para tratamento farmacológico da hipertensão arterial sistêmica publicados no período de 01/2011 a 12/2016, atualizado os GPC incluídos até 11/2017.

\begin{tabular}{|c|c|c|c|c|c|c|c|c|c|c|c|c|}
\hline $\begin{array}{c}\text { Guia de Prática } \\
\text { Clínica }\end{array}$ & $\begin{array}{l}\text { Número de } \\
\text { autores }\end{array}$ & $\begin{array}{c}\text { Ano de } \\
\text { publicação }\end{array}$ & $\begin{array}{l}\text { Tipo do } \\
\text { GPC }\end{array}$ & $\begin{array}{c}\text { Período } \\
\text { previsto } \\
\text { para } \\
\text { atualização } \\
\text { (anos) }\end{array}$ & $\begin{array}{c}\text { Pais } \\
\text { (Continen- } \\
\text { te) }\end{array}$ & $\begin{array}{c}\text { Institui- } \\
\text { ção/orga- } \\
\text { nização } \\
\text { responsável } \\
\text { pela } \\
\text { elaboração }\end{array}$ & $\begin{array}{l}\text { Tipo da } \\
\text { institui- } \\
\text { ção/orga- } \\
\text { nização }\end{array}$ & $\begin{array}{c}\text { Método de } \\
\text { desenvol- } \\
\text { vimento do } \\
\text { GPC }\end{array}$ & $\begin{array}{l}\text { Método } \\
\text { para } \\
\text { formular } \\
\text { as } \\
\text { recomen- } \\
\text { dações }\end{array}$ & $\begin{array}{l}\text { Sistema de } \\
\text { classifi- } \\
\text { cação de } \\
\text { evidências }\end{array}$ & $\begin{array}{l}\text { Financia- } \\
\text { mento (Orgão } \\
\text { financiador) }\end{array}$ & $\begin{array}{c}\text { Tipo do } \\
\text { órgão } \\
\text { financiador }\end{array}$ \\
\hline $\begin{array}{l}2015 \text { Oman Heart } \\
\text { Association } \\
\text { Guidelines for the } \\
\text { Management of } \\
\text { Hypertension (135) }\end{array}$ & 17 & 2015 & Elaborado & $\mathrm{NM}^{*}$ & Omã (Ásia) & $\begin{array}{l}\text { Oman Heart } \\
\text { Association } \\
\text { (OHA) }\end{array}$ & Sociedade & $\mathrm{NM}^{*}$ & $\mathrm{NM}^{*}$ & $\mathrm{NC}^{* *}$ & $\mathrm{NM}^{*}$ & $\mathrm{NM}^{*}$ \\
\hline $\begin{array}{c}\text { Latin American } \\
\text { consensus on } \\
\text { hypertension in } \\
\text { patients with } \\
\text { diabetes type } 2 \text { and } \\
\text { metabolic } \\
\text { syndrome (136) }\end{array}$ & 21 & 2014 & Elaborado & $\mathrm{NM}^{*}$ & $\begin{array}{c}\text { Vários } \\
\text { (América do } \\
\text { Sul) }\end{array}$ & $\begin{array}{c}\text { Autores } \\
\text { independentes }\end{array}$ & $\begin{array}{l}\text { Universida- } \\
\text { de ou } \\
\text { pesquisa- } \\
\text { dor }\end{array}$ & $\begin{array}{l}\text { Outro } \\
\text { método }\end{array}$ & $\begin{array}{l}\text { Consenso } \\
\text { sem } \\
\text { detalhes do } \\
\text { processo }\end{array}$ & $\mathrm{NC}^{* *}$ & $\mathrm{NM}^{*}$ & $\mathrm{NM}^{*}$ \\
\hline $\begin{array}{l}\text { South African } \\
\text { hypertension } \\
\text { practice guideline } \\
2014 \text { (137) }\end{array}$ & 3 & 2014 & Atualizado & $\mathrm{NM}^{*}$ & $\begin{array}{l}\text { Africa do } \\
\text { Sul } \\
\text { (África) }\end{array}$ & $\begin{array}{c}\text { Southern } \\
\text { African } \\
\text { Hypertension } \\
\text { Society } 2014\end{array}$ & Sociedade & $\begin{array}{l}\text { Outro } \\
\text { método }\end{array}$ & $\mathrm{NM}^{*}$ & $\mathrm{NC}^{* *}$ & $\mathrm{NM}^{*}$ & $\mathrm{NM}^{*}$ \\
\hline $\begin{array}{c}\text { Consensus of } \\
\text { Chinese Specialists } \\
\text { on Diagnosis and } \\
\text { Treatment of } \\
\text { Resistant } \\
\text { Hypertension (138) }\end{array}$ & 9 & 2015 & Elaborado & $\mathrm{NM}^{*}$ & $\begin{array}{l}\text { China } \\
\text { (Ásia) }\end{array}$ & $\begin{array}{c}\text { Autores } \\
\text { independentes }\end{array}$ & $\begin{array}{l}\text { Universida- } \\
\text { de ou } \\
\text { pesquisa- } \\
\text { dor }\end{array}$ & $\begin{array}{l}\text { Outro } \\
\text { método }\end{array}$ & $\begin{array}{l}\text { Consenso } \\
\text { sem } \\
\text { detalhes do } \\
\text { processo }\end{array}$ & $\mathrm{NC}^{* *}$ & $\mathrm{NM}^{*}$ & $\mathrm{NM}^{*}$ \\
\hline $\begin{array}{c}\text { Clinical } \\
\text { management of } \\
\text { resistant } \\
\text { hypertension: } \\
\text { recommendations } \\
\text { from the ISH (139) }\end{array}$ & 4 & 2013 & Elaborado & $\mathrm{NM}^{*}$ & $\begin{array}{c}\text { Itália } \\
\text { (Europa) }\end{array}$ & $\begin{array}{l}\text { Italian Society } \\
\text { of Hypertension } \\
\text { (SIIA) }\end{array}$ & Sociedade & $\mathrm{NM}^{*}$ & $\mathrm{NM}^{*}$ & $\mathrm{NC}^{* *}$ & $\mathrm{NM}^{*}$ & $\mathrm{NM}^{*}$ \\
\hline
\end{tabular}


APÊNDICE 3 - Características gerais dos guias de prática clínica (GPC) para tratamento farmacológico da hipertensão arterial sistêmica publicados no período de 01/2011 a 12/2016, atualizado os GPC incluídos até 11/2017.

\begin{tabular}{|c|c|c|c|c|c|c|c|c|c|c|c|c|}
\hline $\begin{array}{l}\text { Guia de Prática } \\
\text { Clínica }\end{array}$ & $\begin{array}{l}\text { Número de } \\
\text { autores }\end{array}$ & $\begin{array}{c}\text { Ano de } \\
\text { publicação }\end{array}$ & $\begin{array}{l}\text { Tipo do } \\
\text { GPC }\end{array}$ & \begin{tabular}{|} 
Período \\
previsto \\
para \\
atualização \\
(anos)
\end{tabular} & $\begin{array}{c}\text { Pais } \\
\text { (Continen- } \\
\text { te) }\end{array}$ & $\begin{array}{c}\text { Institui- } \\
\text { ção/orga- } \\
\text { nização } \\
\text { responsável } \\
\text { pela } \\
\text { elaboração } \\
\end{array}$ & $\begin{array}{l}\text { Tipo da } \\
\text { institui- } \\
\text { ção/orga- } \\
\text { nização }\end{array}$ & $\begin{array}{c}\text { Método de } \\
\text { desenvol- } \\
\text { vimento do } \\
\text { GPC }\end{array}$ & $\begin{array}{l}\text { Método } \\
\text { para } \\
\text { formular } \\
\text { as } \\
\text { recomen- } \\
\text { dações } \\
\end{array}$ & $\begin{array}{l}\text { Sistema de } \\
\text { classifi- } \\
\text { cação de } \\
\text { evidências }\end{array}$ & $\begin{array}{c}\text { Financia- } \\
\text { mento (Orgão } \\
\text { financiador) }\end{array}$ & $\begin{array}{l}\text { Tipo do } \\
\text { órgão } \\
\text { financiador }\end{array}$ \\
\hline $\begin{array}{l}\text { Clinical Practice } \\
\text { Guidelines for the } \\
\text { Management of } \\
\text { Hypertension in the } \\
\text { Community (140) }\end{array}$ & 25 & 2014 & Elaborado & $\mathrm{NM}^{*}$ & $\begin{array}{c}\text { Vários } \\
\text { (Interconti- } \\
\text { nental) }\end{array}$ & $\begin{array}{c}\text { American } \\
\text { Society of } \\
\text { Hypertension } \\
\text { and } \\
\text { International } \\
\text { Society of } \\
\text { Hypertension } \\
\end{array}$ & Sociedade & $\mathrm{NM}^{*}$ & $\mathrm{NM}^{*}$ & $\mathrm{NC}^{* *}$ & $\begin{array}{c}\text { American } \\
\text { Society of } \\
\text { Hypertension } \\
\text { and } \\
\text { International } \\
\text { Society of } \\
\text { Hypertension } \\
\end{array}$ & Sociedade \\
\hline $\begin{array}{c}\text { I brazilian position } \\
\text { paper on } \\
\text { antihypertensive } \\
\text { drug combination } \\
(141) \\
\end{array}$ & 29 & 2014 & Elaborado & $\mathrm{NM}^{*}$ & $\begin{array}{c}\text { Brasil } \\
\text { (América do } \\
\text { Sul) }\end{array}$ & $\begin{array}{c}\text { Sociedade } \\
\text { Brasileira de } \\
\text { Cardiologia }\end{array}$ & Sociedade & $\mathrm{NM}^{*}$ & $\mathrm{NM}^{*}$ & $\mathrm{NC}^{* *}$ & $\mathrm{NM}^{*}$ & $\mathrm{NM}^{*}$ \\
\hline \begin{tabular}{c|} 
I Brazilian Position \\
Paper on \\
Prehypertension, \\
White Coat \\
Hypertension and \\
Masked \\
Hypertension: \\
Diagnosis and \\
Management (142) \\
\end{tabular} & 30 & 2014 & Elaborado & $\mathrm{NM}^{*}$ & $\begin{array}{c}\text { Brasil } \\
\text { (América do } \\
\text { Sul) }\end{array}$ & $\begin{array}{l}\text { Sociedade } \\
\text { Brasileira de } \\
\text { Cardiologia }\end{array}$ & Sociedade & $\mathrm{NM}^{*}$ & $\mathrm{NM}^{*}$ & $\mathrm{NC}^{* *}$ & $\mathrm{NM}^{*}$ & $\mathrm{NM}^{*}$ \\
\hline $\begin{array}{c}\text { Hypertension in the } \\
\text { elderly: new blood } \\
\text { pressure targets } \\
\text { and prescribing tips } \\
(143)\end{array}$ & 3 & 2014 & Elaborado & $\mathrm{NM}^{*}$ & $\begin{array}{c}\text { Canadá } \\
\text { (América do } \\
\text { Norte) }\end{array}$ & $\begin{array}{l}\text { Autores } \\
\text { independentes }\end{array}$ & $\begin{array}{l}\text { Universida- } \\
\text { de ou } \\
\text { pesquisa- } \\
\quad \text { dor }\end{array}$ & $\mathrm{NM}^{*}$ & $\mathrm{NM}^{*}$ & $\mathrm{NC}^{* *}$ & $\begin{array}{l}\text { Saskatchewan } \\
\text { Health to } \\
\text { Saskatoon } \\
\text { Health Region }\end{array}$ & Sociedade \\
\hline
\end{tabular}


APÊNDICE 3 - Características gerais dos guias de prática clínica (GPC) para tratamento farmacológico da hipertensão arterial sistêmica publicados no período de 01/2011 a 12/2016, atualizado os GPC incluídos até 11/2017.

\begin{tabular}{|c|c|c|c|c|c|c|c|c|c|c|c|c|}
\hline $\begin{array}{l}\text { Guia de Prática } \\
\text { Clínica }\end{array}$ & $\begin{array}{l}\text { Número de } \\
\text { autores }\end{array}$ & $\begin{array}{l}\text { Ano de } \\
\text { publicação }\end{array}$ & $\begin{array}{l}\text { Tipo do } \\
\text { GPC }\end{array}$ & $\begin{array}{c}\text { Período } \\
\text { previsto } \\
\text { para } \\
\text { atualização } \\
\text { (anos) }\end{array}$ & $\begin{array}{c}\text { Pais } \\
\text { (Continen- } \\
\text { te) }\end{array}$ & $\begin{array}{c}\text { Institui- } \\
\text { ção/orga- } \\
\text { nização } \\
\text { responsável } \\
\text { pela } \\
\text { elaboração }\end{array}$ & $\begin{array}{c}\text { Tipo da } \\
\text { institui- } \\
\text { ção/orga- } \\
\text { nizaçẫo }\end{array}$ & $\begin{array}{c}\text { Método de } \\
\text { desenvol- } \\
\text { vimento do } \\
\text { GPC }\end{array}$ & $\begin{array}{c}\text { Método } \\
\text { para } \\
\text { formular } \\
\text { as } \\
\text { recomen- } \\
\text { dações }\end{array}$ & $\begin{array}{l}\text { Sistema de } \\
\text { classifi- } \\
\text { cação de } \\
\text { evidências }\end{array}$ & $\begin{array}{c}\text { Financia- } \\
\text { mento (Orgão } \\
\text { financiador) }\end{array}$ & $\begin{array}{c}\text { Tipo do } \\
\text { orgão } \\
\text { financiador }\end{array}$ \\
\hline
\end{tabular}

$\mathrm{NM}^{*}$ - Não mencionado/ $\mathrm{NC}^{* *}$ - Não classifica

Fonte: Elaboração própria. 
APÊNDICE 4- NOTAS ATRIBUÍDAS AOS GUIAS DE PRÁTICA CLÍNICA PARA TRATAMENTO DA HIPERTENSÃO ARTERIAL SISTÊMICA POR CADA AVALIADOR PARA CADA ITEM DO AGREE II.

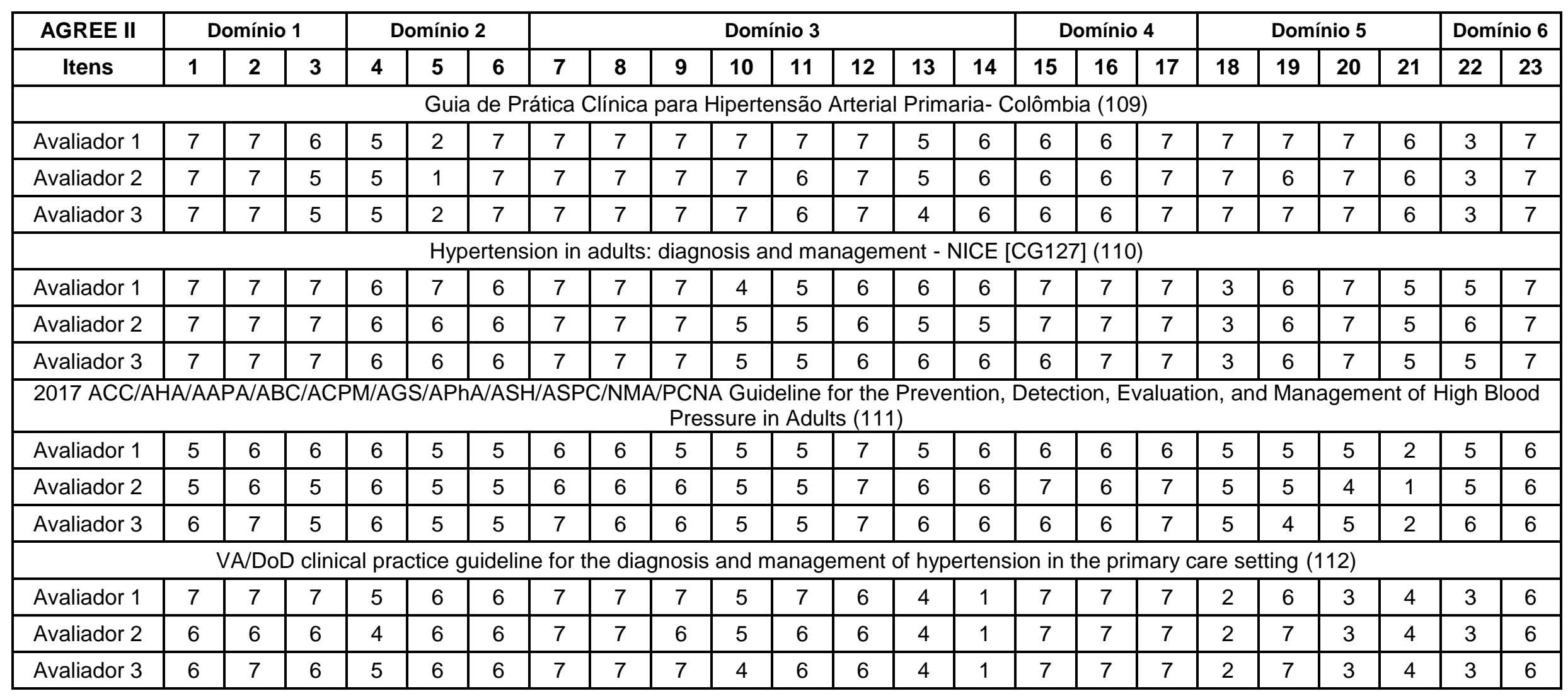


APÊNDICE 4 - Notas atribuídas aos guias de prática clínica para tratamento da hipertensão arterial sistêmica por cada avaliador para cada item do AGREE II.

\begin{tabular}{|c|c|c|c|c|c|c|c|c|c|c|c|c|c|c|c|c|c|c|c|c|c|c|c|}
\hline \multirow{2}{*}{$\begin{array}{c}\text { AGREE II } \\
\text { Itens }\end{array}$} & \multicolumn{3}{|c|}{ Domínio 1} & \multicolumn{3}{|c|}{ Domínio 2} & \multicolumn{8}{|c|}{ Domínio 3} & \multicolumn{3}{|c|}{ Domínio 4} & \multicolumn{4}{|c|}{ Domínio 5} & \multicolumn{2}{|c|}{ Domínio 6} \\
\hline & 1 & 2 & 3 & 4 & 5 & 6 & 7 & 8 & 9 & 10 & 11 & 12 & 13 & 14 & 15 & 16 & 17 & 18 & 19 & 20 & 21 & 22 & 23 \\
\hline \multicolumn{24}{|c|}{ Hypertension Canada's 2017 Guidelines for Diagnosis, Risk Assessment, Prevention, and Treatment of Hypertension in Adults (113) } \\
\hline Avaliador 1 & 5 & 5 & 5 & 6 & 2 & 4 & 5 & 5 & 6 & 4 & 4 & 4 & 6 & 6 & 6 & 6 & 6 & 3 & 4 & 2 & 2 & 6 & 6 \\
\hline Avaliador 3 & 6 & 5 & 5 & 6 & 2 & 4 & 5 & 4 & 6 & 4 & 4 & 4 & 5 & 5 & 6 & 6 & 6 & 3 & 4 & 1 & 2 & 6 & 5 \\
\hline \multicolumn{24}{|c|}{ Diagnóstico y Tratamiento de la HIPERTENSIÓN ARTERIAL en el Primer Nivel de Atención (114) } \\
\hline Avaliador 1 & 6 & 5 & 6 & 4 & 1 & 6 & 7 & 6 & 5 & 1 & 5 & 6 & 3 & 6 & 6 & 6 & 6 & 1 & 5 & 1 & 2 & 5 & 6 \\
\hline \multicolumn{24}{|c|}{ Heart Foundation - HAS 2016 (115) } \\
\hline Avaliador 1 & 6 & 6 & 5 & 4 & 3 & 5 & 5 & 4 & 6 & 4 & 5 & 5 & 4 & 1 & 5 & 5 & 5 & 4 & 5 & 2 & 2 & 4 & 3 \\
\hline Avaliador 2 & 6 & 5 & 5 & 4 & 3 & 5 & 6 & 5 & 7 & 5 & 5 & 4 & 5 & 1 & 6 & 5 & 6 & 4 & 5 & 3 & 2 & 4 & 4 \\
\hline Avaliador 3 & 6 & 6 & 6 & 4 & 3 & 5 & 5 & 4 & 7 & 4 & 5 & 5 & 4 & 1 & 6 & 6 & 6 & 4 & 5 & 3 & 3 & 4 & 4 \\
\hline \multicolumn{24}{|c|}{ Clinical practice guidelines on arterial hypertension - NGC: 015712 (116) } \\
\hline Avaliador 1 & 6 & 5 & 6 & 5 & 1 & 6 & 5 & 4 & 6 & 4 & 5 & 5 & 4 & 1 & 5 & 6 & 5 & 1 & 5 & 2 & 5 & 4 & 4 \\
\hline Avaliador 2 & 5 & 4 & 3 & 3 & 1 & 5 & 3 & 3 & 7 & 7 & 4 & 5 & 5 & 1 & 5 & 6 & 7 & 1 & 4 & 2 & 2 & 3 & 5 \\
\hline Avaliador 3 & 4 & 4 & 3 & 3 & 1 & 5 & 3 & 3 & 7 & 6 & 3 & 4 & 5 & 1 & 5 & 5 & 6 & 1 & 3 & 2 & 2 & 3 & 4 \\
\hline
\end{tabular}


APÊNDICE 4 - Notas atribuídas aos guias de prática clínica para tratamento da hipertensão arterial sistêmica por cada avaliador para cada item do AGREE II.

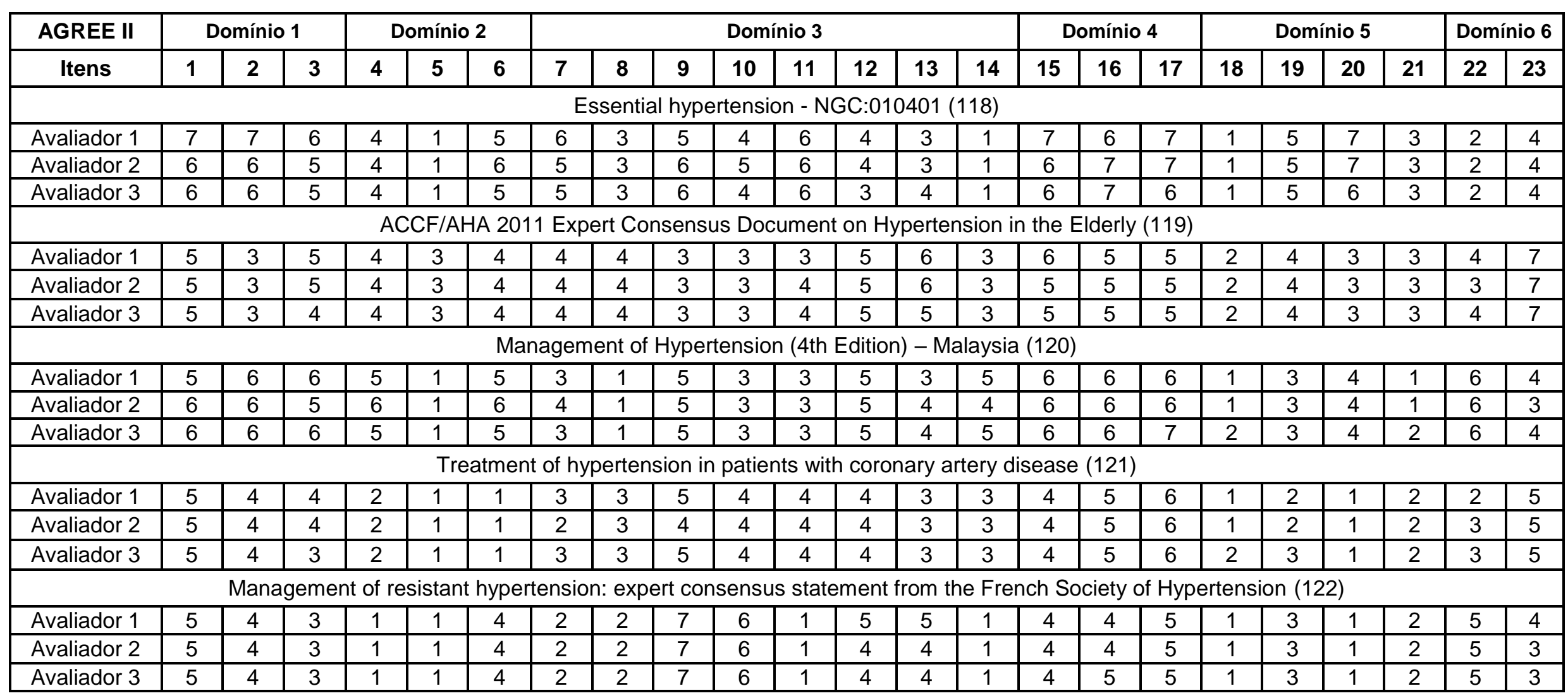


APÊNDICE 4 - Notas atribuídas aos guias de prática clínica para tratamento da hipertensão arterial sistêmica por cada avaliador para cada item do AGREE II.

\begin{tabular}{|c|c|c|c|c|c|c|c|c|c|c|c|c|c|c|c|c|c|c|c|c|c|c|c|}
\hline \multirow{2}{*}{$\begin{array}{c}\text { AGREE II } \\
\text { Itens }\end{array}$} & \multicolumn{3}{|c|}{ Domínio 1} & \multicolumn{3}{|c|}{ Domínio 2} & \multicolumn{8}{|c|}{ Domínio 3} & \multicolumn{3}{|c|}{ Domínio 4} & \multicolumn{4}{|c|}{ Domínio 5} & \multicolumn{2}{|c|}{ Domínio 6} \\
\hline & 1 & 2 & 3 & 4 & 5 & 6 & 7 & 8 & 9 & 10 & 11 & 12 & 13 & 14 & 15 & 16 & 17 & 18 & 19 & 20 & 21 & 22 & 23 \\
\hline \multicolumn{24}{|c|}{ Hypertension- Diagnosis and Management - British Columbia (123) } \\
\hline Avaliador 1 & 6 & 5 & 5 & 2 & 1 & 4 & 2 & 2 & 4 & 2 & 5 & 4 & 4 & 4 & 6 & 5 & 5 & 1 & 5 & 4 & 1 & 3 & 3 \\
\hline Avaliador 3 & 6 & 5 & 5 & 2 & 1 & 5 & 2 & 1 & 4 & 2 & 5 & 4 & 4 & 4 & 6 & 5 & 6 & 1 & 5 & 4 & 2 & 3 & 3 \\
\hline \multicolumn{24}{|c|}{ 7a Diretriz Brasileira de Hipertensão Arterial (124) } \\
\hline Avaliador 1 & 5 & 6 & 6 & 3 & 1 & 4 & 2 & 1 & 5 & 2 & 5 & 5 & 1 & 4 & 6 & 6 & 5 & 1 & 4 & 1 & 1 & 3 & 4 \\
\hline \multicolumn{24}{|c|}{2013 ESH/ESC Guidelines for the management of arterial hypertension (125) } \\
\hline Avaliador 1 & 4 & 4 & 4 & 4 & 1 & 3 & 2 & 2 & 3 & 3 & 2 & 5 & 3 & 3 & 5 & 7 & 6 & 1 & 4 & 3 & 2 & 3 & 4 \\
\hline Avaliador 2 & 4 & 4 & 5 & 4 & 1 & 4 & 2 & 2 & 3 & 3 & 2 & 5 & 3 & 3 & 5 & 7 & 7 & 1 & 4 & 4 & 2 & 3 & 4 \\
\hline Avaliador 3 & 4 & 4 & 4 & 4 & 1 & 4 & 2 & 2 & 3 & 2 & 3 & 5 & 3 & 3 & 5 & 7 & 7 & 1 & 4 & 4 & 2 & 3 & 4 \\
\hline \multicolumn{24}{|c|}{ Expert consensus on blood pressure management of diabetic patients in China (126) } \\
\hline Avaliador 1 & 4 & 4 & 4 & 1 & 1 & 4 & 2 & 2 & 4 & 3 & 4 & 4 & 1 & 1 & 4 & 5 & 4 & 1 & 2 & 2 & 1 & 1 & 3 \\
\hline Avaliador 2 & 6 & 4 & 3 & 1 & 1 & 4 & 1 & 1 & 4 & 1 & 6 & 4 & 1 & 1 & 5 & 5 & 6 & 1 & 5 & 1 & 2 & 3 & 1 \\
\hline Avaliador 3 & 6 & 4 & 3 & 1 & 1 & 3 & 1 & 1 & 4 & 1 & 6 & 4 & 1 & 1 & 5 & 6 & 6 & 1 & 5 & 1 & 2 & 3 & 1 \\
\hline
\end{tabular}


APÊNDICE 4 - Notas atribuídas aos guias de prática clínica para tratamento da hipertensão arterial sistêmica por cada avaliador para cada item do AGREE II.

\begin{tabular}{|c|c|c|c|c|c|c|c|c|c|c|c|c|c|c|c|c|c|c|c|c|c|c|c|}
\hline \multirow{2}{*}{$\begin{array}{c}\text { AGREE II } \\
\text { Itens }\end{array}$} & \multicolumn{3}{|c|}{ Domínio 1} & \multicolumn{3}{|c|}{ Domínio 2} & \multicolumn{8}{|c|}{ Domínio 3} & \multicolumn{3}{|c|}{ Domínio 4} & \multicolumn{4}{|c|}{ Domínio 5} & \multicolumn{2}{|c|}{ Domínio 6} \\
\hline & 1 & 2 & 3 & 4 & 5 & 6 & 7 & 8 & 9 & 10 & 11 & 12 & 13 & 14 & 15 & 16 & 17 & 18 & 19 & 20 & 21 & 22 & 23 \\
\hline \multicolumn{24}{|c|}{ Hypertension in the elderly: how to treat patients in 2013? The essential recommendations of the Polish guidelines (128) } \\
\hline Avaliador 1 & 4 & 4 & 5 & 2 & 1 & 4 & 2 & 2 & 1 & 6 & 3 & 2 & 3 & 1 & 5 & 5 & 5 & 1 & 2 & 1 & 1 & 3 & 2 \\
\hline Avaliador 3 & 3 & 5 & 6 & 2 & 2 & 3 & 2 & 1 & 1 & 7 & 2 & 2 & 3 & 1 & 4 & 5 & 5 & 1 & 2 & 1 & 2 & 3 & 2 \\
\hline \multicolumn{24}{|c|}{ Guía de Práctica Clínica para el Diagnóstico, Tratamiento y Control de la Enfermedad Hipertensiva (129) } \\
\hline Avaliador 1 & 6 & 4 & 3 & 2 & 1 & 3 & 2 & 1 & 4 & 1 & 5 & 4 & 1 & 1 & 5 & 5 & 6 & 1 & 5 & 1 & 2 & 3 & 1 \\
\hline \multicolumn{24}{|c|}{ Hypertension in diverse populations: A New York State Medicaid clinical guidance document (130) } \\
\hline Avaliador 1 & 5 & 3 & 3 & 3 & 2 & 2 & 2 & 2 & 2 & 2 & 4 & 4 & 4 & 1 & 4 & 5 & 4 & 3 & 2 & 1 & 4 & 1 & 2 \\
\hline Avaliador 2 & 5 & 3 & 3 & 3 & 1 & 2 & 1 & 1 & 1 & 2 & 4 & 4 & 4 & 1 & 4 & 5 & 4 & 3 & 2 & 1 & 4 & 1 & 2 \\
\hline Avaliador 3 & 5 & 3 & 3 & 3 & 1 & 2 & 1 & 1 & 1 & 2 & 3 & 4 & 4 & 1 & 4 & 5 & 4 & 3 & 2 & 1 & 4 & 1 & 2 \\
\hline \multicolumn{24}{|c|}{ Indian guidelines on hypertension (I.G.H.) - III (131) } \\
\hline Avaliador 1 & 5 & 4 & 5 & 3 & 1 & 5 & 3 & 2 & 1 & 1 & 4 & 2 & 4 & 1 & 4 & 5 & 4 & 1 & 2 & 1 & 1 & 3 & 1 \\
\hline Avaliador 1 & 5 & 4 & 3 & 5 & 2 & 4 & 2 & 2 & 1 & 4 & 2 & 2 & 1 & 2 & 5 & 5 & 5 & 1 & 2 & 1 & 3 & 6 & 3 \\
\hline Avaliador 2 & 5 & 5 & 4 & 5 & 2 & 4 & 2 & 2 & 1 & 4 & 3 & 1 & 1 & 2 & 5 & 5 & 5 & 1 & 1 & 1 & 3 & 6 & 3 \\
\hline Avaliador 3 & 4 & 4 & 4 & 5 & 2 & 4 & 1 & 2 & 1 & 4 & 2 & 2 & 1 & 3 & 4 & 4 & 4 & 1 & 2 & 1 & 2 & 6 & 3 \\
\hline
\end{tabular}


APÊNDICE 4 - Notas atribuídas aos guias de prática clínica para tratamento da hipertensão arterial sistêmica por cada avaliador para cada item do AGREE II.

\begin{tabular}{|c|c|c|c|c|c|c|c|c|c|c|c|c|c|c|c|c|c|c|c|c|c|c|c|}
\hline \multirow{2}{*}{$\begin{array}{c}\text { AGREE II } \\
\text { Itens }\end{array}$} & \multicolumn{3}{|c|}{ Domínio 1} & \multicolumn{3}{|c|}{ Domínio 2} & \multicolumn{8}{|c|}{ Domínio 3} & \multicolumn{3}{|c|}{ Domínio 4} & \multicolumn{4}{|c|}{ Domínio 5} & \multicolumn{2}{|c|}{ Domínio 6} \\
\hline & 1 & 2 & 3 & 4 & 5 & 6 & 7 & 8 & 9 & 10 & 11 & 12 & 13 & 14 & 15 & 16 & 17 & 18 & 19 & 20 & 21 & 22 & 23 \\
\hline \multicolumn{24}{|c|}{ Abordaje de la hipertension arterial en el paciente anciano (133) } \\
\hline Avaliador 1 & 5 & 3 & 4 & 1 & 1 & 1 & 2 & 2 & 3 & 1 & 1 & 4 & 1 & 1 & 4 & 3 & 5 & 1 & 1 & 1 & 2 & 1 & 6 \\
\hline Avaliador 3 & 5 & 3 & 4 & 1 & 1 & 1 & 1 & 1 & 3 & 1 & 1 & 4 & 1 & 1 & 4 & 3 & 5 & 1 & 1 & 1 & 2 & 1 & 6 \\
\hline \multicolumn{24}{|c|}{ Combination therapy in hypertension: an Asia-Pacific consensus viewpoint (134) } \\
\hline Avaliador 1 & 5 & 5 & 4 & 3 & 2 & 3 & 2 & 2 & 1 & 4 & 2 & 2 & 1 & 1 & 5 & 5 & 5 & 1 & 2 & 2 & 1 & 3 & 3 \\
\hline \multicolumn{24}{|c|}{2015 Oman Heart Association Guidelines for the Management of Hypertension (135) } \\
\hline Avaliador 1 & 4 & 4 & 3 & 2 & 2 & 4 & 2 & 1 & 1 & 1 & 4 & 2 & 1 & 1 & 5 & 5 & 5 & 1 & 3 & 2 & 1 & 2 & 1 \\
\hline Avaliador 2 & 4 & 5 & 3 & 1 & 1 & 4 & 1 & 1 & 1 & 1 & 4 & 2 & 1 & 1 & 5 & 6 & 6 & 1 & 3 & 1 & 1 & 2 & 1 \\
\hline Avaliador 3 & 4 & 4 & 4 & 1 & 1 & 5 & 1 & 1 & 1 & 1 & 5 & 2 & 1 & 1 & 5 & 5 & 5 & 1 & 3 & 2 & 2 & 1 & 1 \\
\hline \multicolumn{24}{|c|}{ Latin American consensus on hypertension in patients with diabetes type 2 and metabolic syndrome (136) } \\
\hline Avaliador 1 & 5 & 4 & 5 & 2 & 1 & 6 & 2 & 1 & 1 & 3 & 3 & 2 & 1 & 1 & 4 & 5 & 3 & 3 & 2 & 2 & 1 & 1 & 4 \\
\hline Avaliador 2 & 5 & 3 & 3 & 2 & 1 & 5 & 1 & 2 & 2 & 1 & 3 & 3 & 1 & 1 & 4 & 5 & 5 & 1 & 4 & 2 & 2 & 1 & 1 \\
\hline Avaliador 3 & 5 & 3 & 3 & 2 & 1 & 4 & 1 & 1 & $\frac{2}{1}$ & 1 & 3 & 3 & 1 & 1 & 4 & 5 & 5 & 1 & 4 & 2 & 2 & 1 & 1 \\
\hline
\end{tabular}


APÊNDICE 4 - Notas atribuídas aos guias de prática clínica para tratamento da hipertensão arterial sistêmica por cada avaliador para cada item do AGREE II.

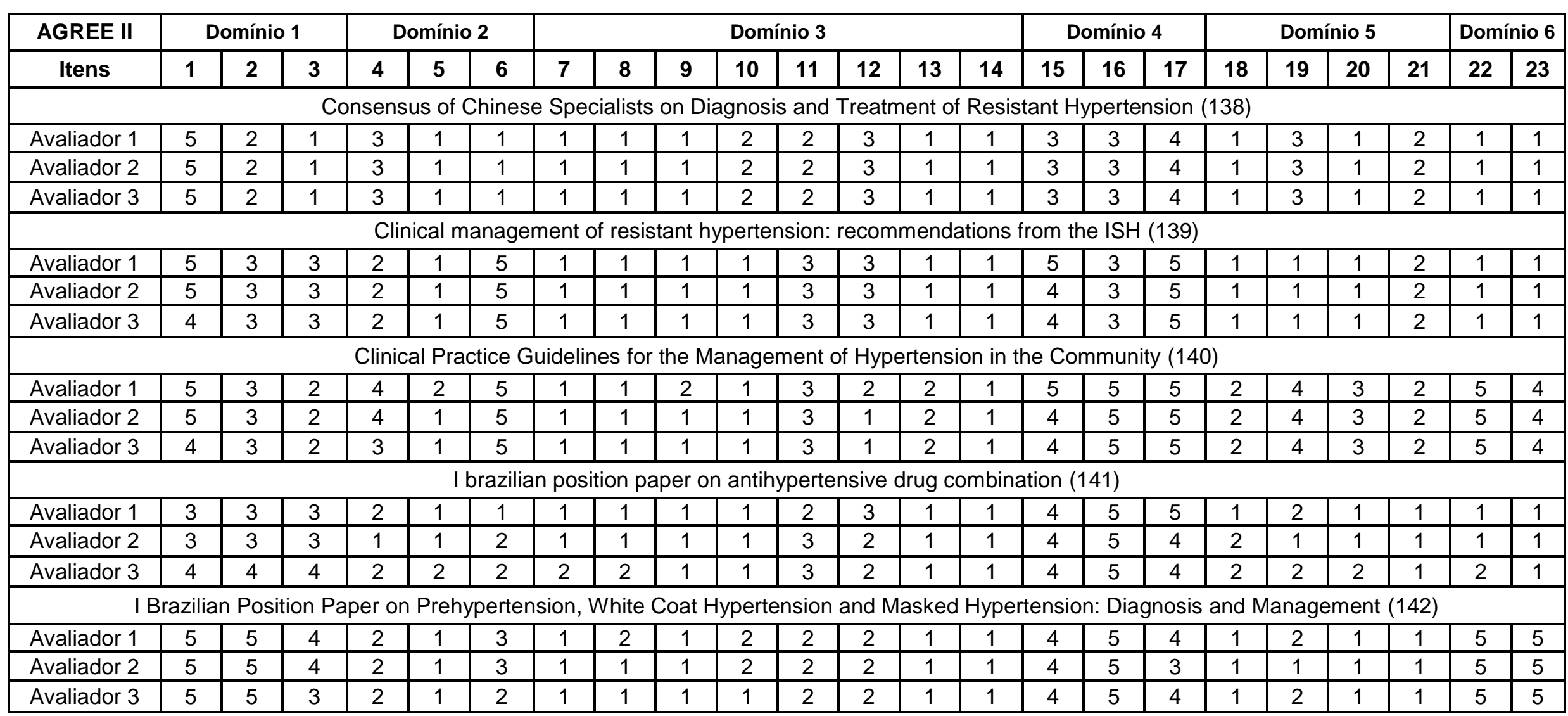


APÊNDICE 4 - Notas atribuídas aos guias de prática clínica para tratamento da hipertensão arterial sistêmica por cada avaliador para cada item do AGREE II.

\begin{tabular}{|c|c|c|c|c|c|c|c|c|c|c|c|c|c|c|c|c|c|c|c|c|c|c|c|}
\hline \multirow{2}{*}{$\begin{array}{c}\text { AGREE II } \\
\text { Itens } \\
\end{array}$} & \multicolumn{3}{|c|}{ Domínio 1} & \multicolumn{3}{|c|}{ Domínio 2} & \multicolumn{8}{|c|}{ Domínio 3} & \multicolumn{3}{|c|}{ Domínio 4} & \multicolumn{4}{|c|}{ Domínio 5} & \multicolumn{2}{|c|}{ Domínio 6} \\
\hline & 1 & 2 & 3 & 4 & 5 & 6 & 7 & 8 & 9 & 10 & 11 & 12 & 13 & 14 & 15 & 16 & 17 & 18 & 19 & 20 & 21 & 22 & 23 \\
\hline \multicolumn{24}{|c|}{ Hypertension in the elderly: new blood pressure targets and prescribing tips (143) } \\
\hline Avaliador 1 & 3 & 3 & 5 & 4 & 1 & 2 & 2 & 1 & 1 & 1 & 2 & 2 & 1 & 1 & 5 & 4 & 4 & 1 & 2 & 1 & 1 & 3 & 5 \\
\hline Avaliador 3 & 3 & 4 & 5 & 3 & 1 & 3 & 1 & 1 & 1 & 1 & 2 & 2 & 1 & 1 & 4 & 4 & 4 & 1 & 2 & 1 & 1 & 3 & 5 \\
\hline \multicolumn{24}{|c|}{ Hipertension Arterial em pacientes con diabetes mellitus tipo 2 (144) } \\
\hline Avaliador 1 & 4 & 4 & 4 & 2 & 1 & 2 & 1 & 1 & 1 & 1 & 2 & 2 & 1 & 1 & 4 & 5 & 4 & 1 & 2 & 1 & 2 & 1 & 1 \\
\hline \multicolumn{24}{|c|}{ Hypertension management in diabetic patients (145) } \\
\hline Avaliador 1 & 3 & 4 & 4 & 2 & 1 & 2 & 2 & 1 & 1 & 1 & 2 & 2 & 1 & 1 & 4 & 5 & 4 & 1 & 2 & 1 & 1 & 1 & 1 \\
\hline Avaliador 2 & 3 & 5 & 5 & 2 & 1 & 2 & 1 & 1 & 1 & 1 & 1 & 2 & 1 & 1 & 4 & 5 & 4 & 1 & 1 & 1 & 1 & 1 & 1 \\
\hline Avaliador 3 & 3 & 4 & 4 & 2 & 1 & 2 & 1 & 1 & 1 & 1 & 2 & 2 & 1 & 1 & 3 & 4 & 4 & 1 & 1 & 1 & 1 & 1 & 1 \\
\hline
\end{tabular}

Fonte: Elaboração própria. 